

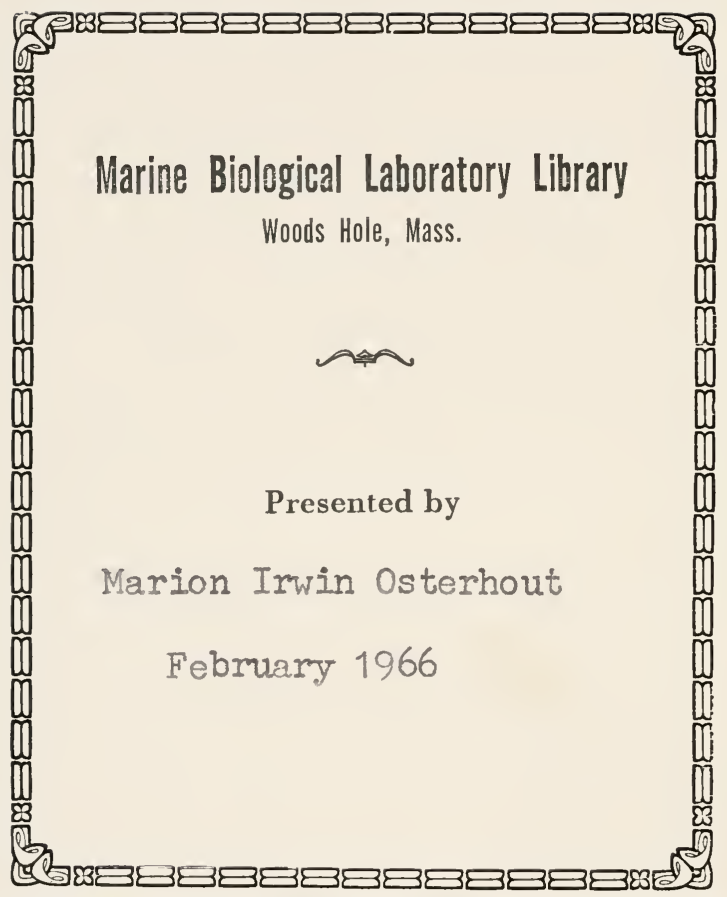





\section{MONOGRAPHS ON EXPERIMENTAL BIOLOGY}

EDITED BY

JACQUES LOEB, Rockefeller Institute

T. H. MORGAN, Columbia University

W. J. V. OSTERHOUT, Harvard University

INJURY, RECOVERY, AND DEATH, IN RELATION TO CONDUCTIVITY AND

PERMEABILITY

BY

W. J. V. OSTERHOUT. 


\section{MONOGRAPHS ON EXPERIMENTAL $B I O L O G Y$}

\section{PUBLISHED}

FORCED MOVEMENTS, TROPISMS, AND ANIMAL CONDUCT

By JACQUES LOEB, Rockefeller Institute

THE ELEMENTARY NERVOUS SYSTEM

By G. H. PARKER, Harvard University

THE PHYSICAL BASIS OF HEREDITY

By T. H. MORGAN, Columbia University

\section{INBREEDING AND OUTBREEDING: THEIR GENETIC}

AND SOCIOLOGICAL SIGNIFICANCE

By E. M. EAST and D. F. JONES, Bussey Institution, Harvard University

THE NATURE OF ANIMAL LIGHT

By E. N. HARVEY, Princeton University

SMELL, TASTE AND ALLIED SENSES IN THE VERTEBRATES

By G. H. PARKER, Harvard University

\section{BIOLOGY OF DEATH}

By R. PEARL, Johns Hopkins University

INJURY, RECOVERY, AND DEATH IN RELATION TO CONDUCTIVITY AND PERMEABILITY

By W. J. V. OSTERHOUT, Harvard University

IN PREPARATION

PURE LINE INHERITANCE

By H.S. JENNINGS, Johns Hopkins University

\section{LOCALIZATION OF MORPHOGENETIC SUBSTANCES IN THE EGG}

By E. G. CONKLIN, Princeton University

TISSUE CULTURE

By R. G. HARRISON, Yale University

THE EQUILIBRIUM BETWEEN ACIDS AND BASES IN ORGANISM AND ENVIRONMENT

By L. J. HENDERSON, Harvard University

CHEMICAL BASIS OF GROWTH By T. B. ROBERTSON, University of Toronto COÖRDINATION IN LOCOMOTION

By A. R. MOORE, Rutgers College 
MONOGRAPHS ON EXPERIMENTAL BIOLOGY

\title{
INJURY, RECOVERY, AND DEATH, IN RELATION TO CONDUCTIVITY AND PERMEABILITY
}

\author{
BY \\ W. J. V. OSTERHOUT, PH.D. \\ PROFESSOR OF BOTANY, HARVARD UNIVERSITY
}
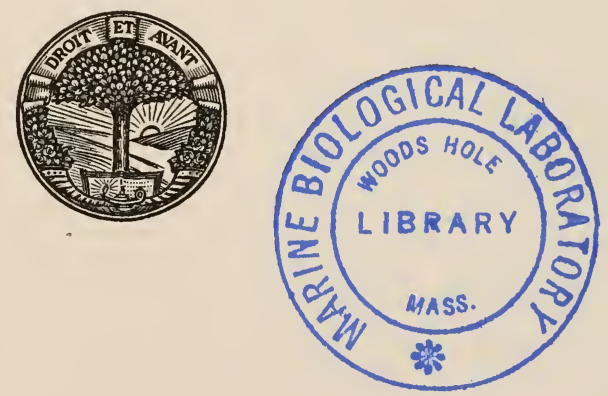

\section{PHILADELPHIA AND LONDON J. B. LIPPINCOTT COMPANY}


COPYRIGHT I922, BY J. B. LIPPINCOTT COMPANY

PRINTED BY J. B. LIPPINCOTT COMPANY AT THE WASHINGTON SQUARE PRESS PHILADELPHIA, U.S.A. 


\section{EDITOR'S ANNOUNCEMENT}

THe rapidly increasing specialization makes it impossible for one author to cover satisfactorily the whole field of modern Biology. This situation, which exists in all the sciences, has induced English authors to issue series of monographs in Biochemistry, Physiology, and Physics. A number of American biologists have decided to provide the same opportunity for the study of Experimental Biology.

Biology, which not long ago was purely descriptive and speculative, has begun to adopt the methods of the exact sciences, recognizing that for permanent progress not only experiments are required but that the experiments should be of a quantitative character. It will be the purpose of this series of monographs to emphasize and further as much as possible this development of Biology.

Experimental Biology and General Physiology are one and the same science, by method as well as by contents, since both aim at explaining life from the physico-chemical constitution of living matter. The series of monographs on Experimental Biology will therefore include the field of traditional General Physiology.

Jacques Loeb,
T. H. Morgan,
W. J. V. Osterhout. 



\section{AUTHOR'S PREFACE}

THis volume endeavors to treat certain aspects of biology according to the spirit and methods of the exact sciences. The treatment is confined to certain fundamental problems which have been studied quantitatively. These studies lead to a theory of some aspects of injury, recovery, and death, as well as of antagonism and permeability. The behavior of the organism in these respects may be predicted with a satisfactory degree of accuracy by means of the equations which express the theory in mathematical form.

The author is under great obligation to the Marine Biological Laboratory at Woods Hole for the facilities generously placed at his disposal. He desires to make grateful acknowledgement to Mr. F. S. Mathews and Mr. G. B. Ray for the preparation of drawings and to Mr. Lee Morrison for technical assistance in conducting the experiments.

Cambridge, Mass.

The Author. 


\section{CONTENTS}

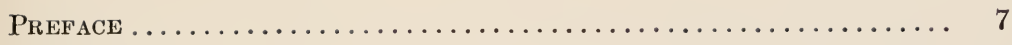

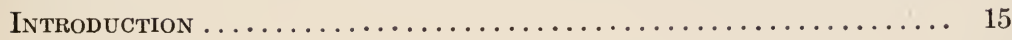

Chapter I. Methods of Measuring Electrical Conductivity...... 21

Chapter II. The Mechanism of the Process of Death......... 40

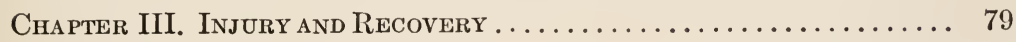

Chapter IV. Antagonism . . . . . . . . . . . . . . . . . . . . 124

Chapter V. Anesthesia ............................. 184

Chapter Vi. Conductivity and Permeability ............... 195

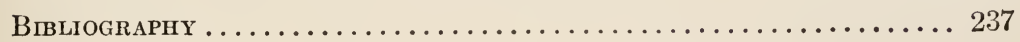





\section{ILLUSTRATIONS}

FIG.

1. Apparatus for Measuring the Electrical Conductivity of Muscle

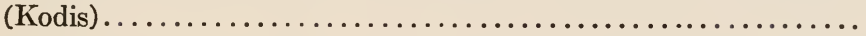

2. Apparatus for Measuring the Electrical Conductivity of Sea

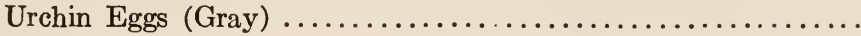

3. Apparatus for Determining the Electrical Conductivity of Living Tissue. .

4. Electrode Carrier............................. 25

5. Hard Rubber Disks, Alternating with Disks of Tissue......... 29

6. Diagram to Show Bridge and Connections.............. 30

7. Electrode Carrier................................. 31

8. Disk of Tissue............................... 32

9. Two Glass Cells each Provided with an Electrode with Strip of

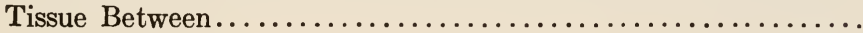

10. A Disk of Hard Rubber, One of Tissue and One of Celluloid,

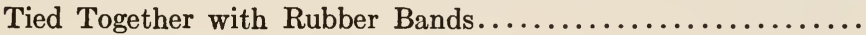

11. Disk of Rubber with a Mass of Tissue Wedged in the Central Opening........................................ 34

12. Apparatus for Measuring the Conductivity of Nitella........ 36

13. Curves of Net Electrical Resistance of Laminaria Agardhii...... 41

14. Curves of Net Electrical Resistance of Laminaria Agardhii..... 42

15. Curve of Net Electrical Resistance of Laminaria Agardhii...... 43

16. Curve Showing Changes in the Hydrogen Ion Concentration of Sea Water.................................... 44

17. Curves of Net Electrical Resistance of Laminaria Agardhii...... 45

18. Curve Showing the Net Electrical Resistance of Laminaria Agardhii 46

19. Curve Showing the Net Electrical Resistance of Laminaria Agardhii 47

20. Curves Showing the Net Electrical Resistance of Laminaria Agardhii 48

21. Curves Showing the Effect of $\mathrm{CaCl}_{2}$ 0. $278 M \ldots \ldots \ldots \ldots \ldots \ldots$

22. Curves Showing Net Electrical Resistance of Laminaria Agardhii 51

23. Curves of Net Electrical Resistance of Laminaria Agardhii...... 52 
FIG.

24. Curves Showing Net Electrical Resistance of Laminaria Agardhii. 53

25. Curves of Net Electrical Resistance of Laminaria Agardhii...... 54

26. Curve Showing Rise in Net Electrical Resistance of Laminaria Agardhii..................................... 56

27. Diagrams Illustrating Consecutive Reactions............. 58

28. Death Curve of Laminaria Agardhii.................. 59

29. Curve Showing the Net Electrical Resistance of Laminaria Agardhii 64

30. Curve Representing Velocity of Processes................. 69

31. Curves Showing Changes in the Net Electrical Resistance of Tissues 71

32. Curve Showing Value of $M$ under Various Velocity Constants.... 76

33. Graph Showing the Fall of Net Electrical Resistance of Laminaria Agardhii.................................. 81

34. Graph Showing Loss of Net Electrical Resistance of Laminaria Agardhii .................................. 82

35. Rise of Net Electrical Resistance of Laminaria Agardhii......... 84

36. Extreme Alterations of Net Electrical Resistance of Laminaria Agardhii ................................. 86

37. Curves Showing Net Electrical Resistance of Laminaria Agardhii.... 92

38. Curves Showing Net Electrical Resistance of Laminaria Agardhii.... 93

39. Curves Showing Rate of Respiration of Laminaria Agardhii....... 96

40. Curves Showing Rate of Respiration of Laminaria Agardhii...... 97

41. Curves Showing Fall of Net Electrical Resistance of Laminaria Agardhii .................................... 102

42. Curves Showing the Rise and Fall of Net Electrical Resistance in Laminaria Agardhii........................... 107

43. Curves Showing the Value of $0+10$ in Various Solutions........ 109

44. Curves Showing the Net Electrical Resistance of Laminaria Agardhii 111

45. Curves Showing the Net Electrical Resistance of Laminaria Agardhii 116 46. Curves Showing the Net Electrical Resistance of Laminaria Agardhii 117 47. Curves Showing the Net Electrical Resistance of Laminaria Agardhii 118 48. Curves Showing the Net Electrical Resistance of Laminaria Agardhii 120 49. Curves Showing the Growth of Roots in Toxic Solutions........ 125 50. Curve Showing the Antagonism Between Two Salts........... 128 51. Curves Showing Growth in Mixtures of Unequally Toxic Solutions.. 129 52. Types of Antagonism Curves...................... 131

53. Diagram Representing the Composition of Various Mixtures..... 132 
FIG.

54. Solid Model Showing the Forms of the Antagonism Curves..... 134

55. Method of Expressing Antagonism..................... 135

56. Effect of Dilutions on the Forms of Antagonism Curves........ 136

57. Diagram Representing the Composition of Solutions........... 138

58. Solid Model Showing Antagonism Affected by Altered Solutions.. 139

59. Curves Showing the Net Electrical Resistance of Laminaria Agardhii 140

60. Curves of Net Electrical Resistance of Laminaria Agardhii....... 143

61. Curve of Net Electrical Resistance of Laminaria Agardhii........ 144

62. Curve of Net Electrical Resistance of Laminaria Agardhii....... 145

63. Curve of Net Electrical Resistance of Laminaria Agardhii....... 146

64. Increase of a Hypothetical Salt Compound................. 149

65. Graph Showing Increase of the Velocity Constant............ 151

66. Curves Showing the Rise of Resistance After Exposure to Toxic

Solution..................................... 154

67. Curves Showing Calculated Value of $s$ in Various Solutions....... 155

68. and 69. Curves Showing the Net Electrical Resistance of Laminaria Agardhii .................................... 156

70. Curves Showing the Net Electrical Resistance of Laminaria Agardhii 157

71. Antagonism Curve of Laminaria Agardhii............... 165

72. Curves Showing Antagonism Between $\mathrm{NaCl}$ and Na-taurocholate.. 169

73. Curves Showing Antagonism Between $\mathrm{NaCl}$ and Nicotine........ 170

74. Curves Showing Antagonism Between $\mathrm{NaCl}$ and Caffeine........ 171

75. Curves Showing Antagonism Between $\mathrm{NaCl}$ and Cevadine Sulfate.. 172

76. Curves Showing Antagonism Between $\mathrm{NaCl}$ and $\mathrm{CaCl}_{2} \ldots \ldots \ldots \ldots 174$

77. Curves Showing the Resistance of Laminaria Agardhii......... 176

78. Electrical Resistance of Laminaria Agardhii in Sodium Acetate 177

79. Increased Toxicity of Laminaria Agardhii................ 178

80. Net Electrical Resistance of Laminaria Agardhii............. 185

81. Net Electrical Resistance of Laminaria Agardhii............. 186

82. Net Electrical Resistance of Laminaria Agardhii............. 189

83. Curves Showing the Net Electrical Resistance of Laminaria Agardhii 190

84. Cross Section of Monostroma Latissima................ 196

85. Cross Section of Ulva Lactuca........................ 196

86. Cross Section of Rhodymenia Palmata.................. 197

87. Cross Section of Laminaria Agardhii................... 198 
FIG.

88. A Vegetable Cell Showing Plasmolysis.................. 201

89. Apparatus for Testing Rate of Diffusion of Salts through Living Tissue 206

90. Diffusion of Various Solutions through Laminaria Agardhii..... 207

91. Exosmosis into Distilled Water from Taraxacum Officinale....... 208

92. Recovery of Taraxacum Officinale from Effect of Various Hypertonic

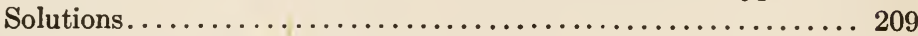

93. Diagram Showing Principle of Resistance................ 218

94. Increase in Value of Velocity Constants $\ldots \ldots \ldots \ldots \ldots \ldots \ldots \ldots \ldots \ldots \ldots . \ldots 22$

95. Decrease in Value of Velocity Constants................. 223

96. A Cell of Griffithsia Bornetiana ....................... 231 


\section{INJURY, RECOVERY, AND DEATH, IN RELATION TO CONDUCTIVITY AND PERMEABILITY}

\section{INTRODUCTION}

Some of the fundamental ideas of biology are most difficult to define with precision. This is especially true of such conceptions as life, vitality, injury, recovery, and death. To put these conceptions on a more definite basis it is necessary to investigate them by quantitative methods.

To illustrate this we may consider some researches on the electrical conductivity of organisms. These experiments show that the electrical resistance of a plant or animal is an excellent indicator of what may be called its normal condition of vitality. Injurious agents invariably change its electrical resistance. For example, if the marine plant, Laminaria, is taken out of its normal environment of sea water and placed in a solution of pure $\mathrm{NaCl}$ it is at once injured, and if the exposure be sufficiently prolonged it is killed. During the whole time of exposure to the solution of $\mathrm{NaCl}$ its electrical resistance falls steadily until the deathpoint is eventually reached; after this there is no further change. A study of the time curve of this process shows that it corresponds to a monomolecular reaction (slightly inhibited at the start). This may be expressed in the form of an equation which can be utilized to predict the curve of death under various con- 
ditions. We find that in testing these predictions we must ascertain when the death process reaches a definite stage, (i. e., when it is one-fourth or one-half completed). This can be determined experimentally with a satisfactory degree of accuracy.

We can therefore follow the process of death in the same manner that we follow the progress of a chemical reaction in vitro; in both cases we obtain curves which may be subjected to mathematical analysis, from which we may draw conclusions regarding the nature of the process. This method has been fruitful in chemistry and it is possible that it may prove equally so in biology.

Studies undertaken from this point of view lead us to look upon the death process as one which is always going on, even in a normal, actively growing cell. ${ }^{1}$ In other words we regard the death process as a normal part of the life process, producing no disturbance unless unduly accelerated by an injurious agent which upsets the normal balance and causes injury so that the lifeprocess comes to a standstill.

The process of death which occurs in a solution of $\mathrm{NaCl}$ may be checked by adding a little $\mathrm{CaCl}_{2}$ to the solution. In this case we speak of antagonism between sodium and calcium. When the calcium is added in the proper proportion the fall of resistance is very slow and the tissue lives for a long time. Any deviation from this optimum proportion hastens death.

In order to explain these results we may assume that

${ }^{1}$ The general conception that the death process goes on continually is in harmony with the ideas expressed by many physiologists from Claude Bernard (1879; I, 28), down to the present day. Cf. Lipschütz, A. (1915). 
both sodium and calcium combine with a constituent of the protoplasm, forming a compound which inhibits the death process. This enables us to formulate an equation by means of which the death curve in any mixture of sodium and calcium can be predicted with considerable accuracy.

The changes in electrical conductivity which occur under the influence of reagents run parallel to changes in the permeability of the protoplasm. This is to be expected, since it is evident that when a current passes from a salt solution into living protoplasm, ions must enter the protoplasm, and if there is an increase in the permeability of the protoplasm to these ions its electrical conductivity must increase, and vice versa. The electrical conductivity of the protoplasm may therefore be regarded as a measure of its permeability to ions.

The resistance of the tissue does not depend upon the protoplasm alone, but also upon the cell wall and the cell sap. But we find, as a matter of fact, that the resistance of the protoplasm rises and falls with that of the tissue as a whole. Hence when we observe that the conductivity of the tissue increases in a solution of $\mathrm{NaCl}$ and decreases in a solution of $\mathrm{CaCl}_{2}$, we may conclude that the permeability is increased by $\mathrm{NaCl}$ and decreased by $\mathrm{CaCl}_{2}$. This is in harmony with experiments in which permeability is measured by other methods (such as plasmolysis, specific gravity, exosmosis, tissue tension, and the diffusion of salts through living tissue). It is likewise confirmed by direct determinations, in which the penetration of various substances is ascertained by testing for their presence in the cell sap.

It has been observed in the course of these investigations that plants which have developed in a normal 
environment are fairly uniform in their electrical resistance, so that we may speak of a normal degree of resistance as indicating a normal condition. If the plant is injured and the resistance falls, we may consider that the loss of resistance gives a measure of the amount of injury. This enables us to place the study of injury upon a quantitative basis. As the result of this we are able to formulate a definite conception of the mechanism of recovery. We find that if injury in a solution of $\mathrm{NaCl}$ amounts to $5 \%$ the tissue recovers its normal resistance when replaced in sea water. But if the injury amounts to $25 \%$ recovery is incomplete: instead of returning to the normal the resistance rises to only $90 \%$ of the normal. The greater the injury the less complete the recovery. When injury amounts to $90 \%$ there is no recovery.

This is of especial interest, since in physiological literature it seems to be generally assumed that when recovery occurs it is always complete, or practically so, as if it obeyed an "all or none" law. But it is evident that partial recovery may be easily overlooked unless accurate measurements can be made. This fact may serve to illustrate the importance of quantitative methods in the study of fundamental problems.

The significance of such methods is further shown by the fact that they have led to the development of equations which enable us to predict with a satisfactory degree of accuracy the recovery curves which are observed under a great variety of conditions.

As the result of these investigations we are led to look upon recovery in a somewhat different fashion from that which is customary. While recovery is usually 
regarded as due to the reversal of the reaction which produces injury, the conception here developed is fundamentally different. It assumes that the reactions involved are irreversible (or practically so) and that injury and recovery differ only in the relative speed at which certain processes take place. The reasons for this are fully explained in the following pages.

The experiments of the writer lead to the view that life depends upon a series of reactions which normally proceed at rates bearing a definite relation to each other. If this is true it is clear that a disturbance of these raterelations may have a profound effect upon the organism, and may produce such diverse phenomena as stimulation, development, injury, and death. Such a disturbance might be produced by changes of temperature (if the temperature coefficients of the reactions differ) or by chemical agents. The same result might be brought about by physical means, especially where structural changes occur which alter the permeability of the plasma membrane or of internal structures (such as the nucleus and plastids) in such a way as to bring together substances which do not normally react.

Throughout these investigations the aim has been to apply to the study of living matter the methods which have proved useful in physics and chemistry. In this attempt no serious difficulty was encountered after accurate methods of measurement had been devised: nor does there seem to be any real obstacle to an extensive use of methods which lead biology in the direction of the exact sciences.

It is evident from what has been said that we may investigate such fundamental conceptions as vitality, in- 
jury, recovery, and death by quantitative methods and obtain a set of equations by which they can be predicted. It may be added that the predictive value of these equations is quite independent of the assumptions upon which they were originally based. The importance of such equations is fully as great in biology as in physics or chemistry.

The measurements described in this volume, and the accompanying mathematical analysis, lead to a quantitative theory of the mechanism which underlies certain important phenomena. The theory can be tested by exact methods and, as far as experiments have gone, appears to be sound. This investigation of certain fundamental life processes seems to show that they obey the laws of chemical dynamics: it likewise illustrates a method which promises to throw light upon the underlying mechanism of these processes and to assist in the analysis and control of life-phenomena. 


\section{CHAPTER I.}

\section{METHODS OF MEASURING ELECTRICAL CONDUCTIVITY}

Since the conclusions set forth in this work depend largely upon researches on the electrical conductivity of organisms it seems desirable to give an account of the methods of conducting such investigations.

In the experiments of some investigators ${ }^{1}$ platinum electrodes have been applied directly to the tissue. It is difficult to obtain good contact by this method and there is danger that some of the platinum black may be rubbed off. Kodis (1901) states that it is impossible to obtain trustworthy results in this manner. He therefore placed the tissue in a U-tube in each arm of which was a funnel plugged at the bottom with plaster of Paris. Each funnel was filled with a solution of $\mathrm{NaCl}$ into which an electrode dipped (Fig. 1).

In measuring the conductivity of red blood corpuscles or of unicellular organisms the electrodes are placed directly in a suspension of the cells, either with or without previous centrifugation. ${ }^{2}$ (Fig. 2.)

In experiments of the writer on unicellular plants (such as Euglena and Chlorella) the organisms were

${ }^{1}$ Regarding methods see Galeotti (1803), Alcock (1905, 1906), Polacci (1907), Mamelli (1909), Stone and Chapman (1912), Henri et Calugareanu (1902, A, B), McClendon (1912), Stiles and Jörgensen (1914), Höber (1914) pp. 381, 440, Small (1918).

'See Roth (1897), Bugarsky und Tangl (1897), Stewart (1897, 1899, 1909-10), Woelfel (1908), McClendon (1910), Gray (1913, 1916), Shearer $(1919, A, B, C)$. 
placed in a centrifuge tube near the bottom of which platinum electrodes were inserted (through the walls of the tube) a short distance apart. The material was then centrifugated and the resistance was measured. The supernatant liquid was then poured off and replaced by a different solution. The material was agitated in order

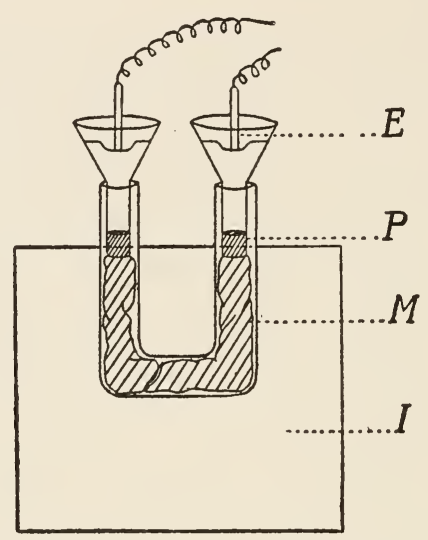

FIG. 1.-Apparatus for measuring the electrical conductivity of muscle (Kodis): $E$, electrode, contained in a funnel (filled with a solution of $\mathrm{NaCl}$ ) plugged at the bottom with plaster of Paris $(P) ; M$, muscle: the whole is placed in a water bath, $I$.

to disperse it through the solution and the process of centrifugation and washing was repeated until the first solution was removed. This must be done frequently since otherwise the organism may change the conductivity of the external solution (by absorbing or giving out electrolytes) and this may be confused with a change in the conductivity of the cells.

A method of measuring the electrical conductivity of bacteria has recently been proposed by Thornton (1912), who states that it depends upon the principle that in an electric field bacteria orient themselves in a 
solution having a lower conductivity than the bacteria, but not in a solution of the same conductivity.

The method therefore consists in placing the bacteria in an electric field and increasing the strength of the salt solution until they cease to orient. The results indicate that the conductivity of living bacteria is usually greater than that of the medium in which they grow. This is opposed to the results of Shearer $(1919, A)$ in which the conductivity was measured in the usual manner. On theoretical grounds there are serious objections to Thornton's technique as well as to his conclusions.

The method $^{3}$ used by the writer gives under the most favorable conditions, measurements which are accurate to within $1 \%$. This degree of accuracy may be regarded as satisfactory for biological purposes.

In the original method ${ }^{4}$ aquatic plants with leaf-like fronds were employed, particularly one of the common kelps of the Atlantic coast (Laminaria agardhii) : disks were cut from this by means of a cork borer and packed together, like a roll of coins,

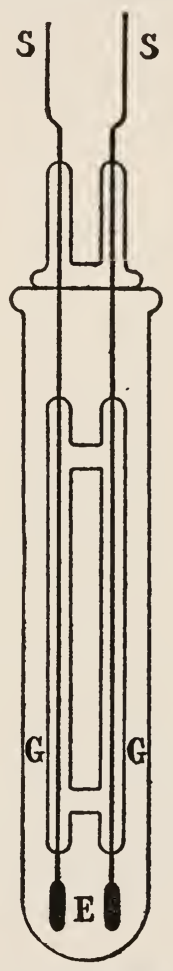

Fra. 2. - Apparatus for moseuring the electrical conductivity of sea urchin eggs (Gray): S, silver wires, $G, G$, glass tubes: $E$, platinum electrodes. in an apparatus which is shown in Fig. 3. It consists of two platinum electrodes (covered with platinum black), $A$, sealed into glass tubes, $B$, which are filled

-This was developed without reference to the methods previously used and differs somewhat from them.

" Osterhout (1918, E), 
with mercury and into which dip copper wires, $C$, which go to the Wheatstone bridge. These tubes are contained in electrode holders of hard rubber, $D$, through which pass a rod, $E$, and a long screw, $F$, by means of which the electrode holders may be drawn toward each other and held firmly in any desired posi-

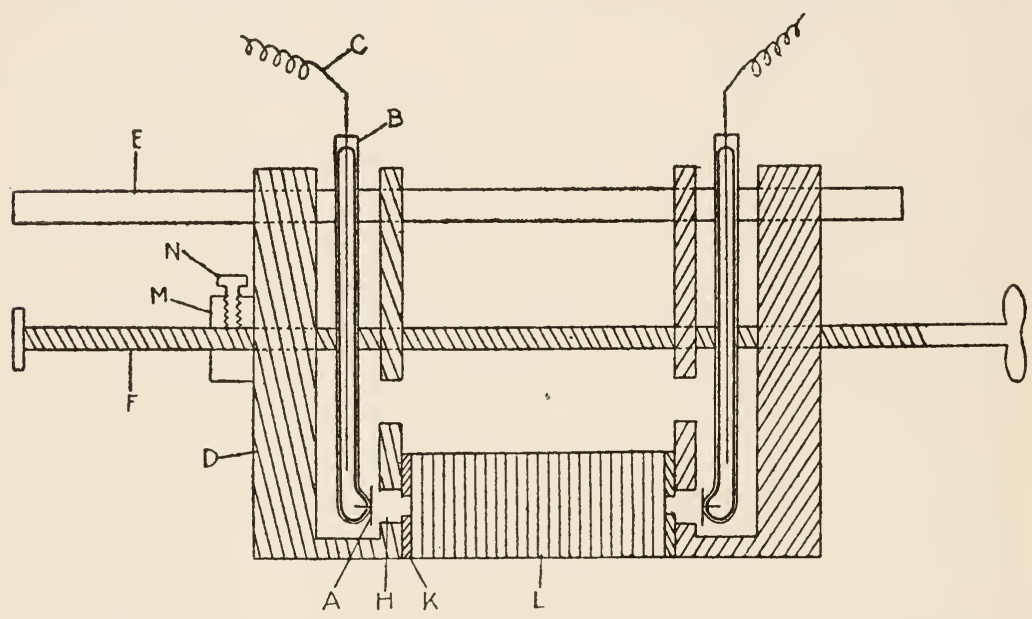

Fig. 3.-Apparatus for determining the electrical conductivity of living tissue. The disks of tissue, $L$, are packed together like a roll of coins. At each end is a platinum electrode, $A$, fastened in an electrode carrier, $D$. By means of the screw, $F$, the electrode carriers can be drawn together, compressing the tissue and holding it firmly in place.

tion. This screw engages an internal screw contained in the electrode holder at the right. This is not the case with the electrode holder at the left in which the screw passes through a sleeve, and in consequence this electrode holder is drawn toward the other only when the block, $M$, is fastened in place by the set screw, $N$, and the screw, $F$, is turned in the proper direction.

An end view of an electrode holder, $D$, is shown in Fig. 4. Its lower portion (which contains the platinum electrode) is shown inserted in a hard rubber support, $G$. The support is pierced by a series of seven holes 
(arranged in a circle as shown in the figure) each of which receives the end of a glass rod about 9 inches long, the other end of each rod being fastened in a similar support. The circle (dotted line) just inside the seven small circles represents a disk of tissue inserted between the glass rods with its surface at right angles to them. The smaller circle, $H$, in the centre represents an opening in the electrode holder through which the current passes from the platinum electrode to the disks of Laminaria. The arrangement is shown in Fig. 3, where $H$ represents the opening and $L$ represents the disks. Before reaching the disks the current passes through $K$, (Fig. 3), a hard rubber disk (with an opening in the centre) which provides mechanical support for the tissue.

The disks are cut from the fronds by means of a cork borer and have about the diameter and thickness of a silver quarter. They are packed together like a roll of coins (about 100 in all). They are firmly held in

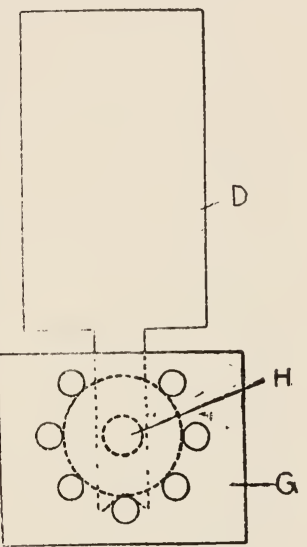

Fig. 4.-Electrode carrier, $D$, seen from the end, resting upon a frame, $G$, in which are set glass rods (seen in section, as a series of circles) which hold in place the disks of tissue (seen in"sectionis as! a dotted line). place by the glass rods which surround them and by the electrode holders which press against them at either end. At the same time the spaces between the glass rods allow free circulation of liquid.

Each disk is placed in sea water as soon as it is cut ${ }^{5}$;

- It was at first thought that cutting might injure the tissues at the edge of the disk sufficiently to interfere with the results, but experiments proved that this is not the case. Not only do the cells adjoining the cut surface live as long as those in the centre of the disk, but it is found that experiments (made by another method) on intact fronds give the same results as experiments on the cut disks. 
from this the disks are transferred to the support $G$, which is submerged in sea water. They are arranged inside the glass rods by means of forceps, and care is taken to see that no bubbles of air are caught in the space around the electrode or in the opening at $H$.

When the effect of a number of different solutions is to be compared the following procedure is adopted. If there are seven solutions seven disks are cut from the same part of a frond: each disk is placed in a separate tumbler of sea water. A second lot of seven disks is cut, as close to each other as possible, and placed in the tumblers, so that each tumbler contains two disks. This is continued until each tumbler contains one hundred disks. By this means the material in the different tumblers is made as similar as possible. The disks in each tumbler are then packed together (like a roll of coins) to form a cylinder whose resistance is measured. Throughout the experiments the different lots are kept side by side and treated as nearly alike as possible, except that they are placed in different solutions.

The electrode holders are now pressed against the ends of the roll of disks, the block, $M$, is firmly fastened by means of the set screw, $N$, and the screw, $F$, is turned until the electrode holders are tightly clamped against the roll of disks. The pressure used in this operation should be fairly uniform. ${ }^{6}$

The apparatus is now lifted out of the sea water ${ }^{7}$

- It was at first thought necessary to use a dynamometer, but it was found that the operator soon becomes so proficient as to make it unnecessary. The resistance is very little affected by variations in pressure.

In the earlier experiments the resistance was taken with the cylinder submerged in sea water, and this may be preferable in special cases. 
and allowed to drain ${ }^{8}$ for a definite time (not over one minute) after which the resistance becomes practically constant.

The current passes for a short distance through sea water before reaching the disks. There is a film of sea water between each pair of disks and likewise a film around the cut edges. Otherwise the current passes only through the tissue.

As soon as the resistance has been measured the apparatus is replaced in sea water; the set screw, $N$, is loosened so that the electrode holders can be moved apart and the disks separated from each other by means of forceps. After standing for a few minutes in sea water the resistance is again determined. The disks are then separated as before and allowed to stand in sea water. This procedure is continued until it becomes evident that the resistance is practically stationary. ${ }^{9}$

The apparatus is then transferred to another solution (e.g., $\mathrm{NaCl} 0.52 \mathrm{M}$ ) having the same conductivity (and temperature ${ }^{10}$ ) as the sea water. There should be at least $1,500 \mathrm{cc}$. of solution, contained in a shallow dish of glass or enameled ware. The disks are at once separated by means of forceps and thoroughly rinsed

- Each support rests on a block of paraffin. Care must be taken that there is no conduction between the blocks; e.g., along the wet surface of the table.

- Unless this is the case the material is rejected. With good material the resistance remains stationary for a long time; in one experiment it remained so for 10 days at about $20^{\circ} \mathrm{C}$. In this case the tissue was kept in running sea water and was only half-submerged, thus ensuring an abundant supply of oxygen. See Osterhout $(1915, B)$. When placed on ice Laminaria can be kept in good condition for a much longer time.

${ }^{10}$ All readings should be made at the same temperature or, if this is not practicable, should be corrected to the standard temperature. For the temperature coefficient, see p. 37 . 
in the new solution, the whole apparatus being moved about in the dish to secure thorough mixing. By means of a medicine dropper the sea water around the platinum electrodes is thoroughly washed out. In some cases it is desirable to transfer to a second dish to ensure against contamination by sea water.

By this means a very rapid change is effected and, as the disks are thin, diffusion is soon completed (this is often the case in 5 minutes and should not in any event require more than 10 minutes). Since the outward diffusion of salts may take place at a different rate from the inward diffusion there may be an apparent rise or fall of resistance in consequence. This effect lasts but a short time and is found in dead as well as in living tissue. It is therefore easy to guard against error due to such causes. ${ }^{11}$

The resistance of the disks at the ends is much greater than that of those in the middle since the current spreads out after issuing from the small opening, ${ }^{12} H$, in the rubber disk (Fig. 1). For this reason the best disks of tissue should be placed at the ends and their positions should not be changed. Care should be taken that they are not cut or injured by contact with the edges of the opening in the rubber disk. ${ }^{13}$ The inequality between the disks at the end and in the center may be minimized by introducing at intervals rubber disks

${ }^{11} C f$. Osterhout (1918, D).

12 It results from this that the resistance does not increase in direct proportion to the number of disks. If we plot the resistance as ordinates and the number of disks as abscissæ, we obtain a curve which is concave toward the base line. The curve is approximately logarithmic.

${ }^{13}$ These edges may be rounded by filing. A soft rubber disk may be placed between the hard rubber disk and the tissue. 
provided with openings in the center (Fig. 5). This is desirable in many cases and makes it possible to get a high resistance with less tissue.

Care must be taken to see that liquid does not leak out of the space around the electrodes while the apparatus is out of the liquid. If a leak should occur fresh liquid may be added by means of a medicine dropper. With a proper adjustment of the rubber disks and sufficient tissue to give elasticity no leakage should occur.

In regard to the accuracy of the readings it may be said at the outset that under favorable conditions successive readings on the same material

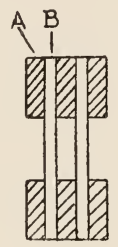
do not vary more than $1 \%$ from the average. This is as great accuracy as can ordinarily be hoped for in biological work and there is no object in striving to get greater accuracy than this in the apparatus itself.

It is usually desirable to introduce a variable capacitance or an arrangement such as is suggested by Taylor and Curtis (1915), by Taylor and Acree (1916) or by McClendon (1920). In the writer's experiments the capacity of the apparatus, filled with living Laminaria and lifted out of the sea water, was about one thousandth of a microfarad.

An advantageous arrangement suggested by Professor G. W. Pierce is shown in Fig. 6.

The frequency is of some importance. The writer has found a thousand cycles convenient; this may be obtained by means of an "audio oscillator" (such as is used in wireless telegraphy) as furnished by the General Radio Co., or by means of a toothed iron wheel re- 
volving in a suitably arranged magnetic circuit such as is furnished by Leeds and Northrup. The results so obtained did not differ from those secured with a Vreeland oscillator.

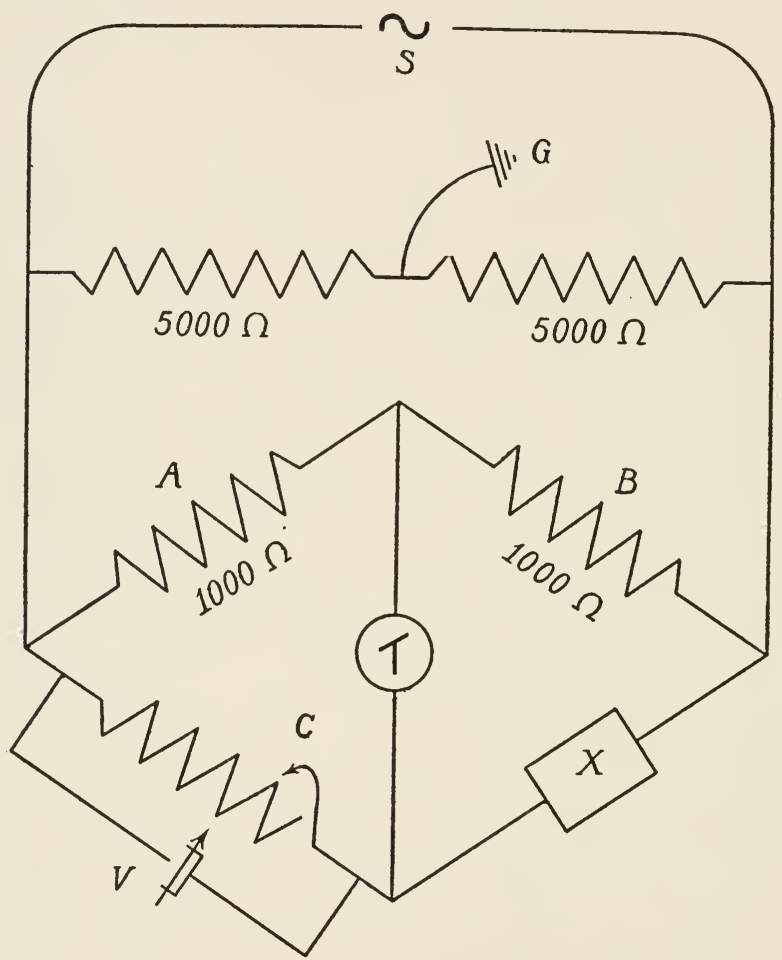

Fig. 6.-Diagram to show bridge and connections. $S$ is an alternating source (1000 cycles or more), $A$ and $B$ are the ratio arms of the bridge, $C$ is the variable resistance of the bridge, $X$ is the unknown resistance (tissue and holder), $T$, telephone, $V$, variable condenser, $G$, a ground wire from the centre of a high resistance (in case the ratio arms of the bridge are unequal the two parts of the high resistawce should also be unequal).

The use of the ordinary lighting circuit (60 cycles) with a vibration galvanometer is recommended by Green (1917). The use of an alternating current galvanometer in connection with a recording device is suggested by Weibel and Thuras (1918). 
For details regarding apparatus the reader is referred to the papers of Hibbard and Chapman (1915), Washburn ${ }^{14}$, Taylor and Acree ${ }^{15}$, Rivers-Moore (1919), Schlesinger and Reed (1919), Newberry (1919), Hall (1919), and Stiles and Jörgensen (1914).

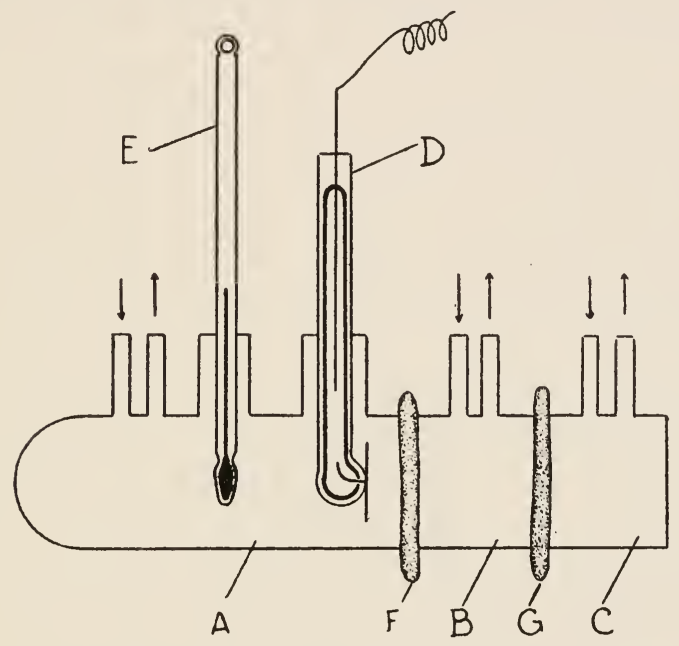

Fra. 7. Electrode carrier, $A$, consisting of a glass tube provided with a series of side tubes to hold an electrode tube, $D$, and a thermometer, $E$, also an inlet tube and an outlet tube. To the right two glass cells, $B, C$, each with an inlet tube and an outlet tube, with disks of tissue, $F$ and $G$.

We may now turn to another form of apparatus which may for convenience be called Type $B$. Fig. 7 shows one end of the apparatus, which consists of an electrode holder, $A$, and a series of glass cells, $B, C$, etc. The electrode holder consists of a glass tube provided with side arms for the admission of the electrode tube, $D$, (which is similar to the tube used in Type $A$ ) as well as of a thermometer, $E$. In addition there is an

${ }^{14}$ See Washburn, E. W. and Bell, J. E. (1913), Washburn, E. W. (1916), Washburn, E. W. and Parker, K. (1917).

See Taylor, W. A. and Acree, S. F. (1916), and previous papers in the same journal. 
inlet tube and an outlet tube by means of which the solution may be changed. Each of the glass cells, $B, C$, etc., has a similar inlet and outlet tube. Each outlet tube has a rubber connection through which liquid can be discharged without wetting the outside of the cells. All of the inlet tubes are connected (by rubber tubing and

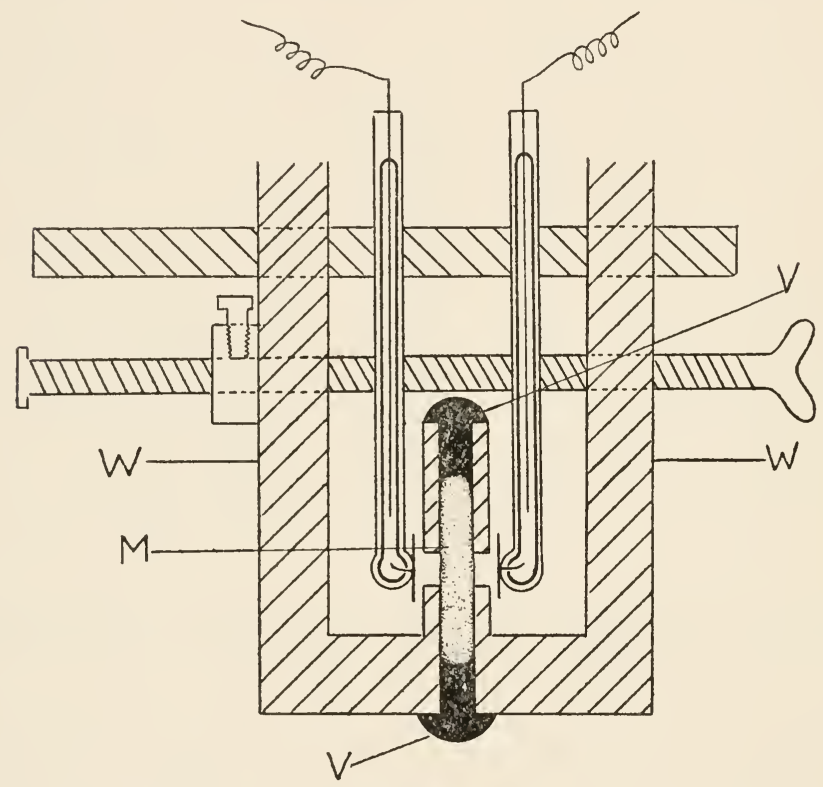

Fig. 8. -Disk of tissue, $\boldsymbol{M}$, the edges surrounded by vaseline, $V V$, with an electrode carrier on each side.

a system of $Y$-tubes) to the same funnel, so that all the cells can be filled simultaneously.

The edges of the glass cells are ground in a plane exactly at right angles to the long axis of the cell. When pieces of Laminaria are placed between them (as at $F$ and $G$ ) and they are pressed together, a tight joint is formed. The series of glass cells (with pieces of mate- 
rial) and an electrode carrier at each end are placed in a $V$-shaped trough with rigid ends; at one end is a screw by means of which they can be foreed together and held with any desired degree of pressure. At the places where the pieces of material are located, the trough is cut away so that they do not come in contact with it. Care is taken to keep the current from leaking along the trough (its surface is covered with paraffin).

The current therefore flows through the glass cells and through the pieces of material placed between them.

The advantages of this type of apparatus are: (1) the end pieces do not have more resistance than those in the middle; (2) the solutions may be changed without disturbing the material.

Types $A$ and $B$ may be combined by substituting disks of Laminaria for the glass cells.

Type $C$ is shown in Fig. 8. It consists of two electrode carriers similar to those in Type $A$. The material is shown at $M$, its edges being completely surrounded by vaseline, $V, V$, so that the current cannot leak out. In many cases it is preferable to use chicle, grafting wax, or art gum in place of vaseline. The apparatus remains partly submerged (the water line being indicated at $W$, $W$ ), thus keeping the temperature more nearly constant. The solutions are chang'ed by siphoning through the openings which admit the electrode tubes. This makes it unnecessary to unscrew and separate the electrode carriers during the experiment.

Type $D$ is shown in Fig. 9. It permits the use of intact plants. One end of the plant is inserted in each of the cells $A$ and $B$ and held in place by a split rubber stopper. The cells $A$ and $B$ are filled with solution. The free portion of the plant is bathed in any desired 
solution until a reading is to be taken, when the solution is allowed to drain off and the reading is made. Care should be taken to prevent the current from leaking through or around the stopper.

The part of the frond which is contained in the stop-

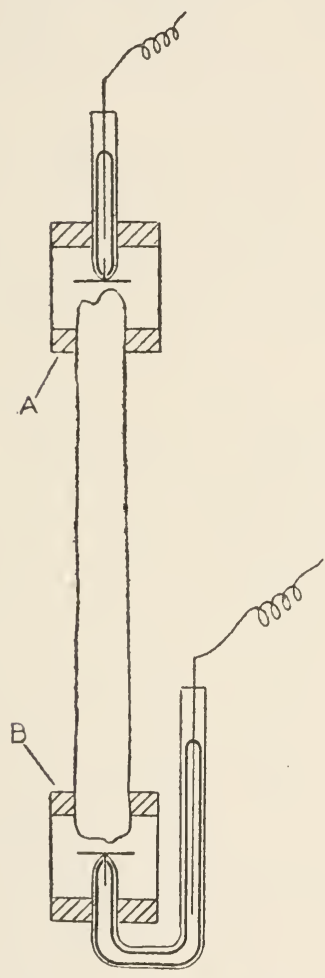

Fig. 9.-Two glass cells, $A$ and $B$, each provided with an electrode with a strip of tissue stretched between.

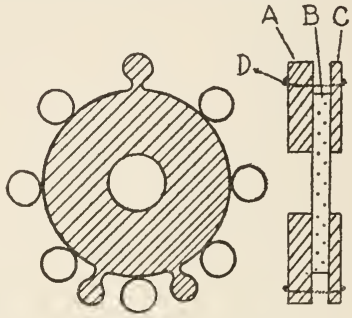

Fig. 10.-A disk of hard rubber, $A$, one of tissue, $B$, and one of celluloid, $C$, tied together with rubber bands, $D$ (all seen in section). Surface view at the left.

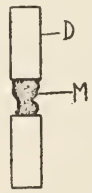

FIG. 11.-Disk of hard rubber, $D$, with a mass of tissue, $M$, wedged in the central opening (seen in section).

per and in the cell may be killed to lessen its resistance.

Material which is too soft to be handled in the manner recommended for Laminaria may be treated as follows: If it forms sheets or membranes it may be fas- 
tened to thin disks of hard rubber $^{16}$ provided with a central opening as shown in Fig. 10, in which $A$ represents the rubber disk (seen in section), $B$ the material, and $C$ another disk of thin rubber or celluloid. These are fastened together by rubber bands, $D$. For this purpose three projecting knobs are provided as shown in the surface view at the left of Fig. 10. The disk is placed in the frame described under Type $A$, and the knobs fit in between the glass rods in the manner shown in Fig. 10 (where the rods appear in section). Every other disk is turned upside down so that the knobs of adjacent disks do not touch and interfere with the close packing of the disks. The disks are treated precisely like the disks of Laminaria as described under Type $A$.

Most of the experiments on frog skin and on Ulva were made with this type of apparatus.

Material which cannot be handled in this way may be treated as shown in Fig. 11, where $D$ represents a hard rubber disk with a central opening into which the material is tightly wedged. The disks are then handled like so many disks of Laminaria. A special type of apparatus has been used in experiments on Zostera ${ }^{17}$.

Experiments were also made with large cells of Nitella, some of which reach a length of 5 or 6 inches and a diameter of a thirty-second of an inch or more. They were packed (Fig. 12) in a trough cut in a block of paraffin (this was then covered with a plate of glass). The trough was previously filled with a solution: this could readily be changed after the cells were in place. The current could be sent lengthwise or across the cells : usually both methods were employed.

20 The edges of each piece of tissue are protected by vaseline.

${ }^{17} C f$. Osterhout $(1919, A)$. 
In order to ascertain the conductivity of the cell sap of Nitella small amounts were expressed (see page 212) and allowed to fill a capillary tube. Platinum electrodes were then inserted into the opposite ends of the tube, care being taken to exclude air bubbles.

By means of these methods a variety of plant and animal material has been studied by the writer. ${ }^{18}$ Cer-

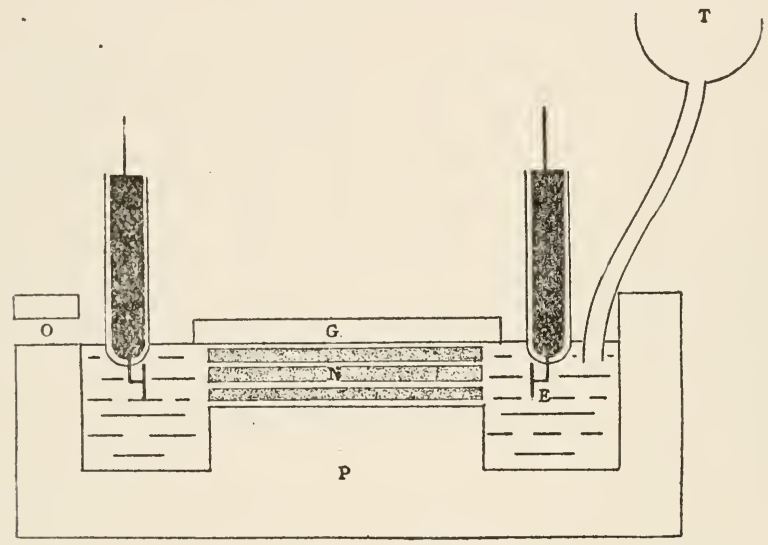

FIG. 12.-Apparatus for measuring the conductivity of $N$ itella. The cells, $N$, are placed in a trough in a block of paraffin, $P$, and covered with plate glass, $G$. The solution is poured in through the funnel, $T$, and runs out through the opening, $O$. At $E$ and $E$ are platinum electrodes.

tain precautions have been observed in the choice of material. It is desirable that the intercellular space or substance shall be constant in amount. This is the case in tissues, such as those of Laminaria, where the cell walls are of a firm consistency and do not change during the experiment. ${ }^{19}$ On the other hand many flowering plants present difficulties, since the spaces between the cells are largely filled with gas, which is

${ }^{18}$ C'f. Osterhout $(1919, A, C)$.

12 Plasmolysis must be avoided since this increases the space between the protoplasmic masses. 
displaced to a varying extent when the tissue is placed in a solution, with the result that the conductivity is altered. In such cases we must select material in which the displacement is very slow or else we must get rid of the gas at the start by submerging the tissue and evacuating by means of an air pump.

As the writer's investigations were largely concerned with alterations in permeability it was necessary to provide for quick changes of reagents and for rapid penetration. This was accomplished by the use of thin sheets of tissue. For example it was found that when Laminaria was transferred from sea water to sea water diluted with an equal volume of distilled water, diffusion was practically completed in 5 to $10 \mathrm{~min}$ utes; this was also the case with the other material used in his investigations.

It is desirable that the thin sheets of tissue should be stiff enough to be handled easily and that they should not adhere to each other, but should tend to separate spontaneously when the pressure is removed so as to allow a free circulation of liquid between them (this is assisted by choosing pieces with a slight curvature).

The material should be able to stand laboratory conditions and the manipulation required by the experiments. It is desirable that it should be available throughout the year. All these requirements are so admirably fulfilled by the marine alga Laminaria agardhii (a common kelp of the Atlantic coast) that it has been largely used in the investigations of the writer. It forms fronds several feet in length, 3 to 6 inches wide (having somewhat the consistency and thickness of a thin leather belt). It remains in normal condition in the laboratory for several weeks if kept in sea water (near $\mathrm{O}^{\circ} \mathrm{C}$.) and is not injured 
by the pressure and the weak electric currents to which it is subjected during the experiments.

The solutions were made with all possible precautions. The salts used were the purest obtainable. The distilled water was, as a rule, twice distilled from quartz or glass, ${ }^{20}$ using cotton plugs in place of cork or rubber stoppers in the distilling apparatus. The first and last parts of the distillate were discarded.

The reaction of the solutions is of great importance. Unless otherwise stated it was close to neutrality.

It may be desirable to add a word of explanation regarding the treatment of results. Most of the curves here presented are time curves in which each point represents the average of several experiments. In such curves it is desirable (as indicated on page 68) to average times (abscissæ) rather than resistances (ordinates).

The probable error of the mean has been calculated in all cases by Peter's formula and expressed as per cent. of the mean. ${ }^{21}$ Since, however, space is lacking to present all the data, a general idea of the accuracy of the results may be given by saying that there is no point on the curve whose probable error of the mean exceeds a certain per cent. of the mean.

The temperature was controlled in short experiments so that the fluctuations did not amount to more than $\pm 2^{\circ} \mathrm{C}$. In longer experiments (lasting several days) greater fluctuations were unavoidable, but the effect of these was minimized by starting all the experiments of a series at the same time so that the fluctuations affected

W Water distilled from a copper still should never be used.

n Thus, if the observations are 99, 104, 102, 97, 100, 96, 103, 101, 98, the mean is 100 , the sum of the deviations 20 and the probable error of the mean $20(.0332)=.664$ which is $.664 \%$ of the mean. 
all of them equally. This answers very well as long as we are comparing experiments which last about the same length of time, but it may happen that one of the series lasts but a short time and after its completion the others proceed at a different temperature. In this case the whole series should be rejected unless the difference in temperature is small.

The temperature coefficient of the electrical conductivity of living Laminaria ${ }^{22}$ is about 1.331; this is higher than that of dead tissue (1.26) which is very close to that of sea water. This coefficient may be employed to correct readings which are not made at the standard temperature, provided the deviation in temperature does not exceed two or three degrees.

${ }^{22} \mathrm{Cf}$. Osterhout $(1914, I)$. 


\section{CHAPTER II}

\section{THE MECHANISM OF THE PROCESS OF DEATH.}

Is studying Laminaria it is found that toxic substances may be divided into two classes according to their effects upon the conductivity of the tissue. The first class includes those which cause a progressive loss of resistance, ending in death $;^{1}$ the second class produces a rise in resistance, ${ }^{2}$ followed by a fall which continues until the death point is reached.

The first group inchudes salts of monovalent metals. ${ }^{3}$ The investigations of Raber (1920) have shown that the higher the valency of the anion (which is combined with the monovalent kation) the more rapid is the fall in resistance. ${ }^{4}$

In subsequent studies ${ }^{5}$ it was found that the trivalent arsenate anion is more efficient than the bivalent molybdate and sulphate and these in turn are more efficient than the univalent formate and chlorate. ${ }^{6}$ Further

${ }^{2}$ Effects of this sort are also produced by hypo- and hypertonic solutions, by drying, by moderate heat $\left(e . g .35^{\circ} \mathrm{C}\right)$, by lack of oxygen, or by exposure to ordinary laboratory conditions.

${ }^{2}$ In some cases a temporary rise is observed, due to the fact that ions diffuse out of the tissue faster than they diffuse in. This is easily recognized because it is as pronounced with dead tissue as it is with living. See Osterhout $(1918, D)$.

${ }^{3} \mathrm{Cf}$. Osterhout $(1912, A)$.

${ }^{4}$ This does not apply to $O H$, which is exceptional.

${ }^{5}$ Raber, O. L. (1921, A).

- In these studies the solutions were not of the same concentration, but all had the conductivity of sea water, except the molybdate, which had the conductivity of $75 \%$ sea water plus $25 \%$ distilled water. Hence the conclusions stated above should be taken in a qualitative rather than a quantitative sense. 
studies by Raber indicate that the rise in resistance which is produced by bivalent and trivalent kations is

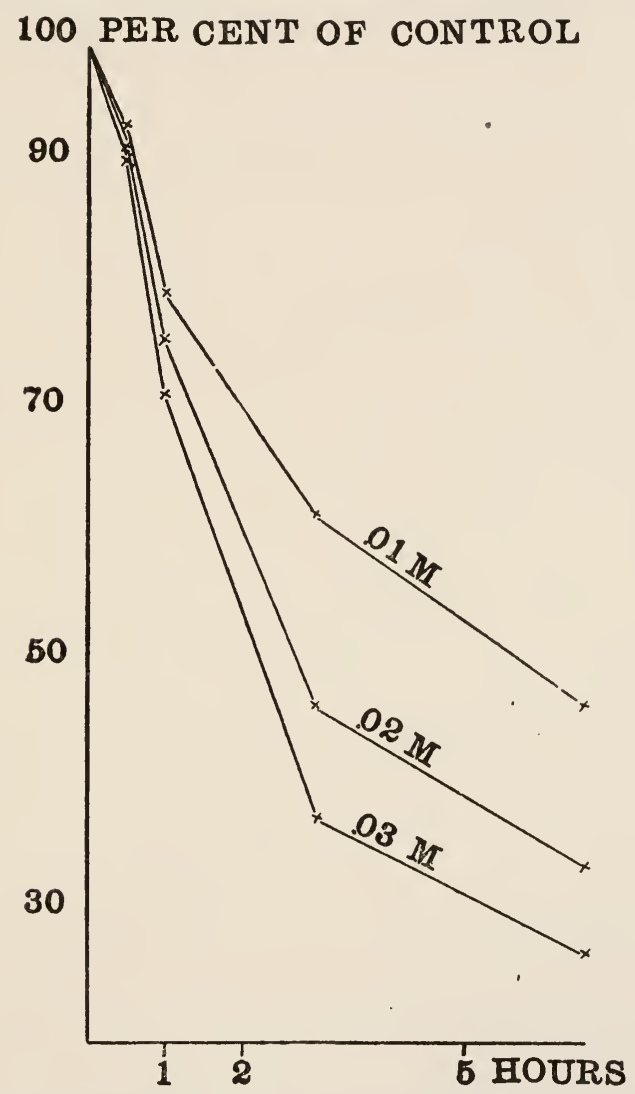

Fig. 13.-Curves of net electrical resistance of Laminaria agardhii in 1793 c.c. $\mathrm{NaCl} 0.52$ $M+207$ c.c. $\mathrm{CaCl}_{2} 0.279 M$ with the addition of $0.01,0.02$, and $0.03 M \mathrm{NaOH}$. "The percentages were calculated on the basis of the net resistance of the control. All readings were taken at $18^{\circ} \mathrm{C}$. or corrected to this temperature. Each curve represents a single experiment less when they are combined with trivalent anions than when combined with univalent.

The writer ${ }^{8}$ has found that $\mathrm{OH}$ is more effective than any other anion in producing a fall in resistance. Since

'Raber, O. L. (1921, $B, C)$.

${ }^{8} \mathrm{Cf}$. Osterhout $(1914, F)$. 
the addition of alkali to sea water produces a precipitate of $\mathrm{Mg}(\mathrm{OH})_{2}$ the experiments were made by adding vari-

\section{PER CENT OF CONTROL}

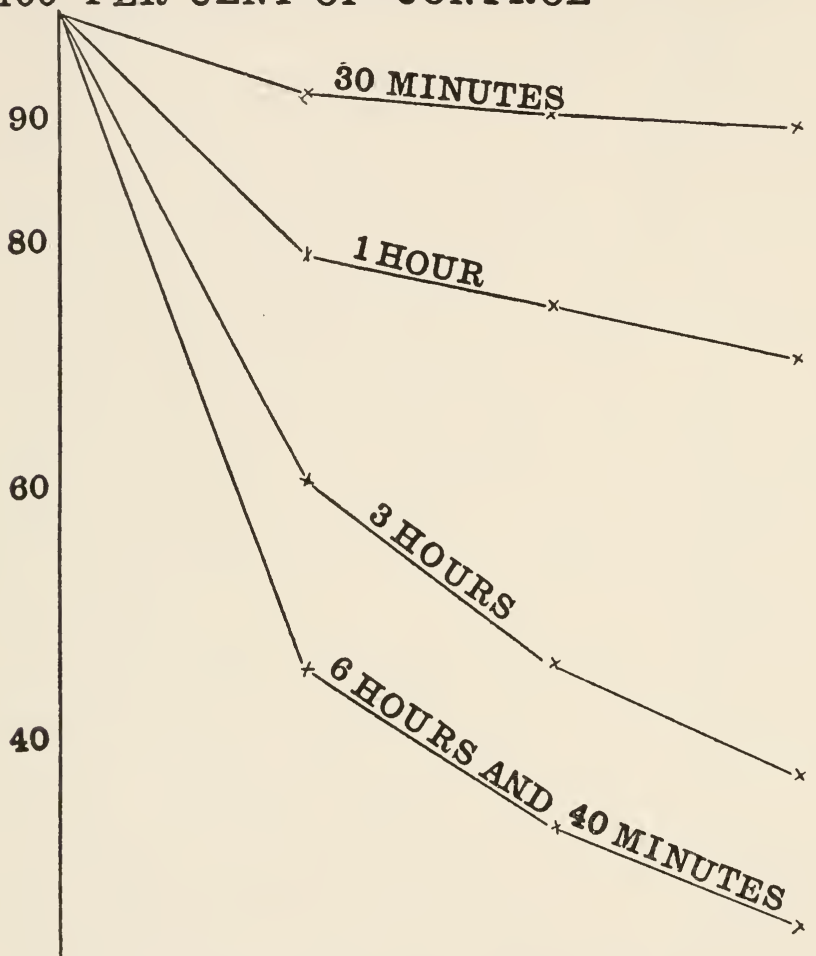

.01

.02

$.03 \mathrm{MIN}_{\wedge} \mathrm{OH}$

FIG. 14.-Curves of net electrical resistance of Laminaria agardhii in 1793 c.c. $\mathrm{NaCl} 0.52$ $M+207$ c.c. $0.279 M$ containing various amounts of $\mathrm{NaOH}$. The abscissæ represent the concentration of $\mathrm{NaOH}$ in the solution: the ordinates represent the percentage of electrical net resistance calculated on the basis of the net resistance of the control. All readings were taken at $18^{\circ} \mathrm{C}$. or corrected to this temperature. Each curve represents a single typical experiment.

ous amounts of $\mathrm{NaOH}$ to a mixture of 1793 cc. $\mathrm{NaCl}$ $0.52 \mathrm{M}+207$ cc. $\mathrm{CaCl}_{2} 0.279 \mathrm{M}$. The results are shown in Figs. 13 and 14.

Experiments were also made by adding alkali to the 
sea water until a slight precipitate of $\mathrm{Mg}(\mathrm{OH})_{2}$ was formed. When tissue was placed in this its resistance

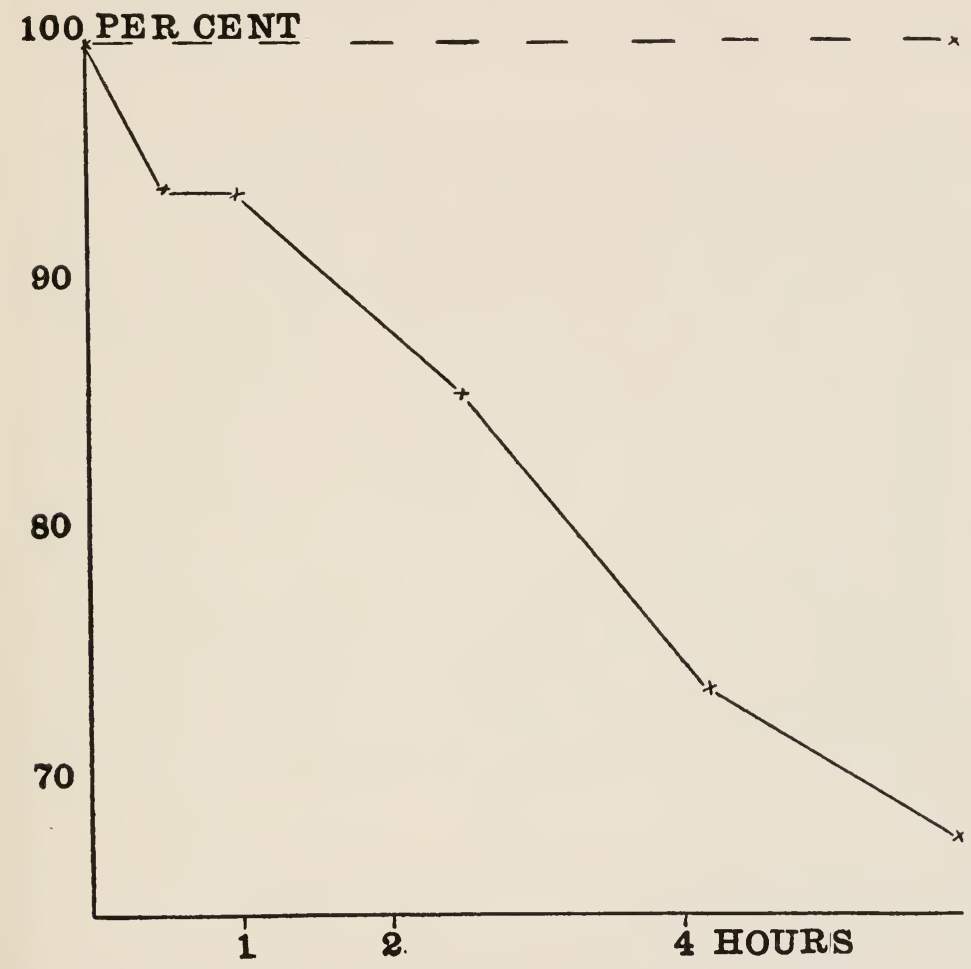

FIg. 15.-Curve of net electrical resistance of Laminaria agardhii in 1975 c.c. sea water plus 48 c.c. $\mathrm{NaOH} 0.22 \mathrm{M}$ ( $p H$ about 10$)$, unbroken line, and of a control in sea water, broken line. The percentages were calculated on the basis of the net resistance in sea water at the beginning of the experiment. The readings were taken at $18^{\circ} \mathrm{C}$. or corrected to this figure. Each curve represents a single typical experiment.

steadily decreased, falling to $68 \%$ in about six hours. (Fig. 15). Haas ${ }^{9}$ has shown that in this case the $\mathrm{pH}$

- Haas, A. R. C. (1916, A). From the table given by Haas it is evident that when the concentration of added $\mathrm{NaOH}$ is about $0.005 M$ (the writer used $0.0052 M$ ) the burette reading has risen from 7.28 to about 7.33 , giving a $\mathrm{pH}$ of about 10 . 
value is about 10 . This is evident from Fig. 16, which shows the increase of $\mathrm{pH}$ value as alkali is added to sea water. $^{10}$ It is therefore evident that small amounts of alkali affect the resistance.

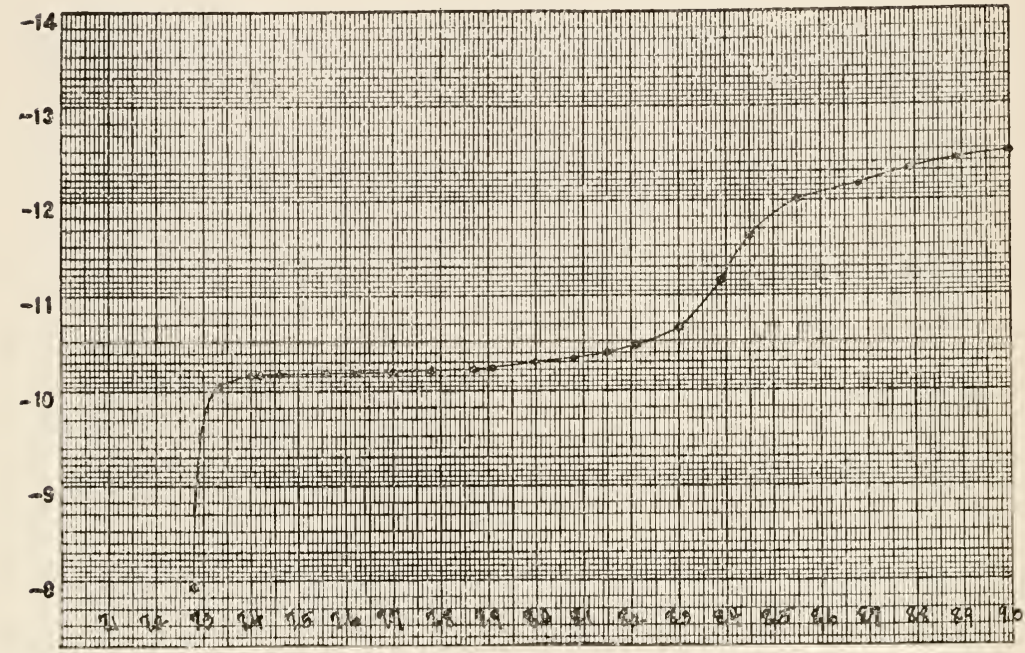

FIg. 16.-Curve showing changes in the hydrogen ion concentration of sea water upon the addition of alkali at $21^{\circ} \mathrm{C}$. Ordinates show the hydrogen ion concentration. In passing from $1 \times 10^{-8}$ to $1 \times 10^{-9}$ the successive divisions are read as follows: $9,8,7,6,5,4,3,2,1,5,1$, each multiplied by $10^{-9}$. Abscissæ show burette readings beginning at $7.28 \mathrm{cc}$. and ending at 9 c.c. The curve shows that on adding alkali to sea water the hydrogen ion concentration at first falls rapidly and then very slowly until the magnesium hydrate has all been precipitated. After this further additions of alkali cause a more rapid fall in the concentration of the hydrogen ion, but this is soon checked by the precipitation of the calcium hydroxide. After the calcium hydroxide is all precipitated further additions of alkali will cause a corresponding decrease in the concentration of the hydrogen ion.

The efficiency of $\mathrm{OH}$ in decreasing resistance is strikingly shown in Fig. 17, which illustrates the rapid fall of resistance in $\mathrm{NaCl}+\mathrm{Ca}(\mathrm{OH})_{2}$ as compared with $\mathrm{NaCl}+\mathrm{CaCl}_{2}$.

Since the alkaline solution contains fewer calcium ions (though the concentration of calcium molecules is the

${ }^{10}$ The sea water was obtained from Woods Hole and was the same as that used in the writer's experiments. 
same) an experiment was made in which the concentration of calcium ions was kept undiminished. For this purpose there was added to a saturated solution of $\mathrm{Ca}(\mathrm{OH})_{2}$ (in distilled water) sufficient $\mathrm{CaCl}_{2} 1.42 M$ to make the conductivity equal to that of sea water. Tissue was placed in this and also in $\mathrm{CaCl}_{2} 0.278 M$. In spite of the fact that the concentration of calcium ions was practically the same in the two solutions the behavior of the tissue was markedly different. In pure $\mathrm{CaCl}_{2}$ the net resistance rose to $171 \%$ of the original net resistance while in $\mathrm{CaCl}_{2}+\mathrm{Ca}(\mathrm{OH})$. it rose to only $113 \%$. At the end of forty-five minutes the resistance in $\mathrm{CaCl}_{2}$ was $146 \%$, while in $\mathrm{CaCl}_{2}+\mathrm{Ca}(\mathrm{OH})_{2}$ it was only $23 \%$.

These experiments make it evident that small amounts of $\mathrm{NaOH}$ are able to produce a considerable increase in permeability. ${ }^{11}$

Let us now consider those substances which increase the resistance of the tissue. In general we find thatbivalentkations are veryeffective in this respect ${ }^{12}$

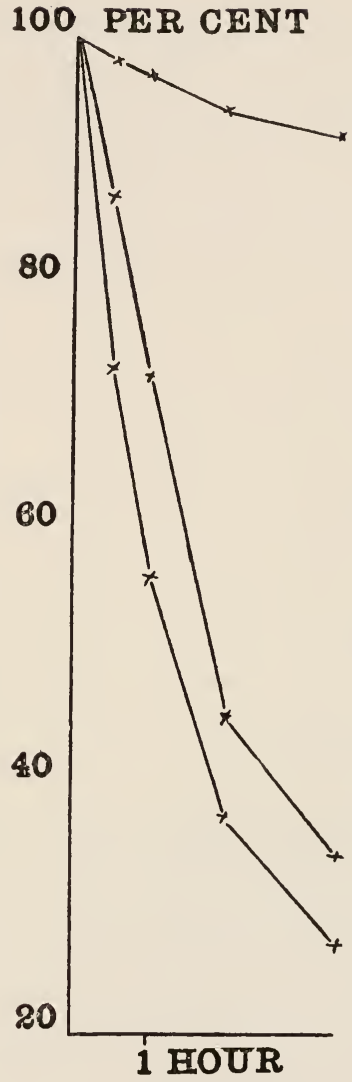

FIG. 17.-Curves of net electrical resistance of Laminaria afardhii in a solution containing $\mathrm{NaCl} 97.2$ mols of $\mathrm{NaCl}$ to $2.8 \mathrm{mols}$ of $\mathrm{CaCl}_{2}$ (uppermost curve); a solution containing $97.2 \mathrm{mols} \mathrm{NaCl}$ to $2.8 \mathrm{mols}$ $\mathrm{Ca}(\mathrm{OH})_{2}$ (middle curve) and in $\mathrm{NaCl} 0.52 M$ (lowest curve). All the solutions had the conductivity of sea water. All readings were taken at $18^{\circ} \mathrm{C}$. or corrected to this temperature. Each curve represents a single typical experiment.

${ }^{11} C f$. Osterhout (1914, $\left.F\right)$.

${ }^{12}$ Cf. Osterhout $(1915, D)$. 
and trivalent still more so. ${ }^{13}$ In most cases the effect is so striking that the addition of the solid salt to the sea water, although decreasing the resistance of the solution, nevertheless increases the resistance of the living tissue so greatly that the net result is an increase in the resistance of the tissue plus solution. As this does not happen

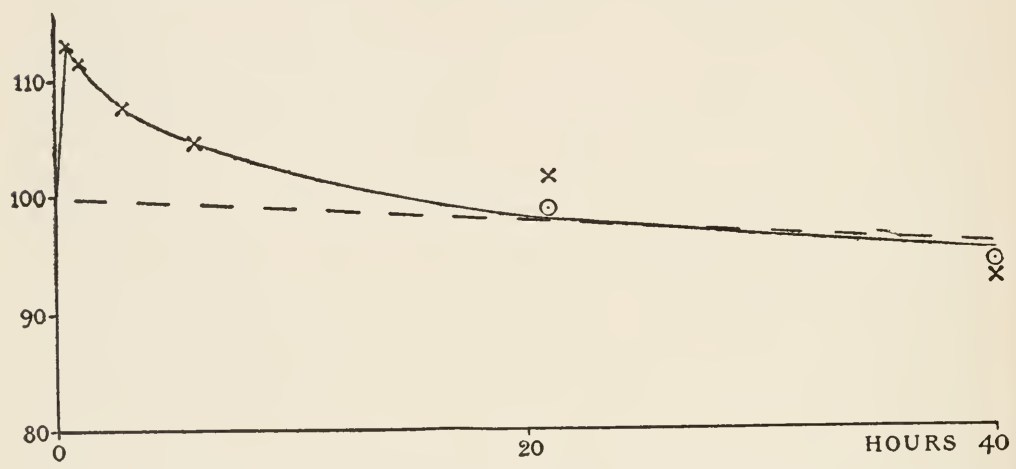

FIG. 18.-Curve showing the net electrical resistance of Laminaria agardhii in sea water to which was added sufficient cobalt chloride (in the form of dry salt) to make the concentration $0.005 \mathrm{M}$. Solution neutral to litmus. All readings were taken at $18^{\circ} \mathrm{C}$. or corrected to this temperature. The curve represents a single experiment. Dead tissue showed no rise.

with dead tissue the increase must be due to an alteration in the living protoplasm. ${ }^{14}$ It is therefore evident that the current must flow in part through the living protoplasm, as well as through the cell walls.

In the case of certain bivalent kations $(\mathrm{Mn}, \mathrm{Co}, \mathrm{Cd}, \mathrm{Ni}$,

${ }^{13} C f$. Osterhout $(1915, E)$.

is It might be suggested that the increase in resistance is due to $\mathbf{a}$ decrease of the spaces between the protoplasmic masses brought about by an expansion of the protoplasm or by a shrinkage of the cell wall. Microscopic and macroscopic examination shows that this does not occur. The tendency is, on the other hand, to increase the spaces between the cells, as the result of incipient plasmolysis.

When dead Laminaria is transferred from sea water to $\mathrm{CaCl}_{2} 0.278 \mathrm{H}$ there is a very slight shrinkage which, however, is entirely inadequate to cause a noticeable rise in resistance if it occurs in the cell walls of living tissue. 
$\mathrm{Zn}$ ) the addition to sea water of sufficient dry salt to make the concentration $0.005 M$ kept the resistance above that of the control for several hours (Fig. 18). In other cases $\left(\mathrm{FeSO}_{4}\right.$ and $\left.\mathrm{SnCl}_{2}\right)$ the resistance rose, but soon fell below that of the control. ${ }^{15}$

In similar experiments with trivalent and tetravalent

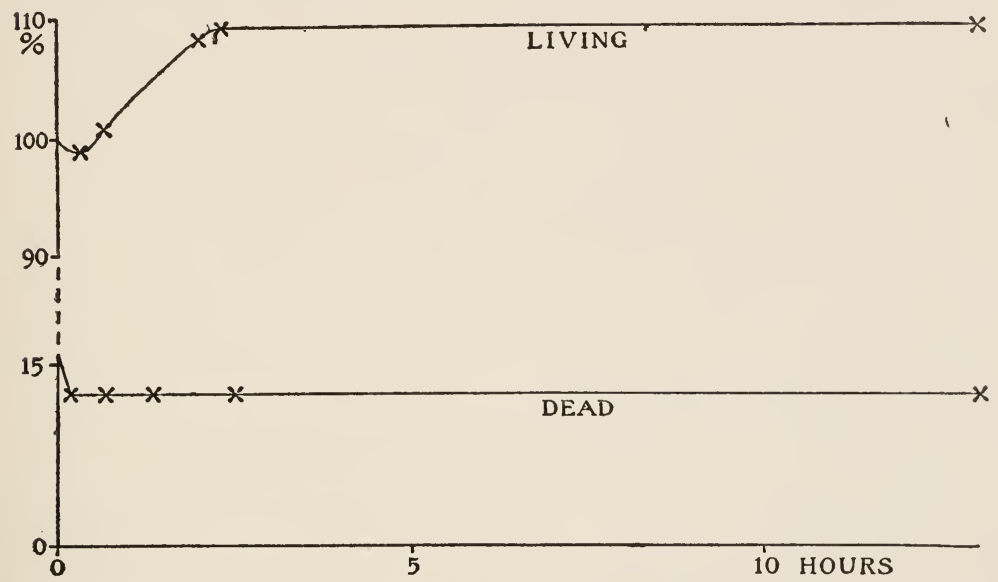

FIa. 19.-Curve showing the net electrical resistance of Laminaria agardhii in 1000 c.c. sea water plus 10 c.c. $\mathrm{CaCl}_{2}$ 5.0 M. Upper curve, living tissue; lower curve, dead tissue. All readings were taken at $18^{\circ} \mathrm{C}$. or corrected to this temperature. Each curve represents a single experiment.

kations it was found that while the resistance remained above that of the control for ten hours or more in the case of $\mathrm{La}\left(\mathrm{NO}_{3}\right)_{3}$ and $\mathrm{Y}\left(\mathrm{NO}_{3}\right)_{3}$ this was not the case ${ }^{16}$ with $\mathrm{Fe}_{2}\left(\mathrm{SO}_{4}\right)_{3}$ and $\mathrm{Th}\left(\mathrm{NO}_{3}\right)_{4}$.

These experiments were varied by adding strong solutions to the sea water in place of the dry salt. The

${ }^{10}$ In the case of $\mathrm{SnCl}_{2}$ this may be due to the acidity of the solution. The concentration is $.005 \mathrm{MI}$ in the case of each of these salts.

${ }^{28}$ The solutions containing $\mathrm{Fe}_{2}\left(\mathrm{SO}_{4}\right)_{8}$ and $\mathrm{Al}_{2}\left(\mathrm{SO}_{4}\right)_{8}$ were acid. The dry salts were added to the sea water in sufficient amounts to make the concentrations as follows: $0.042 M \mathrm{La}\left(\mathrm{NO}_{3}\right)_{3}, 0.006 M \mathrm{Ce}\left(\mathrm{NO}_{3}\right)_{3}, 0.007$ $M, Y\left(N_{3}\right)_{3}, 0.0025 M \mathrm{Fe}_{2}\left(\mathrm{SO}_{4}\right)_{3}, 0.01 M \mathrm{Al}_{2}\left(\mathrm{SO}_{4}\right)_{3}, 0.006 M$ Th $\left(\mathrm{NO}_{3}\right)_{4}$. 
result of such an experiment with $\mathrm{CaCl}_{2}$ is shown in Fig. 19. It will be observed that while the resistance of

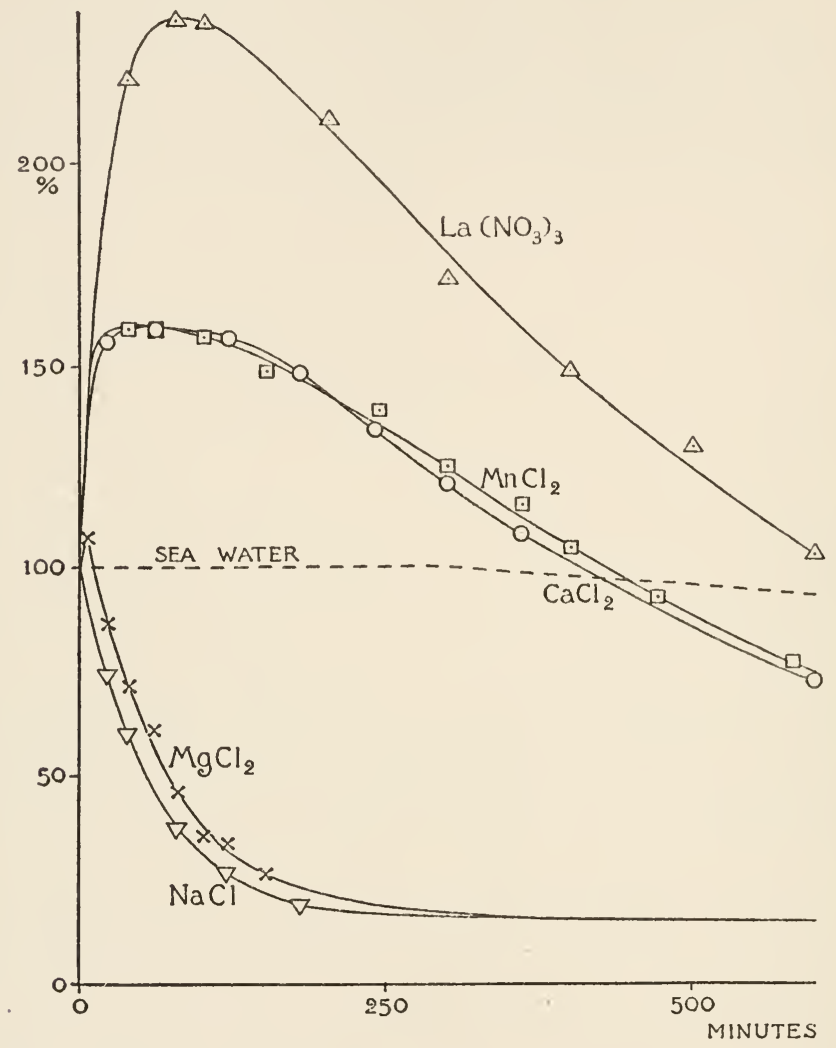

FIG. 20.-Curves showing the net electrical resistance of Laminaria agardhii in solutions of the same conductivity as sea water, $i . e$, in $\mathrm{La}\left(\mathrm{NO}_{3}\right)_{3}$ about $0.126 \mathrm{M}, \mathrm{CaCl}_{2} 0.278 \mathrm{M}_{\text {., }} \mathrm{MnCl}_{2}$ about $0.317 M, \mathrm{MgCl}_{2}$ about $0.28 M$ and in $\mathrm{NaCl} 0.52 M$. The curves for $\mathrm{La}_{2}\left(\mathrm{NO}_{2}\right)_{3}, \mathrm{MnCl}_{2}$ and $\mathrm{MgCl}_{2}$ represent single typical experiments (all readings were taken at $18^{\circ} \mathrm{C}$. or corrected to this temperature); the curves for $\mathrm{CaCl}_{2}$ and $\mathrm{NaCl}$ represent the averages of six or more experiments; probable error of the mean less than $10 \%$ of the mean (all readings were taken at $18^{\circ} \mathrm{C}$. or corrected to this tempernture).

the living tissue increases ${ }^{17}$ to $109.2 \%$ that of the dead

${ }^{17}$ The temporary fall at the start is due to the increased conductivity of the solution contained in the apparatus and in the cell walls. 
tissue falls from $15.2 \%$ to $13.53 \%$, thereby losing $11 \%$ of the resistance it had in sea water. This corresponds quite closely to the loss of resistance of the sea water itself upon the addition of this amount of $\mathrm{CaCl}_{2}$.

Experiments were also performed by placing tissue in solutions (having the same conductivity as sea water) which contained only one salt. It was found (Fig. 20) that the bivalent $\mathrm{Ca}, \mathrm{Ba}, \mathrm{Sr}$, and $\mathrm{Mn}$ raised the resistance (increasing it to $160 \%$ or more) while the trivalent La and Ce gave a much greater rise (increasing it to $220 \%$ or more). On the other hand, $\mathrm{Mg}$ gave very little rise (increasing the resistance as a rule to not more than $115 \%)$. In this respect its behavior is not unexpected, since it is usually less effective than other bivalent kations (as for example in antagonizing the effects of $\mathrm{Na}$ ). ${ }^{18}$

It was found that Ulva (sea lettuce) and Zostera (eel grass) resemble Laminaria in showing a rise with $\mathrm{MgCl}_{2}$ and a much greater rise with $\mathrm{CaCl}_{2} \cdot{ }^{19}$ Rhodymenia palmata (dulse) agrees with Laminaria in showing a rise in resistance in ${ }^{20} \mathrm{CaCl}_{2}, \mathrm{BaCl}_{2}, \mathrm{SrCl}_{2}, \mathrm{MnCl}_{2}$, and $\mathrm{NiCl}_{2}$, and a greater rise in alum, $\mathrm{Ce}\left(\mathrm{NO}_{3}\right)_{3}$, and $\mathrm{La}\left(\mathrm{NO}_{3}\right)_{3}$. The rise with $\mathrm{MgCl}_{2}$ is less than with $\mathrm{CaCl}_{2}$, but the latter is less than that found with Laminaria (Fig. 21).

Experiments on frog skin ${ }^{21}$ showed a rapid rise in $\mathrm{CaCl}_{2}$ (resistance increased to $140 \%$, or less) followed by a fall. In $\mathrm{La}\left(\mathrm{NO}_{3}\right)_{3}$ the rise is greater (resistance increased to $190 \%$ or less) and in $\mathrm{MgCl}_{2}$ it is less (resistance increased to $110 \%$, or less). It is evident

\footnotetext{
18 See Chapter IV.

${ }^{10}$ Osterhout $(1919, A)$.

${ }^{20}$ Osterhout $(1919, A)$.

${ }^{21} C f$. Osterhout (1919, C.). 
that the behavior of frog skin in these solutions resembles that of Laminaria. On the other hand, such substances as $\mathrm{NaCl}$ and $\mathrm{KCl}$ produce in frog skin and in Rhodymenia no rise, but only a fall of resistance, just as in Laminaria.

Gray (1915) found that a rise in resistance is pro-

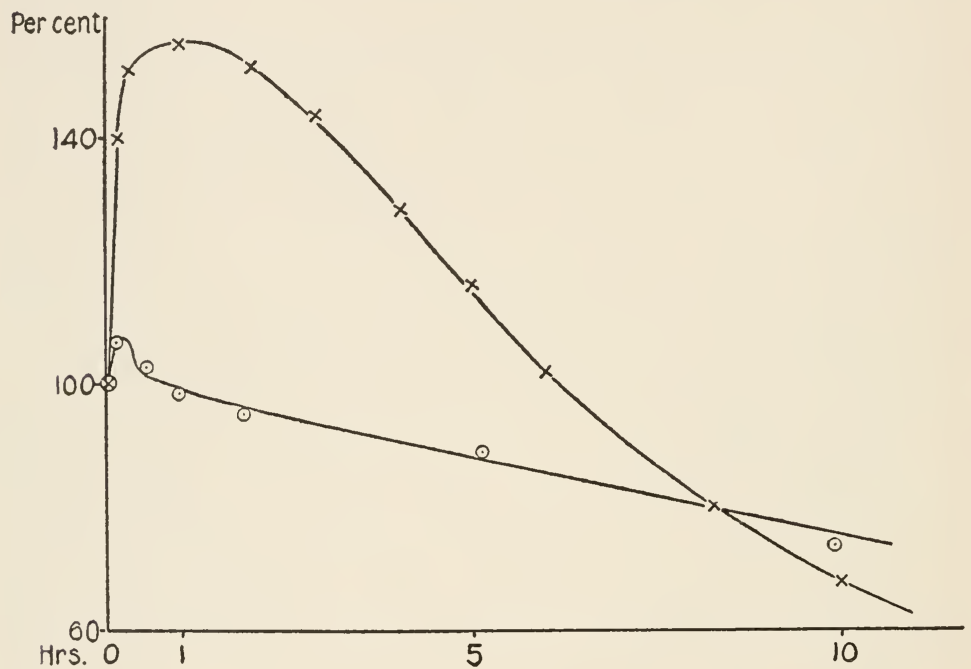

Fia. 21. - Curves showing the effect of $\mathrm{CaCl}_{2} 0.278 \mathrm{M}$ on the net electrical resistance of Laminaria agardhii (upper curve) and of Rhodymenia palmata (lower curve). The ordinatea denote net electrical resistance. Temperature $17 \pm 2^{\circ} \mathrm{C}$. Average of six experiment. Probable error of the mean less than $3 \%$ of the mean.

duced in echinoderm eggs by La and Ce. Shearer (1919, B) was unable to find such an effect in bacteria.

It was of especial interest to investigate the effect of the hydrogen ion, which in many respects behaves unlike other monovalent kations. The first experiments were made by adding to sea water a solution of $\mathrm{HCl}$ of the same conductivity as the sea water (about $0.119 \mathrm{M}$ ). The results are shown in Fig. 22.

It will be seen that a rise occurred and that in higher 


\section{MECHANISM OF PROCESS OF DEATH 51}

concentrations the maximum was reached earlier, while in the lower concentrations it occurred later. It is evident that as the concentration increases, the rise in resistance is more rapid and the maximum point is passed more quickly. If the concentration be sufficiently increased,

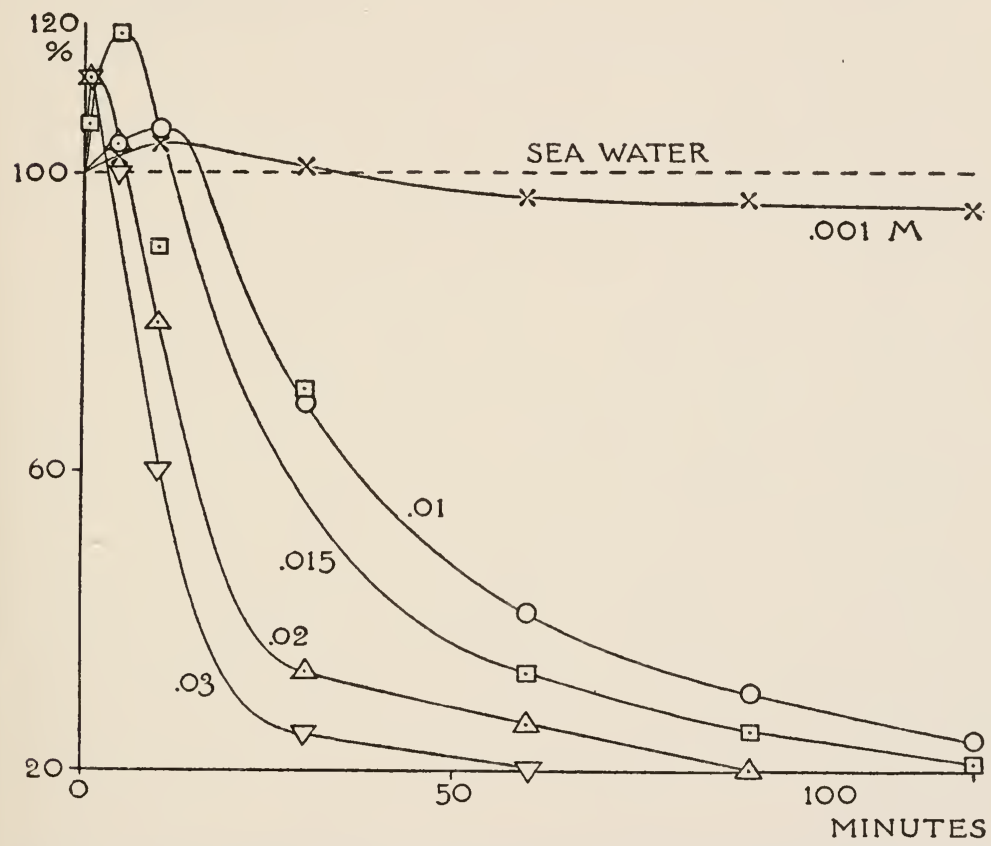

Fra. 22.-Curves showing net electrical resistance of Laminaria agardhii in sea water containing various amounts of $\mathrm{HCl}$, as shown by the figures attached to the curves. Each curve represents a single experiment. All readings were taken at $18^{\circ} \mathrm{C}$. or corrected to this temperature. Each curve represents a single typical experiment.

the period of increased resistance becomes less and less, until it becomes difficult to detect it. The relation between concentration and changes in resistance is better shown in Fig. 23.

Experiments with acetic acid also showed a rise in resistance. 


\section{PER CENT}

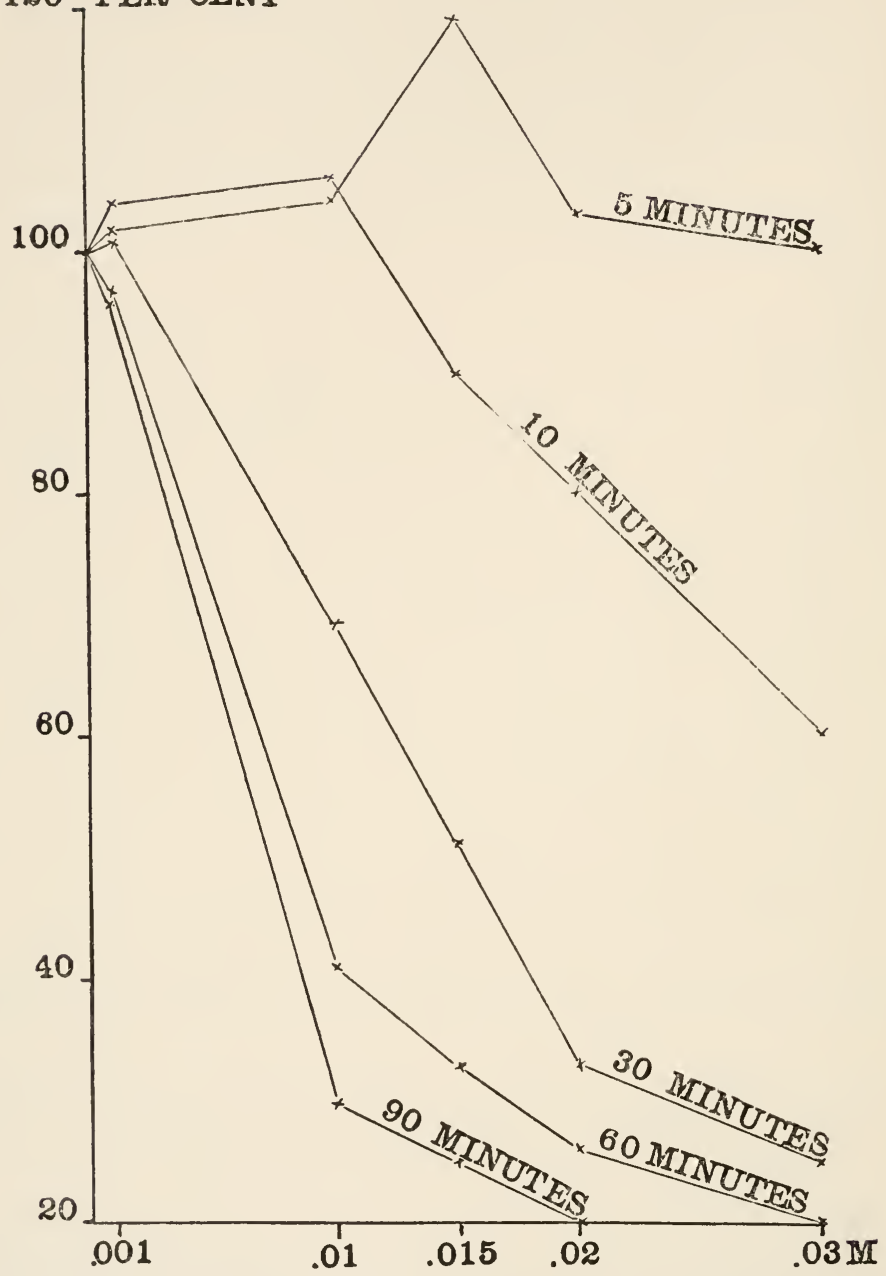

FIG. 23.-Curves of net electrical resistance of Laminaria agardhii in sca water containing various amounts of $\mathrm{HCl}$. The ordinates represent net resistance. The abscissæ represent concentrations of $\mathrm{HCl}$. All readings are taken at $18^{\circ} \mathrm{C}$. or corrected to this temperature. Each curve represents a single typical experiment.

In the previous experiments with alkali ${ }^{22}$ it was found 
necessary to employ a solution containing $\mathrm{NaCl}+\mathrm{CaCl}_{2}$, since the addition of alkali to sea water causes a precipitate of $\mathrm{Mg}(\mathrm{OH})_{2}$. In order to compare the effect of acid with that of alkali a solution of $\mathrm{HCl}$ having the same

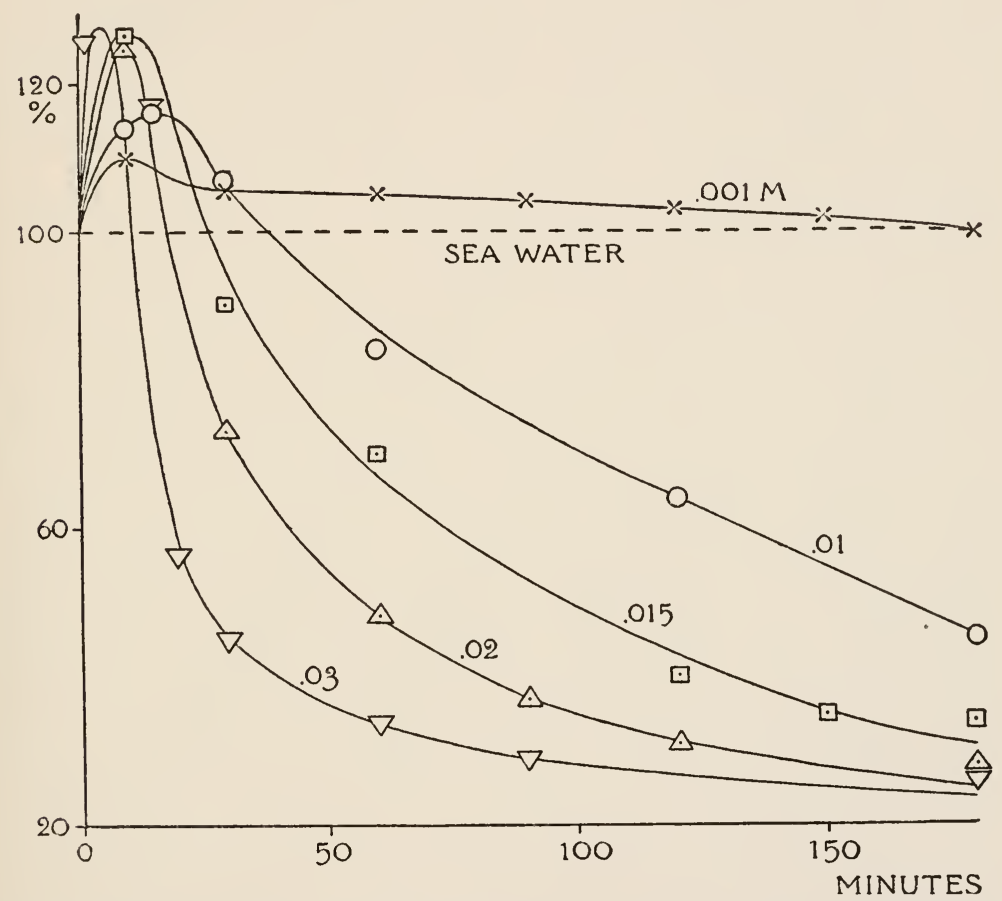

FIa. 24.-Curves showing net electrical resistance of Laminaria agardhii in 1793 c.c. $\mathrm{NaCl}$ $0.52 M+207$ c.c. $\mathrm{CaCl}_{2} 0.279 M$ containing various amounts of $\mathrm{HCl}$, as shown by the figures attached to the curves. Each curve represents a single experiment. All readings were taken at $18^{\circ} \mathrm{C}$. or corrected to this temperature.

conductivity as the sea water was added to a solution containing 1793 cc. $\mathrm{NaCl} 0.52 \mathrm{M}+207$ ce. $\mathrm{CaCl}_{2} 0.278 \mathrm{M}$ (this solution had the same conductivity as sea water). The results are shown in Fig. 24; it will be noted that they are in good agreement with those obtained by adding 


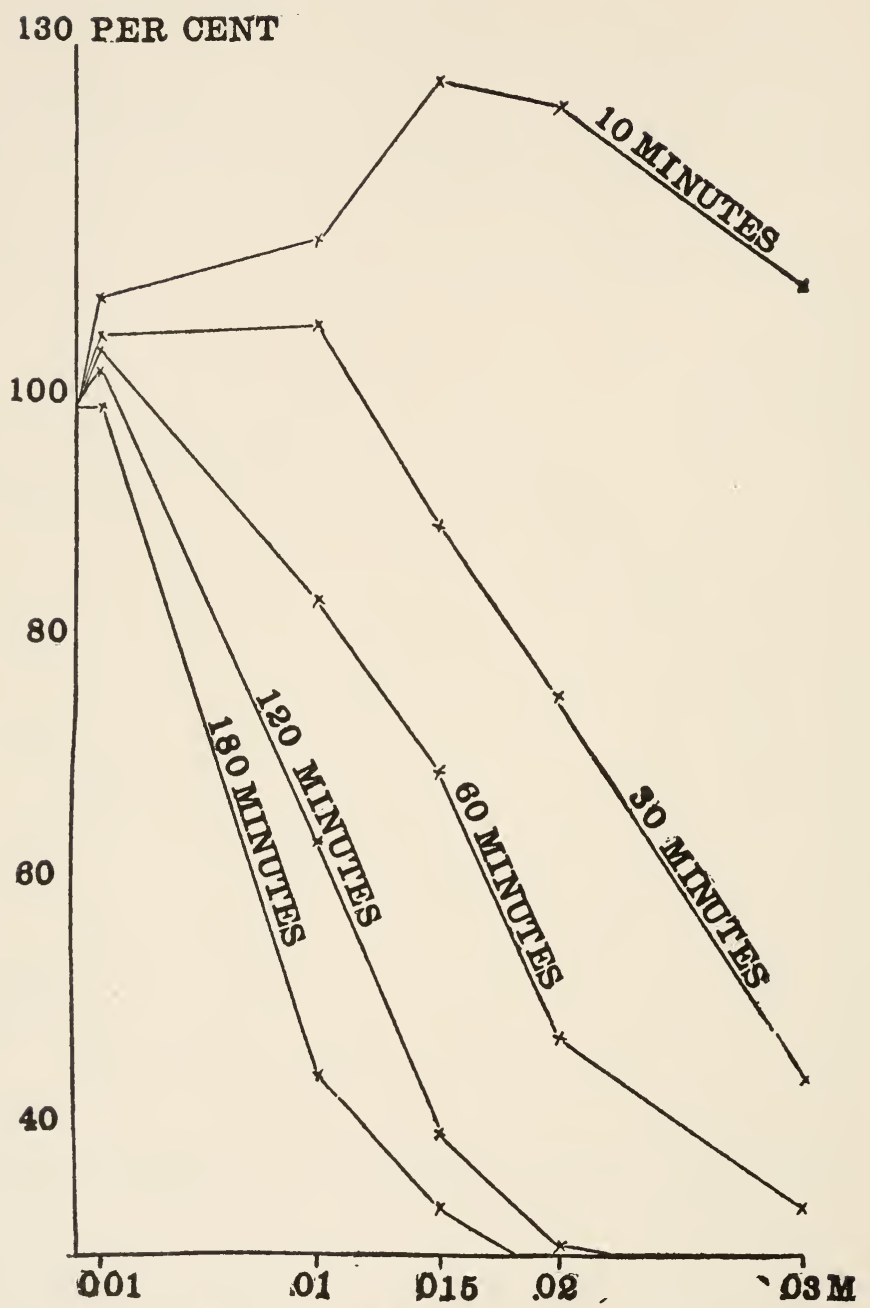

Fro. 25.-Curves of net electrical resistance of Laminaria agardhii in (1793 c.c. $\mathrm{NaCl}$ $0.52 \mathrm{M}+207$ c.c. $\mathrm{CaCl}_{2} 0.278 \mathrm{M}$ ) containing various amounts of $\mathrm{HCl}$. The ordinates represent net resistance; the abscissm represent concentrations of $\mathrm{HCl}$. All resdings were taken at $18^{\circ} \mathrm{C}$. or corrected to this temperature. Each curve represents a single typical experiment.

acid to sea water. These relations are still more clearly shown when the results are plotted as shown in Fig. 25. 
These results present a marked contrast to those obtained by the use of alkali; with the latter there is no rise in resistance, but, on the contrary, a fairly rapid fall which continues until the death point is reached.

In view of the great importance of acid and alkali in life processes these results deserve especial consideration since it would seem that slight changes in the reaction of the medium affect conductivity and permeability.

It may be added that experiments with frog skin ${ }^{23}$ showed that in this case also $\mathrm{HCl}$ produces a rapid rise in resistance followed by a fall. Shearer $(1919, \mathrm{~A})$ found a rise in the case of bacteria.

The writer has also found ${ }^{24}$ that high concentrations of $\mathrm{KCN}$ (0.01 to $0.381 \mathrm{M}$ ) produce a slight temporary rise in the resistance of Laminaria. ${ }^{25}$

It is of considerable interest to find that certain organic substances are able to increase resistance. As an example of this we may consider experiments with bile salts. ${ }^{26}$ In these investigations Na-taurocholate was added to the sea water, which was then restored to its normal conductivity and made approximately neutral to litmus. ${ }^{27}$ All concentrations employed produced an immediate increase in resistance followed by a fall, as illustrated in Fig. 26. Under the conditions of the experiment, the rise lasted about an hour. An increase in resistance was also observed with Ulva rigida (sea

${ }^{23} C f$. Osterhout $(1919, C)$.

24 Osterhout $(1917, A)$.

${ }^{25}$ Possibly this might have been greater had not the solution been alkaline.

${ }^{28}$ Osterhout $(1919, B)$.

${ }^{27}$ The amounts varied from 0.8 to $1.5 \mathrm{gm}$. added to 1000 c.c. of sea water. If the $\mathrm{Na}$-taurocholate were pure $1 \mathrm{gm}$. in 1000 c.c. would make the concentration about $0.002 M$, but its purity is doubtful. 
lettuce) and Rhodymenia palmata (dulse); in the latter case it was much less than in Laminaria.

An increase has also been observed in experiments with ether, chloroform, chloral hydrate, and alcohol. ${ }^{28}$

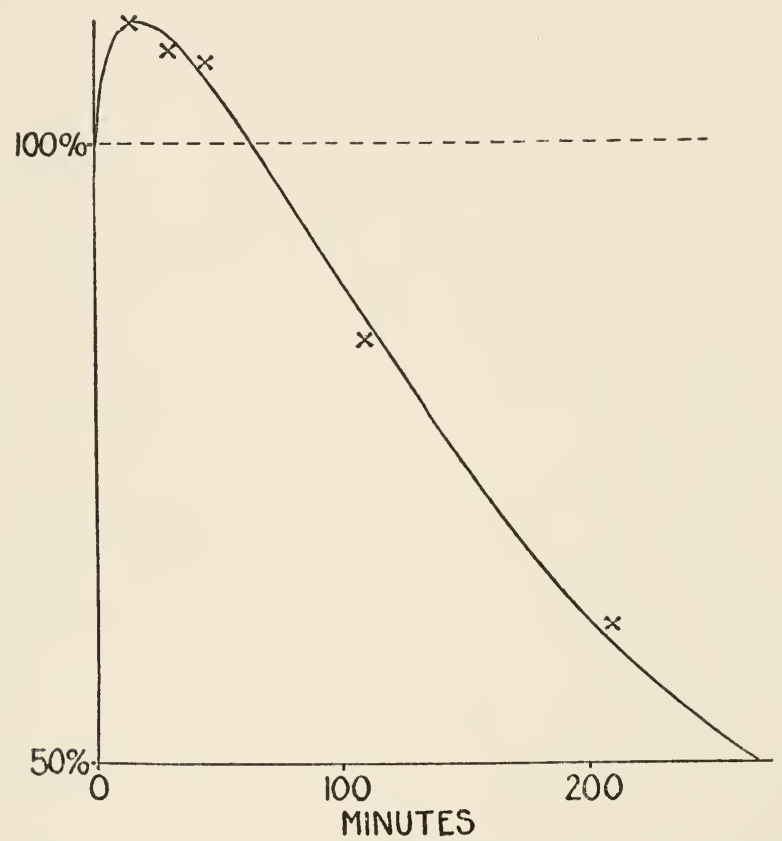

FIG. 26.-Curve showing rise in net electrical resistance of Laminaria agardhii produced by adding $1 \mathrm{gm}$. of Na-taurocholate to $1000 \mathrm{c.c}$. of sea water (solid line). Control in sea water, dotted line. Average of two experiments; probable error of the mean less than $2.3 \%$ of the mean. Temperature $19 \pm 2^{\circ} \mathrm{C}$.

The question arises whether the rise due to these organic substances differs from that produced by inorganic salts and by acids. The writer is inclined to believe that this may be the case, but prefers to await the results of additional experimentation before reaching a definite decision.

${ }^{28}$ See Chapter V. 
The fact that in all these cases there is a rise in resistance followed by a fall suggests that there are two processes at work, one producing an increase and the other a decrease. In order to picture a mechanism which would account for this the writer has assumed that at the surface of the cell there is a substance, $M$, forming a continuous layer ${ }^{29}$ whose thickness determines the amount of resistance. It is assumed that the thickness of this layer is increased by the breaking down of a substance, $A$, to form $M$, according to the monomolecular reaction $A \longrightarrow M$. At the same time $M$ breaks down to form a substance, $B$, according to the monomolecular reaction, $M \longrightarrow B$. The two reactions go on simultaneously according to the scheme ${ }^{30} A \longrightarrow M \longrightarrow B$.

It is obvious that if the rates of the reactions are such that $M$ is formed as rapidly as it is decomposed, it will remain constant in amount; and that an increase in the velocity of the first reaction will cause $M$ to increase, while an increase in the velocity of the second reaction will cause $M$ to decrease.

The nature of this process is evident from a consideration of Fig. 27. If the reservoir $A$ be filled with water while $M$ and $B$ are empty, and if water be allowed to flow from $A$ into $M$, the amount of water in $M$ (for convenience this amount is called y) will first increase and then decrease. The rate of increase and decrease and the maximum attained will depend on the relation between the two outlets $K_{1}$ and $K_{2}$. We may suppose that if $K_{1}$ is equal in diameter to $K_{2}$, we get the upper

It is recognized that the hypothesis will apply if the layer is not continuous and also if the change in properties of the layer is other than that of thickness.

${ }^{30}$ These reactions are regarded as reversible or practically so. 
curve shown in the figure, while if $K_{1}$ is less than $K_{2}$ we get the lower curve (in the latter case both outlets are supposed to be smaller than in the former). This is analogous to what occurs in the reaction $A \rightarrow M \rightarrow \vec{B}$ if $K_{1}$ is the velocity constant of $A \rightarrow M$ and $K_{2}$ is the velocity constant of $M \longrightarrow B$.

We assume that in sea water $A$ is renewed as fast

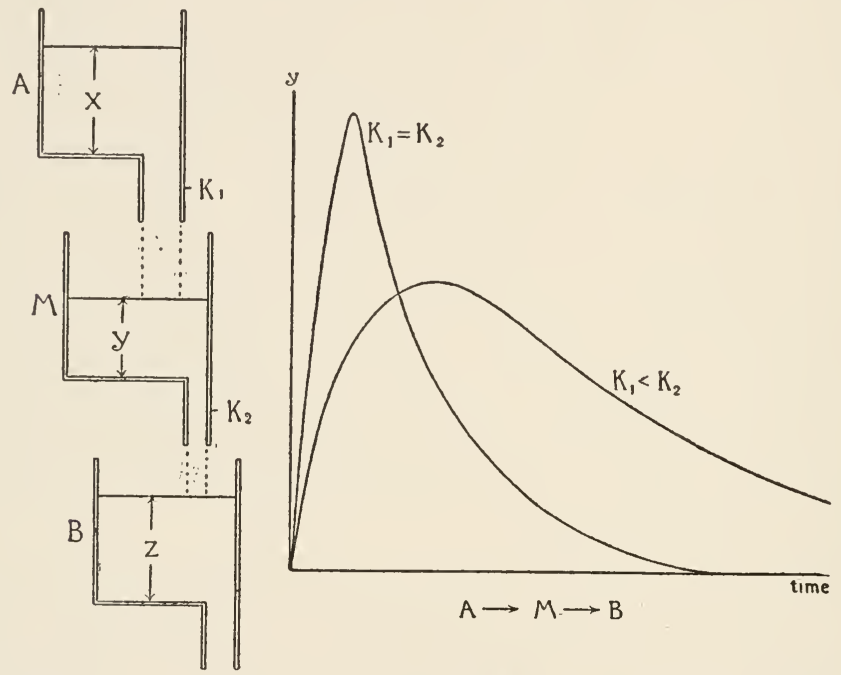

F16. 27.-Diagram illustrating consecutive reactions in which a substance $M$ is formed by the reaction $A \rightarrow M$ and decomposed by the reaction $M \rightarrow B$.

as it is decomposed and has the constant value 2700 , and that $M$ has the constant value 90 . On transferring from sea water to $\mathrm{NaCl} 0.52 \mathrm{M}$ the production of $A$ ceases, but $A$ continues to break down to form $M$ and $B$. The velocity constants $^{31}$ in $\mathrm{NaCl}$ are taken as $K_{1}=0.018$ and $K_{2}=0.540$.

We may now calculate the resistance, putting Net Resistance $=M+10$, because the base line of the death

suterhout $(1916, D)$. 


\section{MECHANISM OF PROCESS OF DEATH 59}

curve, as shown in. Fig. 28, is not zero but ten. $M$ is therefore equal to the resistance of the living tissue after the resistance of the dead tissue and the resistance of the apparatus has been subtracted. We may call this the residual resistance, while the resistance of the living tissue minus that of the apparatus is called the net resistance.

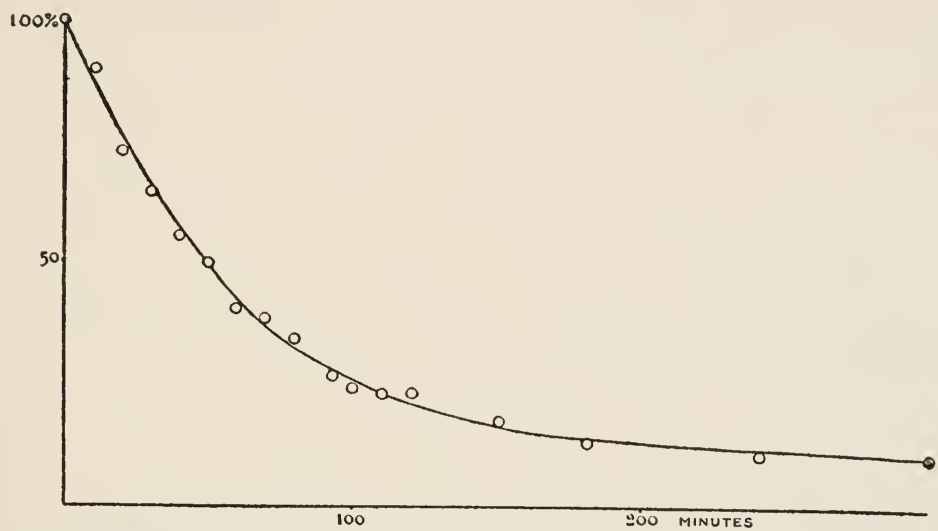

F10. 28.-Death curve of Laminaria agardhii in $\mathrm{NaCl} 0.52 M$. The curve shows the calculated value of the resistance: the observed values are shown by the points $(\mathrm{O}, \mathrm{O})$. All readings were made at $15^{\circ} \mathrm{C}$. or corrected to this temperature. Each point represents the average of ten or more experiments. Probable error of the mean less than $10 \%$ of the mean.

In our calculations we may employ the methods used in calculating the decomposition of radioactive substances. ${ }^{32}$

If we start with $A$ and $M$ in equilibrium in sea water according to the scheme $A \longrightarrow M \longrightarrow B$, and if the value of $A$ is called $A_{0}$ and that of $M$ is called $M_{0}$, the amount of $M$ which is formed in each unit of time is $A_{0} K_{1}$, and the amount of $M$ which decomposes in each unit of time is $M_{0} K_{2}$. Since at equilibrium, $A_{0} K_{1}=M_{0} K_{2}$, the value of $M$ remains constant.

If the tissue is transferred to $\mathrm{NaCl} 0.52 \mathrm{M}$ we have at

Rutherford, E. (1913) p. 421. 
the instant of transfer the following values: $A_{0}=2700$, $M_{0}=90, K_{1}=0.018$, and $K_{2}=0.540$. As no more of $A$ is produced $A_{0}$ diminishes and at the end of time $T$ has the value $A_{T}=A_{0} e^{-K_{1} T}$ During exposure to $\mathrm{NaCl}$ a certain amount of $M$ is formed from $A$. Some of this disappears during exposure. The amount which remains at the time $T$ may be called $M_{T^{*}}$. At the time $T$ the amount of $M_{T}$ which disappears in unit time is $M_{T} K_{2}$. At this time the amount of $M$ produced in unit time is

$$
A_{T} K_{1}=A_{0} e^{-K_{1} T_{1}} K_{1}
$$

The change in $M_{T}$ occurring in unit time, which we may call $\frac{d M_{T}}{d T}$, is equal to the difference between the amount formed and the amount decomposed, or

$$
\frac{d M_{T}}{d T}=A_{0} e^{-K_{1} T} K_{1}-M_{T} K_{2}
$$

The solution of this equation is of the form

$$
M_{T}=A_{0}\left(a e^{-K_{1} T}+b e^{-K_{2} T}\right)
$$

By substitution it is found that $a=\frac{K_{1}}{K_{2}-K_{1}}$

Since $M_{T}=0$ when $T=0, \mathrm{~b}=\frac{K_{1}}{-\left(K_{2}-K_{1}\right)}$

Thus $M_{T}=A_{0}\left(\frac{K_{1}}{K_{2}-K_{1}}\right)\left(e^{-K_{1} T}-e^{-K_{2} T}\right)$

$$
\text { or } M_{T}=2700\left(\frac{K_{1}}{K_{2}-K_{1}}\right)\left(e^{-K_{1} T}-e^{-K_{2} T}\right)
$$

We must also consider that at the beginning of the exposure to $\mathrm{NaCl} 0.52 \mathrm{M}$ there was present a certain 
amount of $M$ (this was called $M_{0}$ ) which diminished during exposure, and the amount remaining at the time $T$ is $M_{0} e^{-K_{2} T}$. If this is added to the amount of $M$ produced from $A$ during exposure we get (substituting the value $M_{0}=90$ )

Total amount of $M=2700\left(\frac{K_{1}}{K_{2}-K_{1}}\right) \quad\left(e^{-K_{1} T}-e^{-K_{2} T}\right)+90 e^{-K_{2} T}$ and since Net Resistance $=M+10$ (because the base line of the curve is taken as 10) we have ${ }^{33}$

Net Resistance $=2700\left(\frac{K_{1}}{K_{2}-K_{1}}\right)\left(e^{-K_{1} T^{\prime}}-e^{-K_{2} T}\right)+90 e^{-K_{2} T}+10$

If we calculate the resistance by means of this formula we get the curve given in Fig. 28, which shows a close agreement between the observed and calculated values. It is therefore evident that, whether our picture of the underlying mechanism is correct or not, it leads to an equation which enables us to predict the death curve with considerable accuracy. The predictive value of the equation is quite independent of the assumptions which led up to it, and while it creates a presumption in favor of these assumptions, it of course does nothing more. It is hardly necessary to emphasize that equations which enable us to predict the course of vital processes are a prime necessity in biology, since they make it possible to employ the methods by which the exact sciences have been able to make rapid progress.

It is evident that we are able to follow the progress of

${ }^{23}$ The values $\mathrm{e}^{-K_{1} T}$ and $\mathrm{e}^{-K_{2} T}$ may be obtained from Table IV in the Smithsonian Mathematical Tables, Hyperbolic Functions, by G. F. Becker and C. E. Van Orstrand, 1909. See also Mellor, J. W. (1909) pp. $16,88,118$. 
death in this case just as a chemist follows the progress of a reaction in vitro. This has also been found to be the case in experiments with a great number of toxic substances and seems to be of very general applicability.

\section{TABLE I.*}

Net electrical resistance of Laminaria in $\mathrm{NaCl} 0.52 \mathrm{M}$. The resistance in sea water (the normal environment) is taken as 100 per cent.

\begin{tabular}{|c|c|c|c|c|}
\hline \multirow{2}{*}{ Time. } & \multicolumn{2}{|c|}{ Resistance. } & \multicolumn{2}{|c|}{$K_{3}$} \\
\hline & Observed. & Calculated. & $\begin{array}{c}\text { From observed } \\
\text { values. }\end{array}$ & $\begin{array}{c}\text { From calculated } \\
\text { values. }\end{array}$ \\
\hline $\min$ & per cent & per cent & & \\
\hline 10 & 87.50 & 87.76 & 0.0065 & 0.0064 \\
\hline 20 & 73.01 & 74.96 & 0.0077 & 0.0071 \\
\hline 30 & 62.51 & 64.26 & 0.0078 & 0.0073 \\
\hline 40 & 55.30 & 55.32 & 0.0075 & 0.0075 \\
\hline 50 & 48.81 & 47.86 & 0.0073 & 0.0075 \\
\hline 60 & 40.21 & 41.62 & 0.0079 & 0.0076 \\
\hline 70 & 36.79 & 36.41 & 0.0075 & 0.0076 \\
\hline 80 & 32.41 & 32.06 & 0.0076 & 0.0076 \\
\hline 90 & 27.52 & 28.43 & 0.0079 & 0.0077 \\
\hline 100 & 24.69 & 25.39 & 0.0079 & 0.0077 \\
\hline 110 & 23.00 & 22.86 & 0.0076 & 0.0077 \\
\hline 120 & 22.82 & 20.74 & 0.0071 & 0.0077 \\
\hline 150 & 16.51 & 16.26 & 0.0076 & 0.0077 \\
\hline 180 & 14.54 & 13.65 & 0.0072 & 0.0077 \\
\hline \multicolumn{3}{|l|}{ Average . } & 0.0075 & 0.0075 \\
\hline
\end{tabular}

* All readings were made at $15^{\circ} \mathrm{C}$, , or corrected to this temperature.

If we were unaware that the death curve in $\mathrm{NaCl} 0.52$ M represented two consecutive reactions, and supposed it to represent a simple monomolecular reaction $(M \rightarrow$ $B$ ), we should calculate its velocity constant (which we may call $K_{3}$ ) by the usual formula $:^{34}$

$$
K_{3}=\frac{1}{T} \log \left(\frac{a}{a-x}\right)
$$

If we make this calculation, employing for this pur-

" Common logarithms are used for convenience, We put $a=100-10$ and $a-x=M-10$. 
pose the calculated values given in the third column of Table I, we obtain the values of the velocity constant $K_{3}$ given in the fifth column of the table.

It is evident from an inspection of these values that the velocity constant $K_{3}$ falls below the average value at the start.

The amount by which it falls below the average value will depend on the relation $K_{1} \div K_{2}$. When $K_{1}$ and $K_{2}$ are nearly equal, the velocity constant falls a good deal below the average value at the start, but as the difference between them is increased the velocity constant $K_{3}$ will be found to fall less and less below the average level at the start. $^{35}$ This is easily shown by assuming various values ${ }^{36}$ of $K_{1}$ and $K_{2}$.

From this it follows that we can tell something about $K_{1} \div K_{2}$ from the experimental values of $K_{3}$. It is evident that in the present case the experimental values of $K$ point to the relation $K_{2} \div K_{1}=30$ (or $K_{1} \div K_{2}=$ 30 ). This relation was actually assumed by the writer, in order to fit, not the $\mathrm{NaCl}$ curve, but antagonism curves ${ }^{37}$ in various mixtures of $\mathrm{NaCl}+\mathrm{CaCl}_{2}$. It is therefore a striking confirmation of the general correctness of the underlying assumption that we are also able by means of this assumption to fit the $\mathrm{NaCl}$ curve so closely.

In general, where a chemical reaction is slower at the start than is expected, we may suspect that we have

${ }^{35}$ It should be noted that we get the same result (as, regards $K_{3}$ falling below the average at the start) when $K_{1} \div K_{2}=30$ as when $K_{2} \div K_{3}$ $=30$. With certain relations of $K_{1} \div K_{2}$ the constant $K_{3}$ may be above the average value at the start.

so When the values of $K_{1}$ and $K_{2}$ are changed, the concentrations of $A$ and $M$ must also be changed in such a way that Conc. $A \div$ Conc. $M=$ $K_{1} \div K_{2}$ if we wish the concentrations of $A$ and $M$ to remain constant in the normal environment.

${ }^{37}$ See Chapter IV. 
to do, not with a simple reaction, but with consecutive reactions of the kind here described. ${ }^{38}$

This explanation also applies to a considerable number of other cases of toxic action.

It is of interest to note that in all these cases death be-

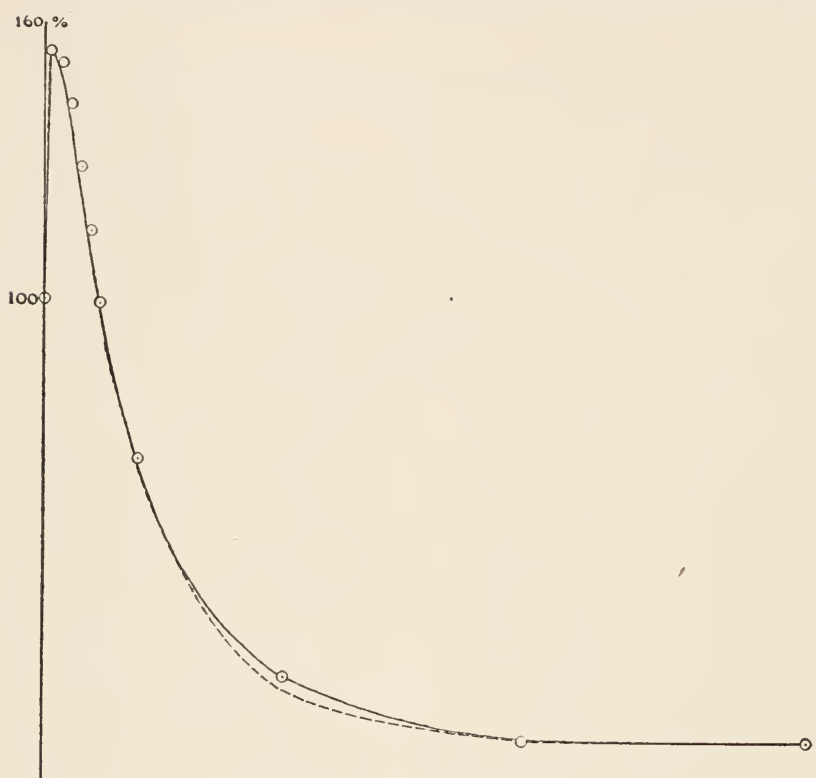

25

50

75 HOURS

FIG. 29.-Curve showing the net electrical resistance of Laminaria agardhii in $\mathrm{CaCl}_{2} 0.278 \mathrm{M}$. Unbroken line, observed values; broken line, calculated values. All observations were made at $18^{\circ} \mathrm{C}$. or corrected to this figure. Average of ten or more observations. Probable error of the mean less than $10 \%$ of the mean.

haves as a reaction which is continually going on, but at a very slow rate until accelerated by the toxic agent. We have assumed this acceleration to consist partly in the increase of the velocity constant and partly in the stopping of the reaction $O \longrightarrow A$, causing a decrease in the substance $(M)$ to which normal permeability (and perhaps other normal properties) are due.

${ }^{2}$ Mellor, J. W. (1909), Chapter VI. 
It may prove to be generally true that death behaves as a monomolecular reaction, which is inhibited (or accelerated) at the start. The assumption of consecutive reactions affords an explanation not only of the inhibition (or acceleration) at the start, but also of the fact that up to a certain point the reaction appears to be

\section{TABLE II.}

Net electrical resistance of Laminaria in $\mathrm{CaCl}_{2}$ 0.278M. The resistance in sea water (the normal environment) is taken as $100 \%$.

\begin{tabular}{l|c|c}
\hline & \multicolumn{2}{|c}{ Per cent. of net resistance in } \\
\cline { 2 - 3 } Time in hours. & Obs. & Calc. \\
\hline 1 & 154.0 & 152.9 \\
2 & 152.1 & 148.9 \\
3 & 143.2 & 136.5 \\
4 & 128.8 & 123.8 \\
5 & 117.2 & 112.2 \\
6 & 101.8 & 101.8 \\
10 & 67.76 & 69.59 \\
25 & 23.90 & 21.79 \\
50 & 11.0 & 10.79 \\
80 & 11.0 & 10.07 \\
100 & & \\
\hline
\end{tabular}

* The measurements were made at $15^{\circ}$ Centigrade or corrected to this figure. Each experimental figure is the average obtained from 6 or more experiments. Probable error of the mean less than $10 \%$ of the mean.

reversible. The latter fact will be fully discussed in a subsequent chapter.

It is evident that if the theory of the writer is sound, the equation which allows us to predict the death curve in experiments with $\mathrm{NaCl}$ should apply equally well in the case of experiments with $\mathrm{CaCl}_{2}$. This is the case, as is evident from Fig. 29 and Table II (in this case we put $K_{1}=0.0018$ and $K_{2}=0.0295$ ).

When the curve has a maximum, the height of the 
maximum may be approximately ascertained by means of the formula..$^{39}$

$$
\text { Maximum resistance }=2830\left(\frac{K_{1}}{K_{2}}\right)^{\frac{K_{2}}{K_{2}-K_{1}}}+10
$$

In the present case $K_{1} \div K_{2}=0.0018 \div 0.0295=1 \div 16.3889$. Hence we may, for convenience, put $K_{1}=1$ and $K_{2}=$ 16.3889. We then have Maximum resistance $=2380$

$$
\left(\frac{1}{16.3889}\right)^{\frac{16.3889}{15.3889}}+10=153.98 \text {. }
$$

The actual maximum found by calculating the curve is close to 153.94 (which occurs at 75 minutes). Such a close approximation must not, however, be expected in most cases.

Where the maximum of the curve is known and it is desired to find the relation $K_{1} \div K_{2}$ (as a preliminary step toward ascertaining the values of $K_{1}$ and $K_{2}$ by trial) we may plot a series of values of $K_{1} \div K_{2}$ as ordinates, and maxima (obtained by calculation) as abscissæ, and thus approximate graphically to the desired figure.

When the height of the maximum is known, the time at which the maximum occurs may be found as follows: When the maximum is attained the value of $M$ may be called $M$ max and the value of $A$ may be called $A_{T}$ !

${ }^{30}$ This may be regarded as an approximation formula. We consider that the value of $A$ before any of it has decomposed to form $M$ and $B$, is 3050 and if this is substituted for 2830 in the formula it will give exact values, provided the constants are not changed as $M$ increases from 0 to the maximum. But if $M$ increases from 0 to 90 with one set of constants and then from 90 to the maximum with another set, the formula no longer holds and the approximation formula may be used. $C f$. Mellor, J. W. (1909) p. 115. In the formula as given by Mellor a misprint occurs. 
Since at this time $M$ is formed as rapidly as it is decomposed, we have

$$
\begin{array}{r}
A_{T} K_{1}=M \max K_{2} \\
A_{T}=\frac{M \max K_{2}}{K_{1}}
\end{array}
$$

At the start (in sea water) the value of $A$ was 2700 , but it has now diminished to a fraction represented by $\left(\frac{M \max K_{2}}{K_{1}}\right) \div 2700$. We can easily find out how long it requires to reach this value, for, as the reaction $A \rightarrow M$ is monomolecular, we may write

$$
\begin{gathered}
A^{T}=2700 e^{-K_{1} T}=\frac{\mathrm{M} \max K}{K_{1}} \\
e^{-K_{1} T}=\frac{M \max K_{2}}{2700 K_{1}}
\end{gathered}
$$

Knowing the values of $M \max , K_{1}$ and $K_{2}$ we can find the value of $T$ by looking up the value of $e^{-K_{1} T}$ in a table. ${ }^{40}$

In the present instance we have $M \max =153.94-$ $10=143.94$

Hence

$$
\begin{aligned}
& \frac{(143.94) 0.0295}{(2700)} 0.0018=e^{-(0.0018) T} \\
& \text { and } 0.87372=e^{-(0.0018) T}
\end{aligned}
$$

We find from the table that

$$
e^{-0.135}=e^{-(0.0018) 75}=0.87372
$$

Whence $T=75$

It should be noted that multiplying $K_{1}$ and $K_{2}$ by the

${ }^{40}$ E.g., Table IV in the Smithsonian Mathematical Tables, Hyperbolic Functions, by G. F. Becker and C. E. Van Orstrand, 1909. See also Van Orstrand, C. E. (1921). 
same factor is equivalent to dividing all the abscissæ by the same factor and that in the case of a curve which rises and falls, this does not change the height of the maximum. If, therefore, both reactions have the same temperature coefficient, raising the temperature is equivalent to multiplying both $K_{1}$ and $K_{2}$ by the same factor and the maximum will not be changed. But if the reactions have different temperature coefficients this will not be true.

Perhaps it may be desirable in this connection to add a word regarding the measurement of life processes. The development of quantitative methods in biology depends largely on finding means of measuring the speed of life processes. In most cases the absolute rate is of less importance that the relative rate $(e . g$., the normal velocity compared with that observed under the influence of a reagent). Examination of the literature shows that the determination of relative rates is frequently made in a faulty manner, which might easily be avoided by a slight change of method.

As an illustration of this we may consider the processes shown in Fig. 30. In the case of Curve $A$ the process is twice as rapid as in the case of Curve $B$. This is shown by the fact that the abscissæ of $A$ are everywhere one-half those of $B$. This means that the velocity constants of $A$ are twice those of $B .{ }^{41}$ In other words the velocity constants are inversely proportional to the abscissæ, or inversely proportional to the times required to bring the reaction to the same stage ${ }^{42}$ (e.g. one-half completed). This is true for chemical processes in general, not only for reactions of the first order (where a

\footnotetext{
${ }^{41} \mathrm{Cf}$. Osterhout $(1918, B)$.

${ }^{42} \mathrm{Cf}$. Osterhout $(1918, B)$.
} 
single substance decomposes) but for reactions of higher orders (where two or more substances combine) as well as for consecutive reactions ${ }^{43}$ and autocatalysis. ${ }^{44}$

It follows that when a chemical process proceeds at different rates under different conditions, we can compare the velocity constants by simply taking the reciprocals of the times required to bring the reaction to the same stage, so that if we wish to know merely the relative

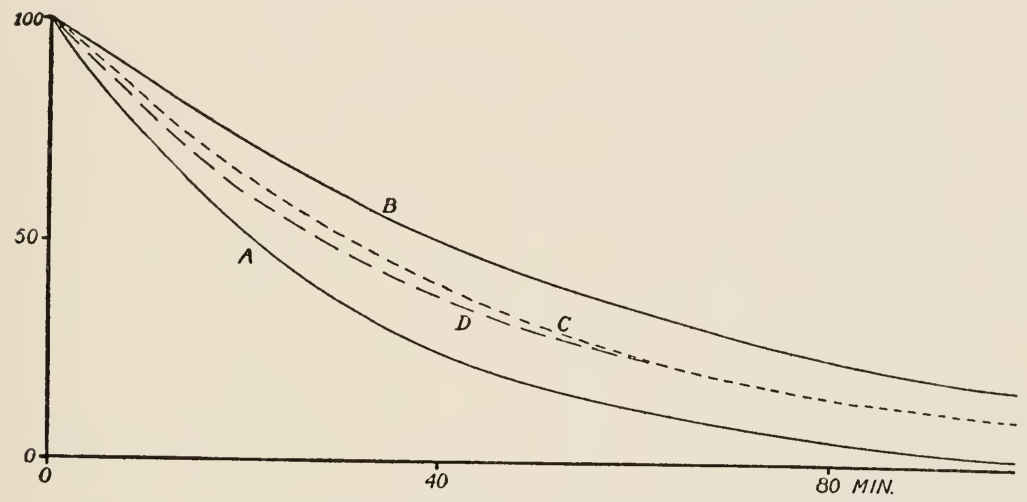

Fig. 30.-Curve $A$ represents a process which proceeds at twice the velocity of $B$. The abscissæ of $B$ are everywhere double those of $A$, but no such relation holds for the ordinates. $C$ is obtained by averaging the abscissæ of $A$ and $B ; D$ is obtained by averaging their ordinates.

rates (as is usually the case in biology) it is not necessary to determine the actual velocity constants at all.

Whenever the initial conditions are the same with respect to concentration we need only compare the times required for equal amounts of work, since these bring the reaction to the same stage. If, on the other hand, one attempts to arrive at the relative rate by comparing the amounts of work performed in equal times (as is frequently done in biological research) he can easily fall

\& The principle holds for consecutive reactions in case all the constants are multiplied by the same factor, otherwise not. $C f$. Osterhout $(1917, E)$.

${ }^{44}$ Cf. Mellor (1909) p. 291. 
into serious error. This is evident from Fig. 30 which shows that while the abscissa of $A$ at any point is just half that of $B$, no such relation obtains among the ordinates. $^{45}$ For example at 40 minutes, the ordinate of $B$ is twice as great as that of $A$, while at 4 minutes, it is less than 1.1 times that of $A$. Hence it is evident that we should compare abscissæ rather than ordinates (i.e., times required to do equal amounts of work rather than amounts of work performed in equal times).

The principle is sufficiently obvious where successive determinations are made and curves are drawn. But there is a common type of experimentation in which, for various reasons, a single observation at one rate is compared with a single observation at another rate. The principle in question is then easily overlooked. In some cases this leads to serious errors. ${ }^{40}$

It is therefore evident that when we average time curves, we should, whenever possible, average abscissæ rather than ordinates. Thus for example, in Fig. 30 the average of Curves $A$ and $B$ would be Curve $C$, obtained by averaging the abscissæ of Curves $A$ and $B$ : this gives a curve whose velocity constants are the arithmetical mean of those of $A$ and $B$. On the other hand, by averaging ordinates we obtain Curve $D$, which does not follow the formula characteristic of the other two curves.

It may be desirable to point out that these methods may be advantageously applied to the measurement of toxicity. ${ }^{47}$

${ }^{45}$ We cannot avoid the difficulty by comparing the rates of the two processes at a given time; for the rates so obtained will bear no constant ratio to each other. Only when they are compared at the same stage of the reaction will they show a constant relation; this gives the relation between the velocity constants.

${ }^{40}$ For a discussion of this see Osterhout $(1918, B)$.

${ }^{47} C f$. Osterhout $(1915, G)$. 
One striking result of the investigations on toxicity carried out by the writer is to emphasize the fact that the apparent toxicity of two substances may depend very largely upon the stage of the reaction at which the meas-

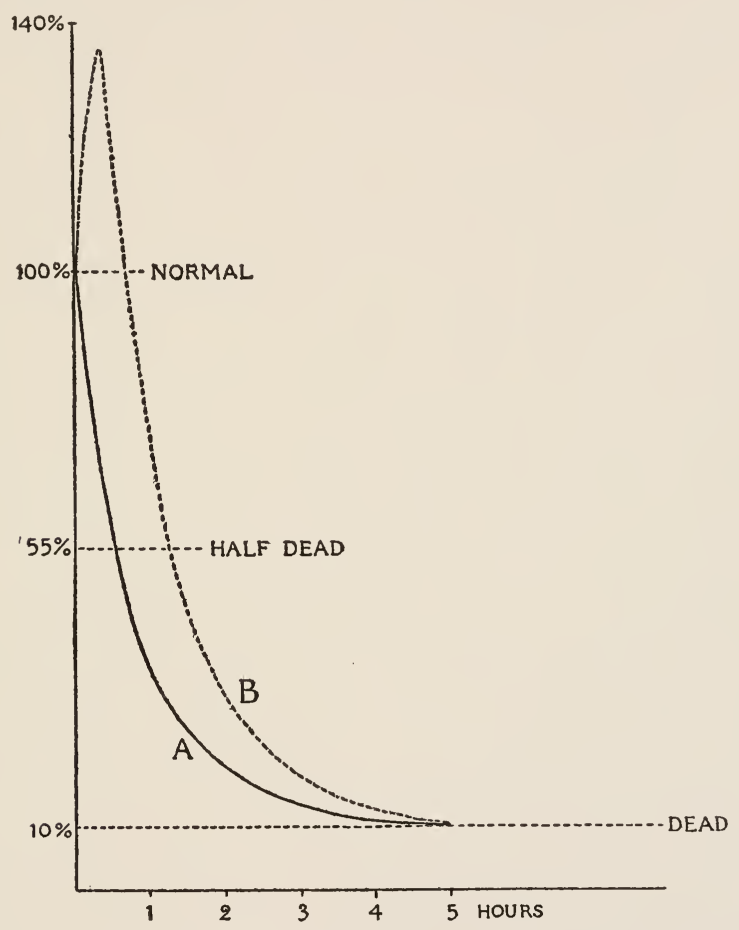

Fig. 31.-Curves showing changes in the net electrical resistance of tissues in two toxic solutions, $A$ and $B$ (the latter causes a rise followed by a fall in resistance). Toxicity may be measured by determining the time required to carry the reaction to a definite stage, as, for example, to $55 \%$ which is half way between the normal condition and the death point.

urement is made. This is evident from an inspection of the curves in Fig. 31. These represent the electrical resistance of Laminaria in sea water and in two toxic solutions. If the tissue be placed in a solution of $\mathrm{NaCl}$ of the same conductivity as sea water, the resistance falls, somewhat as shown in Curve $A$, until it reaches the death 
point. If, on the other hand, the tissue be placed in a solution of some substance which causes a rise, followed by a fall in resistance, we may get a curve somewhat like that shown at $B$.

The most common method of measuring the toxicity of a solution is to determine the time necessary to cause death. But it is evident from an inspection of the curves that it is impossible to determine the precise moment of death, since the death curves approach the axis asymptotically. This is doubtless true of death in all cases. It is therefore obvious that the death point does not offer a perfectly satisfactory criterion of toxicity.

We may avoid this difficulty by taking as a criterion the time needed to reach any convenient point on the curve, as, for example, $55 \%$ (half way between the normal condition and the death point). This may be determined with a good deal of precision by the measurement of electrical resistance or by any method which permits us to follow the reaction accurately from moment to moment. But where this cannot be done, we may employ other criteria. We may assume that as the reaction goes on, certain phenomena appear at definite points on the curve, such, for example, as changes in metabolism, cessation of motion, or loss of irritability. The employment of such criteria may give trustworthy results in many cases if proper precautions be taken.

In the employment of any of these criteria, except that of death, we may meet the difficulty that the relative toxicity of two substances may vary greatly according to the point in the curve at which the comparison is made. Let us suppose that two toxic substances are so chosen that they produce death at about the same time, giving curves as shown in Fig. 31. They must be regarded 
as equally toxic if we adopt death as the criterion, but as unequally toxic if we take any other criterion. For example at $90 \%, A$ appears to be seven times as toxic as $B$.

It is clear that we cannot escape from this difficulty by comparing the effects produced in equal times.

In view of these facts it is obviously undesirable to compare results obtained by the use of unlike criteria, as is often done.

Another method is to measure the degree of recovery which is found where tissues are taken from toxic solutions and replaced in sea water. This will be explained more fully in Chapter III. It has many advantages which entitle it to serious consideration. The writer has found that death in many toxic substances, as measured by the electrical method, follows approximately the course of a monomolecular reaction. In such cases the constants which express the reaction velocities of the two reactions afford a measure of their relative toxicity. In cases where such constants cannot be used, but where the complete curve can be obtained, it would be possible to adopt, as an arbitrary standard, the time necessary for the reaction to proceed half way to the death point. But, when the curves are related to each other as are $A$ and $B$ in Fig. 31, it may be desirable to use some other criterion. It is in any case desirable to give the whole curve, whenever possible, so that the reader may apply his own criterion. The ease with which complete curves can be obtained by determining electrical resistance may render this method useful, especially since the writer has found it possible to apply it to all sorts of plant tissues as well as to some animal tissues.

The electrical method is not restricted to solutions of the same conductivity. For example, we find that 
$\mathrm{NaCl} 0.52 M$ and $\mathrm{CaCl}_{2} \quad 0.278 M$ have the same conducttivity as sea water. If we wish to compare the toxicity of $\mathrm{NaCl} 0.278 M$ with that of $\mathrm{CaCl}_{2} 0.278 M$ we may dilute the sea water until it has the conductivity of $\mathrm{NaCl} 0.278$ $M$. Tissue placed in this may be used as a control. At the outset we make the resistance of the control equal to that of the tissue in $\mathrm{NaCl} 0.278 M$, or we divide the resistance of the control by a figure which reduces it to the same value (and divide all subsequent readings of the control by the same figure). We then express all readings of the tissue in $\mathrm{NaCl} 0.278 \mathrm{M}$ as per cent. of the reading of the control which is taken at the same time. All readings of the tissue in $\mathrm{CaCl}_{2} 0.278 \mathrm{M}$ are likewise expressed as percentage of the readings of a control in sea water having the same conductivity as $\mathrm{CaCl}_{2} 0.278 \mathrm{M}$. Stronger solutions may be treated in the same way, using sea water which has been concentrated by evaporation.

Attention may be called to a further difficulty in determining toxicity. If tissue of Laminaria be transferred from sea water to pure solutions of toxic salts their relative toxicity sometimes appears to be different from that which is observed when the same substances are added directly to the sea water. Similar considerations may be found to apply to animals and plants which live on land or in fresh water, in which cases Ringer's solution or the water of soils and rivers may play the same role as the sea water in experiments with marine forms. These differences depend largely on the antagonistic action of salts, which will be discussed in Chapter IV.

It may be added that in some cases variations in the supply of oxygen may cause changes in relative toxicity; and in view of the fact that the temperature coefficient is not the same in all cases of toxic action it seems 
desirable to carry out determinations as far as possible at a standard temperature, preferably at $18^{\circ} \mathrm{C}$.

In conclusion, attention may be drawn to the effects of temperature ${ }^{48}$ upon consecutive reactions such as are here assumed to be responsible for the phenomena with which we are dealing. The temperature coefficient of death in $\mathrm{NaCl} 0.52 M$, and $\mathrm{CaCl}_{2} 0.278 M$ is not far from 2 .

The temperature coefficients of life processes have within the last few years attracted a good deal of attention. Interest has chiefly centred about the question whether life processes have the temperature coefficients of ordinary chemical reactions and whether investigations of this sort enable us to distinguish between chemical and physical processes (on the ground that in general, the latter possess lower temperature coefficients than the former).

In these discussions of life processes it is generally assumed that we are dealing with simple chemical reactions. A little consideration shows that this cannot always (or even commonly) be the case. Most substances formed in the organism are also broken down, and the amount present must depend on the relative rates of formation and of decomposition. Change of temperature may affect consecutive reactions in an entirely different manner from simple reactions (in which the substance formed is not at once broken down). This may be made clear by a concrete illustration.

Let us take for this purpose the death curve in $\mathrm{NaCl}$ (Curve I, Table III) and consider the effect of raising the temperature $10^{\circ} \mathrm{C}$. If both reactions have the temperature coefficient $2, K_{1}$ becomes 0.036 and $K_{2}$ becomes 1.080 .

${ }^{48} \mathrm{Cf}$. Osterhout $(1917, E)$. For the temperature coefficients of living and dead tissues in sea water see p. 37. 
The values of $M$ under these conditions are given in Table III (Curve II). Inspection of the table, and of the curves in Fig. 32, shows that at the higher temperature it re-

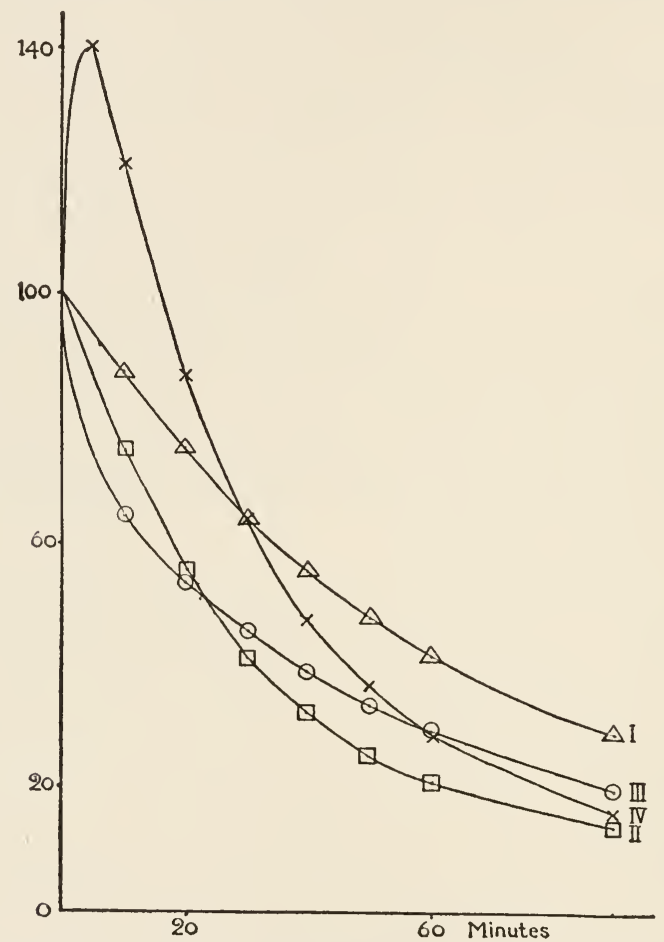

FIG. 32.-Curves showing the value of $M$ when the velocity constants have the values

\begin{tabular}{rcc} 
Curve & $\begin{array}{c}\text { given below. } \\
\mathrm{K}_{1}\end{array}$ & $\mathbf{K}_{\mathbf{2}}$ \\
\hline II & 0.018 & 0.540 \\
II & 0.036 & 1.080 \\
II & 0.0216 & 1.080 \\
IV & 0.036 & 0.648
\end{tabular}

Curves II, III and IV are derived from Curve I by assuming that the temperature is raised $10^{\circ} \mathrm{C}$.; if the two reactions have the temperature coefficient 2 we obtain Curve II; if the coefficients are 1.2 and 2 respectively we obtain Curve III; if the coefficients are 2 aud 1.2 respectively we obtain Curve IV.

quires just half as long to produce the same amount of chemical action as at the lower. Hence the consecutive reaction appears to behave in this instance like a simple reaction. 
The result will be quite different if the two reactions have different temperature coefficients. Let us suppose that the speed of the reaction $A \rightarrow M$ is determined by diffusion (as happens in some heterogeneous reactions) and has in consequence a low temperature coefficient which we will assume to be 1.2. Assuming that the reaction $M \longrightarrow B$ has a temperature coefficient 2 we TABLE III.

\begin{tabular}{|c|c|c|c|c|}
\hline \multirow[b]{2}{*}{ Time. } & \multicolumn{4}{|c|}{ Value of $\boldsymbol{M}$. } \\
\hline & $\begin{array}{c}\text { Curve I } \\
K_{1}=0.018 \\
K_{2}=0.540\end{array}$ & $\begin{array}{c}\text { Curve II. } \\
K_{1}=0.036 \\
K_{2}=1.080\end{array}$ & $\begin{array}{l}\text { Curve III. } \\
K_{1}=0.0216 \\
K_{2}=1.080\end{array}$ & $\begin{array}{c}\text { Curve IV. } \\
K_{1}=0.036 \\
K_{2}=0.648\end{array}$ \\
\hline $\min$. & & & & \\
\hline 10 & 87.76 & 74.96 & 64.39 & 120.70 \\
\hline 20 & 74.96 & 55.32 & 53.82 & 87.31 \\
\hline 30 & 64.26 & 41.62 & 45.31 & 63.94 \\
\hline 40 & 55.32 & 32.06 & 38.45 & 47.63 \\
\hline 50 & 47.86 & 25.35 & 32.92 & 36.26 \\
\hline 60 & 41.62 & 20.74 & 28.47 & 28.32 \\
\hline 90 & 28.43 & 13.65 & 19.62 & 16.22 \\
\hline
\end{tabular}

find than on raising the temperature $10^{\circ} \mathrm{C}$, $\mathrm{K}^{1}$ becomes 0.0216 and $K_{2}$ becomes 1.080. The values under these conditions are given in Table III (Curve III).

Let us now consider the effect when the temperature coefficient of the first reaction is 2 and that of the second is 1.2. On raising the temperature $10^{\circ} \mathrm{C}$. $K_{1}$ becomes 0.036 and $K_{2}$ becomes 0.648 . The values are given in Table III (Curve IV). The form of the curve is quite different from that of the others in that there is first a rise followed by a fall. In experimental work a short period of rise might be overlooked or regarded as due to experimental error or some disturbing ("inhibiting") factor, such as is commonly assumed to account for delay at the beginning of a reaction.

If the observer supposed that he had to do with a 
simple reaction of the type $M \rightarrow B$ and proceeded to calculate the velocity constant, he would obtain the values given in Table IV.

A consideration of these values is very instructive. It is evident that when the relation $K_{2} \div K_{1}$ has a certain value (as in Curves I and II where $K_{2} \div K_{1}=30$ ) the

TABLE IV.

Apparent velocity constants obtained on the supposition that the process is a simple reaction.

\begin{tabular}{|c|c|c|c|c|}
\hline \multirow[b]{2}{*}{ Time. } & \multicolumn{4}{|c|}{ Apparent velocity constant. } \\
\hline & $\begin{array}{c}\text { Curve I. } \\
K_{1}=0.018 \\
K_{2}=0.540\end{array}$ & $\begin{array}{c}\text { Curve II. } \\
K_{1}=0.036 \\
K_{2}=1.080\end{array}$ & $\begin{array}{l}\text { Curve III. } \\
K_{1}=0.0216 \\
K_{2}=1.080\end{array}$ & $\begin{array}{lr}\text { Curve IV. } \\
K_{1}=0 & 0.36 \\
K_{2}=0 & 48\end{array}$ \\
\hline $\min$ & & & & \\
\hline 10 & 0.0064 & 0.013 & 0.022 & \\
\hline 20 & 0.0071 & 0.014 & 0.016 & 0.0033 \\
\hline 30 & 0.0073 & 0.015 & 0.014 & 0.0074 \\
\hline 40 & 0.0075 & 0.015 & 0.013 & 0.0095 \\
\hline 50 & 0.0075 & 0.015 & 0.012 & 0.011 \\
\hline 60 & 0.0076 & 0.015 & 0.012 & 0.012 \\
\hline 90 & 0.0077 & 0.015 & 0.011 & 0.013 \\
\hline
\end{tabular}

reaction appears to proceed as a monomolecular reaction which is somewhat "inhibited" at the start, ${ }^{49}$ while with other values it may appear to be greatly inhibited at the start (Curve IV, $K_{2} \div K_{1}=18$ ) or to go much faster in the beginning than is expected (Curve III, $K_{2} \div K_{1}=50$ ).

These facts deserve consideration in interpreting the temperature coefficients of consecutive reactions, to which category many life processes undoubtedly belong. ${ }^{50}$

${ }^{49}$ Mellor (1909), p. 113.

${ }^{50} C f$. Loeb $(1912, D)$, p. 212. 


\section{CHAPTER III}

\section{INJURY AND RECOVERY}

As investigation of the process of death leads us naturally to a study of the power of the organism to recover from exposure to unfavorable influences.

An interesting aspect of this subject is the connection between injury and permeability. In the opinion of some writers permeability is a relatively fixed property of the cell which changes only as the result of injury, and is then altered $^{1}$ irreversibly, while others assume that reversible changes in permeability may form a normal part of the activities of the cell. ${ }^{2}$ In view of the fact that such changes may control metabolism it seemed desirable to the writer to investigate them by determining conductivity, since (as will be shown in Chapter VI) an increase in conductivity indicates an increase in permeability, and since it is also possible to calculate the increase in protoplasmic conductivity (and hence of permeability) as distinguished from the increase in the conductivity of the tissue as a whole.

The following will serve to illustrate the method of experimentation. ${ }^{3}$ Tissue which had in sea water a net resistance of $770 \mathrm{ohms}$ was placed in a solution of $\mathrm{NaCl}$ $0.52 M$. In the course of 5 minutes the resistance fell to 580 ohms, or $75.32 \%$ of the original resistance. ${ }^{4}$ When

${ }^{1}$ Cf. Höber (1914) Kap. 8, 9 und 13.

${ }^{2} \mathrm{Cf}$. Osterhout $(1912, B)$.

${ }^{3} \mathrm{Cf}$. Osterhout $(1915, B)$.

- Complete recovery after such a large increase of conductance is not always obtainable unless the material is in good condition and is freshly collected. Even in such material a lot will occasionally be found in which recovery is poor. 
the tissue was replaced in sea water the resistance soon rose to normal and so continued during the remainder of the day. ${ }^{5}$

In this case the conductance of the tissue at the start was $1 \div 770=0.0013$ reciprocal ohms and this changed to $1 \div 580=0.00172$ reciprocal ohms, an increase of $32.3 \%$. It would be more convenient to say that the conductance at the start was $1 \div 100$ and that this increased to $1 \div 75.32$. The resistance of the protoplasm at the start ${ }^{6}$ (as distinguished from that of the tissue as a whole) would then be 140 , decreasing to 96.03 , a loss of $31.4 \%$. The conductance at the start would be $1 \div 140=.007143$ increasing to $1 \div 96.03=.010413$; or, if we call the protoplasmic resistance at the start 100 , it decreases from $100 \%$ to $68.60 \%$ and the conductance increases from $1 \div 100=.01$ to $1 \div 68.60=.014578$, a gain of $45.78 \% .^{\top}$

In order to see whether this increase is accompanied by permanent injury, an experiment was made in which the same piece of tissue was exposed to the action of $\mathrm{NaCl}$ several times during the same day. The net resistance of the tissue in sea water was 810 ohms; after 5 minutes in $\mathrm{NaCl}$ the resistance fell to $84 \%$ of the original resistance; the tissue was then placed in sea water and a reading 10 minutes later showed that the resistance had risen to $100 \%$. In this case the fall of protoplasmic resistance was $(100-78.94) \div 100=21.06 \%$ and the increase in permeability (conductance) was $[(1 \div 78.94)$

${ }^{\circ}$ Shearer (1919. A) obtained similar results with bacteria.

' For the method of calculating this see p. 217.

'It might be objected that this increase is not necessarily the result of increase in permeability, but may be due to the fact that the protoplasm is more permeable to $\mathrm{NaCl}$ than to $\mathrm{CaCl}_{2}$ and since the number of $\mathrm{Na}$-ions is increased the conductance also increases. But the increase in $\mathrm{Na}$-ions is much too small to account for the effect since it amounts to about $1 \%$. 
$-(1 \div 100)] \div(1 \div 100)=26.68 \%$. During the next 95 minutes it showed no change. It was then placed in $\mathrm{NaCl}$ for 5 minutes and the resistance fell to $82.8 \%$. It was then replaced in sea water; a reading taken 10 minutes later showed that it had returned to normal, where it remained for 90 minutes. It was then placed in $\mathrm{NaCl}$ for 5 minutes. The resistance fell to $86.42 \%$ and returned to normal during the ensuing 10 minutes in sea water. After 105

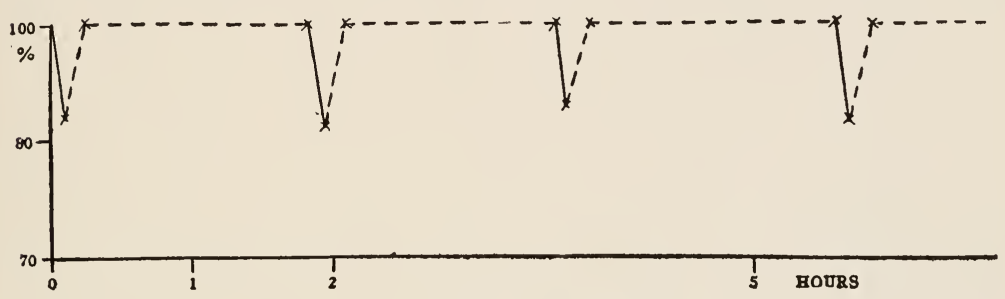

FIG. 33.-Graph showing the fall of net electrical resistance of Laminaria agardhii in $\mathrm{NaC}$ $0.52 \mathrm{M}$ (unbroken line) and recovery in sea water (broken line). All readings were made at $20^{\circ} \mathrm{C}$. or corrected to this temperature. The graph represents a single experiment.

minutes in sea water (during which no change occurred) it was again exposed to $\mathrm{NaCl}$ for 5 minutes. The resistance fell to $82.8 \%$ and returned again to normal during the following 10 minutes in sea water. On the following day its resistance was only $30 \mathrm{ohms}$ below the resistance of the control, which at the beginning of the experiment was 810 ohms. The results are presented in Fig. 33.

The successful outcome of this experiment led to an attempt to carry on such an experiment for several days in succession, giving the tissue one treatment daily with $\mathrm{NaCl}$. The material was selected with especial care. The fronds were fairly thick, without reproductive organs. The experiment was made at Woods Hole, Mass., in July, at which time such fronds may be easily obtained. The disks cut from these fronds were slightly curved, so that when placed in the apparatus they separated spontan- 
eously, thus allowing the running sea water in which they were kept to circulate freely between them. Care was taken to keep them only about two-thirds submerged, so that they had free access to air, but ran no risk of drying up. The tissue in sea water had a net resistance of $780 \mathrm{ohms}$ at $20^{\circ} \mathrm{C}$. As the temperature of the
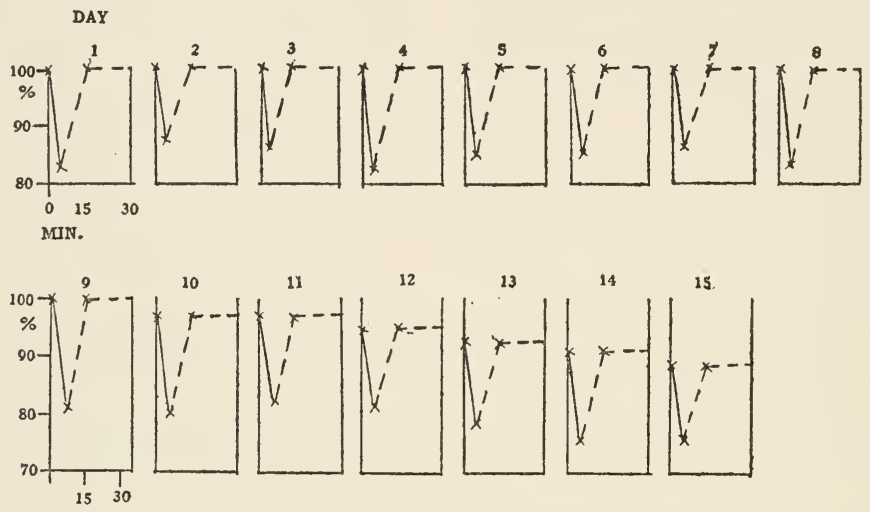

$\mathrm{MnN}$

FIG. 34.-Graph showing loss of "net electrical resistance of Laminaria agardhii in $\mathrm{NaCl}$ $0.52 M$ (unbroken lines) and recovery in sea water (broken lines) on 15 successive days. All readings were made at $20^{\circ} \mathrm{C}$. or corrected to this temperature. Each graph represents a single experiment.

sea water varied but slightly from this during the experiment, all readings were taken at $20^{\circ} \mathrm{C}$. On being placed in $\mathrm{NaCl} 0.52 M$, the resistance fell in 5 minutes to $83.3 \%$; the tissue was then placed in sea water, and a reading taken 10 minutes later showed that it had risen again to the normal. The tissue was then placed in running sea water, with the precautions mentioned above. At the end of 22 hours the resistance was 780 ohms. An exposure of 5 minutes to $\mathrm{NaCl}$ resulted in a drop to $87.2 \%$, with complete recovery within 10 minutes. The same treatment was given once each day for 15 days. On the tenth day the resistance began to fall off, but as this 
falling off was also shown by the control, which remained in sea water through the experiment, it was not due to $\mathrm{NaCl}$ but to other causes. The results are shown in Fig. 34.

Electrolytes may also cause a reversible decrease in permeability. The simplest way of demonstrating this is by means of the following very striking experiment. The net resistance of a cylinder of living tissue in sea water was found to be 500 ohms. It was tested an hour later and found to be the same. Sufficient $\mathrm{La}\left(\mathrm{NO}_{3}\right)_{3}$ was then added in solid form to make its concentration ${ }^{8}$ in the sea water $0.02 M$. After 5 minutes the resistance rose to $130 \%$. In order to ascertain whether this change in permeability is reversible, the tissue was replaced in sea water. In the course of an hour its resistance returned again to the original value. ${ }^{\ominus}$ The experiment was repeated three times on the same lot of material with practically the same result; it was then allowed to stand over night in sea water. On the following day there was no appearance of injury, and the resistance was the same as that of the control, which had remained in sea water throughout the experiment. The tissue was then placed in the sea water plus lanthanum and left until its resistance had increased $100 \mathrm{ohms}$; it was then put back into sea water and left until the resistance fell to nearly normal. This was repeated three times, and the tissue was then allowed to stand over night in sea water. On the

8 The concentration was reduced by the precipitation of a small amount of $\mathrm{La}_{2}\left(\mathrm{SO}_{4}\right)_{3}$; this had practically no influence on the subsequent result, since the outcome is the same if we use in place of sea water a mixture of 1000 c.c. $\mathrm{NaCl} 0.52 M+20$ c.c. $\mathrm{CaCl}_{2} 0.278 M$, in which case no precipitate is formed. It should be noted that the addition of lanthanum chloride has the same effect as the addition of lanthanum nitrate.

- If the material is left in sea water plus $\mathrm{La}\left(\mathrm{NO}_{3}\right)_{3}$ the increased resistance is maintained for a long time. 
third, fourth and fifth days, the same experiment was repeated four times. On the fifth day the tissue appeared to be in as good condition as the control, and had a resistance which was slightly higher. There was no reason, therefore, to suspect that the changes in permea-

DAY 1

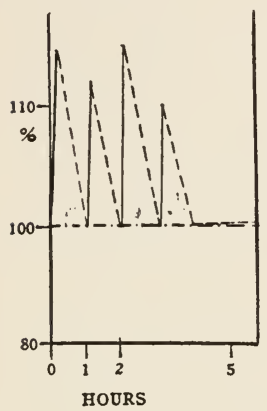

2

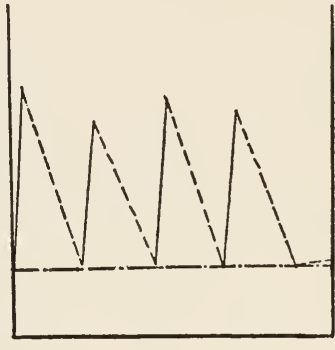

3

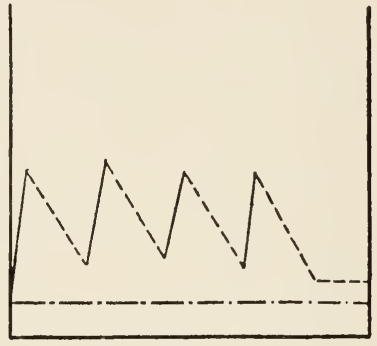

6
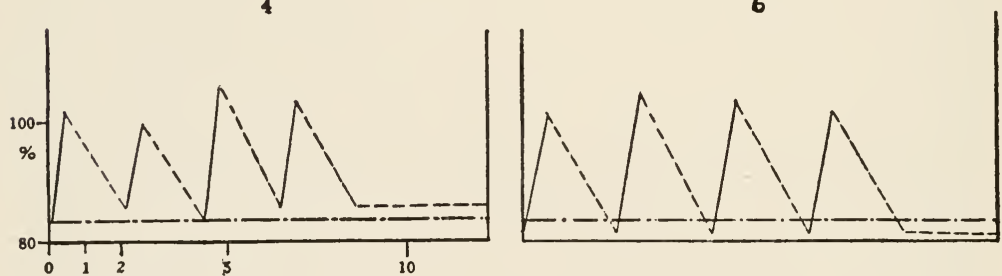

HOURS

FIg. 35.-Rise of net electrical resistance of Laminaria agardhii in 1000 cc. sea water plus sufficient $\mathrm{La}\left(\mathrm{NO}_{3}\right)_{3}$ to make the concentration $0.002 M$ (unbroken line) and subsequent fall on replacing in sea water (broken line). Lower horizontal broken line represents the control in sea water. The same lot of tissue was exposed four times daily on five successive days to the action of $\mathrm{La}\left(\mathrm{NO}_{3}\right)_{3}$. All readings were made at $20^{\circ} \mathrm{C}$. or corrected to this temperature. Each curve represents a single experiment.

bility had been attended by any permanent injury. The results are shown in detail in Fig. 35.

Similar experiments were performed in which $\mathrm{CaCl}_{2}$ was used in place of $\mathrm{La}\left(\mathrm{NO}_{3}\right)_{3}$. In this case $3.3 \mathrm{gm}$. $\mathrm{CaCl}_{2}$ were added to each 1000 cc. of sea water. Owing to the fact that the rise in resistance took place more slowly ${ }^{10}$

${ }^{10}$ If in place of solid $\mathrm{CaCl}_{2}$ a strong solution is added, the rise is more rapid and reaches a higher figure. 
than when lanthanum was used, the experiment was performed twice daily on each of the five successive days. On the sixth day the material was in as good condition as the control, and had the same resistance.

It is evident, therefore, that the conductivity may be greatly decreased and then restored to the normal several times on successive days, without any trace of injury.

Experiments on dead tissue (killed by heat or by formalin or allowed to die a natural death) showed that the results described above are due entirely to the living cells.

A very marked decrease of permeability may be produced by a considerable variety of other salts. The addition of these salts in solid form simultaneously increases the conductivity of the solution and decreases the conductivity of the tissue. This affords the most convincing proof that the change in the conductivity of the tissue in these experiments cannot be due to any cause other than a change in permeability ; for the concentration of the ions of the sea water remains unchanged, and if they were able to penetrate as freely as they did before the addition of the salt, the resistance would not increase. It would, in fact, diminish on account of the increased conductivity of the solution held in the cell walls, as is clearly shown by experiments on dead tissue.

It may be remarked incidentally that these experiments effectually dispose of the possible objection that the current passes between the cells, but not through them. Were this objection well founded, the decrease in conductivity could be explained only as the result of a decrease in the size of the spaces between the cells. This decrease could not be brought about except by greatly reducing the thickness of the cell walls. Both macroscopic 
and microscopic measurements show most conclusively that this does not occur. The contrary effect would be produced by the addition of salts in solid form, for they would tend to produce plasmolysis and thereby increase the space between the cells.

As these remarkable changes in permeability seemed

DAY 1

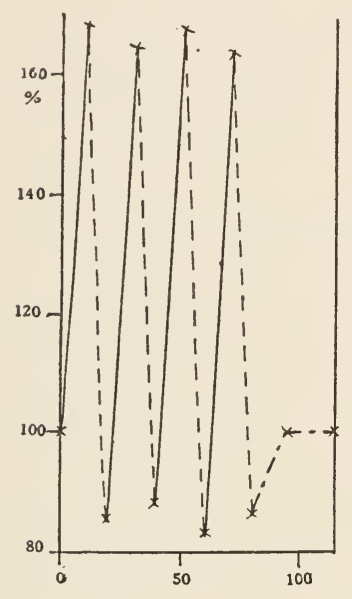

DẢY 2

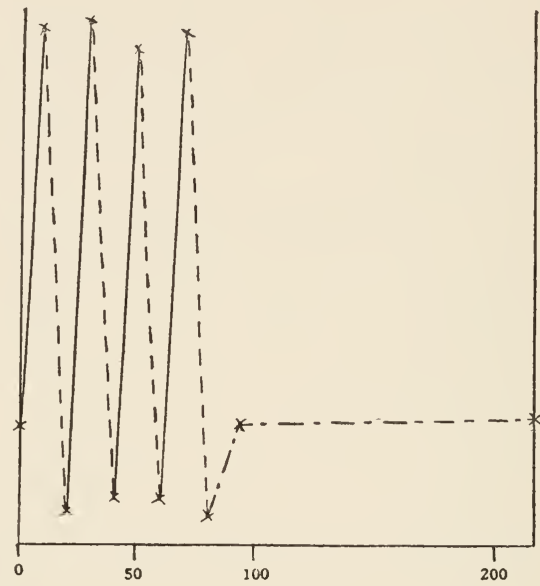

MIN.

FIG. 36.-Extreme alterations of net electrical resistance produced by placing Laminaria agardhii alternately in $\mathrm{CaCl}_{2} 0.278 \mathrm{M}$ (unbroken line) and in $\mathrm{NaCl} 0.52 M$ (broken line) and then in sea water (broken line with dots). The experiment was repeated with the same lot of tissue on the second day. All readings were taken at $18^{\circ} \mathrm{C}$. or corrected to this temperature. The control in sea water remained constant during the two days.

to produce no bad effects, it occurred to the writer to see whether the protoplasm could endure still more violent alterations without permanent injury. In order to test this the following experiment was performed. A lot of tissue was found to have in sea water a net resistance of $750 \mathrm{ohms}$. It was placed in $\mathrm{CaCl}_{2} 0.278 \mathrm{M}$, which had the same conductivity as the sea water. At the end of 10 minutes a reading was taken which showed that the resistance had risen to $168 \%$. The material was 
then placed in $\mathrm{NaCl} 0.52 M$, which had the same conductivity as the sea water ; at the end of 10 minutes the resistance was $85.4 \%$. The experiment was continued by placing the material for 10 minutes alternately in $\mathrm{CaCl}_{2}$ and $\mathrm{NaCl}$, with the results shown in Fig. 36 . After 80 minutes the material was placed in sea water, where it soon regained its normal resistance: 24 hours later the resistance was found to be unaltered, and the experiment was repeated. After 80 minutes of alternate exposure to $\mathrm{CaCl}_{2}$ and $\mathrm{NaCl}$, the material was placed in sea water, where it soon regained its normal resistance, which it maintained for 3 days, when the experiment was discontinued.

Similar results ${ }^{11}$ were obtained with Ulva (sea lettuce), Rhodymenia (dulse) and Zostera (eel grass). Recovery was also observed with frog skin. ${ }^{12}$

The fact that protoplasm is able to endure such violent alterations of conductivity throws a new light on the normal life processes of the cell. In the course of metabolism a great variety of substances are produced which affect the permeability of the protoplasm. Since it is clear that the permeability may be greatly increased or decreased without rendering a return to normal permeability impossible, it is evident that considerable fluctuations in permeability may form a normal part of the life processes of the protoplasm. In this way the whole course of metabolism may be controlled, since this depends on the exchange of substances between the cell and its environment.

It is a striking fact that normal specimens of Laminaria are quite uniform in respect to electrical resist-

${ }^{11} C f$. Osterhout $(1919, A)$.

${ }^{12} C f$. Osterhout $(1919, C)$. 
ance, ${ }^{13}$ but if plants have been subjected to unfavorable conditions $^{1+}$ their resistance is below the normal. This is of considerable practical value, enabling the experimenter to reject abnormal material, and is also theoretically important, for it provides us with a measure of what we may call the normal condition, or normal vitality, of the organism.

Although the idea of normal condition (or normal vitality) is one of the fundamental conceptions of biology, it has never been precisely formulated: nor does it seem possible to attempt this without the employment of quantitative methods. The writer's studies in this field have led to a quantitative treatment of injury and recovery, which may now be discussed.

In practice, we determine the condition of material by measuring the resistance of 'pieces of tissue or of intact organisms. These investigations show that it is of ten difficult to judge of the condition of an organism by its appearance. Tissues were found to be capable of losing much of their vitality without betraying it by their appearance. (This was particularly the case with the eel grass, Zostera, which retained its normal green color and appearance for some days after electrical measurements showed it to be dead). On the other hand, material of doubtful appearance often turned out to be much better than that which looked to be in sound condition.

Material collected in the same locality and examined as soon as taken from the ocean gave a very uniform resistance. To make the comparison as accurate as possible disks of the same average thickness were used in the

${ }^{13}$ I.e., when the fronds are of about the same thickness, etc.

${ }^{14} C f$. Osterhout, $(1914, D)$. 
experiments. Under these circumstances the net resistance at $18^{\circ} \mathrm{C}$. did not vary much from 1070 ohms. For example, in a series of determinations of 10 different lots of tissue, the highest reading was $1090 \mathrm{ohms}$, and the lowest 1055 ohms. These lots of tissue were allowed to remain in the laboratory under different conditions. Some were in running salt water, some in quiet salt water in pans of various sizes, a part being placed in direct sunlight (where the temperature rose to an injurious point) while others were kept in a cool place, in partial shade. At the end of 24 hours, there was no difference in the appearance of these lots, but their net electrical resistance varied from $200 \mathrm{ohms}$ to $1090 \mathrm{ohms}$. All were then placed side by side in the same dish. Those with the lowest resistance were the first to die. The others died in the order indicated by their electrical resistance.

Determinations of the resistance made it evident that in no case did visible signs of death make their appearance until twenty-four hours after death occurred, and subsequent experiments showed that in some cases (especially at low temperatures and in the presence of certain reagents) they may not appear until several days after death.

It was found that material from one locality showed a low resistance, and subsequent examination showed that it was contaminated by fresh-water sewage. The appearance of the plants was not such as to lead to their rejection for experimental purposes. They did not survive as long in the laboratory as plants of normal resistance taken from the other localities.

It may be taken for granted that vitality, whatever else it may signify, means ability to resist unfavorable influences. When organisms which are of the same kind, 
and similar in age, size and general characters, are placed under the same unfavorable conditions, the one which lives longest may be said to have the greatest vitality ${ }^{15}$ the one which lives next longest may be rated second in this respect, and so on. Determination of the electrical resistance of these individuals enables us to predict at the outset which will live longest, which next longest, and so on through the entire group.

It is therefore obvious that determinations of electrical resistance afford a means of measuring vitality and in the course of an extensive series of experiments it has been found that this method may be relied upon to give accurate results.

The fact that determinations of electrical resistance afford an accurate measure of vitality enables us to attach the same sort of quantitative significance to normal vitality as we attach to normal size or to normal weight. For this purpose we may construct a variation curve and determine the mode in the usual way.

There is no reason to suppose that the vitality of an individual organism is constant any more than its weight is. There is probably some fluctuation which usually passes unperceived unless a quantitative method of detecting it exists.

The writer finds that all substances (whether organic or inorganic) and all agents (such as excessive light, heat, electric shock, mechanical shock, partial drying, lack of oxygen, etc.) which alter conductivity of the protoplasm shorten the life of the organism. This is equally true whether the alteration consists in an increase

${ }^{15}$ It might be expected that this individual would also excel in other respects. A discussion of these is unnecessary from our present standpoint: in so far as they can be quantitatively treated they form proper material for a supplementary investigation. 
of conductivity, or in a decrease of conductivity (followed by an increase), as is the case when certain reagents (such as $\mathrm{CaCl}_{2}$ ) are applied. This is a very striking fact and its significance in the present connection seems to be perfectly clear. It shows in a convincing manner, that electrical resistance is a delicate and accurate indicator of normal vitality.

Since it is evident that a fall of resistance indicates injury, it seems reasonable to assume that the amount of fall is a measure of the amount of injury. This may be expressed as per cent. of the total possible loss (this would correspond to the amount of loss of the substance, $M$, as previously discussed). If tissue which has been injured by exposure to a toxic solution be replaced in sea water, it may recover a part or all of the resistance which it had lost. If the resistance should fall to $70 \%$, then recover in sea water to $90 \%$, and remain stationary, we might call the temporary loss of resistance temporary injury and the permanent loss permanent injury. In this case the temporary injury ${ }^{16}$ would be $30 \div 90=33.33 \%$ and the permanent injury $10 \div 90=11.11 \%$. If we calculate the protoplasmic resistance in this case we find that starting at $100 \%$ the resistance decreases to $62.50 \%$ and recovers to $86.4 \%$. In the case of protoplasmic resistance the total possible $\operatorname{loss}^{17}$ is 92.65 , the temporary injury is therefore $(100-62.5) \div 92.65=40.5 \%$ and the permanent injury is $(100-86.4) \div 92.65=14.68 \%$. In this manner we arrive at a quantitative basis for the study of injury and recovery.

${ }^{16}$ We divide by 90 because if the resistance starts at 100 the total possible loss is 90 . This is merely another way of saying that we subtract 10 from 100 because the base line is taken as 10 (see p. 56).

${ }^{17}$ I.e., the base line is $7.35 \%$. 
It is evident from Fig. 37 that in the earlier stages of the death process, recovery may be complete $(i . e$. , the normal resistance may be completely regained), but this is not the case in the later stages. In other words we see that as temporary injury increases, permanent injury also increases.

Another interesting aspect of the subject ${ }^{18}$ is illustrated by the results obtained in mixtures of $\mathrm{NaCl}$ and

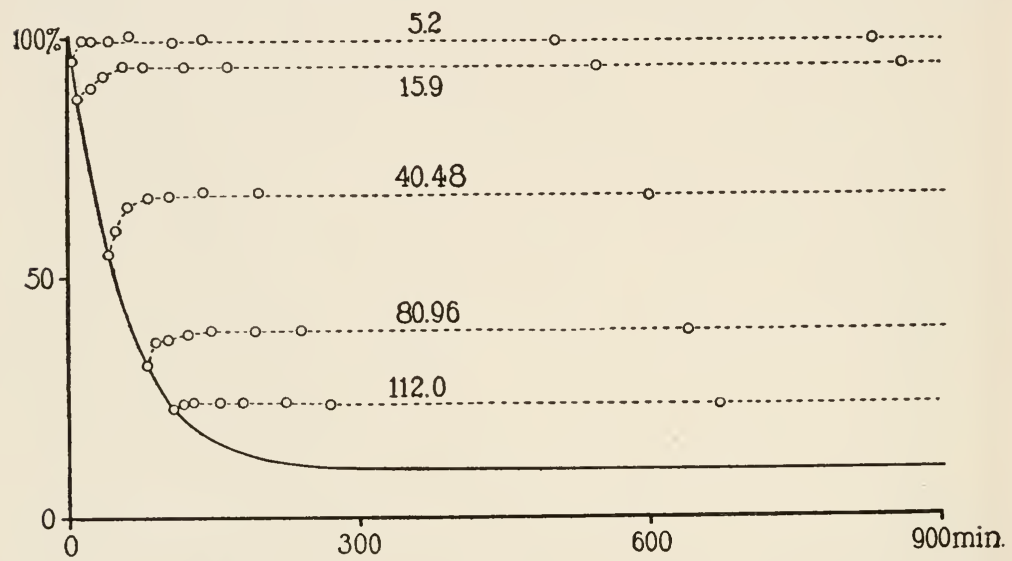

FIg. 37.-Curves showing net electrical resistance of Laminaria agardhii in $\mathrm{NaCl} 0.52 \mathrm{M}$ (unbroken line), and recovery in sea water (dotted lines). The figure attached to eaoh recovery curve denotes the time of exposure (in minutes) to the solution of $\mathrm{NaCl}$.

$\mathrm{CaCl}_{2}$. Curve $C$ in Fig. 38 shows the behavior of tissue placed in a solution containing 97.56 mols of $\mathrm{NaCl}$ to 2.44 of $\mathrm{CaCl}_{2}$; its electrical resistance falling in 37.5 hours to $72.87 \%$ of the original value in sea water. In a solution containing $85 \mathrm{mols}$ of $\mathrm{NaCl}$ to $15 \mathrm{mols}$ of $\mathrm{CaCl}_{2}$ (Curve $A$ ) the resistance fell in the same time to practically the same point $(72.47 \%)$.

When these two lots of tissue were replaced in sea water they behaved differently. The resistance of the

${ }^{18} \mathrm{Cf}$. Osterhout $(1920, A, \mathrm{~B} ; 1921, A, B, C)$. 
first lot rose to $78.2 \%$ (Fig. 38, upper dotted line), but the resistance of the second fell (much more rapidly than if it had not been removed to sea water) and eventu-

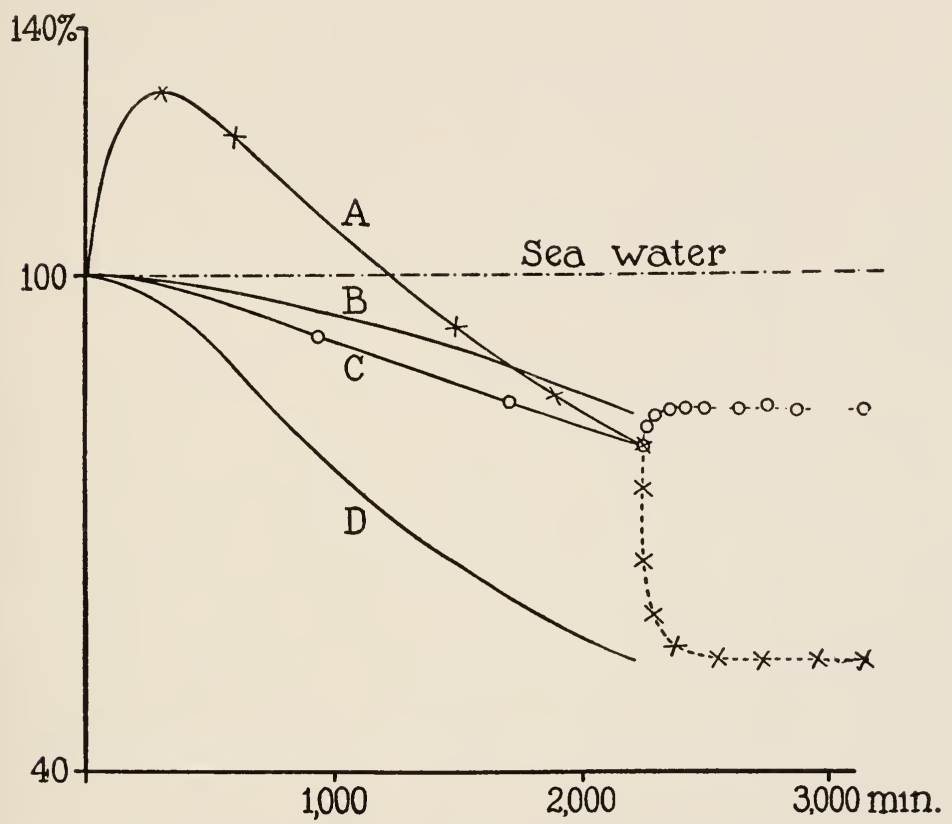

FIG. 38.-Curves showing net electrical resistance of Laminaria agardhii in a solution containing $97.56 \mathrm{mols}$ of $\mathrm{NaCl}$ to 2.44 mols of $\mathrm{CaCl}_{2}$ (Curve $C$ ) and in a solution containing 85 mols of $\mathrm{NaCl}$ to 15 mols of $\mathrm{CaCl}_{2}$ (Curve $A$ ). The dotted lines show recovery in sea water. Curves $B$ and $D$ show the levels to which the resistance rises when the tissue recovers in sea water after exposure to these mixtures; their abscissæ denote the times of exposure. Curve $B$ pertains to the first mixture (belonging with Curve $C$ ), while Curve $D$ pertains to the second mixture (belonging with Curve $A$ ).

ally became practically stationary at $38.1 \%$ (Fig. 38, lower dotted line).

If we plot the curve of permanent injury $(i$. $e$. level to which the resistance rises after replacing the tissue in sea water) after various periods of exposure to the first mixture, we get Curve $B$ (and for the second mixture, Curve $D$ ). 
If we use the term recovery for the rise of resistance which occurs when tissue is transferred to sea water from certain solutions (such as the first mixture) there seems to be no good reason why it should not be applied to the fall of resistance which occurs when tissue is transferred from certain other solutions (such as the second mixture) to sea water. ${ }^{19}$ The amount of recovery after any given period of exposure is equal to the vertical distance between Curves $B$ and $C$, in the case of the first mixture, and between Curves $A$ and $D$ in the case of the second mixture.

It may be asked whether Curves $B$ and $D$ are better criteria of toxicity than Curves $A$ and $C$. The question involves the definition of toxicity. Since this term is used in a variety of ways, it is desirable that it should always have a precise quantitative significance. In the present case it is evident that we need not only $A$ and $C$ but also $B$ and $D$ for a complete description of the facts. It seems possible that this may be generally true in the study of toxicity, although at present we may be unable to construct similar curves in many cases because suitable methods of measurement are lacking.

The fact that recovery is never complete except at the beginning (as shown by Curves $B$ and $D$ ) might also be explained as due to the death of certain cells; for if some of the cells are killed by exposure to a solution of $\mathrm{NaCl}$ the complete recovery of the surviving cells cannot restore the resistance to its normal value. This hypoth-

${ }^{10}$ Substances which cause increase of resistance commonly produce permanent injury; this is apparent when the tissues are replaced in sea water.

It would therefore seem that any alteration of resistance (increase or decrease) may produce permanent injury if sufficiently prolonged. In spite of this it seems preferable to restrict the term temporary injury to the fall of resistance observed in toxic solutions without coining a new term to express the injurious action accompanying rise of resistance. 
esis would in no way invalidate the conception developed above, that an individual cell may lose part of its resistance and subsequently regain it, either partially or completely. But there are serious objections to this hypothesis. The appearance of the cells under the microscope indicates that they all die at about the same time. Moreover, Inman $(1921, B)$ has recently obtained striking experimental evidence that recovery may be far from complete when practically all the cells are alive. In his experiments he employed a unicellular alga, Chlorella, which does not stain readily with methylene blue as long as it is alive, but stains intensely as soon as it dies. Cells were treated with hypertonic salt solutions until the rate of respiration was greatly diminished. When they were replaced in the normal culture medium, the respiration did not return to normal, but the rate appeared to be permanently lowered. In order to determine whether this was due to the death of a part of the cells they were carefully stained with methylene blue. The percentage of dead cells ${ }^{20}$ was practically the same as in the normal culture before treatment with the salt solution. In other words, the incompleteness of the recovery seems to be due to the fact that the metabolism of each cell is permanently lowered. Similar results were obtained when the cells were treated with chloroform; in this case a great depression of respiration was not followed by recovery, but by a greatly lowered metabolism which was permanent and which was not due to the death of a part of the cells.

Some recent experiments of Inman $(1921, A)$ indicate that we obtain similar results whether we use electrical resistance or respiration as the criterion of partial recovery. He found that in $\mathrm{NaCl} 0.52 M$ the rate of production

${ }^{20}$ The cells were counted with a hæmocytometer. 
of carbon dioxide by Laminaria steadily decreased. If the tissue was replaced in sea water after exposure to $\mathrm{NaCl}$ the recovery (as judged by the rate of production of $\mathrm{CO}_{2}$ ) was either partial or complete according to the degree of depression which the rate had undergone. The results are shown in Fig. 39. It will be seen that they

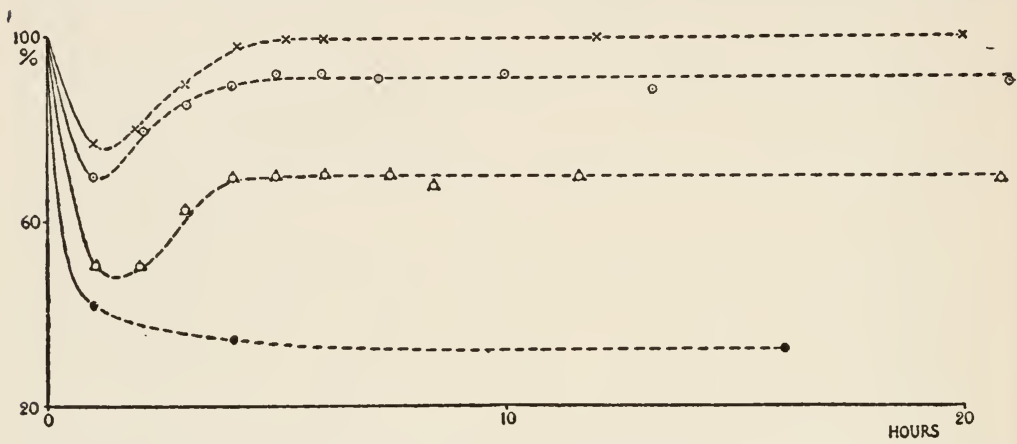

Fig. 39.-Curves showing rate of respiration of Laminaria agardhii (expressed as per cent. of the normal). The normal rate represents a change from $\mathrm{pH} 7.78$ to 7.36 in from $1 \mathrm{r} / 2$ to 2 minutes, depending upon the amount of material used. The solid lines show rate of respiration during one hour of exposure to isotonic sodium chloride $(0.52 M$ for Woods Hole sea water). The dotted lines show stages of recovery after the tissue was put back in normal sea water. Each curve represents a typical experiment.

offer a striking parallel to those obtained by measuring the electrical resistance.

Similar results are observed where we employ hypertonic or hypotonic solutions in place of $\mathrm{NaCl}$. When Laminaria is placed in dilute sea water, or in sea water concentrated by evaporation, injury may occur, and recovery may be partial or complete. This is true whether we use electrical resistance or rate of production of $\mathrm{CO}_{2}$ as the criterion of injury and recovery. The results obtained by Inman $(1921, A)$ with hypertonic solutions are shown in Fig. 40.

The fact that in the case of Laminaria and Chlorella recovery may be either partial or complete, according to circumstances, raises the question whether this is also true of other forms. It is certainly true of all the plants 
investigated by the writer, such as the green alga, Ulva (sea lettuce), the red alga, Rhodymenia (dulse), and the flowering plant, $Z$ ostera, (eel grass). It seems to be also true of frog skin as far as the experiments of the writer have gone. ${ }^{21}$ In physiological literature it seems to be generally assumed that when recovery occurs at all it is practically complete, as though it obeyed an "all or none" law.22 It is evident that partial recovery might

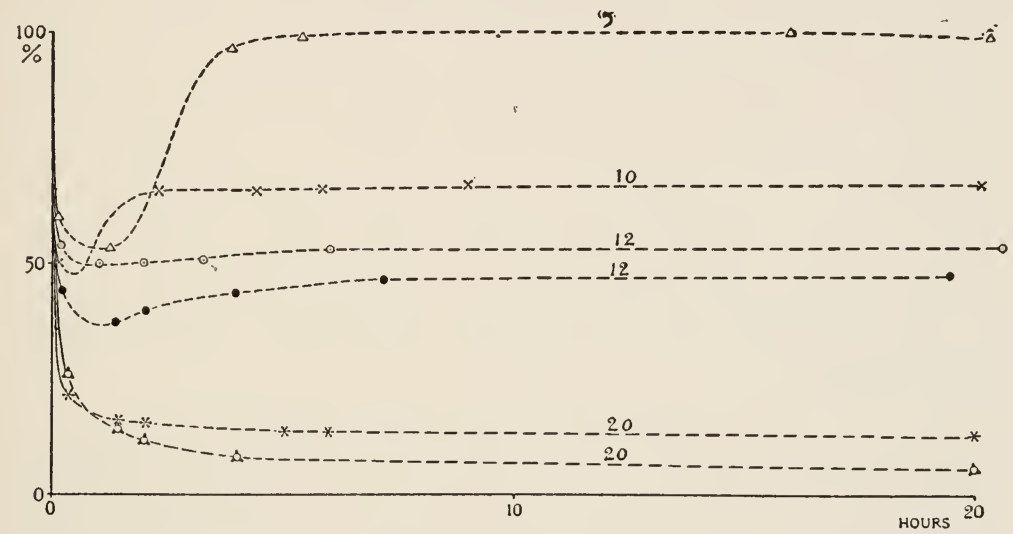

Fig. 40.-Curves showing rate of respiration of Laminaria agardhii (expressed as per cent. of the normal). The normal rate represents a change from $\mathrm{pH} 7.78$ to $7.36 \mathrm{in}$ from $11 / 2$ minutes to 2 minutes, depending upon the amount of material used. The solid lines show rate of respiration while tissue was exposed to hypertonic sea water (sp. gr. 1.130, $\triangle^{\circ}=-9.37^{\circ}$ approximately). The dotted lines show stages of recovery after the tissue was put back in normal sea water. Each curve represents a typical experiment. The figure attached to each recovery curve denotes the time (in minutes) of exposure to the solution of hypertonic sea water; thus the uppermost curve represents recovery after an exposure of 5 minutes.

21 The recovery experiments on frog skin were few in number and dealt chiefly with the effects of anæsthetics.

${ }_{22}$ There are indications in the literature that partial recovery occurs. Thus Leo Loeb and his collaborators Loeb, L. (1903) 1905; Corson-White, E. P. and Loeb, L. (1910) ; Fleischer, M. S., Corson-White, E. P., and Loeb, L. (1912) ; Ishii, O., and Loeb, L. (1914) observed that destruction of the corpora lutea produces a permanently depressing effect on the ovary and that the virulence of tumor tissue is permanently diminished by exposure to heat or certain reagents. In both cases a condition is produced which is intermediate between death and normal vigor. The diminution of the virulence of bacteria by various means cannot be cited as an illustration unless it is certain that it is not due to the selection of less virulent individuals. 
easily be overlooked except in cases where recovery can be measured with considerable accuracy, and it seems possible that further investigation may show that incomplete recovery is a general phenomenon.

Let us now consider the cause of permanent injury. If we assume that the death process proceeds according to the scheme

$$
A \rightarrow M \rightarrow B
$$

it is evident that in sea water $A$ must be continually renewed. Let us assume that this occurs by means of the reactions $O \longrightarrow S \longrightarrow A$ and that $O$ (the origin of all the substances produced) is present in such large amount that its concentration does not appreciably change during the time of the experiment. If we start with $O$ alone, it will produce all the other substances according to the scheme

$$
O \rightarrow S \rightarrow A \rightarrow M \rightarrow B
$$

and their amounts will increase until equilibrium is reached, $i . e$. , until they are decomposed as rapidly as they are formed. Their values will then remain constant.

We assume that when the tissue is placed in $\mathrm{NaCl}$ $0.52 M$, the reactions $O \rightarrow S \rightarrow A$ cease, while the reactions $A \longrightarrow M \longleftarrow B$ continue. In consequence the values of $A, M$, and $B$ steadily fall. If the tissue is now replaced in sea water the reactions $O \longrightarrow S \rightarrow A$ recommence and in consequence the values of $A, M$, and $B$ will rise to their original level (the level which is normal for sea water). But if $O$ is diminished by exposure to the solution of $\mathrm{NaCl}$ it can no longer restore these values to their original level. If, for example, it diminishes to one-half it can restore them only to one-half the normal values. In this case the permanent injury would amount to $50 \%$. We therefore 
see that the permanent injury is an index of the condition of $O$.

We may now calculate the curve of recovery ${ }^{23}$ after exposure to a solution of $\mathrm{NaCl} 0.52 M$. We assume that when the tissue is transferred from sea water to the solution of $\mathrm{NaCl}$ the reactions $O \longrightarrow S \rightarrow A$ cease and that the velocity constant $K_{A}$ of the reaction $A \rightarrow M$ increases from 0.0036 to 0.0180 while the velocity constant $K_{M}$ of the reaction $M \longrightarrow B$ increases from 0.1080 to 0.540 . We may then calculate the resistance in the solution of $\mathrm{NaCl}$ after any length of exposure by means of the formula

Resistance $=2,700\left(\frac{K_{A}}{K_{M}-K_{A}}\right)\left(e^{-K_{A} T_{E}-e^{-K_{M} T E}}\right)+90 e^{-K_{M} T_{E}}+\mathrm{ro}$

in which $T_{E}$ is the time of exposure in minutes, and $e$ is the basis of natural logarithms. 10 is added in the formula because the base line is taken as 10 (not as 0 ) for the reason that the resistance sinks to 10 (as shown in Fig. 28) when the tissue dies.

We assume that when the tissue is replaced in sea water the reactions $O \longrightarrow S \rightarrow A$ recommence and that the values of $K_{A}$ and $K_{M}$ become 0.0036 and 0.1080 respectively, while the other velocity constants likewise acquire the values which they normally have in sea water. Under these conditions $M$ will be formed faster than it is decomposed and the resistance will rise.

The fact that the rise does not reach as high a level after a long exposure as after a short one indicates that during the exposure $O$ gradually diminishes; we assume that this takes place by the reactions

$$
N \rightarrow O \longrightarrow P
$$

We likewise assume that during exposure to the solu-

${ }^{23}$ See Chapter II. 
tion of $\mathrm{NaCl}$ the amount of $S$ changes by means of the reactions

$$
R \rightarrow S \rightarrow T
$$

and that on transferring to sea water $S$ is rapidly converted into $A$. In order to calculate the rate of recovery we find by trial the most satisfactory values of the velocity constants. The values thus found are given in Table V.

TABLE V

Velocity Constants

\begin{tabular}{l|l|l|l}
\hline \multirow{2}{*}{ Reaction } & Velocity constant & \multicolumn{2}{|c}{ Value at $5^{\circ} \mathrm{C}$. in } \\
\cline { 3 - 4 } & & \multicolumn{1}{|c}{$\mathrm{NaCl}$} & \multicolumn{1}{|c}{$\mathrm{CaCl}_{2}$} \\
\cline { 2 - 3 }$N \rightarrow O$ & $K_{N}$ & 0.03 & 0.0045 \\
$O \rightarrow P$ & $K_{O}$ & 0.0297 & 0.004455 \\
$R \rightarrow S$ & $K$ & 0.04998 & 0.0145 \\
$S \rightarrow T$ & $K$ & 0.02856 & 0.007 \\
$A \rightarrow M$ & $K_{A}$ & 0.018 & 0.0018 \\
$M \rightarrow B$ & $K_{M}$ & 0.540 & 0.0295 \\
\hline
\end{tabular}

As an example of the method of calculation we may take the case of tissue exposed for 15 minutes to a solution of $0.52 \mathrm{M} \mathrm{NaCl}$ at $17^{\circ} \mathrm{C}$. The net resistance in sea water at the start was $960 \mathrm{ohms}$; in the course of $15 \mathrm{~min}$ utes in the solution of $\mathrm{NaCl}$ it fell to $775 \mathrm{ohms}$, which is $80.69 \%$ of the original resistance. The fall of resistance is a little more rapid than in the "standard curve" previously obtained. If we assume that this is due to the difference in temperature (these measurements were made at $17^{\circ} \mathrm{C}$. while those on which the standard curve is based were obtained at $15^{\circ} \mathrm{C}$.) we may introduce a correction by multiplying the abscissa by the factor ${ }^{24} 1.06$, which makes it

${ }^{24}$ This agrees closely with the temperature coefficient as determined elsewhere. See page 37 . 
15.9 minutes, and causes it to agree with the standard curve. All the abscissæ are multiplied by the same factor. ${ }^{25}$ The effect of this is to make the process appear to proceed at 15 instead of at $17^{\circ} \mathrm{C}$. If the difference between the two curves is due wholly to difference in temperature this introduces no error, and if the difference is due in part to other factors, the error, if any, is less than the usual experimental error.

The advantages of this procedure are that we can employ for our calculations the constants already obtained for the standard curve and also compare the theoretical curves which start from the same points. This procedure has therefore been followed throughout and the corrected results (i. e., the figures multiplied by a suitable factor) are employed in the following description.

When the tissue was replaced in sea water the resistance began to rise. At the end of 10 minutes it had risen from 80.69 to $89.10 \% .^{28}$ Since, however, the abscissæ of the death curve have been multiplied by 1.06 the same thing must be done for the recovery curve and in place of 10 minutes we must put 10.6 minutes. Proceeding in this manner we obtain the recovery curve which is labeled 15.9 in Fig. 41.

In order to calculate the course of the recovery we must consider the reactions which determine the amount of electrical resistance. When the tissue is placed in the

${ }^{2}$ This procedure may displace the points on the curve so that where several curves are averaged it may be necessary to employ interpolation in order to average points on the same ordinate. In many cases curves were obtained by averaging the ordinates of death curves and recovery curves before multiplying by the factor.

${ }^{20}$ In earlier experiments it was found that complete recovery was possible after the resistance had fallen to about $80 \%$. This was not the case in the present series; the difference may be due to differences in material or in technique. Cf. Osterhout $(1915, B)$. 
solution of $\mathrm{NaCl}$ the reactions which occur are: (1) $A \longrightarrow M \longrightarrow B$; (2) $R \longrightarrow S \longrightarrow T$; and (3) $N \rightarrow O \rightarrow P$. Let us first consider the reactions $A \longrightarrow M \longrightarrow B$. The value of $A$ in sea water is taken as 2,700 and that of $M$ as 90. As previously explained the value of $A$ will diminish

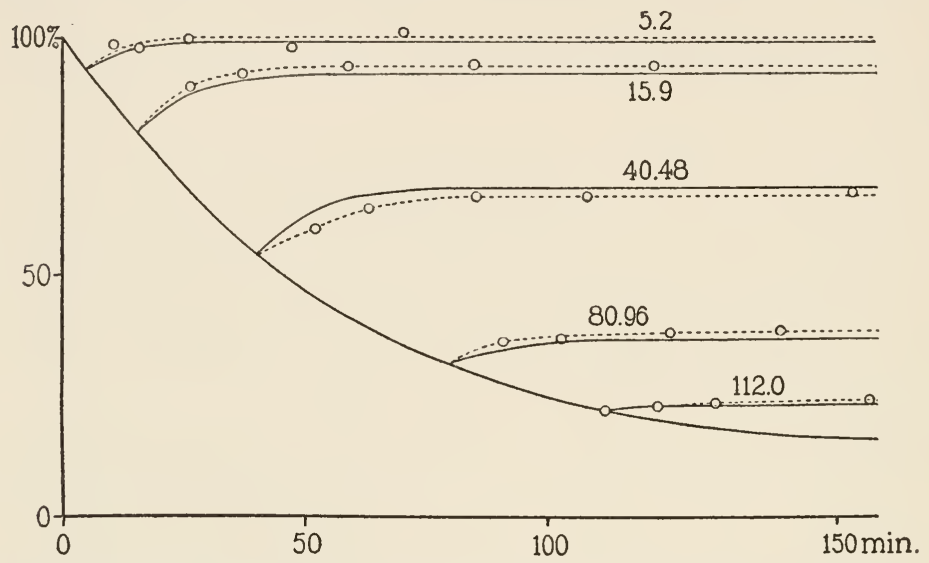

FIG. 41.-Curves showing the fall of net electrical resistance of Laminaria agardhıi in $0.52 M$ $\mathrm{NaCl}$ (descending curve) and recovery in sea water (ascending curves). The figure attached to each recovery curve denotes the time of exposure (in minutes) to the solution of $\mathrm{NaCl}$. In the recovery curves the experimental results are shown by dotted lines, the calculated results by the unbroken lines (the curves are extended beyond the last observed point shown because of later observations which cannot be shown in the figure). The observed points represent the average of eight or more experiments; probable error of the mean less than $10 \%$ of the mean.

during exposure to $\mathrm{NaCl}$ according to the formula

$$
A=2700 e^{-K_{A} T E}
$$

in which $\mathrm{T}_{E}$ is the time of exposure to the solution. Since $K_{A}=0.018$ (see Table $V$ ) the value of $A$ after 15.9 minutes in $\mathrm{NaCl} 0.52 M$ is

$$
2,700 e^{-(0.018) 15.9}=2,027.96
$$

The value of $M$ at the end of 15.9 minutes is the observed resistance 80.69 less 10 (since the base line of the curve is not 0 but 10 ). 
On replacing the tissue in sea water, therefore, we start with $M=70.69$ and $A=2,027.96$, but this value of $A$ is at once augmented by the conversion of $S$ into $A$. In order to find the amount of this augmentation we must know the value of $S$.

During exposure to $\mathrm{NaCl}$ the reaction $R \rightarrow S \rightarrow T$ occurs. The value of $S$ may be easily calculated by employing formula (1) and substituting the appropriate constants. We thus obtain

$$
S=1041.77\left(\frac{K_{R}}{K_{S}-K_{R}}\right)\left(e^{-K_{R} T_{E}-e^{-K_{S} T_{E}}}\right)+2.7 e^{-K_{S} T_{E}}
$$

The value of $R$ at the start in sea water is taken as $1,041.77$ and that of $S$ as 2.7. In the solution of $\mathrm{NaCl}$ the values of $K_{R}$ (the velocity constant of the reaction $R \longrightarrow S$ ) and $K_{S}$ (the velocity constant of the reaction $S \rightarrow T$ ) are taken as 0.04998 and 0.02856 respectively (see Table V). Hence the value ${ }^{27}$ of $S$ at the end of 15.9 minutes is 447.26. When the tissue is replaced in sea water $S$ is rapidly converted into $A$ so that the total value of the latter becomes $447.26+2,027.96=2,475.22$.

On replacing the tissue in sea water $A=2,475.22$ and $M=70.69$. The resistance due to $A$ and $M$ after any given time $T$ in sea water is obtained by modifying formula (1) which becomes

$$
\begin{gathered}
\text { Resistance }=2,475.22\left(\frac{K_{A}}{K_{M-K_{A}}}\right)\left(e^{\left.-K_{A} T_{R}-e^{-K_{M} T_{R}}\right)}\right. \\
+70.69\left(e^{-K_{M} T_{R}}\right)+\text { Io }
\end{gathered}
$$

in which $T_{R}$ denotes the time which has elapsed after

${ }^{2 \pi}$ In general the greater the rise in recovery the greater the value of $S$, while the greater the fall the less the value of $S$. 
replacement in sea water. The velocity constants $K_{A}$ and $K_{M}$ have the normal values in sea water, 0.0036 and 0.1080 respectively. Hence the resistance at the end of 10.6 minutes is 87.44 .

We must likewise remember that on replacing the tissue in sea water the reactions $O \rightarrow S \rightarrow A$ recommence and produce a certain amount of $A$; this breaks down to form $M$, which in turn decomposes. The resulting amount of $M$ may be easily calculated. It will be recalled that in sea water all processes are so adjusted that the amount of $M$ remains constant; it is evident that if the reactions $O \longrightarrow S \longrightarrow A$ were suddenly to stop, allowing $A \rightarrow M \longrightarrow B$ to continue, the amount of $M$ would diminish. At the start the total resistance is 100 . If $O$ should stop producing this would diminish and we may call the loss of resistance $L$. Now if $O$ were producing normally it would just replace this loss, so as to keep the resistance constant at 100: hence the amount produced from $O$ in any given time will be equal to the loss $I$ which would occur in that time if $O$ were to stop producing.

When tissue is exposed to a solution of $\mathrm{NaCl}, \mathrm{O}$ diminishes according to the scheme $N \rightarrow O \rightarrow P$. Assuming that at the $\operatorname{start} N=89.1$ and $O=90$ we find ${ }^{28}$ that the value of $O$ after any given time (TE) of exposure to a solu-

${ }^{28}$ This value of $O$ is assumed merely for convenience in calculation, without reference to other assumed values. Its real value must be much greater than that of $A$, but it is not necessary to assign any definite real value to it, since the only point of interest is to determine what per cent. of $O$ remains after any given time of exposure to sea water. It is assumed that in sea water any change in the amount of $O$ is so small as to be negligible. This might be due to the fact that $O$ is present in large amount and decomposes slowly or to the fact that it is formed as rapidly as it decomposes (by the reactions $\mathrm{N} \longrightarrow \mathrm{O} \longrightarrow \mathrm{P}$ ). 
tion of $\mathrm{NaCl}$ may be obtained by changing the constants in formula (1) thus:

$$
O=89.1\left(\frac{K_{N}}{K_{O}-K_{N}}\right)\left(e^{-K_{N} T_{E}}-e^{-K_{O} T_{E}}\right)+90 e^{-K_{O} T_{E}}
$$

in which $K_{N}$ (the velocity constant of the reaction $N \rightarrow$ $O)$ and $K_{o}$ (the velocity constant of the reaction $O \rightarrow P$ ) have the values 0.03 and 0.0297 respectively (see Table V, page 98).

We find by this formula that at the end of an exposure of 15.9 minutes the value of $O+10$ is 92.57 ; hence it can produce only $(92.57-10) \div(100-10)=0.917$ as much of $M$ in any given time as it could produce if it were intact. $^{20}$ The amount it could produce, if intact, during recovery in sea water is easily found by subtracting from 100 the resistance obtained by means of formula (1), when $K_{A}=0.0036$ and $K_{M}=0.1080$ (these are the normal values in sea water). Using these values we find that at the end of 10.6 minutes the amount of resistance, as given by formula (1), would be 98.55 . Hence the loss during that time would be $100-98.55=1.45$, which is the amount $O$ could produce in 10.6 minutes if intact. This value may be called $L$ and expressed as follows:

$L=100-\left[2700\left(\frac{K_{A}}{K_{M}-K_{A}}\right)\left(e^{-K_{A} T_{R}-K_{M} T_{R}}\right)+90 e^{-K_{M} T_{R}}+\mathrm{I0}\right]$

in which $K_{A}=0.0036$ and $K_{M}=0.1080$ (these are the normal values in sea water) and $T_{R}$ is the time which has clapsed since the tissue was replaced in sea water.

20 In other words, if $S, T$ and $A$ were completely removed, $O$ could raise the level of $M$ to $100-10=90$ in the course of time. But if, for example, half of $O$ is lost the remainder can raise the level of $M$ to only one-half its former value; i.e., to 45 . 
But as $O$ has diminished to 0.917 times its original value it can produce in 10.6 minutes only (1.45) (0.917) $=1.33$. By adding this to that obtained by formula (4) we find the resistance after 10.6 minutes in sea water to be $87.44+1.33=88.77$.

The recovery formula may therefore be expressed as follows:

$$
\begin{aligned}
\text { Resistance }=( & A+S)\left(\frac{K_{A}}{K_{M}-K_{A}}\right)\left(e^{-K_{A} T_{R}}-e^{-K_{M} T_{R}}\right)+M e^{-K_{M} T_{R}} \\
& +L\left(\frac{o}{90}\right)+\text { Iо. }
\end{aligned}
$$

Using this formula, we may find the resistance at any given time after replacement in sea water. A series of TABLE VI.

Recovery in Sea Water after Exposure of 15.9 Minutes to 0.52M NaCl.

\begin{tabular}{c|c|c|c}
\hline \hline $\begin{array}{c}\text { Total time=time in sea } \\
\text { water+15.9 }\end{array}$ & Time in sea water & \multicolumn{2}{|c}{ Electrical resistance } \\
\cline { 2 - 3 } mın. & mın. & por cent. & per cent. \\
26.5 & 10.6 & 89.10 & 88.77 \\
37.1 & 21.2 & 93.21 & 91.34 \\
58.3 & 42.4 & 93.99 & 92.43 \\
84.8 & 68.9 & 94.48 & 92.52 \\
121.9 & 106.0 & 94.20 & 92.55 \\
164.3 & 148.4 & 93.81 & 92.55 \\
545.9 & 530.0 & 94.00 & 92.57 \\
863.9 & 848.0 & 93.87 & 92.57 \\
\hline
\end{tabular}

values so obtained is given in Table VI. It will be seen that they are in good agreement with the experimental values. The calculated and observed values are also plotted in Fig. 41, in which the abscissæ represent the time in the solution of $\mathrm{NaCl}$ plus the time of recovery in sea water (in the case just discussed this would amount to $15.9+10.6=26.5$ minutes $)$. 
Proceeding in this manner with different times of exposure we obtain the series of recovery curves shown in Fig. 41. The number attached to each curve denotes the

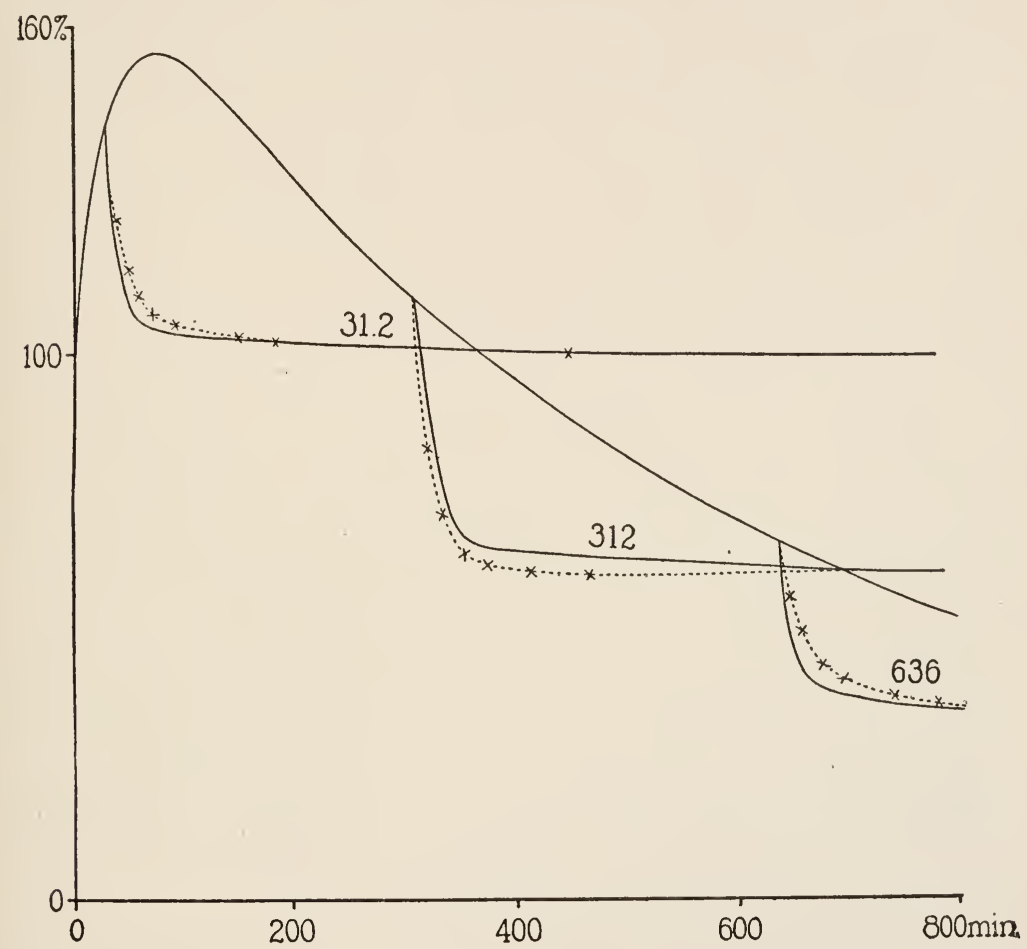

Frg. 42.-Curves showing the rise and fall of net electrical resistance in Laminaria agardhii in $0.278 \mathrm{M} \mathrm{CaCl}_{2}$ (single curve which rises and falls) and recovery in sea water (descending curves). The figure attached to each recovery curve denotes the time of exposure (in minutes) to the solution of $\mathrm{CaCl}_{2}$. In the recovery curves the experimental results are shown by the dotted lines, the calculated results by the unbroken lines. The observed points represent the average of eight or more experiments. Probable error of the mean less than 10\% of the mean.

time of exposure to the solution of $\mathrm{NaCl}$. The observed results are plotted as dotted lines, the calculated values as unbroken lines.

It will be seen that the agreement is satisfactory throughout. In general the greater the number of experi- 
ments which were averaged to obtain the result the nearer it approached to the calculated curve.

Let us now consider the behavior of tissues transferred from a solution of $0.278 \mathrm{M} \mathrm{CaCl}_{2}$ (which has the conductivity of sea water) to sea water. In such a solution the resistance rises and then falls. If tissue is allowed to remain in the solution for a short time and is then replaced in sea water the resistance falls rapidly, as shown in Fig. 42. This fall of resistance may be regarded as analogous to the rise of resistance which occurs in the experiments with $\mathrm{NaCl}$ and the term recovery may be used in both cases. It is evident from the figure that as the exposure to the solution of $\mathrm{CaCl}_{2}$ lengthens the level which is reached as the result of recovery gets lower. This is precisely what happens in the experiments with $\mathrm{NaCl}$. It would therefore appear as though the same mechanism of recovery were involved. If this is so the same method of calculation should enable us to predict recovery in both cases. This is found to be true. Using the same formulas which have already been employed in the experiments with $\mathrm{NaCl}$ we are able to predict the course of the curves obtained in experiments with $\mathrm{CaCl}_{2}$. This is rather striking in view of the fact that the two sets of curves differ so fundamentally in appearance.

In calculating the eurves for $\mathrm{CaCl}_{2}$ the constants given in Table V (page 98) are employed. The results are shown as unbroken lines in Fig 42 (the dotted lines show the experimental results). It is evident that the agreement is very satisfactory.

Some assistance in picturing the reactions which occur during exposure is afforded by Fig. 43, which shows the curve of $\mathrm{O}+10$ in $\mathrm{NaCl}$ (unbroken line) and in $\mathrm{CaCl}_{2}$ (dotted line). These curves are plotted from the calcu- 
lated values; the observed values are shown as points; it will be observed that they lie fairly close to the calculated curve. The figure also shows the calculated values of $S$; in this case no observed values are given because such values cannot be very precisely determined. This is owing to the fact that the value of $S$ affects only

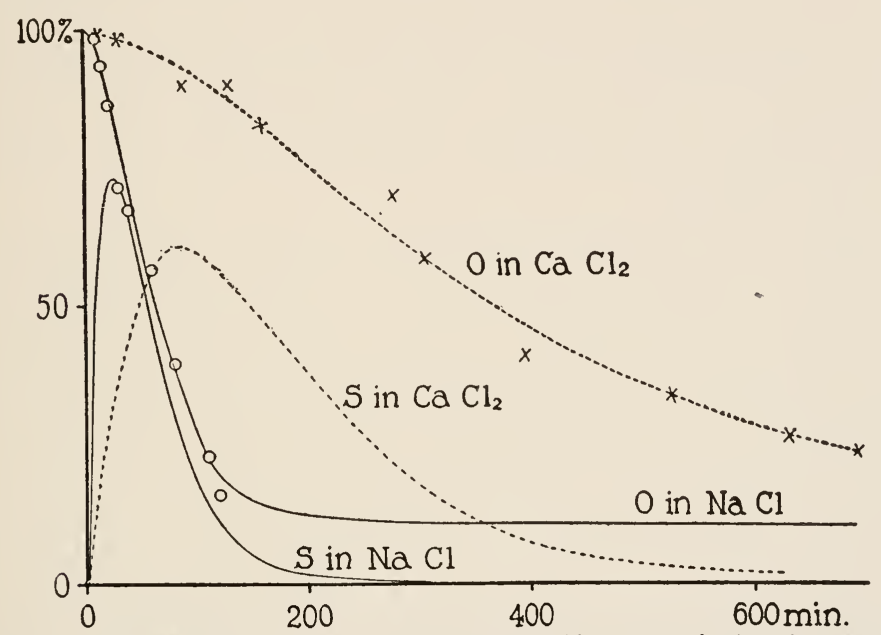

Fig. 43.-Curves showing the values of $O+10$ in $\mathrm{NaCl}$ (upper unbroken line) and in $\mathrm{CaC}$ (upper dotted line); also the values of $S$ in $\mathrm{NaCl}$ (lower unbroken line) and in $\mathrm{CaCl}_{2}$ (lower dotted line). The ordinates give the values of $O$; these must be multiplied by 6.75 to obtain the values of $S$. The observed points represent the average of eight or more experiments; probable error of the mesn less than $10 \%$ of the mesn.

the speed of recovery (not the final level attained) and as the speed is variable the only satisfactory procedure is to assume such values of $K_{R}$ and $K_{S}$ as cause the closest approximation to the observed speed of recovery. When these values have been found the value of $S$ can readily be calculated. The results of these calculations are plotted in Fig. 43.

In this figure the ordinates give the values of $O+10$ : these must be multiplied by 6.75 to obtain the values of $S$. In all curves the value of $S$ at the start is 2.7 (the value of 
$S$ in sea water ${ }^{30}$ ); this appears on the ordinate in the figure as $2.7 \div 6.75=0.4$. The curves rise to a maximum and then fall to zero. The curves for $O+10$ start at 100 and fall to 10 (since the base line is taken as 10 , just as in the curve of $M$ ).

It is found that the rate of recovery is approximately the same in all cases; this applies to the experiments with $\mathrm{CaCl}_{2}$ as well as with those in $\mathrm{NaCl}$. In general it may be said that it usually requires about 60 minutes for the curve to complete nine-tenths of the total rise or fall which occurs in recovery.

If the theory here developed is sound it should also enable us to predict the behavior of tissue transferred from one toxic solution to another. In order to put this to a test a variety of experiments was made in which the tissue was exposed to several solutions in succession.

\section{Alternate Exposure to $\mathrm{NaCl}$ and Sea Water.}

The procedure may be illustrated by a typical experiment, the results of which are shown in Fig. 44.

The tissue was exposed for 20.8 minutes $^{31}$ to $0.52 M$ $\mathrm{NaCl}$, during which time the resistance fell from 100 to $74.03 \%$. After 20.8 minutes in the solution of $\mathrm{NaCl}$ the value of $T_{E}$ (in formulas (2), (3) and (5)) is 20.8 and the following results are obtained: $A=1856.80, S=$ 484.06, $M=64.03, O=88.41$. When the tissue has been

${ }^{30}$ The normal value of $S$ in sea water is taken as 2.7 which is exceedingly small as compared with the amount of 0 . The amount of $S$ which is produced from $O$ in each unit of time is relatively large, but $S$ is so rapidly transferred into $A$ that its amount in sea water never becomes greater than 2.7.

${ }^{31}$ This is corrected from 20 minutes (as previously explained) in order to make it conform to the standard curve. 
replaced in sea water and left for 10.4 minutes $^{32}$ the value of $T_{R}$ (in formulas (6) and (7)) is 10.4 and the value of $L$ is found to be 1.33 .

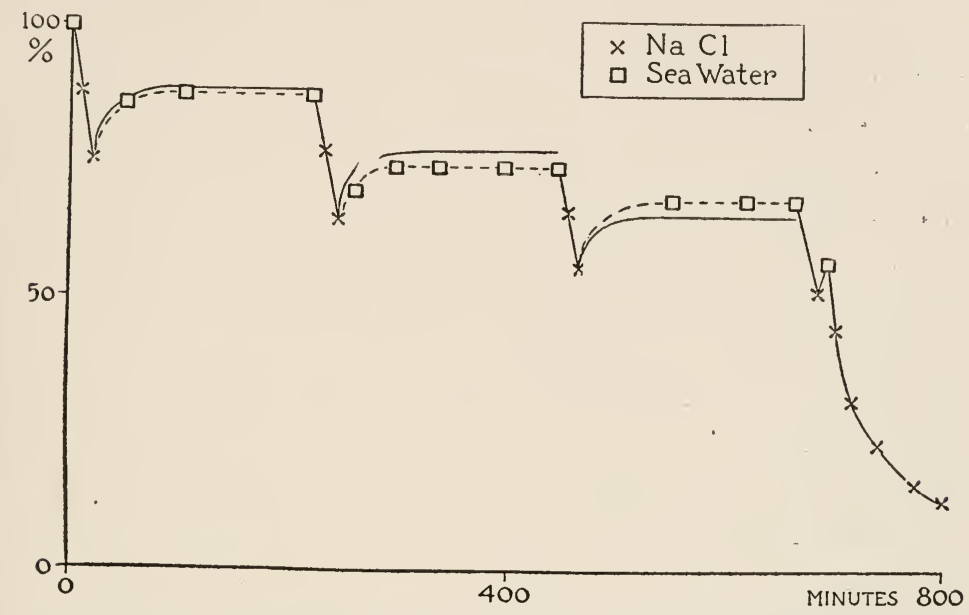

Frg. 44.-Curves showing the net electrical resistance of Laminaria agardhii in $\mathrm{NaCl} 0.52 M$ and in sea water. Unbroken line, calculated values; broken line, observed values. Average i of ten or more experiments; probable error of the mean less than $10 \%$ of the mean.

Substituting these values in formula (1) we find that when the tissue has been replaced in sea water the resistance at the end of 10.4 minutes is 83.49. Proceeding in this manner we calculate the resistance at various intervals after replacement in sea water and obtain the first (calculated) recovery curve shown in Fig. 44. It is evident that it is in fairly good agreement with the observed values.

After 200 minutes in sea water (during which the resistance rose to $87.10 \%$ and remained practically constant) the tissue was replaced in the solution of $\mathrm{NaCl}$. In the course of 21.2 minutes $^{33}$ the resistance fell from

${ }^{30}$ This is corrected from 10 minutes (as previously explained).

${ }^{33}$ The actual time was 20 minutes: the manner in which the corrected figure is obtained is explained in a subsequent paragraph. 
87.10 to 64.18 . It was then replaced in sea water. The recovery curve may be calculated as before, the only differences being as follows:

1. On replacing the tissue in sea water the destruction of $O$ (by the reactions $N \longrightarrow O \longrightarrow P$ ) ceases (or becomes negligible); hence the value of $O$ at the beginning of the second exposure (if equilibrium has been reached) is that of the observed resistance less 10 , or $87.10-10=$ 77.10. We find by means of formula (5) that when $O$ at the start equals 90 it loses 11.95 during an exposure of 21.2 minutes to the solution of $\mathrm{NaCl}$, but as it only equals 77.10 at the start the loss will be $11.95(77.10 \div 90)=$ 10.23. Subtracting this from 77.10 gives 66.87 , the value of $O$ at the end of the second exposure, and adding 10 ( since the base line is 10 ) makes 76.87 , the level to which the resistance should rise after the second exposure.

2. At the start of the first recovery $y^{34} S$ is rapidly converted into $A$, but is partially restored during the subsequent stay in sea water and at the beginning of the second exposure equals $2.7(0 \div 90)$ in which $O$ has the value given above (77.10).

3. During exposure to $\mathrm{NaCl}$ the value of $R$ diminishes from $R_{0}$ to $R_{1}$ according to the formula

$$
R_{1}=R_{\diamond}{ }^{-K_{R} T_{E}}=1011.77 e^{-(0.0198) 42}
$$

in which $R_{0}=$ the value of $R$ before the first exposure (1041.77) and $T_{E}$ equals the total exposure to $\mathrm{NaCl}(20.8$ $+21.2=42)$.

It is evident that unless $R$ is restored during the

"If the value of $O$ were $90, s$ would be completely restored to its original value of $2 . \bar{\tau}$, but since $O$ has fallen to 7.10 it can only restore $S$ to $2.7(77.10 \div 90)$. 
period in sea water the speed of recovery will fall off somewhat with each successive exposure.

4. The value of $M$ is the observed resistance (at the end of the second exposure) less 10 or $64.18-10=54.18$.

5 . The value of $A$ is obtained by multiplying by 30 the resistance observed at equilibrium (less 10). This is based upon the following considerations:

Just before the beginning of the second exposure $A$ and $M$ are assumed to be in equilibrium in sea water, in which case as much of $A$ must decompose in any minute as of $M$ (otherwise $M$ would not remain constant). But the amount of $A$ which decomposes in 1 minute is $A K_{A}$ and of $M$ is $M K_{M}$; and since $K_{M}$ is 30 times as great as $K_{A}$ it follows that $A=30 M$. At the beginning of the second exposure $M=87.10-10=77.10$ and $A=(77.10)$ $30=2313$.

In order to ascertain how the resistance would change during the second exposure if it conformed to the standard curve previously employed, we may employ the formula

$$
\begin{aligned}
\text { Resistance }= & 2313\left(\frac{K_{A}}{K_{M}-K_{A}}\right)\left(e^{-K_{A} T_{E}}-e^{-K_{M} T_{E}}\right) \\
& +77.1 e^{-K_{M} T_{E}}+10
\end{aligned}
$$

in which $K_{A}=0.018, K_{M}=0.540$ and $T_{E}=$ time the tissue has remained in the solution of $\mathrm{NaCl}$. Comparing the values thus obtained with the observed resistance after an exposure of 20 minutes we find that if the time is multiplied by 1.06 (making it 21.2 minutes) the observed resistance $(64.18)$ agrees with the standard curve. This figure is therefore adopted. The value of $T_{E}$ in formulas 
(2), (3) and (5) should now correspond to the total exposure to $\mathrm{NaCl}$, and is $20.8+21.2=42$.

These data were employed in calculating the second recovery curve and the results are shown in Fig. 44. The third recovery curve was calculated in the same fashion.

Instead of waiting for the establishment of equilibrium we may replace the tissue in $\mathrm{NaCl}$ after it has been for a short time in sea water. During the fourth recovery, after the tissue had been 10.2 minutes in sea water and the resistance had risen to $54.92 \%$, it was replaced in sea water: the subsequent fall in resistance was calculated by means of formula (9). For the value 77.1 in this formula we must substitute the observed resistance less 10 , or $55.89-10=45.89$; and in place of 2313 we must substitute the present value of $A$. We assume that at the beginning of the fourth exposure to $\mathrm{NaCl}$ equilibrium had been reached in sea water: hence as the resistance was 68.10 the value of $A$ (which we call $\left.A_{1}\right)$ is, $A_{1}=30(68.10-10)$. During the fourth exposure to $\mathrm{NaCl}$ (lasting 20.4 minutes) the value of $A_{1}$ diminished to $A_{2}$ according to the formula

$$
A_{1} e^{-(0.018) 20.4}=A_{2}
$$

On replacing the tissue in sea water $A_{2}$ was augmented by the conversion of $S$ into $A$. The value of $S$ is found according to formula (3) in which $T_{E}$ is equal to the total time of exposure $(20.8+21.2+20.8+20.4=83.2)$. We may call this $S_{1}$. Hence the value of $A$ immediately after replacement in sea water is $A_{3}=A_{2}+S_{1}$. During the subsequent 10.2 minutes in sea water $A_{3}$ diminished to $A_{4}$ according to the formula

$$
A_{3} e^{-(0.0036) 10.2}=A_{4}
$$

But at the same time it received an addition from the 
decomposition of $O$; the amount of this may be found as follows: The loss of $A$ in sea water under normal conditions $^{35}$ in 10.2 minutes is

$$
\text { Loss }=2700-\left(2700 e^{-(0.0036) 10.2}\right)=97.26
$$

and this could be completely replaced by $O$ if $O$ were intact. But since $O$ has diminished ${ }^{36}$ from 90 to 50.86 it can supply only $97.26(50.86 \div 90)=54.95$. This must be added to $A$ giving $A_{5}=A_{4}+54.95$. The value of $A_{5}$ must be substituted for 2313 in formula (9). This enables us to calculate the fall of resistance after the last recovery (of 10.2 minutes). Fig. 44 shows the values so obtained and also the observed values.

II. Alternate Exposure to $\mathrm{CaCl}_{2}$ and Sea Water.

When the tissue of Laminaria is transferred from sea water to a solution of $\mathrm{CaCl}_{2}$ (of the same conductivity as sea water) the resistance rises and then falls as shown in Fig. 45. When it is replaced in sea water the resistance falls (much more rapidly than if left in the solution of $\mathrm{CaCl}_{2}$ ) and eventually becomes stationary. This fall of resistance may be spoken of as recovery, since it may be regarded as analogous to the rise of resistance which occurs when tissue is transferred from $\mathrm{NaCl}$ to sea water.

${ }^{35}$ The principle upon which this formula is based is explained on page 103 in discussing the loss of $M$ and its replacement by $O$. In the present case the effect of $S$ is negligible since the amount of $S$ in sea water is only 2.7 .

This is calculated as follows: at the beginning of the fourth exposure $O=68.10-10=58.10$. If its value were 90 it would lose 11.23 during an exposure of 20.4 minutes to $\mathrm{NaCl}$. Since $O=58.10$ the loss will be $11.23(58.10 \div 90)=7.24$ : subtracting this from 58.10 we have 50.86 . 
Recovery after exposure to $\mathrm{CaCl}_{2}$ may be calculated in precisely the same manner as recovery after exposure to $\mathrm{NaCl}$. The only difference is that in formulas (2), (3), $(5),(8)$ and (9) we must employ for the velocity constants $\left(K_{N}, K_{O}, K_{R}, K_{S}, K_{A}\right.$ and $\left.K_{M}\right)$ the values given for $\mathrm{CaCl}_{2}$ in Table $\mathrm{V}$, page 98. In formulas (6) and (7) the values of the velocity constants are always the same $\left(K_{A}=0.0036\right.$ and $\left.K_{M}=0.1080\right)$ since these are the values which are normal for sea water.

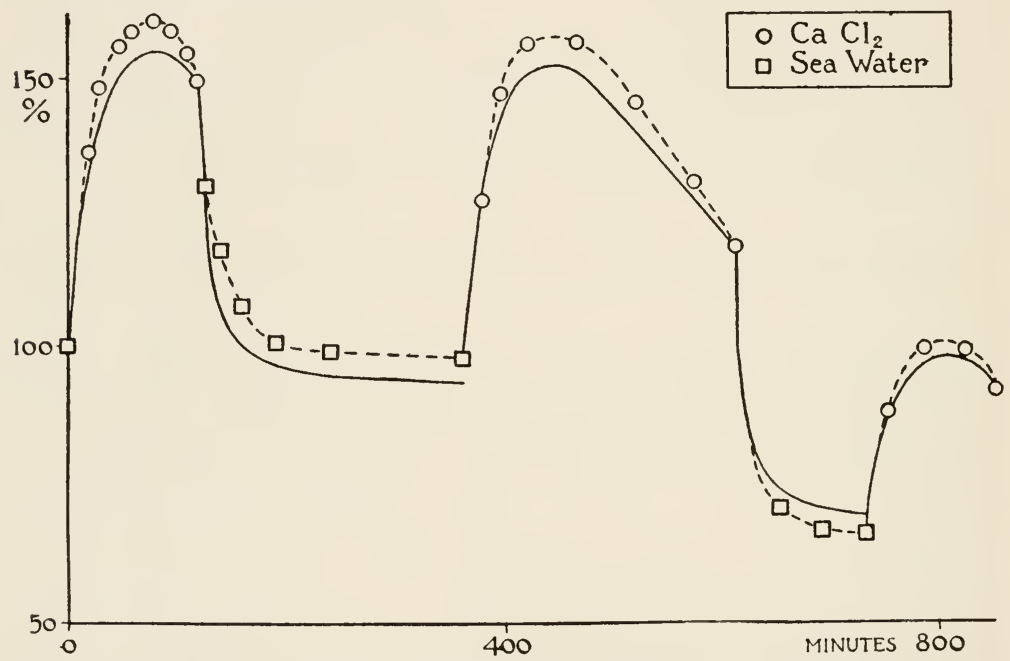

FIg. 45.-Curves showing the net electrical resistance of Laminaria agardhii in $\mathrm{CaCl}_{2} 0.278 \mathrm{M}$ and in sea water. Unbroken line, calculated values; broken line, observed values. Average of ten or more experiments; probable error of the mean less than $10 \%$ of the mean.

Results of such calculations are shown in Fig. 45 together with the observed values.

III. $\mathrm{NaCl}$, Sea Water, $\mathrm{CaCl}_{2}$, Sea Water, etc.

It seemed desirable to test the theory further by varying the experiments in the manner shown in Fig. 46. The calculations are made as already explained. It will be 
noticed that in this and in some other experiments the resistance rises rather more rapidly in $\mathrm{CaCl}_{2}$ than the calculations would lead us to expect. This is due to the

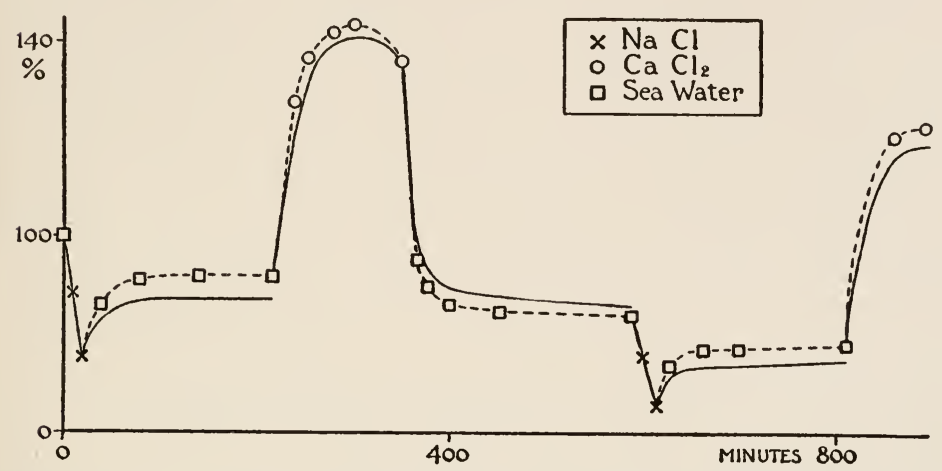

FIG. 46.-Curves showing the net electrical resistance of Laminaria agardhii in $\mathrm{NaCl} 0.52 \mathrm{M}$, in $\mathrm{CaCl}_{2} 0.278 \mathrm{M}$ and in sea water. Unbroken line, calculated values; broken line, observed values. Average of ten or more experiments; probable error of the mean less than $10 \%$ of the nean.

fact that the "standard curve" for $\mathrm{CaCl}_{2}$, which was based upon previous experiments made under different conditions, seems to be a little too low for the present material.

\section{IV. $\mathrm{CaCl}_{2}, \mathrm{NaCl}$, Sea Water, etc.}

A series of experiments was made to determine the effect of $\mathrm{CaCl}_{2}$ followed directly by $\mathrm{NaCl}$. The results are shown in Fig. 47. The rise in $\mathrm{CaCl}_{2}$ during the first 91.8 minutes is calculated in the usual manner. In order to calculate the subsequent drop in $\mathrm{NaCl}$ we must substitute for 77.1 in formula (9) the value of $M$; i.e., the observed resistance (less 10) at the beginning of exposure to $\mathrm{NaCl}$. In place of 2313 we must substitute the value of $A$, which is $A_{1}=2700 e^{-(0.0018) 91.8}$ 
During the exposure of 60.6 minutes to $\mathrm{NaCl}$ the value of $A$ changes from $A_{1}$ to $A_{2}=A_{1} e^{-(0.018) 60.6}$.

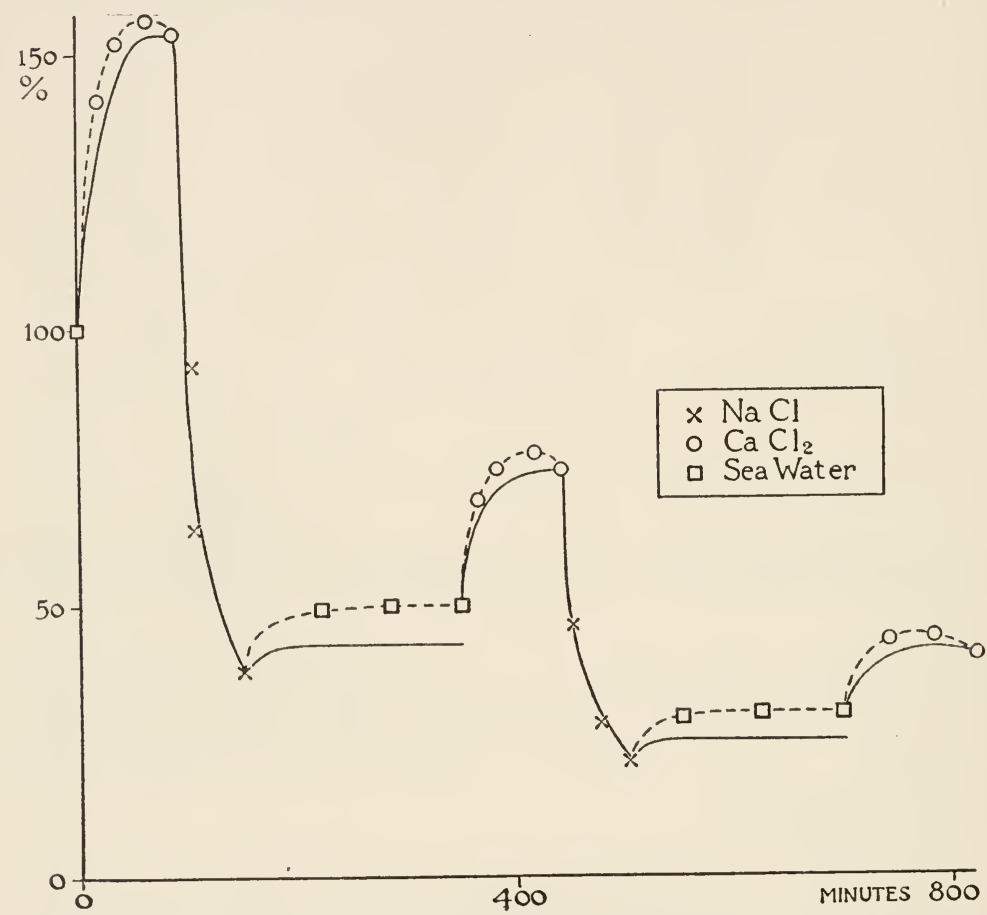

FIG. 47.-Curves showing the net electrical resistance of Laminaria agardhii in $\mathrm{NaCl} 0.52 \mathrm{M}$, in $\mathrm{CaCl}_{2} 0.278 \mathrm{M}$ and in sea water. Unbroken line, calculated values; broken line, observed values. Average of ten or more experiments; probable error of the mean less than $10 \%$ of the mean.

This value must be substituted for $A$ in formula (7) in calculating the recovery in sea water.

In finding the value of $S$ (by means of formula (3)) we must remember that during the 91.8 minutes in $\mathrm{CaCl}_{2}$ the value of $R$ (which at the start is $R_{0}=1041.77$ ) diminishes from $R_{0}$ to $R_{1}$ according to the formula

$$
R_{1}=R_{0} e^{-91.8 K_{R}}
$$

$\mathrm{K}_{R}$ in $\mathrm{CaCl}_{2}=0.012532$ (See Table $\mathrm{V}$, page 98). Dur- 
ing the 60.6 minutes in $\mathrm{NaCl} R_{1}$ diminishes to $R_{2}$ according to the formula

$$
R_{2}=R_{1} e^{-60.6 K_{R}}
$$

$K R$ in $\mathrm{NaCl}=0.04998$.

We must also bear in mind that $O$ diminishes during the exposure. Since this process is 6 times as rapid in $\mathrm{NaCl}$ as in $\mathrm{CaCl}_{2}$ we may consider 91.8 minutes in $\mathrm{CaCl}_{2}$ to be equivalent to $91.8 \div 6=15.3$ minutes in $\mathrm{NaCl}$ and the total exposure to be equivalent to $60.6+15.3=75.9$ minutes in $\mathrm{NaCl}^{37}$ The value of $O$ may then be found by means of formula (5).

V. $\mathrm{CaCl}_{2}, \mathrm{NaCl}, \mathrm{CaCl}_{2}, \mathrm{NaCl}$, Sea Water, etc.

A series of experiments was performed in which tissue was placed in $\mathrm{CaCl}_{2}$ for 30 minutes, then in $\mathrm{NaCl}$ for 10 minutes, then in $\mathrm{CaCl}_{2}$ for 60 minutes. The tissue was allowed to recover in sea water, after which it was placed in $\mathrm{CaCl}_{2}$ for 360 minutes, and then in $\mathrm{NaCl}$ (Fig. 48).

In this case the observed time was not corrected (i.e., was not multiplied by a factor) as in the previous calculations. In consequence the calculated and observed values do not correspond at the beginning of each exposure, the only exception being after recovery in sea water, in which case it was assumed ${ }^{38}$ that equilibrium had been

${ }^{37}$ This involves the assumption that $O$ is not restored to any extent during recovery in sea water. This assumption may not be correct, especially at the start, but even in that case the present calculation would not be appreciably altered.

${ }^{3}$ In this case the tissue did not remain long enough in sea water to establish equilibrium, but it was so nearly established that only a very small error is involved in regarding it as complete. In cases where it is not completely established the final equilibrium may be approximated by extrapolation. 
reached and that in consequence $A_{0}=30 M$ (the value of $M$ being that of the observed resistance less 10). This value of $A$ was taken for the subsequent calculations.

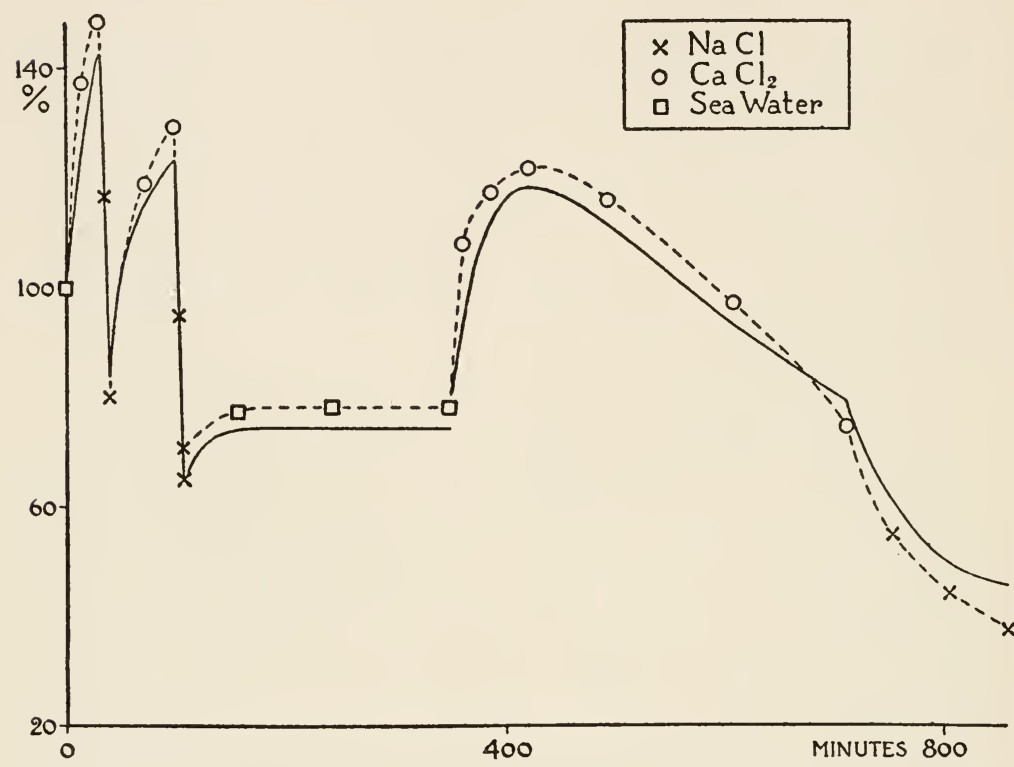

Frg. 48.-Curves showing the net electrical resistance of Laminaria agardhii in $\mathrm{NaCl} 0.52 M$, in $\mathrm{CaCl}_{2} 0.278 M$ and in sea water. Unbroken line, calculated values; broken line, observed values. Average of ten or more experiments; probable error of the mean less than $10 \%$ of the mean.

During the subsequent exposure to $\mathrm{CaCl}_{2} A_{0}$ diminished to $A_{1}$ according to the formula

$$
A_{1}=A_{0} e^{-(0.0018) 360}
$$

and this value was used in calculating the fall of resistance during the final exposure to $\mathrm{NaCl}$.

Experiments similar to those shown in Figs. 44, 45, 46, 47 , and 48 have been made, in which mixtures of $\mathrm{NaCl}$ plus $\mathrm{CaCl}_{2}$ have been used in a variety of ways. In this case we employ for the calculations the constants appro- 
priate for each mixture, as given on page 140. In general the agreement is satisfactory.

With so large a number of constants it might seem possible to fit any sort of curve, and hence the significance of the actual accomplishment might be lessened. This, however, is by no means the case.

It should be noted that we do not employ new constants to fit these curves, but that in every case we use the constants already determined as the result of other and quite different experiments. In view of this the results have a special significance.

If we accept the conclusions stated above we are obliged to look upon recovery in a somewhat different fashion from that which is customary. Recovery is usually regarded as due to the reversal of the reaction which produces injury. The conception of the writer is fundamentally different; it assumes that the reactions involved are irreversible (or practically so) and that injury and recovery differ only in the relative speed at which certain reactions take place.

It would seem that these experiments, and those previously described, afford a sufficient test of the theory. It has been found that the agreement between the calculated and observed values is satisfactory whenever a sufficiently large number of readings are averaged in arriving at the observed values.

In the foregoing account many details are necessarily omitted, owing to lack of space. These, however, are not essential to the main purpose, which is to show how the process of injury and recovery may be analyzed and subjected to mathematical treatment. Starting with certain assumptions we have formulated equations by means of which we can predict the behavior of the tissue. If the 
predictions are fairly accurate it is natural to infer that the assumptions are in accordance with the facts. It is evident from an examination of the figures that the equations enable us to predict with considerable accuracy the behavior of tissues in solutions of $\mathrm{NaCl}$ and $\mathrm{CaCl}_{2}$, as well as the recovery curves after any length of exposure to either of these solutions. But we must not lose sight of the fact that the predictive value of the equations does not depend on the validity of these assumptions and would in no way be impaired if they were to be given up. The equations have a permanent value which is quite independent of assumptions.

The mechanism which has been postulated in developing these equations consists essentially of a series of catenary reactions. There can be no doubt that, as Loeb $(1912, D)$ has emphasized, catenary reactions play a large part in life phenomena, and it would seem that the role assigned to them in the present discussion involves no unreasonable assumption.

A substance which acts as a member of such a catenary system may, as Hopkins (1913) has remarked, be of great importance in the organism even if present in very small amount.

It may be desirable to call attention to certain features of this mechanism which are of general interest from a theoretical viewpoint. It is evident that by means of a simple catenary system we can account for practically all the processes which occur in the organism. If such a system is present in the egg we can easily picture all of the subsequent development as due to this system, without the introduction of any new reactions. All that we need to postulate is that during development the relative rates of the reactions change. The processes involved in irrita- 
bility, as well as those concerned in injury and death, may be accounted for in this same way. We thus arrive at a very simple conception of the underlying mechanism of life processes, which may be useful in formulating a theory of living matter.

If life is dependent upon a series of reactions which normally proceed at rates bearing a definite relation to each other, it is clear that a disturbance of these rate-relations may have profound effects upon the organism. It is evident that such a disturbance might be produced by changes in temperature (in case the temperature coefficients of the reactions differ) or by chemical agents. The same result might be brought about by physical means, especially where structural changes occur which alter the permeability of the plasma membrane or of internal structures (such as the nucleus and plastids) in such a way as to bring together substances which do not normally interact. ${ }^{39}$

This investigation of fundamental life processes shows that they appear to obey the laws of chemical dynamics. It illustrates a method of attack which may throw some light upon the underlying mechanism of these processes and which may assist materially in the analysis and control of life-phenomena.

${ }^{3}$ Or which normally react to a lesser degree. 


\section{CHAPTER IV.}

\section{ANTAGONISM.}

When one toxic substance acts as an antidote to another, we speak of this as antagonism. If the antagonistic substances are mixed in such proportions that toxicity disappears we have a physiologically balanced solution as defined by Loeb. ${ }^{1}$

In seeking an accurate measure of antagonism the writer made experiments on growth. It was found that both $\mathrm{NaCl}$ and $\mathrm{CaCl}_{2}$ are toxic to plants, as shown by the fact that in solutions of these substances there is less growth than in distilled water. ${ }^{2}$ In a series of experiments on wheat, it was found that the growth of roots in $\mathrm{NaCl} 0.12 M$ was practically the same as in $\mathrm{CaCl}_{2} 0.164$ $M$. These solutions were therefore regarded as equally toxic.

On mixing equally toxic salt solutions, we may encounter one of the following conditions : ${ }^{3}$

1. The toxicity is unaltered, that is, the toxic action of the two salts is additive. Each salt produces its own toxic effect precisely as though the other were not present. This is expressed by the horizontal dotted line $L J M$ in Fig. 49.

It is evident that we cannot get increased growth by mixing two such solutions unless the salts have an antagonistic action. If we mix equal volumes of $A 0.1 M$ and

${ }^{1} C f$. Loeb, J. $(1906, B)$. For the literature of antagonism see Loeb (1909), Robertson (1910), Höber (1914).

This statement does not apply to very dilute solutions.

${ }^{8} C f$. Osterhout $(1914, B, C ; 1915, F)$. 
$B 0.1 M$ the dilution of $A$ from $0.1 M$ to $0.05 M$ is exactly compensated by the introduction of molecules of $B$. Or, to put it in another way, the toxic effect depends on the number of molecules present (if both kinds of molecules are equally toxic and there is no antagonism) and it makes no difference whether the solutions are pure or mixed.

If the toxic effect depends on ions, rather than on molecules, then, since the number of ions may be somewhat increased by mixing solutions, the toxicity may be correspondingly increased; but the amount of this increase would ordinarily be negligible.

2. The toxicity is diminished, that is, the effect is antitoxic. We then get a curve rising somewhere above the dotted line, such as the umbroken line $L K M$. 3. The toxicity is increased. We then get a curve which somewhere falls below

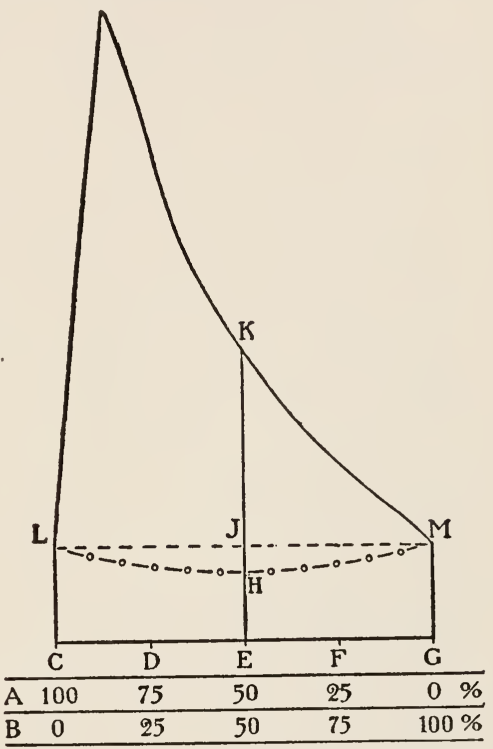

Fig. 49.-Curves showing the growth of roots in mixtures of equally toxic solutions of two salts $A$ and $B$ : the ordinates represent growth; the abscissae represent the composition of the mixtures, thus $A 50, B 50$ means a mixture in which the dissolved molecules are $50 \% A$ and $50 \% B$ : the horizontal dotted line (L.IM) represents the growth which would occur if there were no antagonism (additive effect); $L K M$ is the antagonism curve; $L H M$, curve expressing increased toxicity (opposite of antagonism); the quantitative expression of antagonism at the point $E$ is $K J \div J E$. the dotted line, such as the line interrupted by circles $L H M .^{4}$

The considerations here set forth apply in all cases where two equally toxic solutions are mixed, whether their

${ }^{4}$ See page 177. 
concentration is the same or not. Thus, if a solution of $A 0.05 M$ is just as toxic as a solution of $B 0.1 M$, mixtures of the two will give a horizontal straight line (as in Fig. 49) provided their effects are additive.

Emphasis should be laid upon the fact that the method of mixing two equally toxic solutions eliminates disturbances due to variations of osmotic pressure. If a molecule of $A$ is twice as toxic as a molecule of $B$, a solution of $A 0.05 M$ will be just as toxic as a solution of $B 0.1 M$, provided there are no other factors to be considered. But if the osmotic pressure of the $0.05 M$ solution of $A$ is less than that of the $0.1 M$ solution of $B$, there will in many cases be better growth in the $0.05 M$ solution of $A$. In order to make the solution of $A$ appear equally toxic with the solution of $B$, the concentration of $A$ must be somewhat increased, say to $0.055 M$. We thus compensate for the variation in osmotic pressure, and this compensation is not destroyed when the $0.055 M$ solution of $A$ is mixed with the $0.1 M$ solution of $B$. If the effects of the salts are additive, we must therefore get a horizontal straight line, as shown in Fig. 49.

It is evident that this straight line furnishes a quantitative criterion of antagonism. All that is necessary is to determine what concentrations of $A$ and $B$ are equally toxic, mix these solutions in various proportions, and determine the amount of growth. The antagonism in any mixture may then be expressed in a very simple manner. In the curve $L K M$ (Fig. 49) the antagonism in a mixture in which the molecules are $50 \% A$ and $50 \% \quad B$ may be expressed as $K J \div J E$. JE is the growth which would have been obtained if the effect of the salts had been additive (that is, if there had been no antagonism, but each salt had produced its effect inde- 
pendent of the other.) $K J$ is the increased growth due to antagonism; it is best expressed as percentage of $J E$ or as $K J \div J E \times 100$.

In the same way increased toxicity (when the mixture is more toxic than either of the pure solutions) may be expressed as $J H \div J E$. This sometimes occurs, but it is much less common than antagonism. ${ }^{5}$

\section{TABLE VII}

MIXTURES OF EQUALLY TOXIC SOLUTIONS

Wheat (growth during 30 days) ( $\mathrm{NaCl} 0.12 M+\mathrm{CaCl}_{2} 0.164 M$ )

\begin{tabular}{|c|c|c|c|c|c|}
\hline \multicolumn{3}{|c|}{ Culture solution } & $\begin{array}{l}\text { Aggregate length of } \\
\text { roots per plant } \\
\text { in } \mathrm{mm} \text {. }\end{array}$ & Additive effect & Antagonism \\
\hline \multicolumn{3}{|c|}{$\mathrm{CaCl}_{2}$} & 55 & 55 & $\ldots \ldots \ldots \ldots \ldots$ \\
\hline \multicolumn{3}{|c|}{75 per cent. $\mathrm{CaCl}_{2}$. } & 105 & 55 & $\frac{105-55}{55}=0.91$ \\
\hline $\begin{array}{l}50 \\
50\end{array}$ & “6 & $\begin{array}{l}\mathrm{CaCl}_{2} \ldots \\
\mathrm{NaCl} \ldots\end{array}$ & 180 & 55 & $\frac{180-55}{55}=2.27$ \\
\hline $\begin{array}{l}25 \\
75\end{array}$ & “ & $\begin{array}{l}\mathrm{CaCl}_{2} \ldots \\
\mathrm{NaCl} .\end{array}$ & 298 & 55 & $\frac{298-55}{55}=4.42$ \\
\hline $\begin{array}{l}15 \\
85\end{array}$ & & $\begin{array}{l}\mathrm{CaCl}_{2} \ldots \\
\mathrm{NaCl} .\end{array}$ & 370 & 55 & $\frac{370-55}{55}=5.73$ \\
\hline $\begin{array}{r}5 \\
95\end{array}$ & “ & $\begin{array}{l}\mathrm{CaCl}_{2} \ldots \\
\mathrm{NaCl} .\end{array}$ & 435 & 55 & $\frac{435-55}{55}=6.91$ \\
\hline $\begin{array}{r}1 \\
99\end{array}$ & “" & $\begin{array}{l}\mathrm{CaCl}_{2} \ldots \\
\mathrm{NaCl} .\end{array}$ & 300 & 55 & $\frac{300-55}{55}=4.45$ \\
\hline $\mathrm{Na}$ & & & 55 & 55 & \\
\hline
\end{tabular}

The percentages refer to molecular proportions; that is, 75 per cent. $\mathrm{CaCl} 2+25$ per cent. $\mathrm{NaCl}$ means a solution in which 75 per cent. of the dissolved molecules are $\mathrm{CaCl} 2$ and 25 per cent, are $\mathrm{NaCl}$.

As an illustration of this method the results given in Table VII may be cited. In this case the growth in the various mixtures was in part determined directly and in part was calculated from results obtained by growing

- See page 177. 
plants in mixtures having almost the same composition as the solutions given in the table.

In another method ${ }^{6}$ of measuring antagonism we may look at the matter from the following standpoint. A certain amount of growth occurs in distilled water as shown in Fig. 50; when salts are added to distilled water the

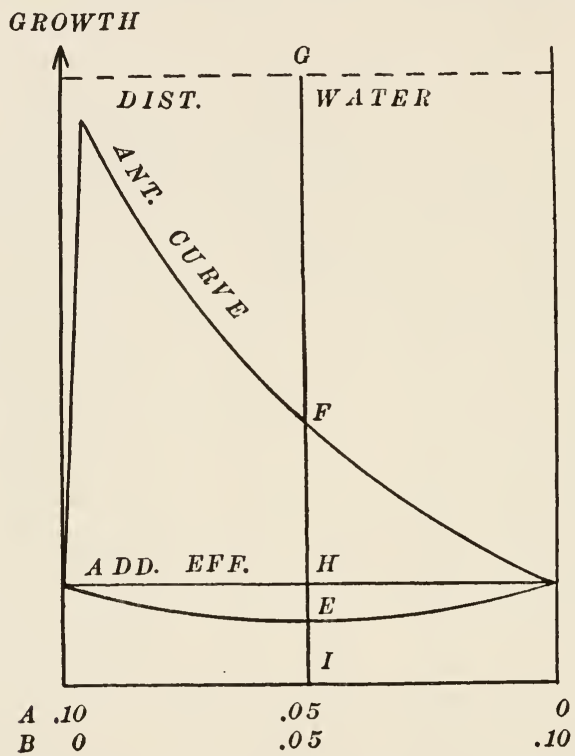

Fra. 50.-Curve showing antagonism between two salts, $A$ and $B$. The additive effect is $G H$. Antagonism at the ordinate $I$ may be expressed as $100 \times F H \div G H$; the opposite of antagonism as $100 \times E H \div G H$. The dotted line represents growth in distilled water. The abscissæ represent the molecular concentrations of the salts.

growth is lessened. The lessening of growth due to the action of the salts where no antagonism (or its opposite) occurs is regarded as the additive effect. When the salts are antagonistic growth is less hindered. The additive effect is then $G H$; the antagonism is $F H$ and may be expressed as $100 \times F H \div G H$. The opposite of antagonism is $100 \times E H \div G H$.

${ }^{8}$ Cf. Osterhout $(1918, A)$. 
We may now consider the effect of mixing two solutions which are not equally toxic. Suppose solution $A 0.1$ $M$ to be twice as toxic as solution $B 0.1 M$. The effect of mixing these, if the effects were equally additive, would be the same as mixing a solution of $A 0.1 M$ with another solution $A$ just half as toxic, or in other words, would be the same as decreasing the concentration of $A$. In this case the curve expressing purely additive effects would not be a straight line, but would assume the form of a curved line, convex to the horizontal axis, similar to $V T W$ in Fig. 51. This is evident $^{7}$ from the curves given by Magowan, showing growth in toxic solutions of various concentrations.

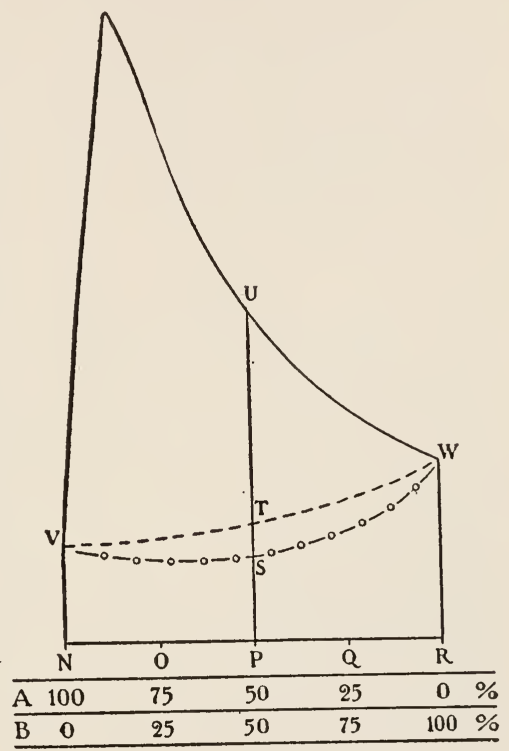

It would be possible to determine this additive curve experimentally, and then to express antagonism quantitatively; for example, at the point $P$ it would be expressed

Fra. 51.-Curves showing growth in mixtures of unequally toxic solutions: the ordinates express growth; the abscisse express the composition of the mixtures as in Fig. 49 ; the dotted line $V T W$ expresses the growth which would occur if there were no antagonism (additive effect); $V^{\prime} U W$, antagonism curve; $V S W$, curve expressing increased toxicity (opposite of antagonism); the quantitative expression of antagonism at the point $P$ is $U T \div T P$.

as $U T \div T P$. But the labor would be much greater than by the method of mixing equally toxic solutions. The additive curve would be determined by growing plants, not in mixtures of $A$ with $B$, but in mixtures of $A$ with another solution of $A$ having the same toxicity as $B$. Or

${ }^{7}$ Magowan (1908). 
we might use mixtures of $B$ with another solution of $B$ having the same toxicity as $A$. The two methods might not give exactly the same result. This is an additional argument in favor of using equally toxic solutions.

An illustration of this method is found in the results given in Table VIII. The growth in the various mixtures (additive and antagonistic) was in part determined directly and in part was calculated from results obtained by growing plants in mixtures having almost the

TABLE VIII

MIXTURES OF UNEQUALLY TOXIC SOLUTIONS

Wheat (growth during 30 days) $\left(\mathrm{NaCl} 0.12 M+\mathrm{CaCl}_{2} 0.12 M\right)$

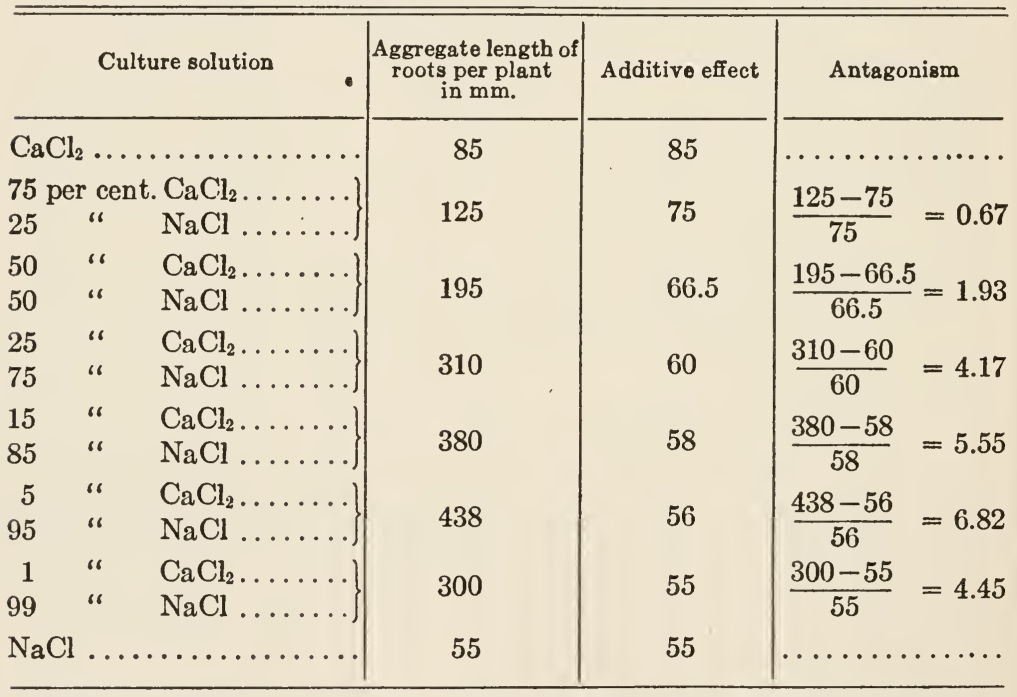

The percentages refer to molecular proportions; that is, 75 per cent. $\mathrm{CaCl}_{2}+25$ per cent. $\mathrm{NaCl}$ means a solution in which 75 per cent. of the dissolved molecules are $\mathrm{CaCl}_{2}$ and 25 per cent. are $\mathrm{NaCl}$.

same composition as the solutions given in the table mentioned.

For the sake of completeness it may be mentioned that other types of antagonism curves are found; for 
example, flat-topped curves and also curves with two maxima, as shown in Fig. 52.

If instead of mixing two equally toxic solutions we keep the concentration of one salt constant while varying that of the other, it becomes very difficult to determine the additive curve, especially when variations in osmotic pressure influence the result. It is therefore difficult to obtain an accurate quantitative expression of antagonism by this method, and in critical cases it may be impossible to decide whether antagonism exists or not.

Emphasis should be laid on the fact that the growth of parts not in immediate contact with the solution does not furnish a trustworthy criterion of antagonism. Thus the leaves of wheat (which are not in contact with the solution) often grow well at the

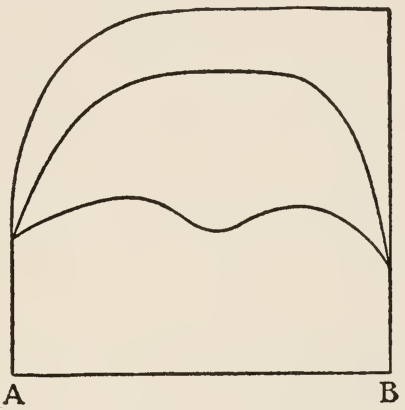

Fig. 52.-Types of antagonism curves: the ordinates express growth; the abscissæ express the composition of the mixtures as in Fig. 49 . start in solutions of toxic substances because the latter are held back by the roots.

The method of mixing equally toxic solutions has also a great advantage when three solutions are employed. As an illustration of this we may take mixtures of $\mathrm{NaCl}+$ $\mathrm{KCl}+\mathrm{CaCl}_{2}$. In the case of wheat it was found that the roots grew equally well in solutions of $\mathrm{NaCl} .12 M, \mathrm{KCl} .13$ $M$, and $\mathrm{CaCl}_{2}$ 0.164 $M$. Mixtures of these solutions were prepared and the growth of the roots in these mixtures was measured after a period of 30 days. In order to show the results graphically, the composition of the solutions may be conveniently expressed by means of a triangular diagram as drawn in Fig. 53. 
The diagram consists of an equilateral triangle, the apices of which represent equally toxic pure solutions. Thus the point $A$ represents pure $\mathrm{CaCl}_{2}(0.164 M), B$ represents pure $\mathrm{KCl}(0.13 M)$, and $C$ represents pure $\mathrm{NaCl}(0.12 M)$. All points on the sides of the triangle represent mixtures of two solutions only, the composition depending on the position of the point. Thus the point

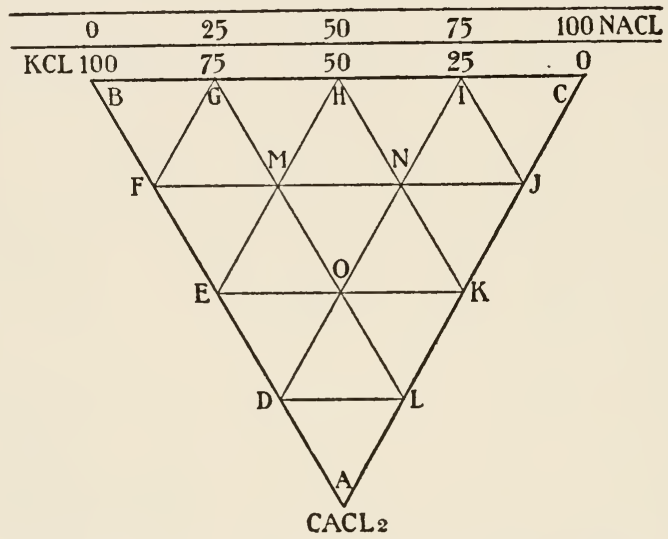

FIa. 53.-Diagram representing the composition of various mixtures of $\mathrm{KCl}+\mathrm{NaCl}+\mathrm{CaCl}_{\mathbf{2}}$ : this serves as the base of the solid model shown in Fig. 54 .

$H$ represents a solution made by mixing the equally toxic solutions $\mathrm{NaCl} 0.12 M$ and $\mathrm{KCl} 0.13 M$ in such proportions that in the mixture $50 \%$ of the dissolved molecules are $\mathrm{NaCl}$ and $50 \%$ are $\mathrm{KCl}$. In the same way $G$ represents a solution in which the molecular proportions are $\mathrm{NaCl}$ $25 \%+\mathrm{KCl} 75 \% ; I$ represents $\mathrm{NaCl} 75 \%+\mathrm{KCl} 25 \%$; $E$ represents $\mathrm{KCl} 50 \%+\mathrm{CaCl}_{2} 50 \% ; K$ represents $\mathrm{NaCl}$ $50 \%+\mathrm{CaCl}_{2} 50 \%$.

All points in the interior of the triangle represent mixtures of the three equally toxic solutions $\mathrm{NaCl} 0.12 M$, $\mathrm{KCl} 0.13 M$, and $\mathrm{CaCl}_{2} 0.164 M$. Along the line $F J$ are represented mixtures in which the dissolved molecules are 
$25 \% \mathrm{CaCl}_{2}$; the line $E K$ represents mixtures in which the dissolved molecules are $50 \% \mathrm{CaCl}_{2}$; the line $D L$ mixtures in which the dissolved molecules are $75 \% \mathrm{CaCl}_{2}$. In the same way $F G$ means $75 \% \mathrm{KCl} ; E H, 50 \% \mathrm{KCl} ; D I$, $25 \% \mathrm{KCl} ; G L, 25 \% \mathrm{NaCl} ; H K, 50 \% \mathrm{NaCl}$; and $I J$, $75 \% \mathrm{NaCl}$.

The point $M$ is on the line $F J$, meaning $25 \% \mathrm{CaCl}_{2}$; it is also on the line $E H$, meaning $50 \% \mathrm{KCl}$; and likewise on the line $G L$, meaning $25 \% \mathrm{NaCl}$. It therefore represents a mixture of the three equally toxic solutions, $\mathrm{NaCl} 0.12 M, \mathrm{KCl} 0.13 M$, and $\mathrm{CaCl}_{2} 0.164 M$, in which the dissolved molecules are $25 \% \mathrm{CaCl}_{2}+50 \% \mathrm{KCl}+25 \%$ $\mathrm{NaCl}$. In the same way the point $O$ represents a mixture in which the dissolved molecules are $50 \% \mathrm{CaCl}_{2} 25 \% \mathrm{KCl}$ $+25 \% \mathrm{NaCl}$.

It is obvious that the composition of any solution can be represented by selecting a suitable point on the diagram. At any such point an ordinate may be erected expressing the growth of the plant in that solution. When this has been done for a sufficient number of points, a solid model may be constructed which gives a complete description of the growth of the plant in all the solutions. Such a model is shown, in Fig. 54. The ordinates represent the aggregate length of roots per plant of wheat at the end of 30 days. The ordinates in the pure solutions are equal (55 mm.), showing that the solutions are equally toxic. The ordinates were in part determined directly by experiment and in part calculated from data obtained by growing plants in solutions of approximately the same composition as those represented.

From such a model the antagonism in any solution may be determined at once by measuring with calipers the height of the ordinate at the required point, subtract- 
ing 55, which is the amount of growth in the pure solutions, and in this case (since all the pure solutions are equally toxic) the amount of growth which would occur if the toxic

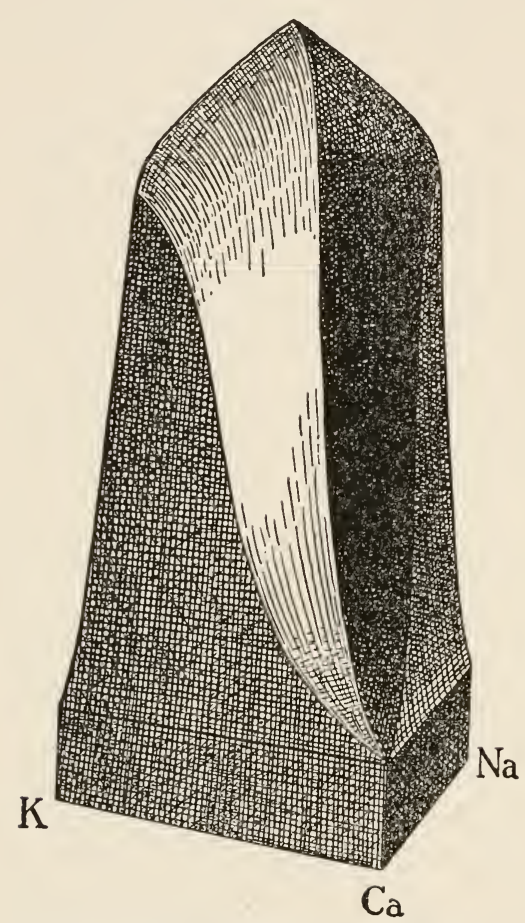

Fig. 54.-Solid model showing the forms of the antagonism/ curves in all possible mixtures of $\mathrm{NaCl} 0.12 M$, IKCl $0.13 M$, and $\mathrm{CaCl}_{2} 0.164 M$. actions of the salts were additive (that is, if each salt exerted its own toxic effect independently of the other salts); the result should then be divided by 55 .

In this case the additive effect is represented by a plane surface parallel to the plane which forms the base of the model. The height of this plane is indicated by the shading in the figure.

Other methods (as mixing unequally toxic solutions or keeping the concentration of one salt constant while varying that of the others) will give for the additive effect a curved surface very difficult to determine and not easily represented or measured on the model.

With solutions of more than three components the results cannot be expressed in a solid model; but a graphical expression may easily be obtained in the following way. Let us suppose that equally toxic solutions of $A, B, C$ and $D$ are to be mixed. A mixture of the first 
three may be made and called solution 1 (different mixtures may be called solution 2 , etc.). To solution 1 various amounts of $D$ may be added and the results plotted as shown in Fig. 55, in which the additive effect is expressed by the dotted line and the growth in the mixtures by the unbroken line. Antagonism at any point may be easily expressed. For example, the antagonism at the point $M$ is $(M O-M N) \div M N$.

By the method of mixing unequally toxic, pure solu-

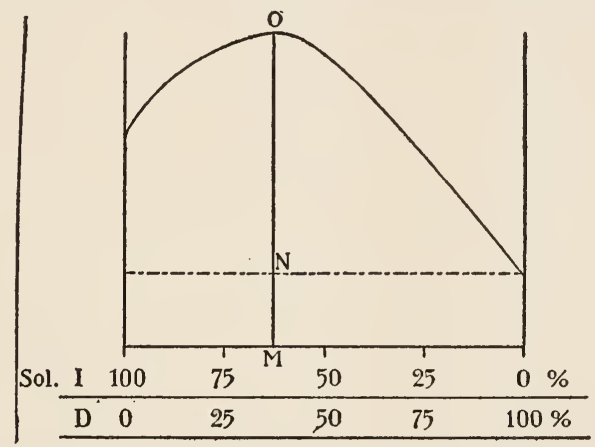

FIG. 55.-Method of expressing antagonism in mixtures containing more than three components: three of the components $(A, B$ and $C)$ are combined into solution $I$ and various amounts of the fourth component $(D)$ are added; the ordinates represent growth; the abscis$\mathbf{8} \boldsymbol{\otimes}$ represent the composition of the mixtures; thus at the point $M$ the mixture contains 62.5 o.o. of solution 1 to each 37.5 c.c. of solution $D$; the antagonism at $M$ is $O N+M N$.

tions or by the method of keeping the concentration of one salt constant while varying that of the others, the dotted line would become a curved one.

If we mix such solutions as $\mathrm{NaCl} 0.12 \mathrm{M}$ and $\mathrm{CaCl}_{2}$ $0.164 M$ the antagonism curve resembles the one in Fig. 49. If, however, we reduce the concentration by one-half there will be less toxicity and in consequence the antagonism will appear less pronounced. In order to illustrate this, curves have been prepared which are diagrammatic composites of the curves obtained by the use of several pairs of salts; these composite curves are shown. 
in Fig. 56. For the sake of simplicity they are represented as having been obtained by the use of one pair of salts, which are designated as $A$ and $B$. The curve $C D E$, therefore, represents diagrammatically the growth of roots

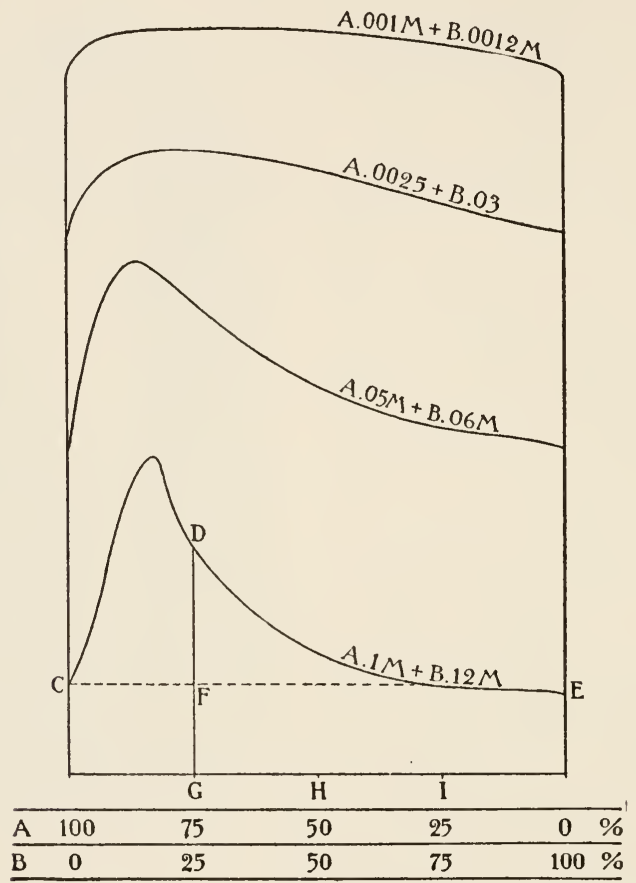

Fia. 56.-Effect of dilution on the forms of antagonism curves: the ordinates represent the growth of roots in solutions, the composition of which is represented by the abscissæ; for example, on the curve $C D E$ the ordinate at $G$ represents growth in a mixture of $A 0.1 M$ and $B 0.12 M$ in such proportions that $75 \%$ of the dissolved molecules are $A$ and $25 \%$ are $B$; on the curve which lies immediately above $C D E$ the ordinate at $G$ represents growth in $B$ mixture of $A 0.05 M$ and $B 0.06 M$ in such proportions that $75 \%$ of the dissolved molecules are $A$ and $25 \%$ are $B$.

in mixtures of equally toxic solutions of two salts, $A$ and $B$. The abscissa represent molecular proportions; thus the point $G$ represents a mixture in which the dissolved molecules are $75 \% A$ and $25 \% B$; the point $H$ a mixture in which the dissolved molecules are $50 \% A$ and $50 \% B$. 
The ordinates represent the growth of roots in the various mixtures.

The antagonism at any point is the total growth minus the growth which would have taken place if no antagonism existed. This antagonism is best expressed as percentage of the growth which would have taken place in the absence of antagonism. Hence the antagonism at the point $G$ is expressed as $100(G D-F G) \div F G$.

The figure shows in a diagrammatic way the effect of dilution on the form of an antagonism curve. The lowest curve $C D E$ shows the effect on growth of various mixtures of two equally toxic solutions $A 0.1 M+B 0.12 M$. The next curve shows the form of the antagonism curve when all of these mixtures were diluted by the addition of an equal volume of water $(A 0.05 M+B 0.06 M)$. The next curve was produced by growing plants in mixtures of $A 0.0025 M+B 0.03 M$. The topmost curve was obtained with mixtures of $A 0.001 M+B 0.0012 M$.

The pairs of pure solutions were in each case equally toxic, as is shown by the fact that the two ordinates at the ends of each curve are equal in height.

It will be observed that as the solutions become more dilute, the antagonism curve becomes flatter, and it is evident that at still greater dilutions it must tend to become a horizontal straight line.

In order to give a complete description of the changes in the antagonism curve as dilution increases, it is necessary to construct a solid model. This might have as its base a triangular diagram as previously described. The apices of the triangle would in that case represent, $A, B$, and $\mathrm{H}_{2} \mathrm{O}$.

It is more suitable for our present purpose to employ a square as the base and to represent the composition of 
the solutions according to the scheme shown in Fig. 57. In this figure the abscissæ have the same significance as in Fig. 56, while the ordinates represent various dilutions of the mixtures. Thus all points on the line $C D$ represent distilled water, while a point such as $E$, halfway between

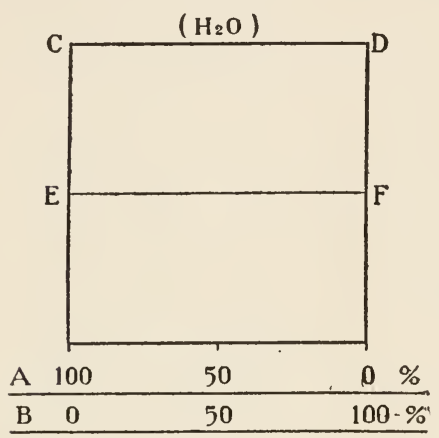

Fra. 57.-Diagram representing the composition of solutions (this serves as the base of the solid model shown in Fig. 58): the lowest line represents various mixtures of solutions of two salts, $A$ and $B$; the line $E F$ represents the same mixtures diluted with equal volume of water; any line drawn parallel to $E F$ will express the same mixtures diluted to a degree corresponding to the position of the line, the nearer it approaches to $C D$ the greater the dilution; on the line $C D$ all points represent distilled water.

$A$ and $C$, represents a mixture containing equal quantities of distilled water and of $A 0.1 \mathrm{M}$. The points on the line $E F$, therefore, represent the same mixtures as the corresponding points on the lowest line, except that the concentrations are in all cases just one-half as great as those represented on the base line. It is evident that the growth in any concentration may be expressed by erecting at the proper point a line perpendicular to the plane of the paper. In this way, we may obtain a solid model which gives a complete description of the changes in growth produced by diluting the various mixtures. Such a model is shown in Fig. 58.

In all of these cases the measurements are made after growth has ceased and in consequence they represent a final condition of development. If, however, we use electrical conductivity as a criterion of antagonism, we obtain curves which change constantly. (See Fig. 78). In this case the best method of procedure is to construct the time curves of the death process and to compare the 


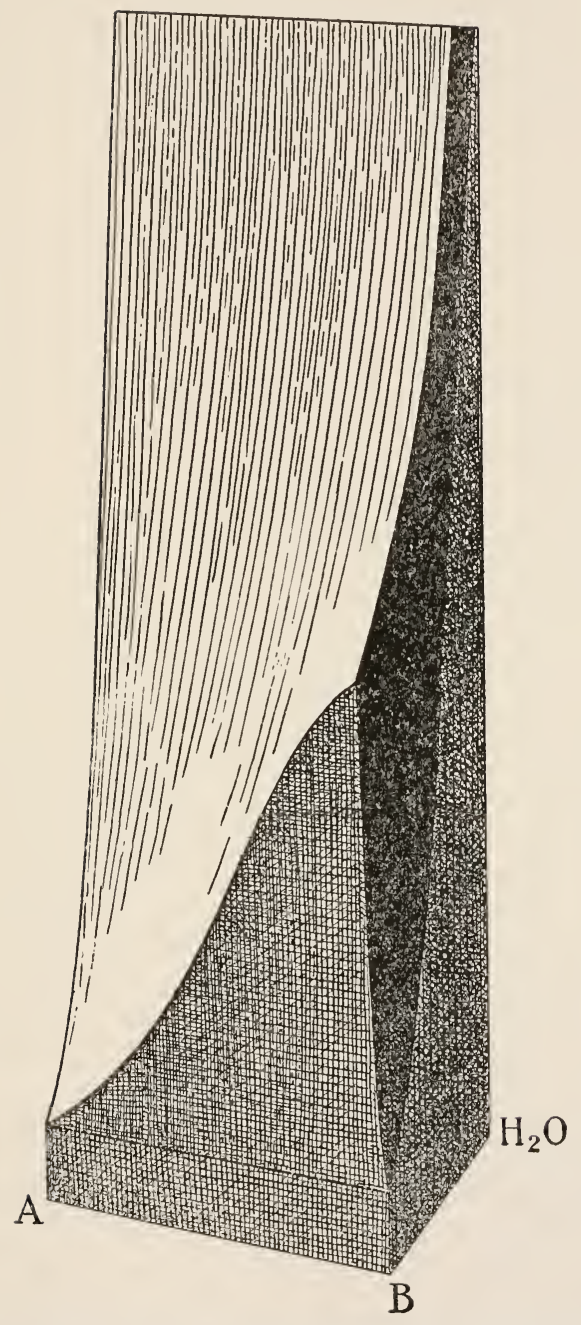

Fra. 58.-A solid model which gives a complete description of the changes produced in the form of the antagonism curve by altering the concentrations of the solutions.

velocity of the process in various mixtures. A series of such time curves is shown in Fig. 59. 
In the preceding pages a theory is developed which enables us to predict the behavior of Laminaria when transferred from sea water to certain solutions, e.g., $\mathrm{NaCl}$

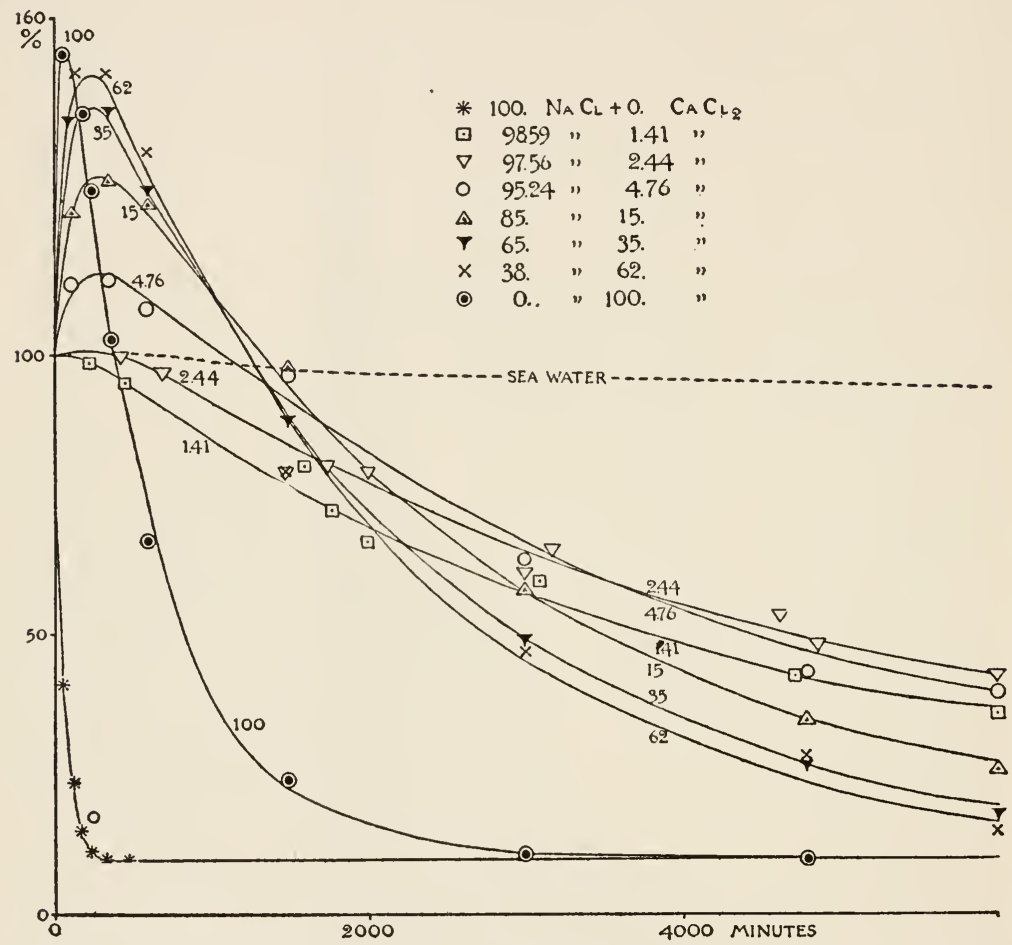

Fra. 59.-Curves showing the net electrical resistance of Laminaria agardhii in $0.52 M$ $\mathrm{NaCl}$, in $0.278 M \mathrm{CaCl}_{2}$, and in mixtures of these (the figures attached to the curves show the molecular per cent. of $\mathrm{CaCl}_{2}$ in the solution). The curves show the calculated values (from constants obtained by trial) which are given in Table $\mathrm{X}$, the points show the observed values (some are omitted in order to avoid undue crowding); each represents the average of six or more experiments. Probable error of the mean less than $10 \%$ of the mean.

$0.52 M$ and $\mathrm{CaCl}_{2} 0.278 M$. If the theory is sound it should also enable us to predict the behavior of the tissue in mixtures of these solutions.

In order to test this theory experiments were made with a variety of mixtures. The solutions employed are 
given in Table IX. The electrical resistance of the tissue in these solutions, is shown in Fig. 59. The curves are in good agreement with the formula

Resistance $=2,700\left(\frac{K_{A}}{K_{M}-K_{A}}\right)\left(e^{-K_{A} T}-e^{-K_{M} T}\right)+90 e^{-K_{M} T}+10$ This is evident from Figs. 59 to 63, which show the curves calculated by means of this formula and also the observed values.

As previously explained, this formula is based upon the assumption that the electrical resistance is propor-

TABLE IX.

Composition of Mixtures.

\begin{tabular}{c|c|c|c}
\hline \multirow{2}{*}{$0.52 M \mathrm{NaCl}$} & $0.278 M \mathrm{CaCl}_{2}$ & \multicolumn{2}{|c}{ Molecular proportions in the mixture } \\
\cline { 3 - 4 } & $c c$. & $\mathrm{NaCl}$ & $\mathrm{CaCl}_{2}$ \\
\hline$c c$. & 27 & per cent. & per cent. \\
973 & 45 & 98.59 & 1.41 \\
955 & 86 & 97.56 & 2.44 \\
914 & 249 & 95.24 & 4.76 \\
751 & 504 & 85.00 & 15.00 \\
496 & 753 & 65.00 & 35.00 \\
247 & 38.00 & 62.00 \\
\hline
\end{tabular}

tional to a substance, $M$, which is formed and decomposed by the reactions

$$
O \longrightarrow S \longrightarrow A \longrightarrow M \longrightarrow B
$$

We assume that when the tissue is transferred from sea water to $\mathrm{NaCl}$, or to $\mathrm{CaCl}_{2}$, or to a mixture of these two solutions, the reactions $O \longrightarrow S \rightarrow A$ cease, while the reactions $A \longrightarrow M \longrightarrow B$ continue. By assuming various values of $K_{A}$ (the velocity constant of the reaction $A \rightarrow$ $M$ ) and of $K_{M}$ (the velocity constant of the reaction $M \longrightarrow$ $B$ ), and employing these in the formula, we obtain curves which closely approximate those which we find by experi- 


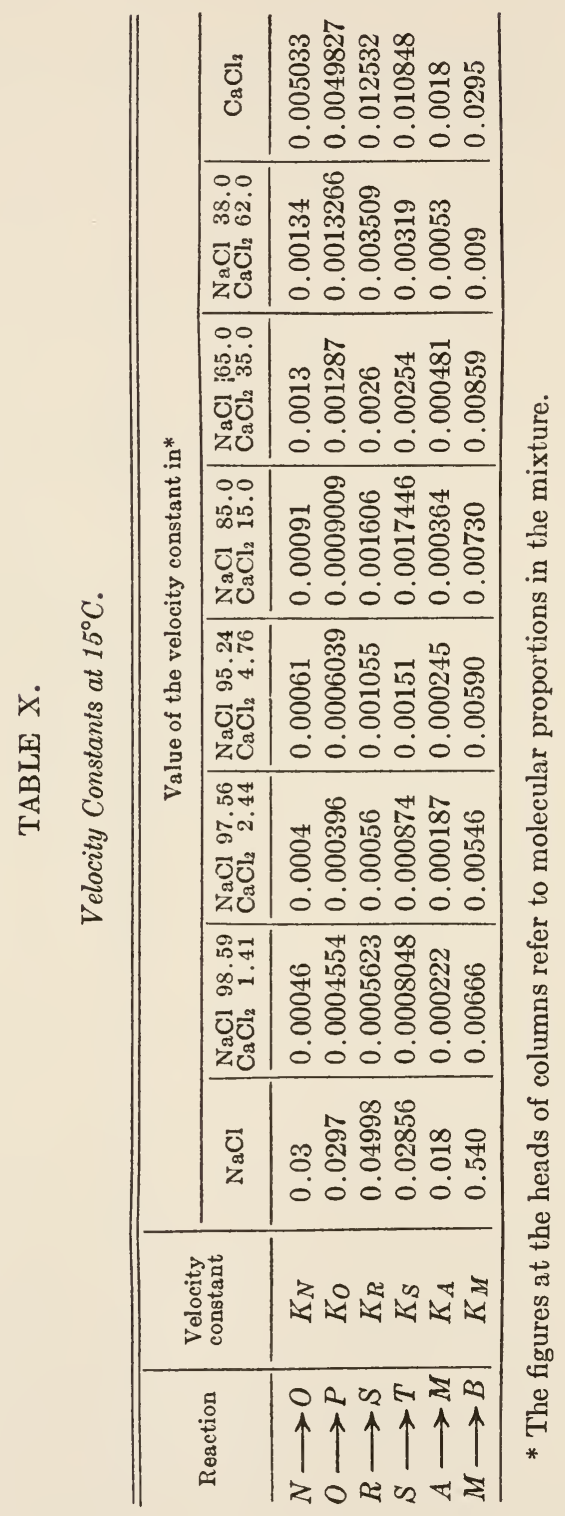


ment. The values of the velocity constants which are thus obtained, are given in Table $\mathrm{X}$.

It is evident from Table $\mathrm{X}$, that as the per cent. of $\mathrm{CaCl}_{2}$ in the mixtures increases (beginning at $1.41 \%$ $\mathrm{CaCl}_{2}$ ) the value of $K_{M}$ first falls and then rises, its

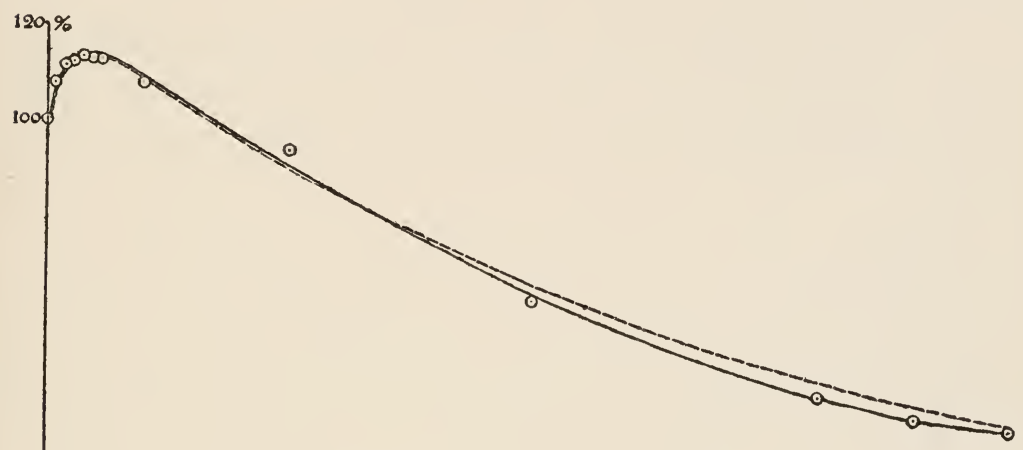

25

50

75 HOURS

Fig. 60.-Curve of net electrical resistance of Laminaria agardhii in $95.24 \mathrm{NaCl}+4.76$ $\mathrm{CaCl}_{2}$ (unbroken line) the trial curve (broken line) calculated from the velocity constants $\mathrm{KA}_{\mathrm{A}}$ $=.000245$ and $K_{M}=.00590$. Each observed point represents the average of six or more experiments: probable error of the mean less than $10 \%$ of the mean. All readings were made at $15^{\circ} \mathrm{C}$. or corrected to this temperature.

minimum value occurring in $97.56 \mathrm{NaCl}+2.44 \mathrm{CaCl}_{2}$ (which is the mixture in which the tissue lives the longest.). It seems reasonable to assume that in each mixture a substance is formed which reduces the value of $K_{M}$. We may assume that the decrease of $K_{M}$ is directly proportional to the amount of this substance, which may be assumed to occur in maximum amount in $97.56 \mathrm{NaCl}+$ $2.44 \mathrm{CaCl}_{2}$.

The simplest assumption which we can make is that $\mathrm{NaCl}$ and $\mathrm{CaCl}_{2}$ combine with some constituent of the 
protoplasm, as $\mathrm{X}_{2}$, to form a compound. ${ }^{8}$ If we suppose that the compound is $\mathrm{Na}_{4} \mathrm{XCa}$, formed by the reversible reaction

$$
4 \mathrm{NaCl}+\mathrm{XZ}_{2}+\mathrm{CaCl}_{2} \rightleftharpoons \mathrm{Na}_{4} \mathrm{XCa}+2 \mathrm{ZCl}_{3}
$$

we can calculate the amount of $\mathrm{Na}_{4} \mathrm{XCa}$ which is formed in each mixture of $\mathrm{NaCl}$ and $\mathrm{CaCl}_{2}$.

If antagonism really depends on the production of a salt compound, it is evident that some mechanism must exist which insures that an increase in the total concen-

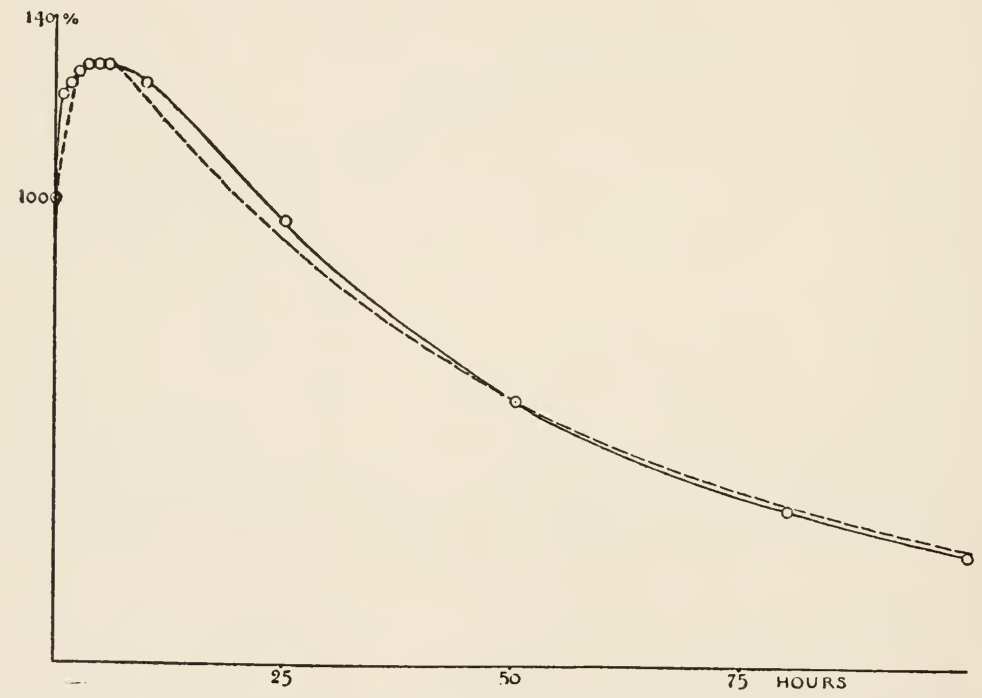

Frg. 61.-Curve of net electrical resistance of Laminaria agardhii in $85 \mathrm{NaCl}+15 \mathrm{CaC}$ (unbroken line); the trial curve (broken line) calculated from the velocity constants $\mathbf{K}_{\mathrm{A}}=$ .000364 and $K_{M}=.0073$. Each observed point represents the average of six or more experiments: probable error of the mean less than $10 \%$ of the mean. All readings were made at $15^{\circ} \mathrm{C}$. or corrected to this temperature.

tration of salts can have but little effect as compared with that produced by a change in their relative proportions.

- It is assumed that $\mathrm{XZ}_{2}, \mathrm{Na}_{4} \mathrm{XCa}$, and $\mathrm{ZCl}_{8}$ are in solution. Since the per cent. of $\mathrm{XZ}_{2}$ which is transformed to $\mathrm{Na}_{4} \mathrm{XCa}$ is negligible, the concentration of $\mathrm{XZ}_{2}$ may be regarded as constant. 
It is easy to see how such a mechanism must exist if the formation of the salt compound takes place at a surface (at the external surface of the cell or at internal surfaces). In a surface, substances usually exist in a different concentration from that which they have elsewhere

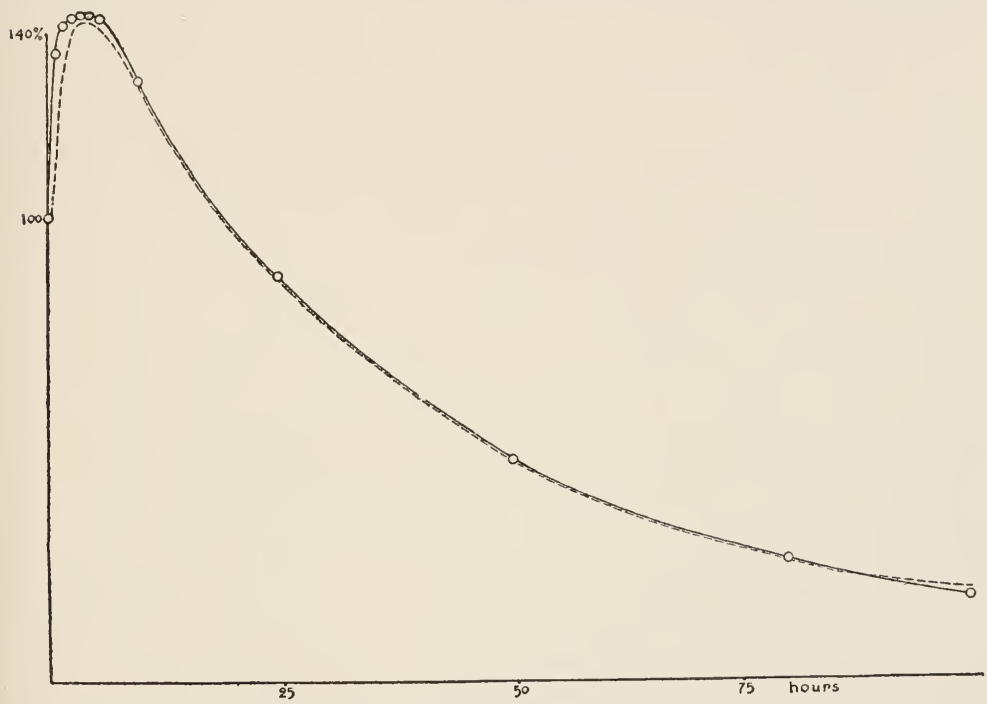

FIG. 62.-Curve of net electrical resistance of Laminaria agardhii in $65 \mathrm{NaCl}+35 \mathrm{CaCl}_{2}$ (unbroken line), the trial curve (broken line) calculated from the velocity constants $K_{A}=$ .000481 and $\mathrm{KM}=.00859$. Each observed point represents the average of six or more experiments: probable error of the mean less than $10 \%$ of the mean. All readings were made at $15^{\circ} \mathrm{C}$. or corrected to this temperature.

in the solution. If $\mathrm{NaCl}$ and $\mathrm{CaCl}_{2}$ migrate into the surface, so as to become more concentrated there than in the rest of the solution, their concentration in the surface must increase as their concentration in the solution increases until a certain point (called the saturation point) is reached. Beyond this point an increase in their concentration in the solution produces no effect on their concentration in the surface.

When this stage has been reached the formation of 
the salt compound, if it takes place in the surface, will not be affected by an increase in the concentration of the salts in the solution. It will, however, be affected by changes in the relative proportions of the salts. The

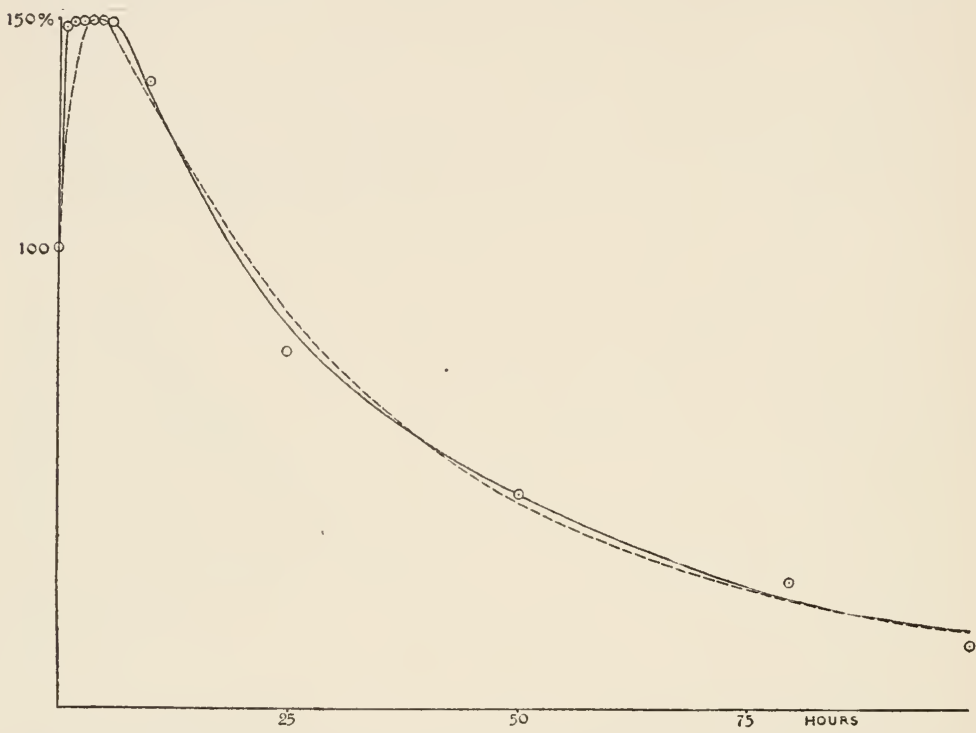

Fra. 63.-Curve of net electrical resistance of Laminaria agardhii in $38 \mathrm{NaCl}+62 \mathrm{CaCl}_{2}$ (unbroken line) and the trial curve (broken line) calculated from the velocity constants $K_{A}=.000530$ and $K_{M}=.0090$. Each observed point represents the average of six or more experiments: probable error of the mean less than $10 \%$ of the mean. All readings were made at $15^{\circ} \mathrm{C}$. or corrected to this temperature.

number of molecules of salt in a unit of surface will remain nearly constant, but if the proportion of $\mathrm{NaCl}$ in the solution be increased some of the $\mathrm{CaCl}_{2}$ in the surface will be displaced by $\mathrm{NaCl}$.

Below the saturation point the relative proportions of the salts will be of less importance than their total concentration: this is the case at low concentrations in the region of the so-called "nutritive effects." 
It has been pointed out by the writer ${ }^{9}$ that while variations in concentration affect the form of the antagonism curve, they do not in general affect the proportions which are most favorable for life processes.

It is therefore evident that if we wish to preserve the favorable character of a mixture when the concentration

TABLE XI.

Amount of $\mathrm{Na}_{4} \mathrm{XCa}$.

\begin{tabular}{|c|c|c|c|c|c|}
\hline \multicolumn{4}{|c|}{ Molecular proportions } & \multirow{3}{*}{$\underset{N a_{4} \mathrm{X} C a}{\text { Amount of }}$} & \multirow{3}{*}{$\begin{array}{c}\text { Increase in } \\
\mathrm{Na} \times \mathrm{XCa}\end{array}$} \\
\hline \multicolumn{2}{|c|}{ In the solution } & \multicolumn{2}{|c|}{ In the surface } & & \\
\hline $\mathrm{NaCl}$ & $\mathrm{CaCl}_{2}$ & $\mathrm{NaCl}$ & $\mathrm{CaCl}_{2}$ & & \\
\hline per cent. & per cent. & per cent. & per cent. & & \\
\hline 100.0 & 0 & 100.0 & 0 & 0 & 0 \\
\hline 98.59 & 1.41 & 87.5 & 12.5 & 0.000902 & 0.000855 \\
\hline 97.56 & 2.44 & 80.0 & 20.0 & 0.000936 & 0.000889 \\
\hline 95.24 & 4.76 & 66.67 & 33.33 & 0.000870 & 0.000823 \\
\hline 85.0 & 15.0 & 36.27 & 63.73 & 0.000488 & 0.000441 \\
\hline 65.0 & 35.0 & 15.66 & 84.34 & 0.000177 & 0.000125 \\
\hline 38.0 & 62.0 & 5.78 & 94.22 & 0.000047 & 0 \\
\hline 0 & 100.0 & 0 & 100.00 & 0 & 0 \\
\hline
\end{tabular}

of any antagonistic substance is increased we must at the same time increase the concentration of the others in the same proportion.

In discussing the results of his experiments on animals, Loeb ${ }^{10}$ states that the law of direct proportionality, found in such cases is in reality Weber's law. ${ }^{11}$ In regard to the significance of this, Loeb says:

"Since this law underlies many phenomena of stimulation, if appears possible that changes in the concentration of antagonistic ions or salts are the means by which

${ }^{9}$ See page 135.

${ }^{10}$ Loeb, J. (1915, A).

${ }^{11} C f$. Osterhout (1916, $C$ ). 
these stimulations are brought about, as suggested by my ion-protein theory and by the investigations of Lasareff."

In view of the importance of these relations it seems desirable to point out that the hypothesis of the writer explains the mechanism which makes one proportion better than others and preserves this preëminence in spite of variations in concentration.

We assume that $\mathrm{CaCl}_{2}$ accumulates in the surface to a greater degree than $\mathrm{NaCl}$. The increase in concentration of $\mathrm{CaCl}_{2}$ in the surface is supposed to be ten times as great as the corresponding increase of $\mathrm{NaCl}$, so that the proportions in the surface are those given in Table XI. For example, when the proportions in the solution are $97.56 \mathrm{NaCl}+2.44 \mathrm{CaCl}_{2}$, the proportion of $\mathrm{NaCl}$ to $\mathrm{CaCl}_{2}$ in the surface is as 97.56 to 24.40 , which is equivalent ${ }^{12}$ to $80 \mathrm{NaCl}+20 \mathrm{CaCl}_{2}$.

We calculate the amount of $\mathrm{Na}_{4} \mathrm{XCa}$ by the usual formula:

$$
K=\frac{\left(\mathrm{C}_{\mathrm{Na} u \mathrm{XCa}}\right)\left(\mathrm{CZCl}_{3}\right)^{2}}{\left(\mathrm{CNaCl}^{4}\left(\mathrm{C}_{\mathrm{CaCl}}\right)\left(\mathrm{CXZ}_{2}\right)\right.}
$$

but since $2 \mathrm{C}_{\mathrm{Na}} \mathrm{XCa}=\mathrm{C}_{\mathrm{ZCl}}$ we may write

$$
K=\frac{\left(\mathrm{C}_{\mathrm{Na}_{1} \mathrm{XCa}}\right)\left(2 \mathrm{C}_{\mathrm{Na}_{\mathrm{X}} \mathrm{Xa}}\right)^{2}}{\left(\mathrm{C}_{\mathrm{NaCl}}\right)^{4}\left(\mathrm{C}_{\mathrm{CaCl}_{2}}\right)\left(\mathrm{CXz}_{2}\right)}
$$

Putting $K=4\left(10^{-17}\right)$ and $\mathrm{Cxz}_{2}=0.1$ we get

$$
10^{-17}=\frac{\left(\mathrm{CNa}_{\mathrm{NCa}}\right)^{3}}{(80)^{4}(20)(0.1)}
$$

whence $\mathrm{C}_{\mathrm{Na} \mathrm{XCa}}=0.000936$.

${ }^{13}$ As previously explained it is assumed that the reaction takes place in a surface which is saturated with respect to $\mathrm{NaCl}$ and $\mathrm{CaCl}_{a}$ so that while one of these may be displaced by the other (in case their relative proportions in the solution are altered) the total concentration does not change; for convenience this concentration is taken as 100 and the sum of $\mathrm{NaCl}+\mathrm{CaCl}_{2}$ is therefore always equal to 100 . 
Proceeding in the same manner with the other mixtures, we get the values given in Table XI. Starting with

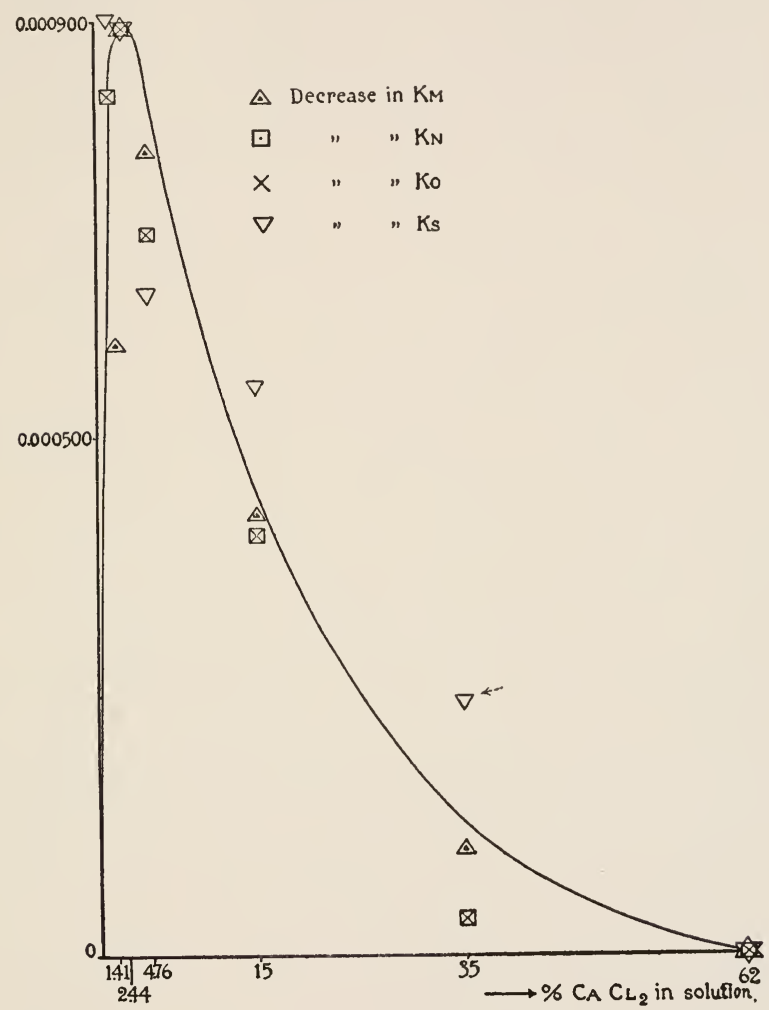

Fig. 64. - Shows the increase of a hypothetical salt compound $\mathrm{Na} \mathrm{XCa}_{\mathrm{X}}$ (see $\mathrm{Table} \mathrm{XI}$ ) and the corresponding decrease of the velocity constants $K_{N}, K_{O}, K_{S}$ and $K_{M}$ (these constants are given in $\mathrm{Table} \mathrm{X}$ ). The figures on the abscissæ give the molecular per cent. of $\mathrm{CaCl}_{2}$ in the mixture. The mixture containing $62.0 \% \mathrm{CaCl}_{2}$ is taken as the standard of comparison: proceeding from this to the mixtures containing less $\mathrm{CaCl}_{2}$ we find that $\mathrm{Na} \mathrm{XCa}^{\mathrm{X}} \mathrm{increases}$ and the velocity constants decrease as shown by the ordinates. In order to facilitate comparison the values of $K_{N}$ have been multiplied by 0.989 ; of $K_{O}$ by 0.991 ; of $K_{S}$ by 0.383 ; and of $K_{M}$ by 0.251 .

the lowest value (that in $62.0 \% \mathrm{CaCl}_{2}$ ) we observe that there is an increase as the per cent. of $\mathrm{CaCl}_{2}$ decreases until $2.44 \%$ is reached (the amount of this increase is 
shown in Column 6 of the table). Conversely we find (Table $\mathrm{X}$ ) that the velocity constants are higher in $62.0 \%$ $\mathrm{CaCl}_{2}$ than in any other mixture and that they decrease as the per cent. of $\mathrm{CaCl}_{2}$ decreases to $2.44 \%$. Thus in the case of $K_{M}$ the value in $62.0 \% \mathrm{CaCl}_{2}$ is 0.009 , in $2.44 \%$ $\mathrm{CaCl}_{2}$ it is less by 0.00354 , while in $15.0 \%$ it is less by 0.0017 , and in $35.0 \%$ by 0.00041 ; if we multiply these numbers by the constant factor 0.251 they agree very closely with the figures for the increase in $\mathrm{Na}_{4} \mathrm{XCa}$. These values are plotted in Fig. 64, which shows that the decrease in $K_{M}$ is directly proportional to the increase in the amount of $\mathrm{Na}_{4} \mathrm{XCa}$. Hence we assume that $\mathrm{Na}_{4} \mathrm{XCa}$ acts as a negative catalyzer or inhibitor of the reaction $M \rightarrow B$.

An inspection of Table $\mathrm{X}$ shows that the value of $K_{A}$ fluctuates with that of $K_{M}$, except that as $\mathrm{CaCl}_{2}$ increases the value of $K_{A}$ rises more rapidly than that of $K_{M}$. This is also obvious from Fig. 59, which shows that the greater the per cent. of $\mathrm{CaCl}_{2}$ in the mixture, the greater the maximum attained. Since this maximum increases as the value of $K_{A} \div K_{M}$ increases, it is evident that the value of $K_{A} \div K_{M}$ must rise as the per cent. of $\mathrm{CaCl}_{2}$ becomes greater. The value of $K_{A} \div K_{M}$ in the solution containing $1.41 \%$ of $\mathrm{CaCl}_{2}$ is 0.03333 while in the solution containing $62.0 \% \mathrm{CaCl}_{2}$ it is 0.05889 , an increase of 0.02556 . If we calculate this increase for the other mixtures and plot the values so obtained against the per cent. of $\mathrm{CaCl}_{2}$ in the surface, we obtain a straight line as shown in Fig. 65. This indicates that $\mathrm{CaCl}_{2}$ catalyzes $^{13}$ the reaction $A \longrightarrow M$; for if this were not the case the value of $K_{A}$ and $K_{M}$ would rise

${ }^{13}$ In the absence of $\mathrm{Na}_{\star} \mathrm{XCa}$ it would appear that $\mathrm{NaCl}$ catalyzes the death process, since death is more rapid in $\mathrm{NaCl} 0.52 M$ than in $0.26 M$. 
and fall in such a way that the value of $K_{A} \div K_{M}$ would remain constant.

It is evident from Figs. 64 and 65 that the values of $K_{A}$ and $K_{M}$ are determined by the amount of $\mathrm{Na}_{4} \mathrm{XCa}$ and by the per cent. of $\mathrm{CaCl}_{2}$ in the mixture, and that when these values are experimentally determined for any two

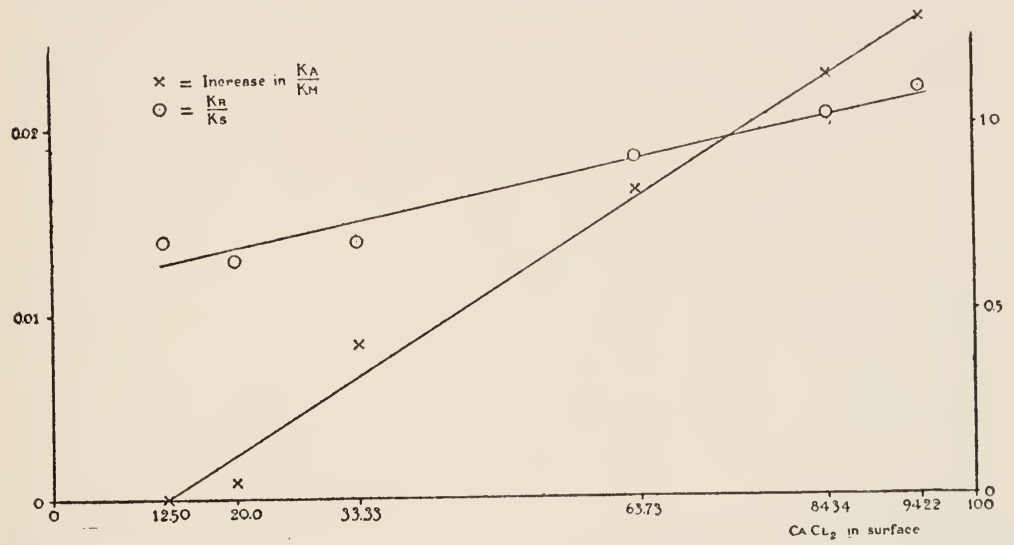

FIG. 65.-Graph showing the increase of $K_{A} \div K_{M}$ and the value of $K_{R} \div K_{S}$ as the molecular per cent. of $\mathrm{CaCl}_{2}$ increases. The figure shows that $\mathrm{CaCl}_{2}$ acts as a catalyzer of the reaction $A \rightarrow M$ (which has the velocity constant $\mathrm{K}_{A}$ ) and also of the reaction $R \rightarrow S$ (which has the velocity constant $K_{R}$ ). The figures on the ordinate at the right show the values of $K_{R} \div K_{S}$; those on the ordinate at the left show the increase in the value of $K_{A} \div K_{M}$ over the value found in the mixture containing $1.41 \% \mathrm{CaCl}_{2}$. The abscissæ denote molecular per cent. of $\mathrm{CaCl}_{2}$ in the surface (not in the solution).

mixtures they can be calculated for any other mixture. When this is done we can calculate the course of the death curve in that mixture.

Having thus accounted for the death curves, we may turn our attention to the process of recovery. We find that, when tissue is removed from a mixture of $\mathrm{NaCl}$ and $\mathrm{CaCl}_{2}$, and replaced in sea water, the resistance at once rises or falls and after a time becomes stationary. This. rise or fall of resistance may be called recovery.

In order to account for the facts we suppose that when 
we replace the tissue in sea water the reactions $O \rightarrow$ $S \rightarrow A \longrightarrow M \longrightarrow B$ proceed at the rates which are normal for sea water. The manner in which the rate of recovery is calculated has already been explained in detail. It is assumed that during the exposure to any of the mixtures the following reactions occur: (1) $N \longrightarrow O \longrightarrow P$; (2) $R \longrightarrow S \longrightarrow T$; (3) $A \longrightarrow M \longrightarrow B$. By assuming values of the velocity constants of these reactions we can approximate the observed results. The velocity constants thus found are given in Table $\mathrm{X}$. An inspection of the table shows that all these velocity constants behave like $K_{A}$ and $K_{M}$ in that as the per cent. of $\mathrm{CaCl}_{2}$ in the mixture increases (beginning with $1.41 \%$ $\mathrm{CaCl}_{2}$ ) the value of the velocity constant first falls and then rises, and that this value in every case reaches its minumum in the mixture containing $97.56 \mathrm{NaCl}+2.44$ $\mathrm{CaCl}_{2}$. It would therefore appear that the reactions $N \longrightarrow O \longrightarrow P$ and $R \longrightarrow S \longrightarrow T$ are inhibited by $\mathrm{Na}_{4}$ XCa in the same manner as the reactions $A \longrightarrow M \longrightarrow B$. This is borne out by an inspection of Fig. 64, in which the decrease ${ }^{14}$ of the velocity constants is plotted, together with the increase of $\mathrm{Na}_{4} \mathrm{XCa}$.

${ }^{14} \mathrm{By}$ the decrease in the velocity constant is meant the decrease which we observe as we pass from the solution containing the highest per cent. of ealcium $\left(38.0 \% \mathrm{NaCl}+62.0 \% \mathrm{CaCl}_{2}\right)$ to mixtures containing smaller per cents of calcium. Thus the decrease of $K_{M}=0.009-K_{M}$ the decrease of $K_{N}=0.00134-K_{N}$; the decrease of $K_{O}=0.0013266-K_{O}$; and the decrease of $K_{S}=0.00319-K_{O}$. In the same manner we find that the increase in the amount of $\mathrm{Na}_{4} \mathrm{XCa}=$ amount of $\mathrm{Na}_{4} \mathrm{XCa}-0.000047$.

The decrease of the amount of $K_{A}$ and $K_{R}$ is not shown in the figure because it depends not only on $\mathrm{Na}_{4} \mathrm{XCa}$, but also on the per cent. of $\mathrm{CaCl}_{2}$.

The fact that even in the presence of the maximum amount of $\mathrm{Na}_{4} \mathrm{XCa}$ these velocity constants are greater than in sea water is of course to be attributed to the other substances present in sea water. 
We have seen that the value of $K_{A} \div K_{M}$ increases as the per cent. of $\mathrm{CaCl}_{2}$ increases and we interpreted this to mean that the reaction $A \longrightarrow M$ is catalyzed by $\mathrm{CaCl}_{2}$. In the same manner we infer that the reaction $R \rightarrow S$ is catalyzed by $\mathrm{CaCl}_{2}$, since we find that the value of $K_{R} \div$ $K_{S}$ increases with increasing percentage of $\mathrm{CaCl}_{2}$, as shown in Fig. 65. It is not certain that the curve does not reach a minimum in the mixture of $97.56 \mathrm{NaCl}+$ $2.44 \mathrm{CaCl}_{2}$, but for practical purposes we may, for the present, regard it as a straight line. ${ }^{15}$

The relation between $K_{N}$ and $K_{O}$ is taken as constant in the proportion of 100 to 99 .

It is evident that when the constants have been empirically determined for two mixtures the constants for any other mixture can be calculated at once, since all of them depend in a definite manner on $\mathrm{Na}_{4} \mathrm{XCa}\left(K_{A}\right.$ and $K_{R}$ also depend on the per cent.of $\mathrm{CaCl}_{2}$ ). The agreement between the constants thus obtained by calculation and those found by trial is fairly close, as is evident from Figs. 64 and $65 .^{16}$

It has already been shown that the height to

${ }^{15}$ Since in pure $\mathrm{NaCl}$ or $\mathrm{CaCl}_{2}$ the salt compound $\mathrm{Na}_{4} \mathrm{XCa}$ is not formed, we should expect that in these solutions all the reactions would be more rapid than in the mixtures. That this expectation is fully realized is evident from Table $\mathrm{X}$.

The velocity constants are somewhat higher in $\mathrm{NaCl}$ than in $\mathrm{CaCl}_{2}$; this is not explained by the assumptions already made, but it does not seem desirable at present to make additional assumptions for this purpose. We might expect the values of $K_{A} \div K_{M}$ and $K_{R} \div K_{S}$ to reach a maximum in $\mathrm{CaCl}_{2}$. This is actually the case. It might perhaps be expected that these values would fall to a minimum in $\mathrm{NaCl}$. This is the case with $K_{A} \div K_{M}$, but not for $K_{R} \div K_{S}$.

${ }^{16}$ The constants obtained by calculation would fall exactly on the graphs in these figures while those found by trial are indicated by the points given. 
which the recovery curve rises depends on the value of $O$ : the value of $O+10$ is shown for all the solutions ${ }^{17}$ in Fig. 66, which shows the agreement between observation and calculation in respect to the final level reached by the recovery curve, but not in respect to speed of recovery, which depends more on the value of $S$ than on that of $O$. The rate of recovery seems to be about the same in the mixtures as in the pure salts. In general it is found that

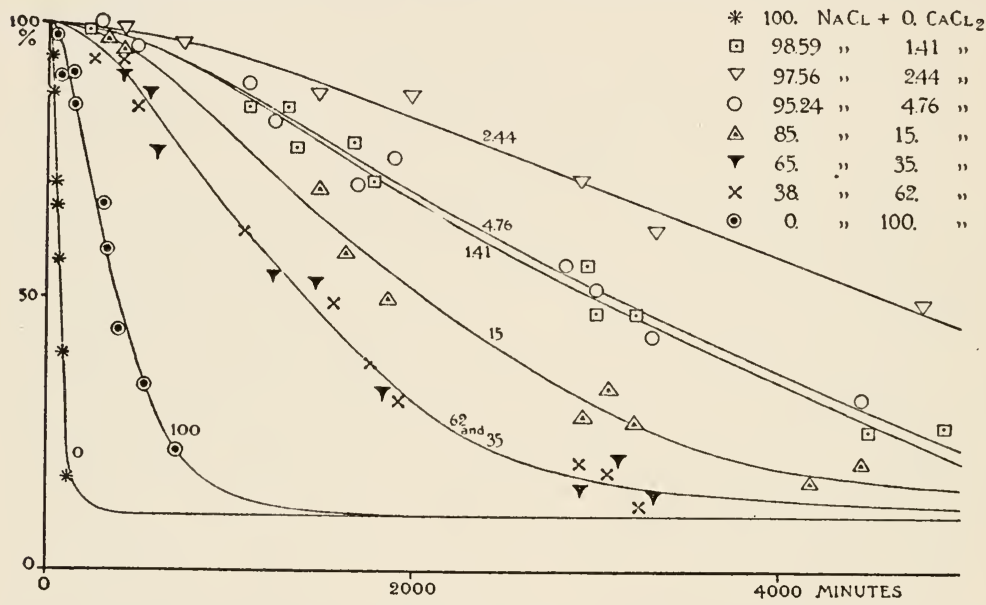

FIa. 66.-Curves showing the value of $O+10$ in $0.52 M \mathrm{NaCl}$ in $0.278 \mathrm{M} \mathrm{CaCl}_{2}$, and in mixtures of these (the figures attached to the curves show the molecular per cent. of $\mathrm{CaCl}_{2}$ in the solution). The ordinates give the relative values of $O+110$, the value in sea water being arbitrarily taken as $100 \%$. These values are obtained by exposing tissue to toxic solutions and then finding the level to which the resistance rises or falls after the tissue is replaced in sea water: they are therefore a mcasure of permanent injury. The abscissæ give the length of exposure to the toxic solution. The curves show the calculated values (using the velocity constants given in Table X). The points show the observed values; each represents the average of six or more experiments. Probable error of the mean less than $10 \%$ of the mean.

the rise or fall is nine-tenths completed in about an hour.

Fig. 67 shows the calculated values of $S$; observed values are not given because they cannot be very pre-

${ }^{17}$ The values of $O+10$ for solutions containing 2.44 and $15.0 \%$ $\mathrm{CaCl}_{2}$ differ slightly from those given earlier for the reason that the curves here presented include a larger series of experiments. 10 is added to the value of $O$ because the base line is taken as 10 , just as in the case of $M$. 
cisely determined. This is owing to the fact that $S$ affects only the speed of recovery (not the final level attained)

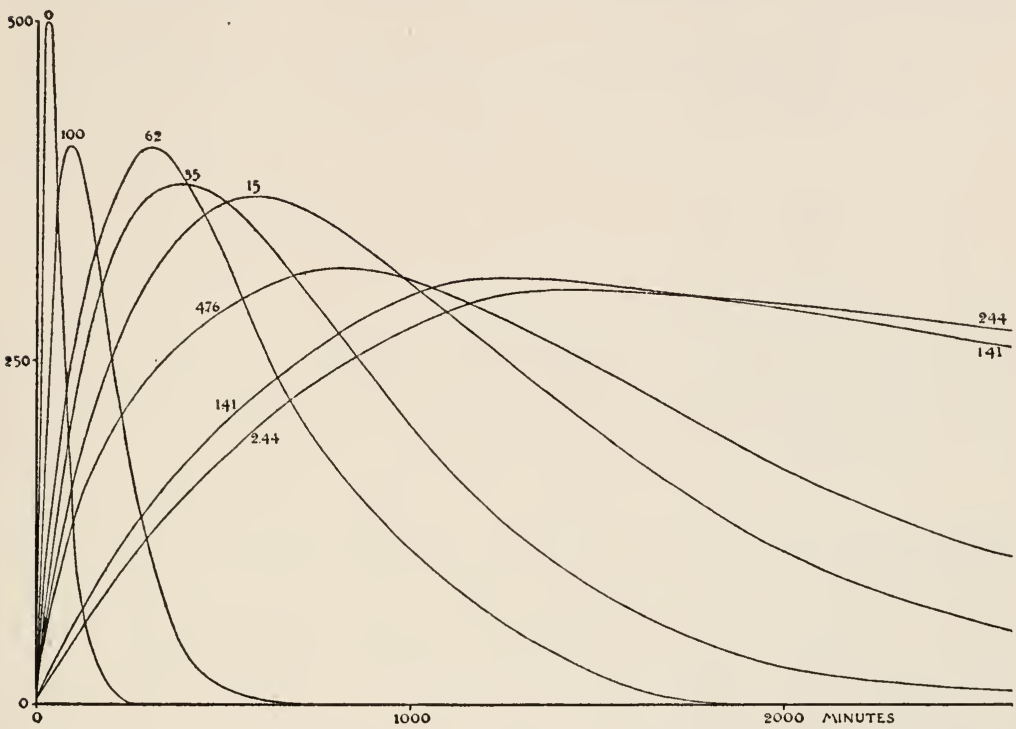

Fig. 67.-Curves showing the (calculated) values of $S$ in $0.52 \mathrm{M} \mathrm{NaCl}, 0.278 \mathrm{M} \mathrm{CaCl}_{2}$, and in mixtures of these (the figures attached to the curves show the molecular per cent. of $\mathrm{CaCl}$, in the solution). The curves show the values calculated from constants obtained by trial which are given in Table $\mathrm{X}$. The abscissæ represent the time of exposure to the toxic solution. The value of $S$ at the start is in all cases 2.7 .

and, as the speed is variable, the most satisfactory procedure is to assume such values of $K_{R}$ and $K_{S}$ in the equation ${ }^{18}$

$$
S=R\left(\frac{K_{R}}{K_{S}-K_{R}}\right)\left(e^{-K_{R} T}-e^{-K_{S} T}\right)+S_{O} e^{-K_{S} T}
$$

as cause the closest approximation to the observed speed of recovery. The values of $S$ thus obtained for each solution are shown in the figure. In general, the speed of recovery, as calculated from these values of $S$, is in satisfactory agreement with the observations.

By means of the equations already given and of the

is $($ ' $f$. equation (3), page 103 . 
velocity constants in Table $\mathrm{X}$, we are able to calculate the recovery curves for any solution after any length of exposure.

Lack of space prevents a tabulation of the observed

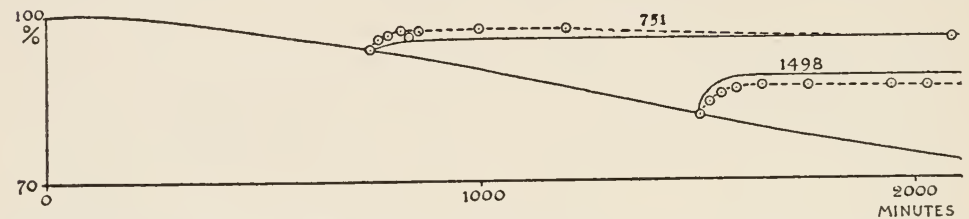

Fra. 68.-Curves showing the net electrical resistance (descending curve) of Laminaria agardhii in a mixture containing 97.56 mols of $\mathrm{NaCl}$ to 2.44 mols of $\mathrm{CaCl}_{2}$ and recovery in sea water (ascending curves). The figure attached to each recovery curve denotes the time of exposure to the toxic solution. In the recovery curves the experimental results are shown by the broken lines, the calculated results by the unbroken lines. The observed points represent the average of six or more experiments. Probable error of the mean less than $10 \%$ of the mean.

and calculated values, but it is possible to exhibit graphically the data for three mixtures and for this purpose one in which recovery consists in a rise of resistance (Fig. 68), one in which it shows a moderate fall (Fig. 69), and

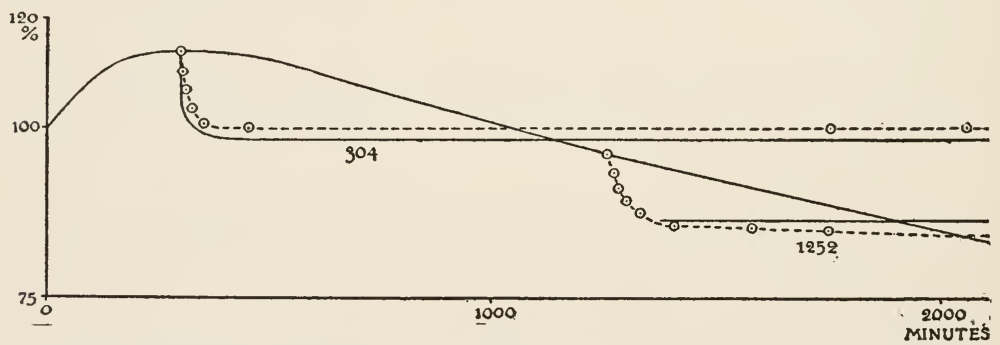

FIG. 69.-Curves showing the net electrical resistance (curve which ascends and descends) of Laminaria agardhii in a mixture containing 95.24 mols of $\mathrm{NaCl}$ to $4.76 \mathrm{mols}$ of $\mathrm{CaCl}_{2}$ and recovery in sea water (descending curves). The figure attached to each recovery curve denotes the time of exposure to the toxic solution. In the recovery curves the experimental results are shown by broken lines, the calculated results by unbroken lines. The observed points represent the average of six or more experiments. Probable error of the mean less than $10 \%$ of the mean.

one showing a very decided fall (Fig. 70) are presented. In general the agreement between observation and calculation is satisfactory for all the solutions employed in the investigation. 
It might be thought that the number of constants is sufficient to make it possible to fit any sort of experimental curve and that the consequent agreement between observed and calculated results is less significant than would otherwise be the case. But, as a matter of fact,

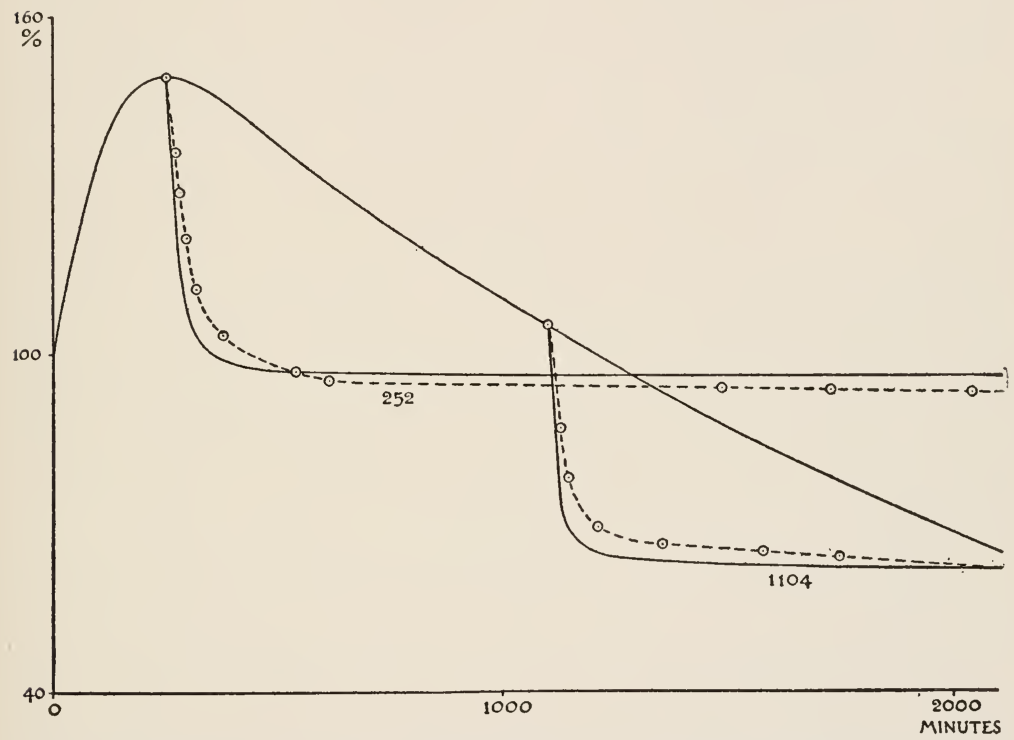

FIG. 70.-Curves showing the net electrical resistance (curve which ascends and descends) of Laminaria agardhii in a mixture containing 38 mols of $\mathrm{NaCl}$ to $62 \mathrm{mols}$ of $\mathrm{CaCl}_{2}$, and recovery in sea water (descending curves). The figure attached to each recovery curve denotes the time of exposure to the toxic solution. In the recovcry curves, the experimental results are shown by the broken lines, the calculated results by the unbroken lines. The observed points represent the average of six or more experiments. Probable error of the mean less than $10 \%$ of the mean.

the constants are so related to each other and to the salt compound, $\mathrm{Na}_{4} \mathrm{XCa}$ that the whole set of curves fits into a consistent scheme, so that when the constants are determined for any two mixtures the theoretical curves for all the other mixtures are thereby fixed. Under these circumstances the close agreement in the six different mixtures (ranging from 1.41 to $62.0 \% \mathrm{CaCl}_{2}$ ) seems to be significant. 
There seems to be no doubt that the behavior of the tissue is such as to indicate an underlying mechanism which is the same in all cases. ${ }^{19}$ We have assumed that this mechanism consists in the production and decomposition of a substance, $M$, the amount of which, in the mixtures, depends largely on a compound $\mathrm{Na}_{4} \mathrm{XCa}$ formed by the combination of $\mathrm{Na}$ and $\mathrm{Ca}$ with a constituent $\mathrm{X}$ of the protoplasm. It is not necessary to discuss these assumptions more fully at present. But it may be pointed out that two things seem to be fairly well established; (1) a consistent mechanism underlies the entire behavior of the tissue, and (2) its operation can be predicted with a fair degree of accuracy by means of the equations which have been developed. The predictive value of these equations may be regarded as permanently established, since it does not depend on our views regarding the underlying assumptions.

The results of these experiments may be summarized as follows:

1. The equations which serve to predict the injury of tissue in $0.52 \mathrm{M} \mathrm{NaCl}$ and in $0.278 \mathrm{M} \mathrm{CaCl}_{2}$ and its subsequent recovery (when it is replaced in sea water) also enable us to predict the behavior of tissue in mixtures of these solutions, as well as its recovery in sea water after exposure to mixtures.

2. The reactions which are assumed in order to account for the behavior of the tissue proceed as if they

${ }^{10}$ This is shown, for example, by the fact that the rapidity of permanent injury (as observed after replacement in sea water) corresponds throughout with the rate of death, and that the rate of change of $\boldsymbol{M}$ corresponds throughout with the rate of change of $O, S$ and $A$. In other words if we change the solution in such a way as to increase (or decrease) one of the reactions on which the resistance depends we simultaneously increase (or decrease) all the others in a definite and predictable manner. 
were inhibited by a salt compound, formed by the union of $\mathrm{NaCl}$ and $\mathrm{CaCl}_{2}$ with some constituent of the protoplasm (certain of these reactions are accelerated by $\mathrm{CaCl}_{2}$ ).

3. A quantitative theory is developed in order to explain: (a) the toxicity of $\mathrm{NaCl}$ and $\mathrm{CaCl}_{2}$; (b) the antagonism between these two substances; (c) the fact that the optimum proportions do not change with alterations of concentration, and (d) the fact that recovery (in sea water) may be partial or complete, depending on the length of exposure to the toxic solution.

It may be appropriate to call attention to some applications of this theory. Antagonism has been explained by Loeb, and by the writer on the ground that antagonistic substances prevent each other from entering the cell. As the writer has repeatedly pointed out ${ }^{20}$, this explanation encounters a difficulty in the fact that antagonistic substances penetrate the cell in a balanced solution (although the penetration is much slower than in unbalanced solutions). The proof of this has been obtained by the writer by means of the method of plasmolysis $^{21}$ as well as that of electrical resistance ${ }^{22}$; it has recently been confirmed by Brooks ${ }^{23}$ by means of the method of tissue tension as well as of diffusion through a disk of living tissue and by direct determinations of the penetrating substances made by the writer (see page 216).

It is obvious that antagonistic substances must penetrate from a balanced solution since otherwise the cell could not obtain the salts necessary to its existence.

\footnotetext{
${ }^{20} C f$. Osterhout $(1911,1912, A, C, 1913, B)$.

${ }^{21} \mathrm{Cf}$. Osterhout 1911. See page 214.

${ }^{2}$ Cf. Osterhout (1912. A. C; 1915, C).

${ }^{23} C f$. Brooks (1916, A. C.; 1917, B). See pages 206 to 209.
} 
As a way out of this difficulty, the writer has suggested $^{24}$ that the slow penetration of salts may produce effects quite different from those produced by rapid penetration.

This difficulty completely disappears if we adopt the standpoint outlined above in developing a dynamical theory of antagonism. From this point of view, we regard the slowness of the penetration of salts in balanced solutions, not as the cause of the antagonistic action but rather the result of it; or we may regard both the slow penetration and the increased length of life (or growth, etc.) by which we measure antagonism, as the results of certain life processes which are directly acted on by the antagonistic substances.

The essential feature of the explanation lies in the behavior of these life processes rather than in the manner or rate of penetration.

We assume, as explained above, that certain life processes may consist of consecutive reactions of the type

$$
O \longrightarrow S \longrightarrow A \longrightarrow M \longrightarrow B
$$

in which $M$ is a substance which determines the rate of penetration of salts and the electrical resistance of the protoplasm.

If the antagonistic substances are $\mathrm{NaCl}$ and $\mathrm{CaCl}_{2}$, it appears that $\mathrm{CaCl}$ accelerates the reaction $A \longrightarrow M$, while both $A \longrightarrow M$ and $M \longrightarrow B$ are inhibited by a salt compound formed by the union of $\mathrm{NaCl}$ and $\mathrm{CaCl}_{2}$ with a constituent of the protoplasm.

From this standpoint the slow penetration of antagonistic substances should not have unfavorable results provided these substances are properly balanced at the

${ }^{24} C f$. Osterhout (1911, 1912, $\left.A, C ; 1913, B ; 1916, E ; 1917, B\right)$. 
start and remain so (i. e., if their relative proportions are not too much changed by unequal speed of diffusion, precipitation, chemical union, etc.) after they enter the cell. For they must affect the life processes mentioned above in quite the same way in the interior of the cell as at the surface, and these life processes will go on in the normal way so long as the antagonistic substances within the cell remain properly balanced.

The result will be the preservation of normal permeability as well as of all other properties essential to life.

It has been shown ${ }^{25}$ that the normal permeability may be regarded as a sensitive and accurate indicator of health and vitality. All factors which disturb it bring about temporary or permanent injury and eventually produce death if the action be sufficiently prolonged. It is therefore evident that the life processes which preserve normal permeability are of peculiar importance and that the manner in which they are influenced by antagonistic substances is of especial interest.

We may now turn our attention to another aspect of the subject. Explanations have been suggested by Loeb and others to account for the antagonistic action of various substances on living protoplasm, but none of them have thus far developed to the point where they enable us to predict what substances (including both electrolytes and non-electrolytes) will antagonize each other and what degree of antagonism may be expected.

This kind of prediction is apparently made possible by a hypothesis formulated by the writer, as the result

${ }^{20}$ Whatever effects are found at the outer surface of the cell may doubtless be found also at many of the internal surfaces, such as the surfaces of vacuoles, plastids, microsomes, etc. See Chapter VII. 
of his investigations on the conductivity of protoplasm.

Substances which alter the conductivity of protoplasm may be divided into (1) those which cause an increase, but not a decrease, of conductivity and (2) those which can produce a decrease of conductivity (followed by an increase). ${ }^{26}$

The hypothesis states that substances belonging to the first class will antagonize those belonging to the second, and vice versa. In order to predict which substances will antagonize each other it is only necessary to determine to which of these classes the substances belong. The amount of antagonism may also be predicted; at least to a considerable extent, since the greater effect of the substances on permeability, the greater will be their antagonistic action. This relation may be obscured by secondary causes, so that the predictions which it allows will not be of equal value in all cases. ${ }^{27}$

As we have seen above, $\mathrm{NaCl}$ belongs to the first class, being able to increase conductivity but not to decrease it, while $\mathrm{CaCl}_{2}$ belong's to the second class, as it is able to decrease conductivity. ${ }^{28}$ It was found that the antagonism between $\mathrm{NaCl}$ and $\mathrm{CaCl}_{2}$ in the case of Laminaria is well marked. These facts led the writer to formulate the hypothesis as stated above. The next step was to test the hypothesis by the investigation of other salts. Magnesium seemed of especial interest for this purpose, as in most of the writer's previous experiments (on other plants) it had shown no antagonism to sodium, though it might be expected on chemical grounds that magnesium and calcium would behave alike. To the surprise of the

${ }^{26}$ See page 40 .

${ }^{27}$ Cf. Osterhout (1915, A).

${ }^{28}$ The decrease is followed by an increase if the exposure is sufficiently prolonged. 
writer, it turned out that magnesium was able to decrease conductivity, though its effect was much inferior to that of calcium. The antagonistic relations for Laminaria were then investigated, and it was found that $\mathrm{MgCl}_{2}$ was able to antagonize $\mathrm{NaCl}$, though its antagonistic action was much less than that of $\mathrm{CaCl}_{2}$.

This unexpected and striking result strengthened the writer's confidence in the hypothesis and led to further investigations. One of these which was of special interest related to acids. For a number of reasons it was supposed that acid would not cause a decrease in permeability. But investigation showed that such a decrease actually occurred in the presence of $\mathrm{HCl}$ and it was then a simple matter to predict that antagonism would be found between $\mathrm{NaCl}$ and $\mathrm{HCl}$. This turned out to be the case, the amount of antagonism corresponding to the amount of decrease of conductivity.

These results are also of interest in view of the fact that Loeb ${ }^{29}$ has shown that salts are antagonized by acids and has pointed out that this has a special significance for the theory of permeability, since it indicates that the permeability of the plasma membrane (for water and substances soluble in water) depends on the presence of protein rather than of lipoid substances. The investigations of the writer show that similar (though less striking) antagonism occurs in plants. This affords evidence of the protein character of the plasma membrane in plants and is in harmony with the fact that (as the writer has shown) various ions pass through the plasma membrane of plants, ${ }^{30}$ which would not be expected if it were composed of lipoid.

Loeb, J. $(1899 ; A, B ; 1912, A, B ; 1917)$ : Loeb and Wasteneys (1911, B; 1912).

${ }^{30} \mathrm{Cf}$. Osterhout (1912, A, B; 1913, B). 
In carrying out these investigations a solution of $\mathrm{HCl}$ having the same conductivity as sea water (about 0.119 $M \mathrm{HCl}$ ) was prepared. Various amounts of this were added to a solution of $\mathrm{NaCl} 0.52 M$ (which had the same conductivity as sea water). Several lots of tissue were prepared with a view of making them as much alike as possible. One lot of tissue was placed in each of the mixtures of $\mathrm{NaCl}+\mathrm{HCl}$; other lots were also placed in pure $\mathrm{NaCl}$ and in pure $\mathrm{HCl}$.

The results are shown in Fig. 71. It will be seen that in pure $\mathrm{NaCl}$ and in pure $\mathrm{HCl}$ the resistance fell rapidly, indicating injury; while in a mixture in which the dissolved molecules are $99.09 \% \mathrm{NaCl}$ and $0.91 \% \mathrm{HCl}$, the resistance fell less rapidly, indicating that this mixture was less injurious than either of the pure solutions. In other words, the salt and the acid have an antagonistic action. This antagonism may be expressed quantitatively (as previously explained ${ }^{31}$ ) in the following manner: The ends of the antagonism curve are connected by a straight line $\mathrm{e}^{32}$ and an ordinate is erected at the point on the curve which is to be measured. For example, the ends of the 30 minute curve in Fig. 71 are connected by the dotted line. The antagonism at the point $A$ (representing a mixture in which the dissolved molecules are $99.09 \% \mathrm{NaCl}$ and $0.91 \% \mathrm{HCl}$ ) is expressed as $A B \div B C$.

The rise in resistance at the end of 1 minute in pure $\mathrm{HCl}$ agrees with the results previously described. ${ }^{33}$

${ }^{31}$ See pages 122 to 129 .

${ }^{32}$ This should in many cases be a curved line, provided the pure solutions are not equally toxic. But in the present case the curvature would be small, and at the maximum point of the curve very small indeed. This line expresses the additive effect; i.e., the effect which would be produced if there were no antagonism, and each component of the solution acted independently. (See page 72).

${ }^{33}$ See page 48 . 


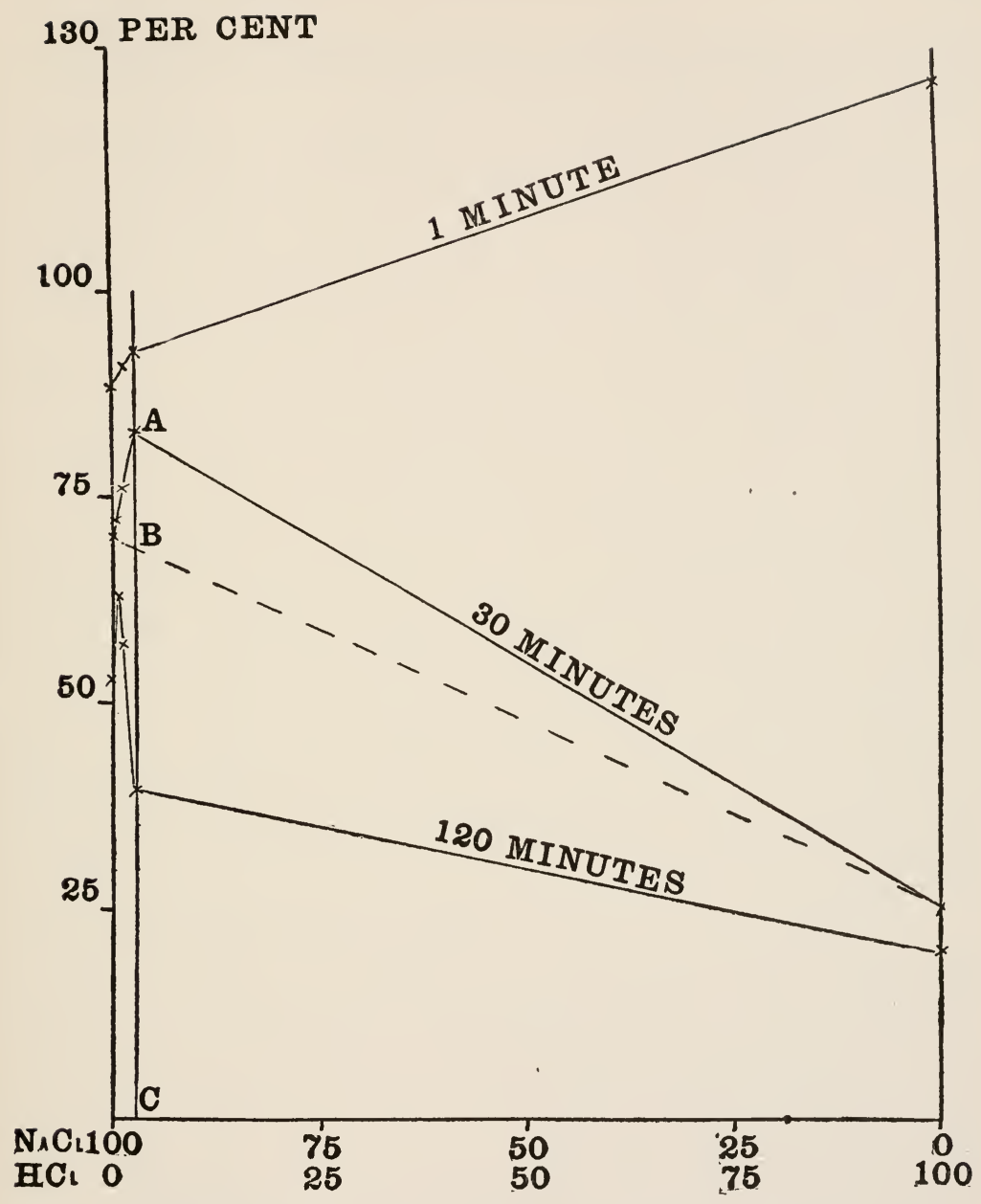

FIg. 71.-Antagonism curve of Laminaria agardhii in $\mathrm{NaCl} 0.52 \mathrm{M}$, in $\mathrm{HCl} 0.119 \mathrm{M}$, and in mixtures of these. The ordinates represent net electrical resistance (expressed as per cent. of the normal net resistance); the abscissæ represent the molecular proportions in the mixtures. Thus $\mathrm{NaCl} 50, \mathrm{HCl} 50$ means a mixture of $\mathrm{NaCl} 0.52 \mathrm{M}$ and $\mathrm{HCl} 0.119 \mathrm{M}$ in such proportions that $50 \%$ of the dissolved molecules is $\mathrm{NaCl}$ and $50 \%$ is $\mathrm{HCl}$. Each curve represents a single experiment. All readings were taken at $18^{\circ} \mathrm{C}$. or corrected to this temperature.

A reading taken at the end of 18 hours showed that the tissue was dead in all the solutions. The plants can be kept alive much longer than this in mixtures of $\mathrm{NaCl}+$ $\mathrm{CaCl}_{2}$; it is also noteworthy that the degree of antagon- 
ism, as shown by the electrical resistance, is greater in $\mathrm{NaCl}+\mathrm{CaCl}_{2}$ than in $\mathrm{NaCl}+\mathrm{HCl}^{3+}$

The hypothesis was further tested by investigations on other salts, the most interesting of which are those which (in contrast to those just mentioned) are more effective than $\mathrm{CaCl}_{2}$ in decreasing permeability, such as La $\left(\mathrm{NO}_{3}\right)_{3}, \mathrm{Ce}\left(\mathrm{NO}_{3}\right)_{3}$, etc. Here also it was found that the degree of antagonistic action could be foretold by observing the amount of decrease of permeability produced by the pure salts. The results of these investigations afford strong support to the hypothesis.

The soundness of this point of view is indicated not only by the fact that we are able to predict both qualitatively (and to a considerable extent quantitatively) the effect of combinations of salts ${ }^{35}$ but also by the very

${ }^{34}$ See page 140 .

${ }^{25}$ It should be noted that mixing solutions of two salts which belong to different classes does not produce an effect which is merely intermediate between the two. For example, tissue may be killed by an exposure of 24 hours to $\mathrm{NaCl}$ or to $\mathrm{CaCl}_{2}$, but not in a mixture of these in the proper proportions.

The writer has found cases in which two substances which can decrease permeability are able to antagonize each other. So far as the writer's experiments with Laminaria have gone there is no great amount of antagonism in such cases and what there is may perhaps be correlated with the fact that all substances which decrease permeability do not act alike, some producing a much greater decrease than others. Moreover these substances will, if the exposure be sufficiently prolonged, alter their action and increase permeability. The rapidity of this change varies with different substances, and this may be related to the fact that some of these substances antagonize each other to some degree.

Experiments on some plants (in which the criterion of antagonism is not electrical resistance, but growtl) show a fairly strong antagonism between magnesium and calcium. It is possible that for these plants magnesium belongs in the first class.

It will be noted that the hypothesis, as here set forth, says nothing about the mutual relations of substances belonging to the same class, but merely states that substances of one class will antagonize those of the other. In this form the hypothesis is completely justified by all the experiments, including those on organic substances. 
significant fact that we are able to extend this conception to organic compounds and to show that non-electrolytes which decrease permeability can also antagonize such substances as $\mathrm{NaCl}$. These facts indicate that the hypothesis may perhaps be applied in a general manner so as to include both electrolytes and non-electrolytes.

As an example of antagonism between salts and organic substances we may cite some experiments with bile salts. The writer found, very early in the course of his experiments, that $\mathrm{Na}$-taurocholate increases the electrical resistance of Laminaria. This was somewhat striking in view of the fact that agents which increase permeability have long been known, but the discovery of substances which have the opposite effect, is comparatively recent. The number of such substances known at present (especially organic substances) is very small and it is therefore of interest to find that bile salts possess this property.

The experiments were made by determining the electrical conductivity of Laminaria in solutions to which $\mathrm{Na}$-taurocholate was added. ${ }^{36}$

In the first experiments the bile salt was dissolved in sea water. The amounts added to $1,000 \mathrm{cc}$. of sea water varied from 0.8 to $1.5 \mathrm{gm}$. If the Na-taurocholate were pure, $1 \mathrm{gm}$. in 1,000 cc., would make the concentration about $0.002 M$, but as its purity is doubtful the concentration cannot be accurately determined.

After dissolving the Na-taurocholate the sea water was restored to the normal conductivity and made approximately neutral to litmus.

At all the concentrations employed there was an immediate increase in resistance ${ }^{37}$ followed by a fall.

${ }^{86} C f$. Osterhout $(1919, B, C$.$) .$

${ }^{87}$ See page 55 . 
Under the conditions of the experiment (temperature $19^{\circ} \pm 2{ }^{\circ} \mathrm{C}$.) the rise lasted about an hour. The effect is comparable with that of anesthetics ${ }^{38}$ (ether, chloroform, and alcohol) as described by the writer. An increase in resistance was also observed with Ulva rigida and with Rhodymenia palmata.

In the experiments on antagonism the tissue was placed in a solution of $\mathrm{NaCl} 0.52 M$ to which various amounts of Na-taurocholate were added (all the solutions having the same conductivity as the sea water and being approximately neutral to litmus). The temperature was $18.5 \pm 2.5^{\circ} \mathrm{C}$ :

The results are shown in Fig. 72. There is a gradual fall of resistance in all the solutions which continues until the death point $(10 \%)$ is reached. In the solution containing 1,000 c.c. of $\mathrm{NaCl} 0.52 \mathrm{M}+0.52 \mathrm{gm}$. of $\mathrm{Na}$ taurocholate the fall of resistance is much slower, indicating that this is the most favorable mixture.

It should be emphasized that the effect is not an intermediate but an antagonistic one. By this is meant that the resistance is not merely the algebraic mean between a rise in resistance produced by the bile salt and a fall produced by $\mathrm{NaCl}$. A consideration of the lowest curve shows that at 180 minutes the tissue is dead in $\mathrm{NaCl} 0.52 M$ as well as in 1,000 c.c. of $\mathrm{NaCl} 0.52 M+10$ $\mathrm{gm}$. of Na-taurocholate, but in the mixture containing only $0.5 \mathrm{gm}$. of taurocholate it is not yet half dead, its resistance being much higher than in the other mixtures. ${ }^{39}$

The result serves as a striking confirmation of the idea that antagonistic relations can be predicted, to a considerable extent at least, by ascertaining the effect

${ }^{38}$ See Chapter V.

At the end of 180 minutes the resistance of the control in sea water was $100 \%$. 
upon permeability of each substance taken by itself, inasmuch as substances which decrease permeability antagonize those which increase it.

Similar investigations were made upon alkaloids. Antagonism between salts and alkaloids has been reported

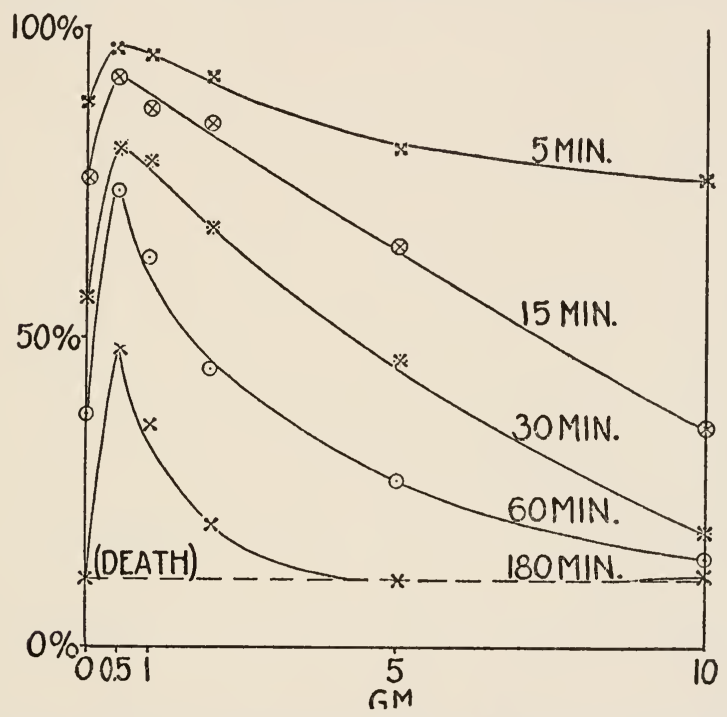

Fig. 72.-Curves showing antagonism between $\mathrm{NaCl}$ and Na-taurocholate. The ordinates represent the net electrical resistance of Laminaria agardhii (expressed as per cent. of the control in sea water which is taken as $100 \%$ ). The abscissæ represent the amount of $\mathrm{Na}$-taurocholate added to 1000 c.c. of $\mathrm{NaCl} 0.52 \mathrm{M}$. Average of two experiments; probable error of the mean less than $5 \%$ of the mean.

by several authors, the most extensive investigation being that of Robertson. ${ }^{40}$

The alkaloids studied were nicotine, caffeine and cevadine. They were added in varying amounts to $\mathrm{NaCl}$ $0.52 M^{41}$, and their effect upon the electrical conductivity of Laminaria was determined.

The results obtained with nicotine are shown in Fig.

${ }^{40}$ For the literature see Robertson, T. B. $(1906,1910$, pp. 238, 311). Also Szücs (1912).

${ }^{41}$ All the solutions had the same conductivity as sea water. 
73. The lower curve shows that after $181 / 2$ hours the resistance of the tissue has dropped to $10 \%$ (the death

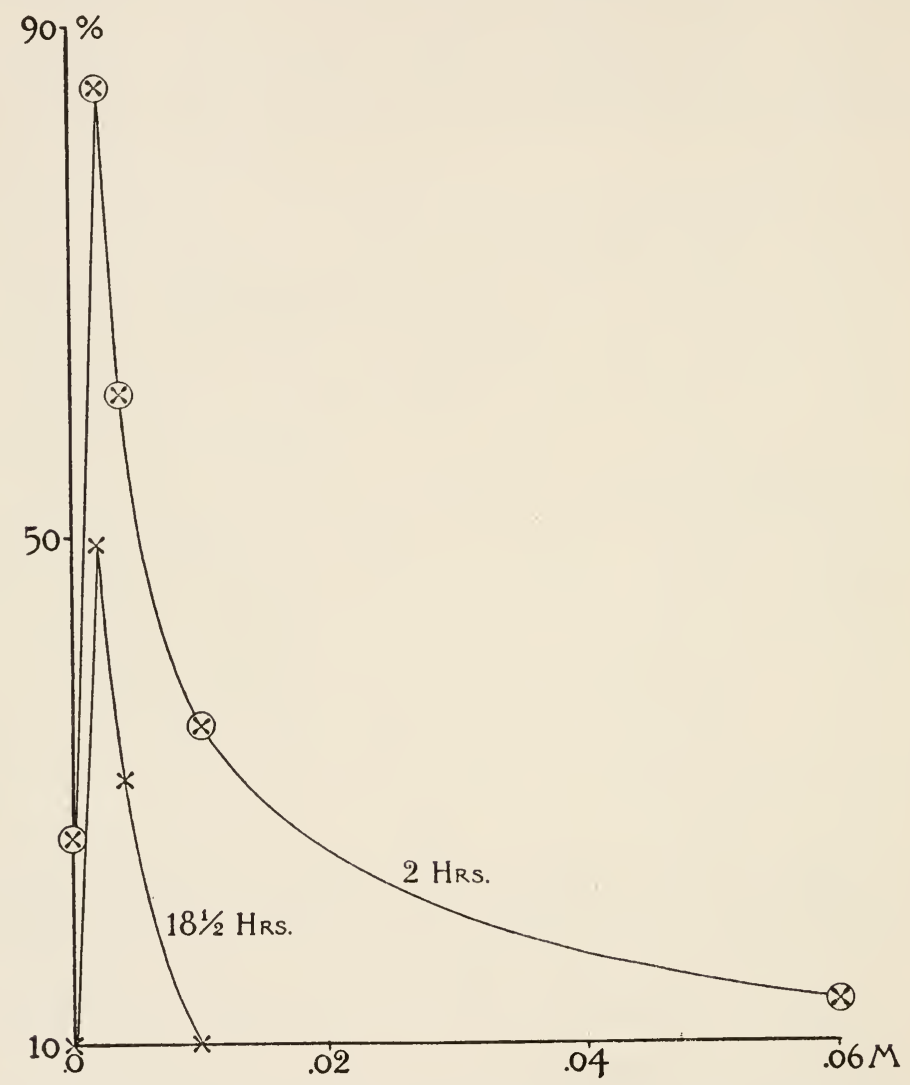

FIa. 73.-Curves showing antagonism between $\mathrm{NaCl}$ and nicotine. Ordinates represent net electrical resistance of Laminaria agardhii (expressed as per cent. of the normal); abscissæ represent concentrations of nicotine added to $0.52 M \mathrm{MaCl}$. The resistance of the control at $181 / 2$ hours was $94 \%$. Average of two experiments; probable error of the mean less than $3 \%$ of the mean.

point) in $0.52 M \mathrm{NaCl}$, as well as in $0.52 M \mathrm{NaCl}$ to which sufficient nicotine has been added to make the concentration $0.01 M$. In $\mathrm{NaCl} 0.52 M$ plus nicotine $0.002 M$ the resistance has dropped to $49.5 \%$ (i.e., the tissue is about 
half dead). It is evident that nicotine antagonizes the action of $\mathrm{NaCl}$ by inhibiting the fall of resistance which occurs in pure $\mathrm{NaCl}$. The upper curve (2 hours) shows even more pronounced antagonism.

The results with caffeine (Fig. 74) are similar except that the curve does not fall as rapidly with increasing

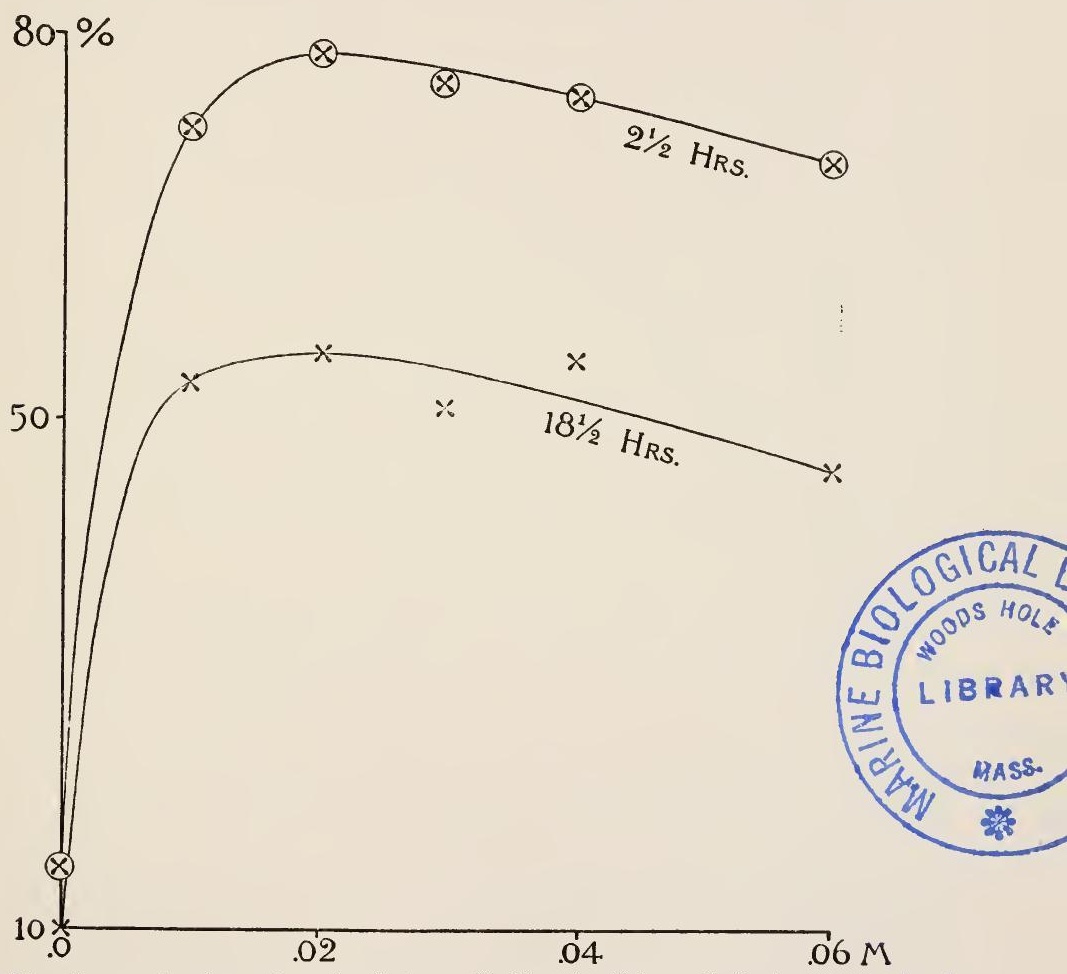

FIG. 74.-Curves showing antagonism between $\mathrm{NaCl}$ and caffeine. Ordinates represent net electrical resistance of Laminaria agardhii (expressed as per cent. of the normal); abscissæ represent concentrations of caffeine added to $0.52 M \mathrm{NaCl}$. The resistance of the control at $181 / 2$ hours was $96 \%$. Average of two experiments; probable error of the mean less than $5 \%$ of the mean.

concentrations of alkaloid. With cevadine (Fig. 75) the curve falls much more rapidly, the maximum being in the neighborhood of $0.005 M$ cevadine sulfate. Here death 
is more rapid, the tissue being killed in 18 hours or less, even in the most favorable solution.

The experiments with cevadine were carried out dur-

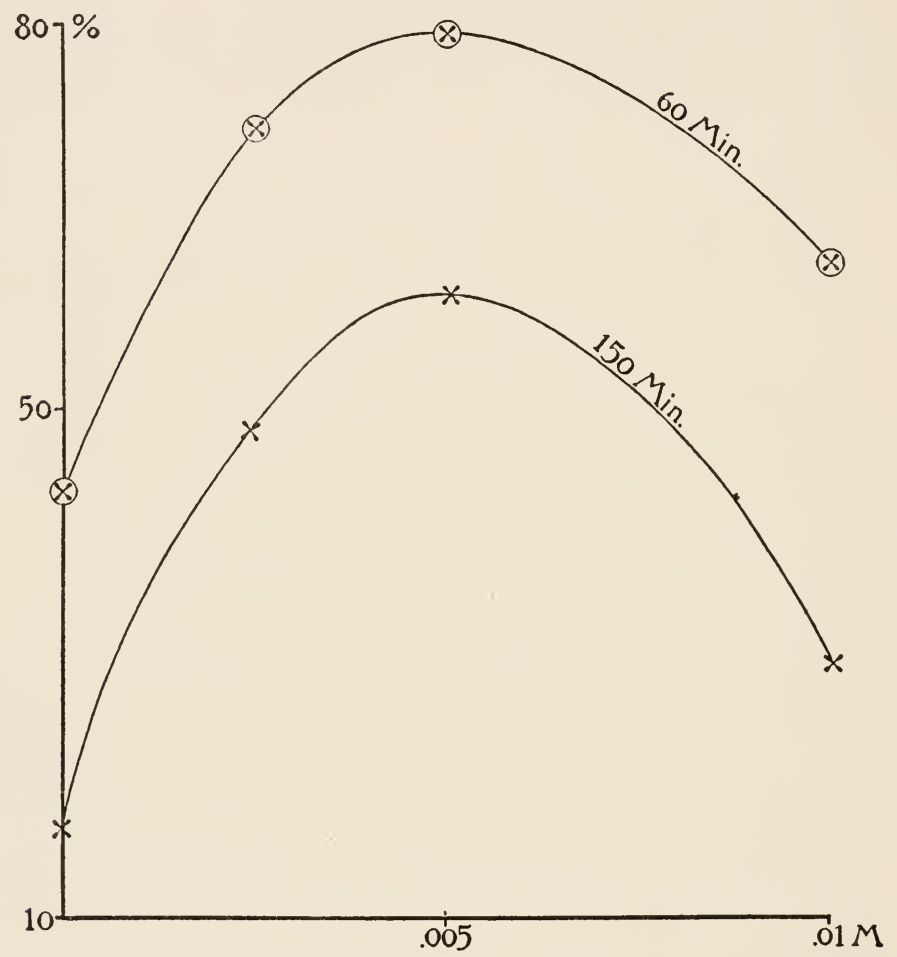

FIG. 75.-Curves showing antagonism between $\mathrm{NaCl}$ and cevadine sulfate. Ordinates represent net electrical resistance of Laminaria agardhii (expressed as per cent. of the normal); abscissæ represent concentrations of cevadine sulfate added to $0.52 M \mathrm{NaCl}$. The resistance of the control at 150 minutes was $100 \%$. Average of two experiments; probable error of the mean less than $5 \%$ of the mean.

ing the day at $15 \pm 2^{\circ}$, and the time curves in the various solutions follow more or less closely a monomolecular course. In the case of nicotine and caffeine (where the experiment ran during the day and the following night) this is not the case, except in the earlier part of the reac- 
tion. This is perhaps explained by the fall of temperature which occurred during the night and retarded the speed of the process. It should be noted that all the experiments in any. set were begun at the same time, so that all shared equally in the variations of temperature; in consequence the form of the antagonism curve is not greatly affected by such variations.

In order to determine whether these alkaloids produce a decrease in permeability they were added to sea water. The experiment was not successful in the case of nicotine, owing to the formation of a visible precipitate, which was apparently due to the presence of calcium and magnesium in the sea water. In the case of caffeine $(0.01$ to $0.04 M$ ) and of cevadine sulfate ${ }^{42}(0.0006$ to $0.0025 \mathrm{M})$ a distinct decrease in permeability was found (as shown by the rise in resistance); this was followed by an increase. In this respect they resemble $\mathrm{CaCl}_{2}$ which also produces a decrease in permeability when added to sea water.

The idea that substances which have opposite effects on permeability can antagonize each other seems to apply to alkaloids as well as to salts.

The question arises whether the decrease of conductivity and the antagonistic action produced by organic substances are of the same nature as those produced by salts. Are they, in terms of the theory outlined above, due to an increase in the thickness of the layer of $M$ at the surface of the cell? The writer is not prepared to answer this question at present, but there is no reason to suppose that their effects may not differ from those produced by

12 This is regarded as two molecules of cevadine united to one molecule of $\mathrm{H}_{2} \mathrm{SO}_{4}$. It was purchased from Merck under the name of veratrine sulfate $\left(\mathrm{C}_{32} \mathrm{H}_{49} \mathrm{NO}_{9}\right)_{2} \cdot \mathrm{H}_{2} \mathrm{SO}_{4}$. Cf. Osterhout (1919.D). 
salts. We may assume that they may act upon the hypothetical substance $M$, and increase its resistance by changing properties other than the thickness of the layer. In order to ascertain whether these results have gen-

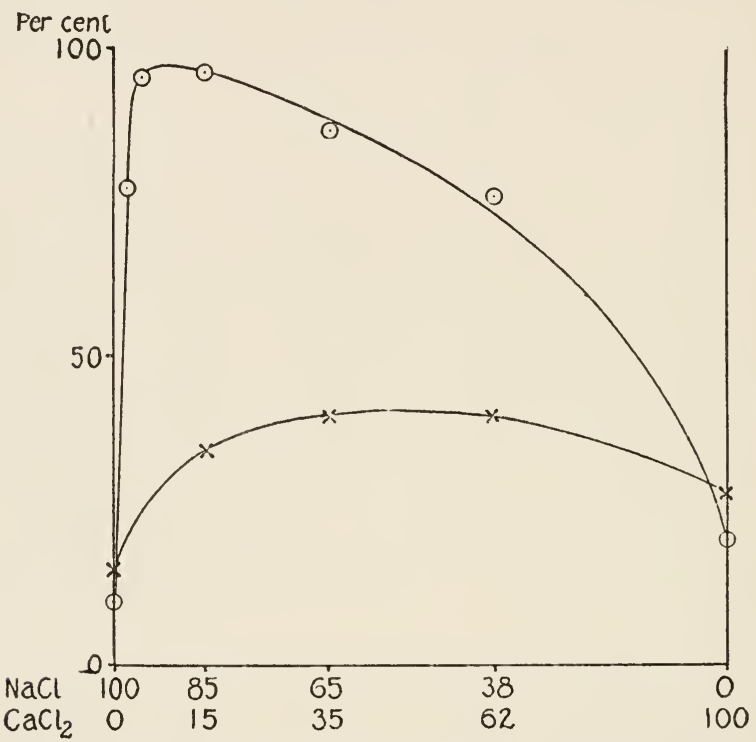

Fia. 76.-Curves showing antagonism (after an exposure of 24 hours) between $\mathrm{NaCl} 0.52$ $\boldsymbol{M}$ and $\mathrm{CaCl}_{2} 0.278 M$ in Laminaria agardhii (upper curve) and Rhodymenia palmata (lower curve). The ordinates denote net electrical resistance. The abscissæ denote molecular proportions of the solutions (all the solutions having the conductivity of sea water). Thus $\mathrm{NaCl} 85, \mathrm{CaCl}_{2} 15$ signifies a mixture of 75 c.c. $\mathrm{NaCl} 0.52 M+25$ c.c. $\mathrm{CaCl}_{2} 0.278 M$ in which the molecular proportions of $\mathrm{Na}$ to $\mathrm{Ca}$ are as 85 to 15 . Temperature $17.5^{\circ} \pm 5^{\circ} \mathrm{C}$. During the 24 hours the resistance of Laminaria in sea water remained practically unaltered while that of Rhodymenia fell to $84.5 \%$. Average of six experiments. Probable error of the mean less than $5.2 \%$ of the mean.

eral validity, experiments were made upon other plants and upon animals. In general the outcome (as far as the experiments have gone) is similar to what has been described for Laminaria. Thus antagonism between $\mathrm{NaCl}$ and $\mathrm{CaCl}_{2}$ was observed in the cases of Ulva (sea lettuce), Rhodymenia (dulse) and Zostera (eel grass). ${ }^{43}$

As was to be expected, the most favorable proportions were not always exactly the same for the different plants. 
Thus it was found that in the case of Rhodymenia it required more $\mathrm{Ca}$ to antagonize $\mathrm{Na}$ than it did in the case of Laminaria. It was also observed that in the case of Rhodymenia (Fig. 76) the antagonism was not so great as in Laminaria and this appears to be correlated with the fact that less decrease of permeability is produced by $\mathrm{Ca}$ in Rhodymenia. In other words, the effect of such a substance as $\mathrm{Ca}$ upon permeability not only indicates what substances it will antagonize but also, to some degree at least, the amount of antagonism.

It may be added that Rhodymenia affords an interesting confirmation of the value of the electrical method in measuring antagonism, since the plants begin to change color soon after injury occurs. It was found that the relative rates of death as indicated by color changes in $\mathrm{NaCl}, \mathrm{CaCl}_{2}$, and the various mixtures, correspond with the results obtained by determining conductivity.

Antagonism between $\mathrm{NaCl}$ and $\mathrm{CaCl}_{2}$ was also observed in the case of frog skin. ${ }^{44}$

Shearer (1919) in an experiment on bacteria finds that $\mathrm{NaCl}$ and $\mathrm{KCl}$ decrease, and that $\mathrm{CaCl}_{2}$ increases the resistance, but that a mixture of these (Ringer's solution) in the proper proportions preserves the normal resistance.

Thus far, we have confined ourselves to the consideration of antagonism among kations. Numerous cases of this are known, but the search for similar relations among anions has achieved little result. Some cases have been described by Loeb ${ }^{45}$ and Miss Moore (1901, 1902). Lipman and his associates ${ }^{48}$ have reported antagonistic action of anions as the result of studies on bacteria in

\footnotetext{
${ }^{44}$ Osterhout $(1919, C)$.

${ }^{45}$ Loeb, J. (1905, 1912, A, B) and literature there cited.

${ }^{46}$ Lipman, C. B. $(1912-13,1914)$. Lipman, C. B., and Burgess, P.
} S. $(1914,1914-1915)$. 
which salts were added to the soil, but it is very difficult to separate the effects of the added salts from those

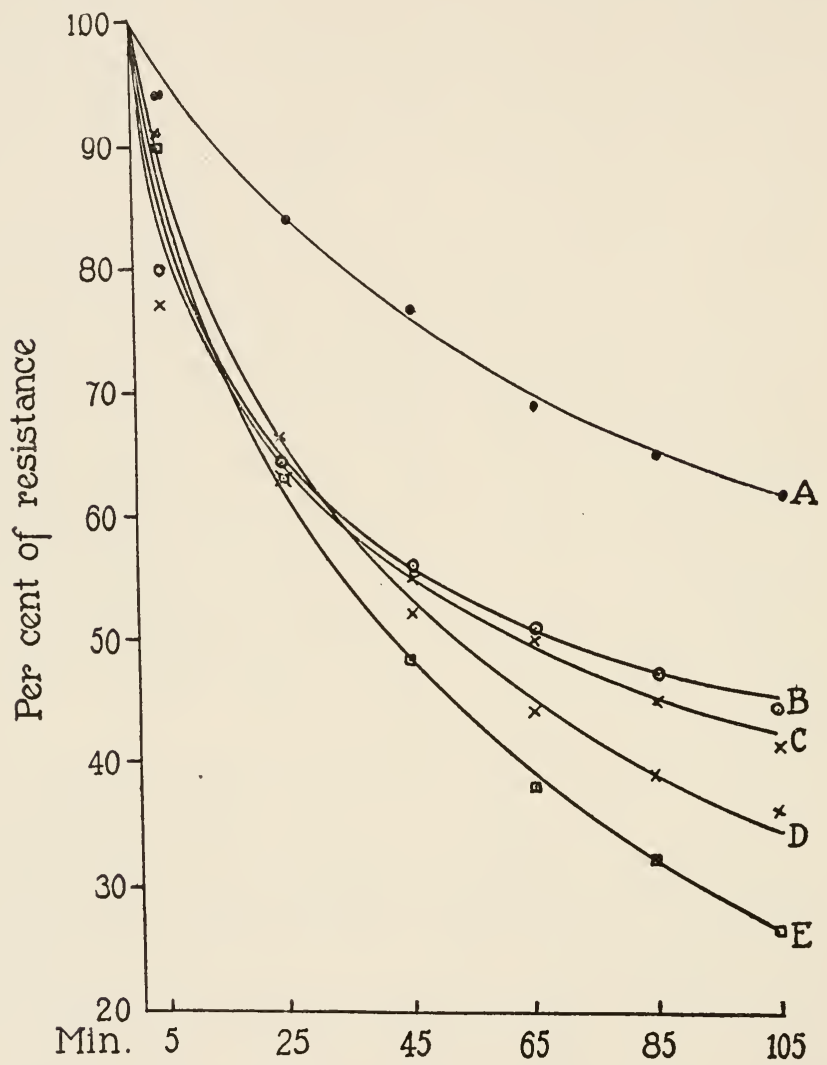

F1a. 77.-Curves showing the resistance of Laminaria agardhii in $1.1 M$ sodium acetate, in $0.36 M$ sodium sulfate, and in mixtures of both: $A$ in equal parts (by volume) of acetate and sulfate; $B$ in acetate 75 , sulfate $25 ; C$ in acetate; $D$ in acetate 25 , sulfate $75 ; E$ in sulfate. Ordinstes represent net electrical resistance (expressed as per cent. of the original resistance in sea water which is taken as $100 \%$ ). Each point represents the average of ten experiments: probable error of the mean less than $5 \%$ of the mean.

of salts already present in the soil. Miyake (1913) found some antagonism among anions in studying the growth of rice. Fenn (1918) has called attention to the fact that this kind of antagonism is commonly met with in experiments on gelatin. 
Using electrical conductivity as a criterion, Raber (1920) has found well marked antagonism between

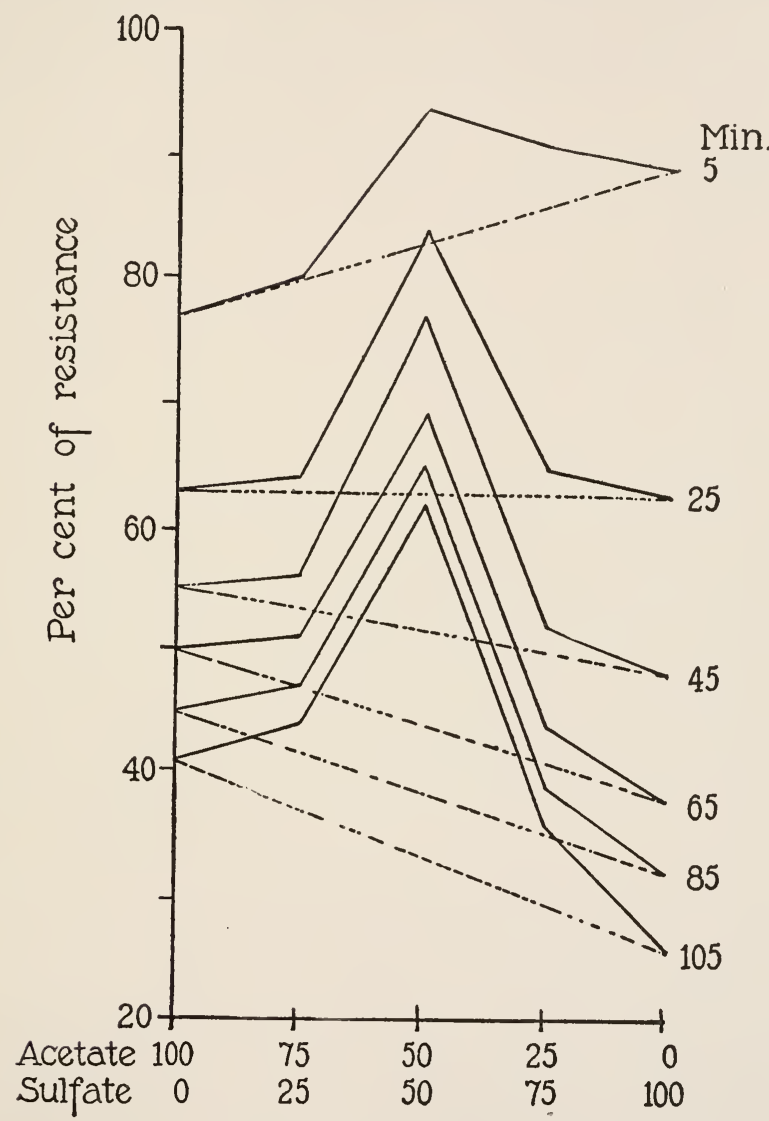

FIg. 78.-Antagonism curves showing the net electrical resistance of Laminaria agardhii in $1.1 M$ sodium acetate, in $0.36 \mathrm{M}$ sodium sulfate, and in mixtures of both. Ordinates represent resistance (expressed as per cent. of the original resistance in sea water which is taken as $100 \%$ ); abscissæ represent volumetric proportions of the two salts. The dotted line connecting the ends of each curve shows the approximate additive effect; the vertical distance of the curve above this dotted line may be regarded as a measure of antagonism.

$\mathrm{Na}$-acetate and $\mathrm{Na}_{2} \mathrm{SO}_{4}$ in experiments on Laminaria, as shown in Fig. 77.

On placing tissue in the pure acetate we observe that at the end of $13 / 4$ hours, the resistance has fallen to about 
$40 \%$ of the original and in the pure sulfate it has fallen to about $25 \%$ of the original, while in the mixture composed of equal volumes of the solution of each salt, the resistance has fallen only to about $60 \%$. If no antagon-

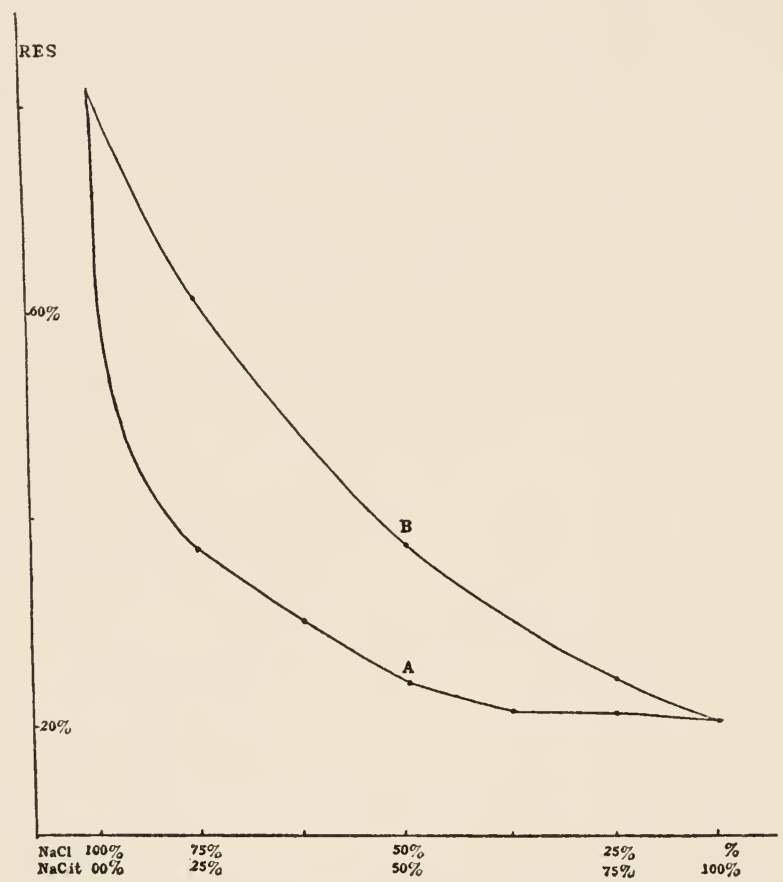

Frg. 79.- Increased toxicity shown by curves of the electrical resistance of Laminaria agardhii in $\mathrm{NaCl} 0.52 M$, Na-citrate $0.58 M$ (approximate) and in mixtures of these (the proportions, representing c.c. of the component solutions, are indicated on the abscissa. Curve $A$, observed values, after an exposure of 15 minutes to the solution, Curve $B$ values. expected on the supposition that neither salt affects the action of the other (additive effect). The increase of toxicity is measured by the vertical distance between the curves. All readings were made at $23^{\circ} \mathrm{C}$. or corrected to this temperature. Each observed point presents the average of 10 experiments: probable error of the mean less than $10 \%$ of the mean.

ism were present, the resistance in the mixture should drop to about $35 \%$ (additive effect):

Fig. 78 shows the antagonism curves after various intervals, using resistance for ordinates and salt proportions as abscissæ. Here the antagonism is clearly evident. Similar experiments with $\mathrm{NaCl}$ and $\mathrm{Na}$-citrate, by 
Raber (1917) gave quite the opposite result. In this case a distinct increase of toxicity occurs on mixing the components. This is evident from Fig. 79. Similar results were obtained when Na-citrate was combined with NaI, $\mathrm{NaSCN}, \mathrm{NaNO}_{3}$ or $\mathrm{Na}_{2} \mathrm{SO}_{4}$.

Cases which show increased toxicity (as judged by other criteria) have been reported by Lipman ${ }^{47}$ and by Loeb. ${ }^{48}$

It may be of interest to call attention to certain phenomena in non-living matter which bear at least a superficial resemblance to some of the facts discussed above.

In the course of experiments on Laminaria, the writer frequently observed that fronds kept in $\mathrm{NaCl}$ become softer, ${ }^{49}$ but that in $\mathrm{CaCl}_{2}$, and in $\mathrm{LaCl}_{3}$, they become harder. The changes in viscosity are so great as to suggest that they are fully capable of explaining the fall of electrical resistance which occurs when tissue is placed in $\mathrm{NaCl}$ and the rise of resistance which occurs in $\mathrm{CaCl}_{2}$ and $\mathrm{LaCl}_{3}$ (which is always followed by a fall of resistance).

In the hope of throwing some light upon this process, sections of tissue were observed in $\mathrm{CaCl}_{2}$ under the microscope. It was then seen that after a time the protoplasm assumed a coagulated appearance: it seemed obvious that the process which increased the viscosity might produce a coagulation of the protoplasm or some other change in its structure whereby it became more permeable.

This enception led the writer to expect decreased resistance in tissues placed in $\mathrm{NaCl}$ (because of decreased

${ }^{47}$ Lipman, C. B. $(1909,1912)$.

${ }^{48}$ Loeb, J. $(1911, A ; 1912, B ; 1916, D)$.

${ }^{40}$ The cell walls not only soften, but eventually go partly into solution. Cf. Hansteen-Cranner, B. (1910, 1914); Lillie, R. S. (1221). 
viscosity) while in $\mathrm{CaCl}_{2}$ we should expect to find increased resistance (due to increased viscosity) followed by a fall of resistance (due to coagulation or other structural change in the protoplasm).

It soon became apparent that there were several serious objections to this conception. The most important of these may be briefly stated as follows: ${ }^{50}$

1. If to a solution of $\mathrm{NaCl}$ we add $\mathrm{CaCl}_{2}$ until the increase of viscosity produced by one salt is just balanced by the decrease produced by the other, the resistance should remain stationary. This is not the case: there is always a fall, or a rise followed by a fall, of resistance.

2. If more $\mathrm{CaCl}_{2}$ be added there should be a rise of resistance: this should after a while become stationary, provided there is not enough $\mathrm{CaCl}_{2}$ to produce the coagulation or other structural change which decreases the resistance. This does not occur: the tissue never maintains its increased resistance, but shows a fall of resistance which begins soon after the maximum is reached.

3. If still more $\mathrm{CaCl}_{2}$ be added, so as to produce the coagulation or other structural change which decreases resistance, we should expect to find in all cases the same viscosity (and consequently the same maximum of resistance) just before the fall begins. Still further increase of $\mathrm{CaCl}_{2}$ would only hasten this process without changing the maximum. This does not correspond with the facts. The maximum steadily rises as the proportion of $\mathrm{CaCl}_{2}$ increases, so that the greatest maximum is found in pure $\mathrm{CaCl}_{2}$.

4. If the fall of resistance in $\mathrm{CaCl}_{2}$ is due to coagulation, or to some other structural change, it might be expected to be irreversible almost from the start; but this

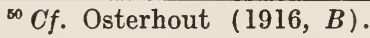


is not the case. Only when it has proceeded a good way toward the death point, does it become irreversible. On the other hand, the fall in $\mathrm{NaCl}$ (due to liquefaction) might be expected to be reversible at every stage. But it ceases to be wholly reversible after it has proceeded one sixth of the way (or less) to the death point.

5 . Since the changes in viscosity occur in dead as well as in living tissue we should expect to find in both cases similar changes in resistance. It is found that in tissue which has been killed in such a manner as not to alter the properties of the cell wall, the decrease in viscosity in $\mathrm{NaCl}$ produces no appreciable effect on resistance. Even when the process goes so far that the tissue is reduced to a very soft jelly, there is little or no change in resistance. ${ }^{51}$ The hardening in $\mathrm{CaCl}_{2}$ produces some rise in resistance, but it is much too small to account for the great changes which occur in living tissue.

It might be supposed that the reason that no change in resistance occurs in dead tissue is because the hardening and softening do not proceed as far as in living plants, but this is not the case. Moreover, it is found that the decrease of viscosity in $\mathrm{NaCl}$ is accompanied by absorption of water, while the increase of viscosity in $\mathrm{CaCl}_{2}$ is accompanied by loss of water, and these processes take place in the same way in living and dead tissue.

It would seem that these and other important objections must be removed before we can accept the idea that changes in permeability are determined by changes in viscosity. ${ }^{52}$

These objections apply to the theory advanced by

${ }^{61}$ In a liquid a change of viscosity alters the resistance, but this is not necessarily the case in a gel. Where a gelatin gel is converted to a sol, the change in resistance is very slight.

${ }^{82}$ It would appear that the term viscosity is loosely applied to a variety of phenomena which may be produced in different ways. 
Spaeth (1916) to account for variations in permeability under the influence of salts.

The great variations in the electrical resistance produced in living protoplasm by the action of salts seem to the writer to depend on the fact that living protoplasm is in a state of dynamic equilibrium so that the material of which it is composed is constantly changing. This constant change is due to a succession of chemical processes which may be easily influenced so as to produce great changes in electrical resistance which appear to become irreversible if carried beyond a certain point. ${ }^{53}$

In dead protoplasm, as in gelatin, such processes do not occur, or at least they go on much more slowly. As a result we cannot expect such great variations in electrical conductivity. If we wish to imitate these it would seem advisable to work with systems, which, like living protoplasm, are in dynamic equilibrium.

Clowes (1918), states that he has prepared emulsions of oil in soap, which change their electrical resistance under the influence of $\mathrm{NaCl}$ and $\mathrm{CaCl}_{2}$, in a manner similar to that observed in Laminaria. It remains to be seen whether this parallel extends to the effect of other substances.

The writer obtained similar results some years ago, ${ }^{54}$ with the shells of the Horse Chestnut (Aesculus) which had been killed by boiling or by soaking for 24 hours in $5 \%$ formaldehyde. He was not able to convince himself, however, that the factors involved here are the same as in living protoplasm.

${ }^{53}$ This apparent reversibility finds a ready explanation on the theory of successive reactions. See page 121.

s $A$ brief account of these was given at the Boston meeting of the American Physiological Society, in 1915. 
The writer has experimented with a great variety of materials in order to determine whether it is possible to imitate by means of non-living materials, the change in permeability found in living cells. In some cases membranes have been found which show an increase of conductivity when transferred from sea water to $\mathrm{NaCl}$ and a decrease when transferred from sea water to $\mathrm{CaCl}_{2}$ or $\mathrm{LaCl}_{3}{ }^{55} \mathrm{But}$ in no case was the alteration great enough, nor produced by a sufficient variety of substances, to justify the author in concluding that the effects were really the same as those found in living material. The relatively small changes found in dead material, in so far as they are due to the cell walls (or intercellular substance), must in the living conditions be superimposed on the changes due to the activities of the protoplasm.

Until we succeed in finding a membrane (or other static system) which imitates qualitatively and quantitatively the permeability of the living protoplasm, the author is inclined to regard a dynamic equilibrium as essential.

${ }^{55}$ The solutions of $\mathrm{NaCl}, \mathrm{CaCl}_{2}$ and $\mathrm{LaCl}_{3}$ had the same conductivity as sea water. When transferring from sea water to another solution a temporary rise or fall may occur which is due to diffusion. See page 28. 


\section{CHAPTER V.}

\section{ANESTHESIA.}

In order to ascertain the effect of anesthetics on conductivity, experiments were performed with ether, ${ }^{1}$ chloroform, chloral hydrate and alcohol. ${ }^{2}$ Subsequently alkaloids were employed. ${ }^{3}$

The method may be illustrated by the following experiment with ether. Tissue was transferred from sea water to a mixture consisting of 990 c.c. sea water +10 c.c. ether +5 c.c. sea water which had been concentrated by evaporation until its conductivity was about double that of ordinary sea water. This mixture contained approximately $1 \%$ by volume of ether $(=.099 M)$ and had the conductivity of sea water. In 10 minutes the resistance had risen to $113.4 \%,{ }^{4}$ but, in 10 minutes more it had fallen to $109.4 \%$. It continued to fall until it had reached $98.8 \%$, after which it fell very slowly (at about the same rate as the control). The fact that it fell below the starting point is not necessarily to be attributed to any injury, but rather to the fact that the exaporation of the ether increases the conductivity of the sea water, which is contained in the apparatus, and in the cell walls between the protoplasmic masses. The results of the experiment are shown in Fig. 80.

In order to see how the evaporation of the ether

${ }^{1}$ Since ether, chloroform, and alcohol deteriorate on standing, especially when in contact with metal or with cork stoppers, special care must be taken to obtain pure reagents. Those used were Kahlbaum's or Squibb's. Cf. Baskerville (1913).

${ }^{2}$ Cf. Osterhout (1913, A; 1916, A).

${ }^{3}$ Cf. Osterhout $(1919, D)$.

* All readings were made at $18^{\circ} \mathrm{C}$. or corrected to this temperature. 
from the solution influenced the result, another experiment was performed in which the solution was renewed every 5 minutes during the first 60 minutes, and thereafter every 15 minutes. In this way the concentration of ether was kept more nearly constant. It was then found that the resistance rose as before, but did not fall during

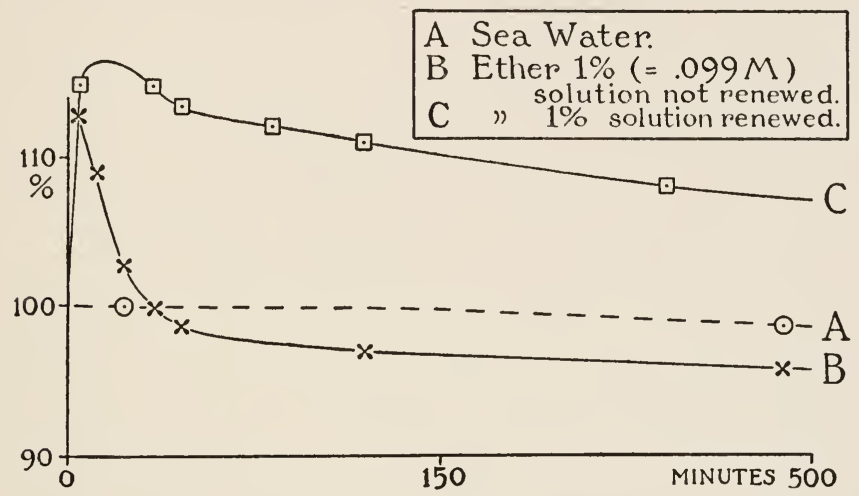

FIG. 80.-Curve $A$ shows the net electrical resistance of Laminaria agardhii in sea water; $B$ in sea water containing $1 \%$ ether by volume $(.099 M)$ from which the ether was allowed to evaporate in an open dish; $C$ in the same mixture in which the concentration of ether was maintained by frequent renewal.

the first 80 minutes, and after this fell very slowly, so that after 300 minutes it was still 80 ohms above that of the control. At this point, the experiment was discontinued. The results are shown in Fig. 80.

In order to see whether the effect of the anesthetic could be quickly reversed, some tissue was kept in sea water containing $0.099 M$ ether for 50 minutes (the solution being renewed every 5 minutes). During this time the resistance rose to $113.7 \%$. It was then placed in sea water. At the end of 10 minutes the resistance had fallen to $100 \%$. It was then left in sea water containing $0.099 M$ ether (the solution being renewed every 15 minutes). The resistance promptly rose to $113.7 \%$, and 
remained there for an hour; 240 minutes later, when the experiment was discontinued, the resistance was $111.4 \%$. The results are shown in Fig. 81.

The effect of higher concentrations of ether was next investigated. Tissue was placed in a mixture of 970 c.c. sea water +30 c.c. ether +15 c.c. of concentrater sea

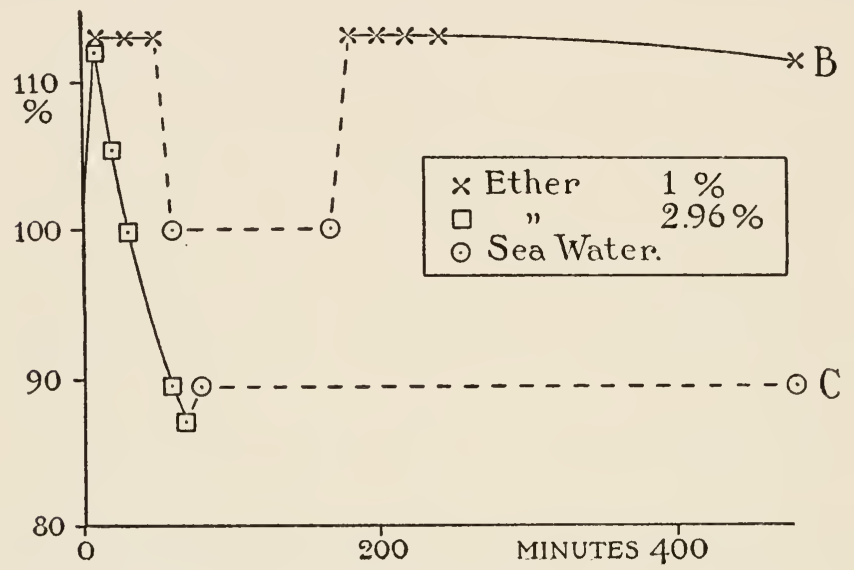

FIg. 81.-Curve $A$ shows the net electrical resistance of Laminaria agardhii in sea water, Curve $B$, unbroken line, in sea water containing $1 \%$ ether $(.099 M)$, the solution being frequently renewed, broken line in sea water; Curve $C$, unbroken line in sea water containing $2.96 \%$ ether $(0.293 \dot{M})$, broken line, in sea water.

water, which was added to make the conductivity of the mixture equal to that of sea water. The concentration of the ether was therefore $2.96 \%$ by volume $(=0.293 M)$. In the course of 10 minutes the resistance rose to $112 \%$; during the next 10 minutes it fell to $105.3 \%$; it continued to fall rapidly during the next 40 minutes, reaching $89.5 \%$ at the end of this period. The tissue was then placed in sea water; in the next 10 minutes, the resistance fell to $87 \%$. This fall in resistance was doubtless due to the continued action of the ether, which required time to diffuse out of the tissue. During the next 10 minutes, there was a rise 
of $2.5 \%$, which was probably due, either wholly or in part, to the fact that the resistance of the sea water was greater than that of the mixture from which the ether had partly evaporated. During the next 400 minutes no rise occurred. The results are shown in Fig. 81.

This outcome is very significant, for it shows that the increase of permeability produced by ether is not reversible, while, as we have seen, the decrease of permeability is easily reversed. Since the essential characteristic of an anesthetic is the reversibility of its action, we must conclude that anesthesia is associated with the reversible decrease of permeability and not with the irreversible increase of permeability.

In view of the importance of this result the experiment was repeated many times, the fall of resistance (before placing in sea water) varying from 6 to $25 \%$, but always with practically the same result. On placing in sea water there were sometimes irregular fluctuations (amounting to $5 \%$ or less) but no recovery.

This result is the more striking inasmuch as material of which the resistance has fallen as much as 5 to $10 \%$ in $\mathrm{NaCl}$ recovers completely when placed in sea water, and may even undergo this treatment daily for several days in succession without injury. ${ }^{5}$

The fall of resistance below the normal may be taken as a measure of the toxicity. The toxicity increases with the concentration, and it should be noted that it is greatly decreased if the material is allowed to stand in an open dish, owing to the evaporation of the ether. If the material be placed in a closed jar, oxygen must be supplied. The other alternative, frequent renewal of the solution, is usually preferable.

${ }^{5}$ See page 82. 
A series of investigations on chloroform gave similar results, the chief difference being that chloroform is much more toxic, and that the concentration necessary for long continued decrease of permeability is much lower, being about $0.05 \%$ by volume (or $0.064 M$ ). This is evident from Fig. 82, which shows the results of an experiment with a mixture containing 999.5 cc. sea water +0.5 c.c. chloroform +0.25 c.c. concentrated sea water (this mixture had the same conductivity as sea water). In this experiment the solution was renewed every 5 minutes during the first 80 minutes, and every 15 minutes thereafter.

If we increase the concentration of chloroform to $0.1 \%$ by volume $(=0.0128 \mathrm{M})$, the result is quite similar to that obtained with $0.293 M$ ether. This is shown in Fig. 82, which gives the results of an experiment containing 999 c.c. sea water +1 c.c. chlor of orm +0.5 c.c. concentrated sea water (this mixture had the conductivity of sea water). ${ }^{6}$ The solution was renewed every 5 minutes during the first 80 minutes, after which it was kept in sea water. There is no indication of recovery after the tissue is replaced in sea water.

Experiments with chloral hydrate gave results very similar to those obtained with chloroform, the corresponding effects being produced in both cases by approximately the same percentage concentrations, ${ }^{7}$ that is, chloral hydrate $0.1 \%(=0.006 M)$ acts similarly to chloroform $0.1 \%$ by volume $(=0.0128 M)$.

- Stiles and Jörgensen (1914) report a decrease of resistance as the result of exposure to chloroform. See also Waller, A. D. (1919).

${ }^{7}$ No effort was made to find the exact percentages which are required to produce given effects, as this was not the primary object of the investigation. The actual concentration of chloral hydrate may have been somewhat lower than those given, owing to the presence of water in the chloral hydrate. 
The experiments with alcohol lead to somewhat different results. In the first place, alcohol is not so toxic as ether, chloroform, or chloral hydrate, and higher concentrations must be used to produce the same effects on permeability. In sea water containing alcohol $0.051 M$, or $2.955 \%$ by volume, (the solution being renewed every

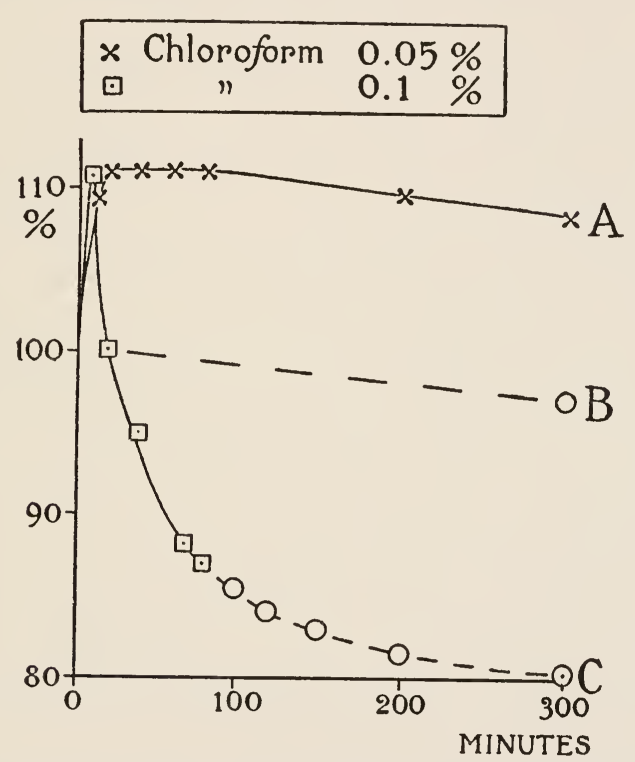

Fra. 82.-Curve B shows the net electrical resistance of Laminaria agardhii in sea water; Curve $A$ in sea water containing $0.05 \%$ chloroform, Curve $C$ placed for 80 minutes in sea water containing $0.1 \%$ of chloroform and then put back into sea water.

15 minutes) the results were much the same as in $0.099 \mathrm{M}$ ether (the solution being renewed every 5 minutes), except that the rise in resistance took place more slowly, sometimes occupying 30 minutes or more. It was found that $0.2385 M$, or $13.875 \%$ by volume, is decidedly toxic.

An interesting feature of the results with alcohol is that the increase of permeability is reversible. If the increase be carried too far it is not reversible (or at 
least recovery is incomplete); in the first experiments this condition was unintentionally realized and led the writer to suppose that alcohol behaves like ether. The course of a typical experiment is shown in Fig. 83. The tissue was first placed in a mixture containing 970 c.c. sea water +30 c.c. Squibb's absolute alcohol + about 15

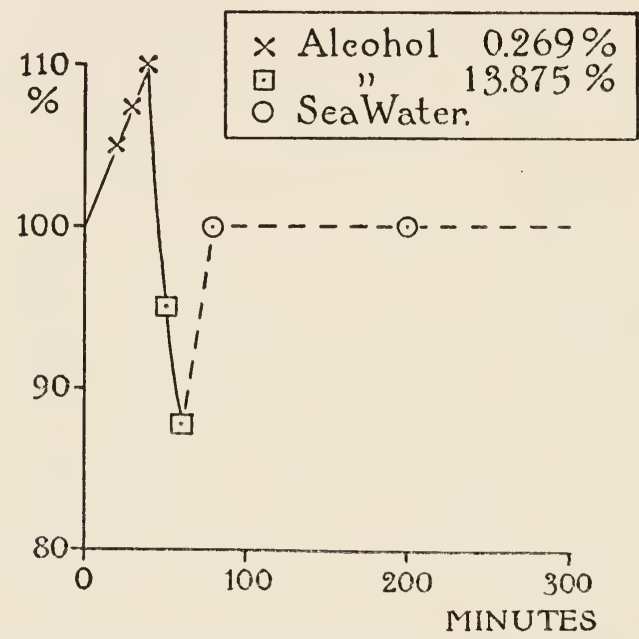

Fia. 83.-Curves showing the net electrical resistance of Laminaria agardhii placed for 40 minutes in ses water containing $0.269 \%$ ethyl alcohol, then in $13.875 \%$ for 20 minutes and then put back into sea water.

c.c. of concentrated sea water. The mixture had the conductivity of sea water; the concentration of the alcohol was $0.051 M(2.96 \%$ by volume $)$. The net resistance rose to $110 \%$ in the course of 40 minutes. The tissue was then placed in sea water containing $0.2385 M$ alcohol ( $13.875 \%$ by volume); and in the course of 20 minutes the resistance fell to $87.6 \%$. The tissue was then placed in sea water and the resistance again rose to $100 \%$.

The facts that recovery occurs in alcohol, and that irregular fluctuations are often observed in experiments on recovery from ether, suggest that the difference 
between the behavior of alcohol and the other anesthetics investigated may be only one of degree. It is probable that there is some recovery in ether, chloroform, and chloral hydrate, but that it is so slight and so transitory as to be difficult to detect.

It is evident that suitable concentrations of anesthetics produce a marked decrease of permeability. ${ }^{8}$ This condition may be maintained for a long time if the concentration is not too high; with higher concentrations the period is shortened and may become so short as to be observed with difficulty. This decrease of permeability can be easily and quickly reversed by replacing the tissue in sea water. It does not seem to produce any injury if the concentration is not too high. The relative concentrations necessary to produce this result, correspond closely with those required to produce anesthesia, being least for chloral hydrate and greatest for alcohol.

On the other hand, the increase of permeability, (except in the case of alcohol, within certain limits) produces permanent injury and is not reversible. It cannot be regarded, therefore, as the characteristic effect of the anesthetic. The characteristic effect must be regarded as in some way connected with decrease of permeability. ${ }^{9}$

$s$ The amount depends somewhat on the condition of the material. Material in poor condition generally shows less rise in resistance than good material.

- Winterstein (1916) says that these experiments are not convincing because the anesthetic may act on the interior of the cell rather than on the surface of the protoplasm. This objection can hardly apply, since the interior of the cell is filled with cell sap: this is surrounded by a thin layer of protoplasm (see page 197). If the anesthetic decreased the conductivity of the cell sap to any marked degree, this effect would be observed in the material immediately after death: this, however, is not the case; if any rise in resistance occurs in dead tissue it is much less than in living tissue. Loewe, (1913) states that anesthetics decrease the conductivity of artificial lipoid membranes. See also Moore and Roaf (1905). 
It is easy to see how a decrease of permeability to ions must hinder the production and the transmission of stimuli in so far as these are dependent on the movement of ions in the tissues, and there is abundant evidence that stimulation is always accompanied by such movements of ions in the protoplasm. It seems clear, therefore, that a decrease of permeability may result in the decrease of irritability, which is the characteristic effect of an anesthetic. ${ }^{10}$

These investigations are of interest in view of the fact that a number of writers hold the view that anesthetics increase permeability, while others believe that anesthetics bring about a decrease of permeability. ${ }^{11}$ It appeared desirable to clear up this uncertainty as a necessary step toward a satisfactory theory of anesthesia.

In order to see whether these facts are generally true, the scope of the investigation was widened to include a variety of material. Similar results were obtained in experiments on frog skin, ${ }^{12}$ but the effect was much more striking. The increase of resistance was greater and occurred with lower concentrations. ${ }^{13}$ With respect to recovery, the same difference was found between alcohol, on the one hand, and ether, chloroform, and chloral hydrate on the other.

${ }^{10}$ It might be expected on this basis that substances which decrease permeability, such as $\mathrm{Ca}$, La, etc. would act as anesthetics. To what extent this is the case must be decided by future investigation.

${ }^{11}$ Cf. Höber (1914) pp. 466, 597; Lillie (1912, A, B; 1913, A, B; 1916, 1918); Lepeschkin (1911); Ruhland (1912, $A)$; Katz (1918), Weinstein (1916).

${ }^{12}$ For technique see page 33.

${ }^{13} C f$. Osterhout $(1919, C)$. 
Experiments were also made $\mathrm{e}^{14}$ to determine the effects of ether on a variety of plants. An increase of resistance (followed by a decrease) was observed in Laminaria and Ulva. In Rhodymenia ether $(2.5,3,5$ and $5.5 \%$ by volume), and alcohol (1,3.5, 7, 8\% by volume) added to sea water produced little or no rise. This is not surprising in view of the fact that these substances always produce less rise in Laminaria than does $\mathrm{Ca}$ and that even $\mathrm{Ca}$ produces very little rise in Rhodymenia. In respect to recovery from the injury caused by these substances, Rhodymenia agrees with Laminaria in that recovery is practically complete in alcohol (if the fall in resistance has not gone too far), but is almost entirely absent in ether and chloroform.

While the writer has found no records of similar experiments made by other investigators, it may be desirable to refer briefly to the work of Joel on the conductivity of red blood corpuscles. When red blood corpuscles are repeatedly washed in an isotonic solution of cane sugar and allowed to stand in this solution the conductivity of the suspension gradually increases. This is due in part to the exosmosis of electrolytes (which increases the conductivity of the solution) and probably in part to the fact that the permeability of the corpuscles to ions increases. The experiments of Joel, ${ }^{15}$ show that this increase in conductivity can be hindered by the addition of "indifferent" narcotics (at certain concentrations).

In order to determine whether alkaloids decrease the

${ }^{14}$ Cf. Osterhout $(1919, A)$.

15 Joel, A. (1915). 
conductivity of Laminaria, experiments were made by adding small amounts of nicotine, caffeine and cevadine sulfate to sea water (and then making the solution the same conductivity as sea water). The experiment was not successful in the case of nicotine, owing to the formation of a visible precipitate, which was apparently due to the presence of calcium and magnesium in the sea water. In the case of caffeine $(0.01$ to $0.04 M)$ and of cevadine sulfate $^{16}(0.0006$ to $0.0025 M)$ a distinct decrease in permeability was found / as shown by the rise in resistance); this was followed by an increase.

${ }^{16}$ This is regarded as two molecules of cevadine united to one molecule of $\mathrm{H}_{2} \mathrm{SO}_{4}$. It was purchased from Merck under the name of veratrine sulfate $\left(\mathrm{C}_{22} \mathrm{H}_{40} \mathrm{NO}_{0}\right)_{2} \cdot \mathrm{H}_{2} \mathrm{SO}_{4}$. 


\section{CHAPTER VI.}

\section{CONDUCTIVITY AND PERMEABILITY}

It is well known that death is accompanied by an increase of permeability. Thus a slice of red beet kept in water will live for a long time without giving off pigment, but as soon as it is killed the color begins to escape from the cells. In this case the coloring matter is dissolved in the large central vacuole which fills the interior of the cell. In order to escape, it must pass out through the layer of protoplasm which surrounds the vacuole. As long as the protoplasm remains in its normal condition it is impermeable to the dissolved pigment, but as soon as death occurs it become freely permeable and the color escapes.

We meet the same condition if we study the penetration of substances from without. It is a matter of common observation that cells may resist the penetration of certain dyes as long as they 'are alive, but absorb them readily as soon as they are killed.

The increase in permeability which accompanies death is paralleled in a striking manner by a simultaneous increase in electrical conductivity. ${ }^{1}$ This suggests that

${ }^{1}$ An apparent exception to this statement is found in two articles by Galeotti $(1901,1903)$ who states that death produces an increase in the electrical resistance of muscle, kidney, etc., followed by a decrease. He suggests that the increase is due to the fixation of electrolytes by the tissues. In Galeotti's experiments the tissues were not immersed in solutions and in consequence the electrodes had to be applied directly to the surfaces of the tissue. It is possible that his results were due in part to faulty technique (bubbles of gas readily form in dying tissue, increasing the resistance). The matter requires further investigation.

Kodis (1901) whose technique seems to be decidedly preferable to that of Galeotti, (see page 21) found that dead frog muscle had less electrical resistance than living. The writer has confirmed this, using the method employed by Kodis. 
the two phenomena may be closely connected. If this is the case it may be possible to use electrical conductivity as a measure of permeability.

Let us consider this from the standpoint of the permeability of protoplasm to salts.

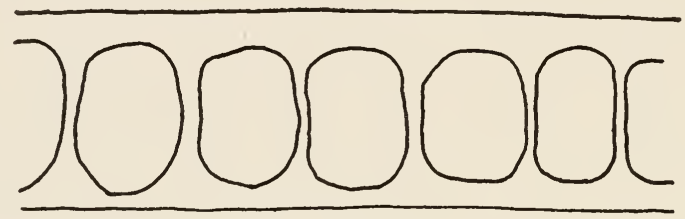

Frg. 84.-Cross section of Monostroma latissima (X 450).

When an electrical current passes from a salt solution into a living cell, ions must enter the protoplasm. ${ }^{2}$ An increase in the permeability of the protoplasm to ions

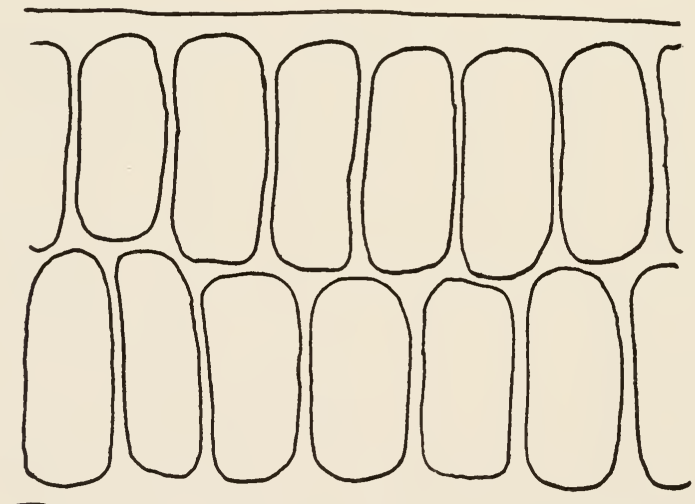

FIG. 85.-Cross section of Ulva lactuca, var. latissima (sea lettuce). (X 450).

must decrease its electrical resistance, and vice versa. The electrical resistance of the protoplasm may therefore be regarded as a measure of its permeability to ions.

'In this connection it should be noted that experiments have been made with direct currents. Cf. Stiles and Jörgensen (1914). 
If we attempt to measure the electrical resistance of the protoplasm we must first consider the structure of the tissue.

Very useful for experiments on tissues are plants which form membranes consisting of a single (Fig. 84) or a double layer (Fig. 85) of cells. In measuring the conductivity of these plants we obtain much the same results as with the more complex tissues of Rhodymenia (Fig. 86) and Laminaria (Fig. 87). We

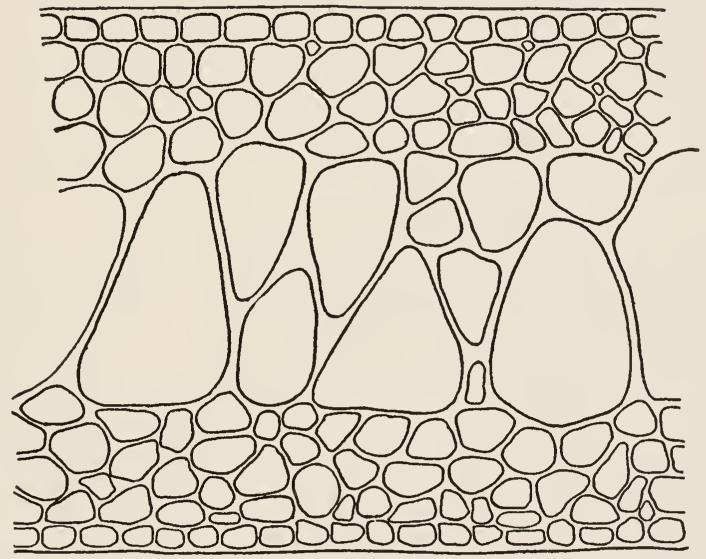

FIG. 86.-Cross section of Rhodymenia palmata (dulse). (X 150).

may therefore conclude that the complexity of structure is not a factor of importance in the interpretation of the results. As a matter of fact in the case of Laminaria the resistance appears to be due chiefly to the rounded cells lying at and below the surface, while the elongated cells which occupy the center of frond have large spaces between them through which the current can easily pass.

If we consider the structure of the individual cells, we find that in Laminaria (as in the other plants employed in the experiments of the writer) the protoplasm of 
each cell forms a thin layer, which surrounds a large central vacuole filled with cell sap. When tissue (either with or without previous treatment with liquid air) is ground with powdered quartz (so as to open the cells) and a little sea water is added, and the juice is subsequently expressed, it is found to have a little higher conductivity than sea water. Since this expressed juice consists to a

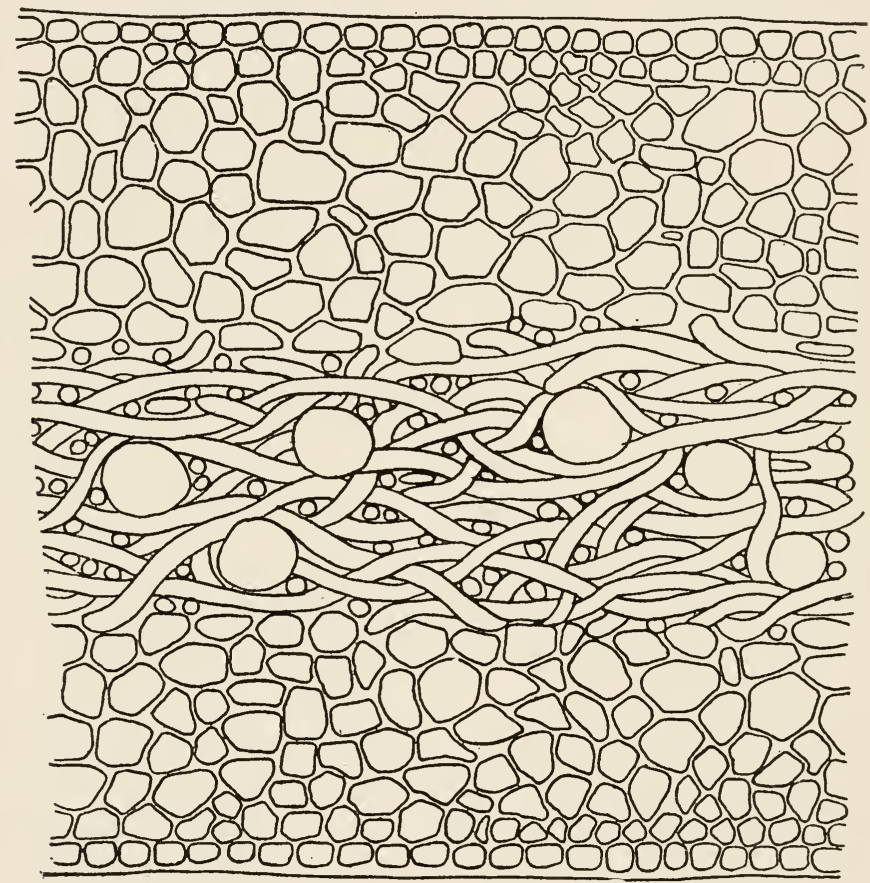

FIo. 87.-Cross section of Laminaria agardhii. (X 150).

considerable extent of cell sap we may conclude that the conductivity of the sap does not differ very much from that of sea water. The fact that the conductivity is higher, may be due in part to evaporation during the manipulation. When the juice is obtained by merely 
heating the plants to $100^{\circ} \mathrm{C}$ in a tightly stoppered bottle (without addition of sea water) the conductivity equals that of sea water.

This is confirmed by some observations on Valonia. This marine alga forms a large, multinucleate cell consisting of a cell wall, within which is a delicate layer of protoplasm, forming a sac which encloses a very large central vauole. By drying the exterior and pricking the cell, the sap can be made to spurt out and may then be collected for examination. It was found by Wodehouse (1917) that the sap of uninjured cells gives little or no test for $\mathrm{SO}_{4}$ : the contents of each cell were accordingly tested by this method by Dr. Crozier, who kindly collected the sap for these experiments, and rejected those which contained more than a minimum amount of $\mathrm{SO}_{4}$. Determinations of the electrical conductivity of the sap, by the writer, showed that it was not much higher (in no case more than $20 \%$ ) than that of the surrounding sea water.

Since the cell sap of Laminaria has about the same electrical resistance as the solution which bathes the cell, it is evident that if the electrical resistance of the cell increases when it is transferred from sea water to another solution of the same conductivity, the change must be due to an increase in the resistance of the thin layer of protoplasm which bounds the cell. This has led the writer to assume that the resistance is proportional to a substance, $M$, at the surface of the cell; if $M$ forms a layer at the surface, it is obvious that an increase in the thickness of this layer will increase the resistance, and vice versa. It is therefore assumed that the resistance depends upon the amount of $M$ which is present in the surface. ${ }^{3}$

${ }^{3}$ See page 57 . 
Since the protoplasmic masses (cells) are separated from each other by thin layers of substance (cell wall) a part of the current goes through the protoplasm and another part passes between the protoplasmic masses, in the substance of the cell wall. ${ }^{*}$ Consequently when we employ the electrical method we must ascertain whether we are investigating the permeability of the protoplasm or merely that of the cell wall.

Obviously the best method of attacking this problem is to kill the tissue by such means (e.g., partial drying, heating to $35^{\circ} \mathrm{C}$., weak alcohol, etc.) as cannot alter the cell wall, and then investigate its behavior under the influence of various reagents. We find that all of these methods produce the same result. After death the tissue no longer shows the changes in resistance which are observed when living tissue is subjected to the influence of reagents. It is therefore evident that the changes are due to the living protoplasm.

The cell wall appears in all cases to have practically the same conductivity as the surrounding solution. If we subject living tissue to solutions of the same conductivity, but of different chemical composition, the resistance of the cell wall remains unaltered, while that of the protoplasm undergoes great variations. If, for example, living tissue is placed in a solution of $\mathrm{NaCl}$ or $\mathrm{CaCl}_{2}$ (of the same conductivity as sea water) its behavior differs. In $\mathrm{NaCl}$ the resistance falls; in $\mathrm{CaCl}_{2}$, it rapidly rises and later falls to a minimum. We infer that the permeability

${ }^{4}$ As previously explained ( $C f$. Osterhout, 1918, $C$ ), a part of the current must pass through the protoplasm; this is shown by the fact that $\mathrm{CaCl}_{2}$ (which has little effect on the resistance of the cell wall) raises the resistance of the tissue and that the temperature coefficient of electrical conductivity is not the same for dead as for living tissue. 
of the protoplasm increases in $\mathrm{NaCl}$; and that in $\mathrm{CaCl}_{2}$ there is a decrease followed by an increase.

This is in complete agreement with results obtained when permeability is measured by such methods as plasmolysis, specific gravity, tissue tension, exosmosis, diffusion through living tissue and direct determination of penetrating substances.
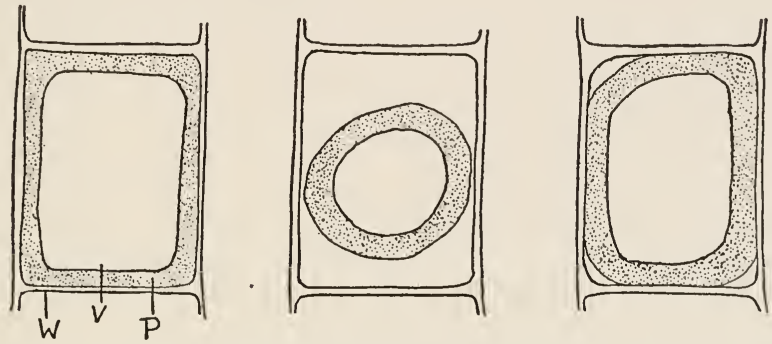

Fig. 88.-A vegetable cell showing plasmolysis. At left, normal; in the center, plasmolyzed; at the right, nearly recovered.

In order to show the bearing of these measurements on the problem, the methods employed will be briefly described.

The measurement of osmotic pressure by means of plasmolysis depends upon the fact that when the osmotic pressure within a cell is greater than that of the surrounding solution, water is absorbed. In the case of plant cells, there is usually a central vacuole, the contents of which exert pressure against the protoplasmic sac which surrounds the vacuole: in consequence the protoplasmic sac is pressed against the cell wall. If, however, the osmotic pressure of the external solution exceeds that of the vacuole, water is withdrawn from the cell and the protoplasmic sac contracts. This contraction is called plasmolysis (Fig. 88). At the moment when contraction begins, the osmotic pressure of the solution within the cell is regarded as slightly less than that of the external 
solution. We therefore obtain in this manner an approximate measure of the osmotic pressure of the cell. ${ }^{5}$

Strictly speaking, plasmolysis measures the osmotic pressure within the cell without telling us anything regarding the penetration of substances into the protoplasm. We may, nevertheless, learn something about permeability by this method. When, for example, we find that a substance (such as alcohol) fails to produce as much plasmolysis as is expected, we infer that this substance penetrates the cell so rapidly, as to partially offset its own osmotic effect. Let us suppose that the osmotic pressure within the cell is 10 atmospheres. On placing the cell in a solution of alcohol, whose osmotic pressure is 11 atmospheres, plasmolysis might be expected to occur, but if there is an immediate penetration of alcohol, which raises the osmotic pressure within the cell to 11 atmospheres, no plasmolysis will take place.

On placing the cell in a solution of alcohol strong enough to cause plasmolysis we should expect the alcohol to penetrate until the osmotic pressure of alcohol is the same inside and outside of the cell. When this has occurred, the osmotic pressure in the cell will be equal to

- There are a number of disturbing factors which interfere with such measurements. Among these may be mentioned:

1. The plasmolyzing agent may have a toxic action and may alter the permeability of the cell.

2. Plasmolysis may produce mechanical injury due to the tearing of the outer layer of protoplasm.

3. Exosmosis of dissolved substances may occur during exposure to the reagent.

4. The time necessary to produce plasmolysis is an important factor which is frequently overlooked.

5. The shrinkage of the protoplasm away from the cell wall is preceded by a diminution of volume of the entire cell. In some cases, where the cellulose wall is considerably stretched by the internal osmotic pressure, this may be of considerable importance. 
the original osmotic pressure, plus the increased pressure due to the withdrawal of water (thus increasing the concentration) plus the osmotic pressure due to the penetration of alcohol. The total osmotic pressure will therefore be greater than that of the external solution and water will accordingly be absorbed by the cell. The result will be that the plasmolyzed cell will recover, and return to its original expanded condition. ${ }^{6}$ The time required for recovery is usually regarded as approximately proportional to the rate of penetration of the alcohol.

In this way we may obtain a rough measure of permeability.

This method was employed by Overton (1895) in the well-known studies on permeability which gave rise to the lipoid theory. He came to the conclusion that there is rapid penetration of alcohol, and of many other organic substances, but that inorganic salts do not penetrate. He attributed this to their insolubility in the lipoid layer, by which he supposed the cell to be surrounded. The writer repeated his experiments with salts, and came to the opposite conclusion. ${ }^{7}$ It was found in experiments with salts of $\mathrm{NH}_{4}, \mathrm{Cs}, \mathrm{Rb}, \mathrm{Na}, \mathrm{K}, \mathrm{Li}, \mathrm{Mg}, \mathrm{Ca}, \mathrm{Sr}$ and $\mathrm{Al}$, that the protoplast which is plasmolyzed and left in the solution expands again to its normal size, showing that all these salts penetrate the protoplasm.

The following experiment will serve to illustrate the procedure. Filaments of Spirogyra were placed in $0.4 M$ $\mathrm{NaCl}$ solution. Within two minutes the protoplasts of the cells were so far plasmolyzed that they no longer touched the end walls of the cells. Several of these were

- Since the effect of the alcohol outside the cell is exactly balanced by that within the cell the final effect is the same as that of placing the cell in pure water.

${ }^{7}$ Cf. Osterhout (1911). 
accurately sketched with the camera lucida and kept under continuous observation. In the course of ten minutes, several of them had begun to expand and in thirty minutes all had expanded so as to completely fill their respective cells. To avoid the injurious action of the salt, the filaments were then transferred to $0.18 \mathrm{M} \mathrm{CaCl}_{2}$ solution, and this was gradually diluted until its osmotic pressure was not greater than that of tap water. The cells were then transferred to tap water. They were examined the next day and found to be alive. On being placed in $0.4 \mathrm{M} \mathrm{NaCl}$, they were plasmolyzed and they afterward expanded as before.

Certain facts may be worthy of mention which tend to obscure these results and which may have caused them to be overlooked.

In the experiment just described, the cells were transferred to a favorable solution as soon as expansion was complete. If this precaution be neglected and the cells be allowed to remain in the solution of $\mathrm{NaCl}$, the injurious action of the salt soon causes the protoplast to shrink. In salts which are more toxic than $\mathrm{NaCl}$, this contraction may be more rapid and more pronounced. This shrinkage, which may be called false plasmolysis, ${ }^{8}$ may also be produced by very weak (hypotonic) solutions and has nothing to do with plasmolysis, but may simulate it in very misleading fashion. If the cells are not continuously observed, but only examined at intervals, the expansion of the protoplast may easily be overlooked, and the subsequent shrinkage may be easily mistaken for plasmolysis. It is therefore desirable to keep the same individual cell under observation during the entire course of the experiment.

${ }^{8}$ Cf. Osterhout (1908, 1913, C). 
It was found that recovery from plasmolysis is much slower in $\mathrm{CaCl}_{2}$ than in $\mathrm{NaCl}$, indicating that the latter penetrates more readily. This is in harmony with the results of measuring electrical conductivity.

Other experiments indicate that the penetration of $\mathrm{NaCl}$ is more rapid in a solution of pure $\mathrm{NaCl}$ than it is in a mixture containing $\mathrm{NaCl}$ plus $\mathrm{CaCl}_{2}$, in such proportions as to make a balanced solution. This is also in agreement with the results of measurements on electrical conductivity.

Another method of measuring permeability was used by Loeb, ${ }^{9}$ who has shown that eggs of Fundulus will float for a time in $\mathrm{NaCl} 3 M$, but not, as a rule longer than 3 hours. "Before sinking they lose water, as is indicated by the collapse of the membrane and the shrinkage of the yolk sac. Probably some $\mathrm{NaCl}$ enters the egg." In $\mathrm{CaCl}_{2}$ $1.25 M$, they sink in about half an hour. If, however, they are placed in a mixture of $50 \mathrm{cc}$. $\mathrm{NaCl} 3 M+2$ cc. $\mathrm{CaCl}_{2}$ 1.25 $M$ they float for three days or longer. Loeb interprets this as showing that the membrane of the Fundulus egg is practically impermeable to water and to salts in a physiologically balanced solution. But when transferred to a hypertonic non-balanced solution the natural impermeability of the membrane is gradually lost, so that water diffuses out of the egg and its specific gravity is increased to such an extent that it sinks. This action, and likewise the entrance of $\mathrm{NaCl}$ into the egg, is prevented by the addition of small amounts of $\mathrm{CaCl}_{2}$.

A very interesting series of experiments was made by S. C. Brooks, using the following methods: (1) diffusion through living tissue, (2) exosmosis, (3) change of curvature of strips of tissue.

${ }^{\circ}$ Loeb $(1912, C, D)$. 
In the first of these methods ${ }^{10}$ different solutions were placed on opposite sides of a piece of tissue. The apparatus used is shown in Fig. 89. The diffusion of salts through the tissue was then measured. In the first

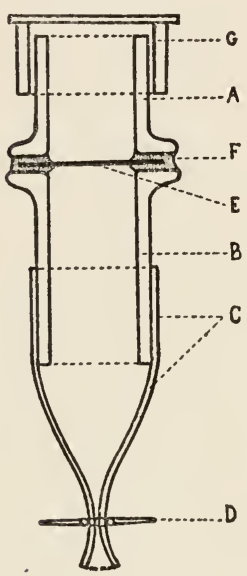

Fig. 89.-Apparatus for testing the rate of diffusion of salts through living tissue. It consists of two glass cells $A$ and $B$ (the former is provided with a cover, $G$ ) separated by a layer of living tissue of Laminaria, $E$. which is sealed to the glass cells by a mixture of vaseline and beeswax, $F$. The lower cell is provided with a piece of rubber tubing, $C$, and a pinch cock, $D$.

experiments, a solution of $\mathrm{NaCl} 0.52 M$ was placed on one side, $\mathrm{NaCl} 0.26 M$ was placed on the other: $\mathrm{CaCl}_{2} 0.28 \mathrm{M}$ and $0.14 M$, as well as sea water and sea water diluted with one volume of distilled water were employed in the same way. As the stronger solution diffused into the weaker the increase in the electrical conductance of the latter was measured. In Fig. 90, the rate of change of the electrical conductance is plotted against time. It will be observed that $\mathrm{NaCl}$ diffuses through the tissue more rapidly than sea water, while $\mathrm{CaCl}_{2}$ at first diffuses more slowly than sea water and then more rapidly:

If dead tissue be substituted for living, we find that the rate of diffusion is very much more rapid in all cases, and that all the solutions pass through at about the same rate of speed.

These results are precisely what would be expected in view of the results of the electrical experiments.

In the second of these methods, ${ }^{11}$ tissues of the dandelion (Taraxacum officinale) were placed for a short time in a salt solution and the rate at which salts subsequently diffused out of the cell was measured by placing the

${ }^{10} C f$. Brooks, S. C. $(1917, B)$.

${ }^{21} C f$. Brooks, S. C. $(1916, A)$. 
tissue in distilled water and observing the increase in conductance of the latter. The results are shown in Fig. 91 , in which the ordinates denote the amount of exosmosis. It will be seen that there is more exosmosis from tissue

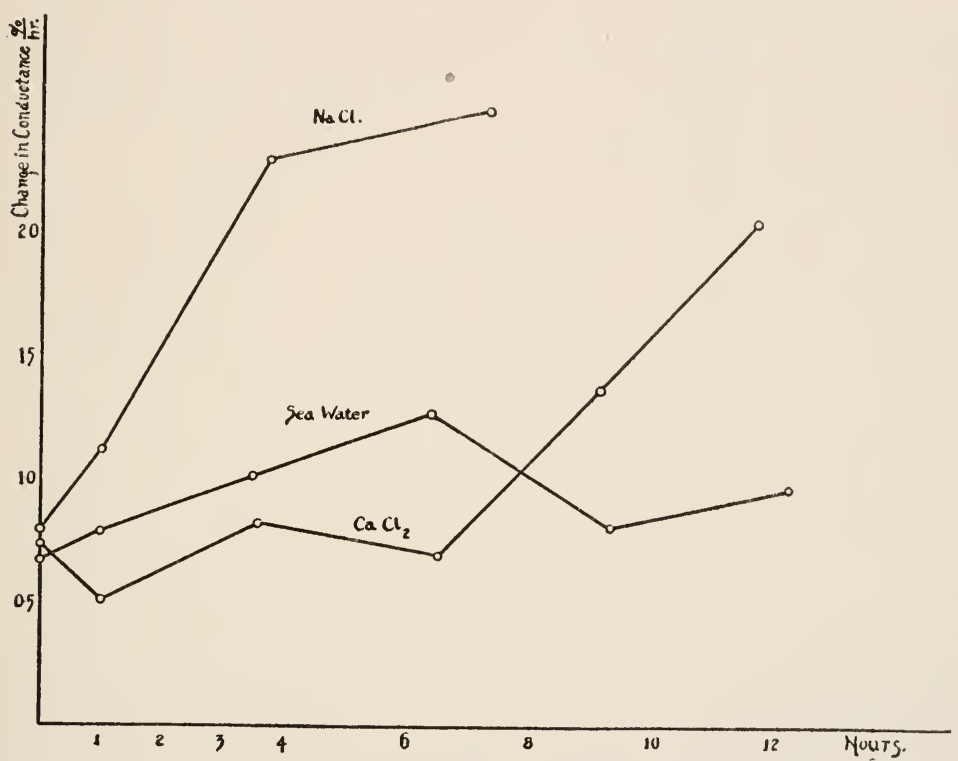

FIG. 90.-The ordinates denote the rate of diffusion of $\mathrm{NaCl}, \mathrm{CaCl}_{2}$ and sea water through living tissue of Laminaria. $\mathrm{NaCl}$ diffuses more rapidly than sea water, while $\mathrm{CaCl}_{2}$ at first diffuses more slowly, then more rapidly than sea water.

which has been previously treated with $\mathrm{NaCl} 0.22 M$ than from tissue treated with a balanced solution. ${ }^{12}$

Tissue treated with $\mathrm{CaCl}_{2} 0.17 M$ showed less exosmosis than that treated with the balanced solution. ${ }^{13}$

These results are also in harmony with the experiments on electrical conductivity.

${ }^{12}$ For exosmosis of pigments of Rhodymenia in relation to electrical resistance see Osterhout $(1919, C)$.

${ }^{13}$ The concentrations of $\mathrm{NaCl}, \mathrm{CaCl}_{2}$ and of the balanced solution were chosen so as to be approximately isotonic with the tissue. 
In the third method employed by Brooks, ${ }^{14}$ strips of the peduncle of the dandelion were placed in hypertonic solutions and the rate of penetration of the salt into the protoplasm was calculated from the rate at which the

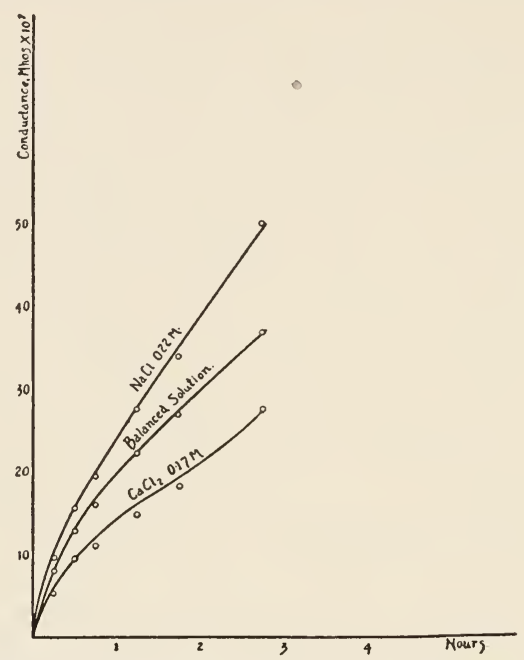

FIG. 91.-The ordinates denote the amount of exosmosis into distilled water from living tissue of Taraxacum officinale which had been previously treated with various solutions and then placed in distilled water. Treatment with $\mathrm{NaCl}$ produces more exosmosis than treatment with a balanced solution, while treatment with $\mathrm{CaCl}_{2}$ produces less exosmosis. The experiments indicate that the measured exosmosis is largely due to salts present in the cells before the application of reagents. If it were caused by the reagents (by diffusion out of the cell walls and intercellular spaces) it would be greater in $\mathrm{CaCl}_{2}$ than in $\mathrm{NaCl}$.

strips recovered their normal shape after being curved by the action of hypertonic solution (the strips remaining in the solution during recovery). This gives the same kind of information as plasmolysis, but avoids the most serious errors of that method.

In Fig. 92, the rate of recovery is plotted against time. The more rapid rate of recovery in $\mathrm{NaCl}, \mathrm{KNO}_{3}$, and $\mathrm{NH}_{4} \mathrm{Cl}$ shows that in these salts penetration is more rapid than in the balanced solution. On the other hand,

${ }^{14} C f$. Brooks, S. C. $(1916, B)$. 
the slower rate of recovery in $\mathrm{MgCl}_{2}, \mathrm{CaCl}_{2}, \mathrm{Al}_{2} \mathrm{Cl}_{6}$ and $\mathrm{Ce}\left(\mathrm{NO}_{3}\right)_{3}$ shows that in these salts penetration is slower than in the balanced solution.

This is in complete agreement with the results of the electrical experiments (even the order of penetration of the salts of $\mathrm{Mg}, \mathrm{Ca}, \mathrm{Al}$ and $\mathrm{Ce}$, is the same as that found by the electrical method).

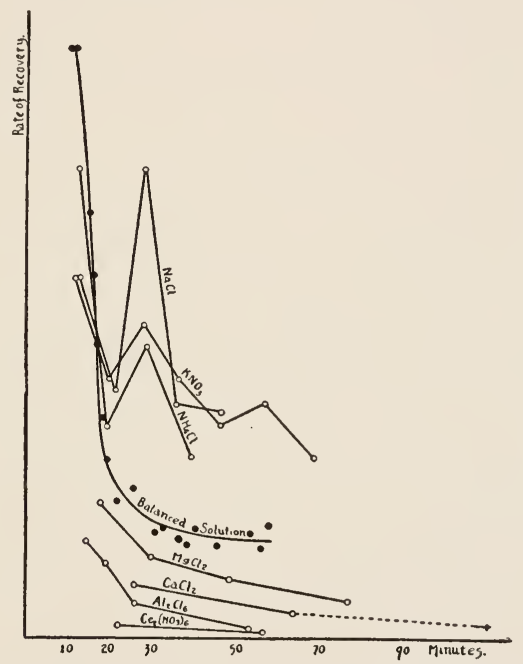

F rG. 92.-The ordinates denote rate of recovery from the effect of hypertonic solutions of strips of the peduncle of the Taraxacum officinale. The rapid rate of recovery in $\mathrm{NaCl}$, $\mathrm{KNO}_{3}$ and $\mathrm{NH}_{4} \mathrm{Cl}$ shows rapid penetration of these salts. On the other hand in $\mathrm{MgCl}_{3}$,

$\mathrm{CaCl}_{2}, \mathrm{Al}_{2} \mathrm{Cl}_{6}$ and $\mathrm{Ce}\left(\mathrm{NO}_{3}\right)_{3}$ penetration is slower than in the balanced solution.

Recently the writer has had an opportunity to test some of these conclusions by direct determinations of the penetration of substances into the cell sap. The advantages of this are obvious, when we consider the uncertainty of most indirect methods.

Some investigators have sought to avoid the difficulties of indirect methods by making analyses of tissues, but these must obviously include too much intercellular material to be satisfactory. Analysis of the solutions 
in which the tissue lies is open to the objection that substances are absorbed on the surfaces of the cells and in the spaces between them, and it is impossible to say what actually penetrates the protoplasm.

Others have attempted to analyze the cell sap. The most favorable cells for this purpose are those of plants, since they contain, as a rule, vacuoles filled with sap. In general, the method has been to crush the tissues and express the sap, but it is obvious that this procedure involves too many possibilities of error. ${ }^{15}$

The entrance of dyes has been extensively investigated, but this method is beset by many pitfalls, ${ }^{16}$ and the results hitherto obtained are confusing.

${ }^{15}$ Among these may be mentioned contamination of the cell sap by substances present in the cell walls or intercellular spaces and chemical reaction between the cell sap and the crushed protoplasm and cell walls. The degree of pressure used in expressing has a marked influence on the concentration of the sap. Cf. Mameli (1908), Dixon and Atkins (1913) Gortner and Harris (1914), Gortner, Lawrence and Harris (1916). The investigation of blood and other body fluids is open to the objection that we do not know to what extent substances penetrate between the cells in reaching these fluids. In many cases penetration into these fluids seems to present very special features.

${ }^{10}$ To a great extent the coloration of the cell by a dye shows the extent to which the dye can combine with substances within the cell rather than the rate at which the dye penetrates. Thus many cells contain substances which combine with methylene blue so that it becomes far more concentrated within the cell than in the external solution (Pfeffer $1900,1: 96)$. Unless the cell has this power it often fails to appear colored even though it may contain the dye in the same concentration in which It exists outside. In such cases it may sometimes be detected by plasmolyzing the cell and thus concentrating the dye. A further complication is that a cell may appear to have taken the dye into its interior when in reality only the surface or the cell wall is stained. There are many other difficulties, which need not be discussed here, such as toxic action of the dye and changes in the dye (decolorization etc.) as it enters the cell. A very serious objection to this method is that it does not give quantitative results. A review of the literature will be found in Höber (1914). 
The penetration of acids and alkalies has been studied by employing organisms containing natural indicators, or by introducing indicators into the cell. ${ }^{17}$ In some cases the penetrating substance may cause a visible precipitate with the cell: this is especially the case with alkaloids. ${ }^{18}$ The absorption of $\mathrm{Ca}^{19}$ has been detected by observing the formation of crystals of Ca-oxalate within the cell. It is evident, however, that these methods have but limited application and that in many cases they are open to the objection that the penetrating substance injures the cell.

The penetration of a substance may of ten be demonstrated by observing its effect upon metabolism, but this method is unsatisfactory from a quantitative standpoint. Some investigators state that substances may produce effects on metabolism by their action at the surface, without actually penetrating the cell.

It is evident that the most satisfactory method would be to place the cell in a solution containing the substance whose penetration was to be investigated, and, after a definite time of exposure, to obtain the cell sap without contamination and test it for the presence of the substance. Experiments of this sort have apparently not been carried out, though interesting results have been obtained by Meyer, ${ }^{20}$ Hansen, ${ }^{21}$ Wodehouse, ${ }^{22}$ and Crozier, ${ }^{23}$ by comparing the cell sap of Valonia (which can be obtained without contamination) with the sea

${ }^{17}$ For the literature see Haas, A. R. C. $(1916, B)$, Crozier $(1916, A$, $B ; 1918$ ).

${ }^{18}$ For the literature see Czapek (1911).

${ }^{10}$ Osterhout (1909).

${ }^{20}$ Meyer (1891).

"1 Hansen (1893).

${ }^{22}$ Wodehouse (1917).

${ }^{23}$ Crozier (1919). 
water. Janse ${ }^{24}$ found that filaments of Spirogyra which had been kept for a time in a solution of $\mathrm{KNO}_{3}$, gave a test for $\mathrm{NO}_{3}$ after being rinsed and caused to burst in a solution of diphenylamine. It is evident that in his method, there is serious risk of contamination by the substance in and upon the cell wall (or between the cell wall and the protoplasm).

In order to avoid this difficulty, the writer has employed the cells of a species of Nitella, some of which reach a length of four or five inches and a diameter of a thirty-second of an inch.

Within the cell wall the protoplasm forms a thin layer in which are imbedded the chlorophyll bodies. Inside this layer of protoplasm is the large central vacuole filled with cell sap. It is possible to obtain the cell sap without contamination in various ways. The writer has made use of the following methods: The cells are placed for the desired length of time in a solution containing the substance whose penetration is to be tested. They are removed, washed in running tap water (followed in many cases by distilled water) and dried by means of filter paper. The cells are so large and turgid, that this manipulation presents no difficulty. A cell is then placed on a piece of glass or filter paper and pierced with the point of a capillary tube (which has been drawn out to a fine tip). The cell sap is drawn up into the tube (by capillary action) quite free from protoplasm or chloroplasts. ${ }^{25}$ Another method, which is preferable in many cases, is to suspend the cell by a pair of forceps attached to the upper end, cut off the lower end and bring it in contact with a glass slide, and then grasp the upper end

${ }^{24}$ Janse (1887).

${ }^{25}$ During the manipulation care should be taken to prevent the sap from running out of the cell and coming in contact with its outer surface. 
gently with another pair of forceps, which is slowly moved downwards. The cell sap then flows out on to the glass slide in contact with the drop. By uniting the drops from a number of cells it is possible to get a sufficient amount for qualitative chemical tests, and in many cases approximate quantitative results may be obtained.

Since in previous investigations the writer had employed indirect methods of testing permeability, it was of considerable interest to compare these results with those obtained by direct tests of the cell sap. An investigation was therefore made in which the permeability of Nitella was tested by the direct method, as well as by determinations of plasmolysis and of electrical conductivity. This may be illustrated by a series of experiments ${ }^{26}$ with $\mathrm{NaNO}_{3}$ and $\mathrm{Ca}\left(\mathrm{NO}_{3}\right)_{2}$.

Experiments on plasmolysis were carried out by placing the cells in a hypertonic solution and observing the time required to recover from plasmolysis (without removing the cells from the solution) on the assumption that the more rapid the recovery, the more rapid is the penetration of the salt.

In these experiments the smaller cells near the tip of the plant were largely employed. They were observed in Syracuse watch glasses or placed on glass slides and covered with large cover glasses, the edges of which were sealed with vaseline.

Plasmolysis may be harmful to many cells, even in a balanced solution, ${ }^{27}$ while in an unbalanced solution there

${ }^{20}$ All the experiments were performed at about $19^{\circ} \mathrm{C}$. All the solutions were approximately neutral. Cf. Osterhout (1922).

${ }^{27}$ For this reason penetration may be more rapid than would otherwise be the case. In order to reduce toxicity chemically pure salts should be used and the water should be distilled from quartz (or from glass which has been in use for some time), using cotton plugs in place of rubber or cork stoppers and rejecting the first and last parts of the distillate. 
may be the additional injury due to the toxic action of the salt. For this reason many cells which would recover if very slightly plasmolyzed may not do so if plasmolyzed more strongly, since recovery may require so long a time that the process of injury gets the upper hand.

It was found that recovery was more rapid in $\mathrm{NaNO}_{3}$ than in a balanced solution of $\mathrm{NaNO}_{3}+\mathrm{Ca}\left(\mathrm{NO}_{3}\right)_{2}$ or in $\mathrm{Ca}\left(\mathrm{NO}_{3}\right)_{2}$ alone. Similar experiments with $\mathrm{RbCl}, \mathrm{CsCl}$, and $\mathrm{CaCl}_{2}$ gave the same result. This indicates that in a solution of $\mathrm{NaNO}_{3}, \mathrm{NaCl}, \mathrm{RbCl}$, or $\mathrm{CsCl}$ penetration is more rapid than in $\mathrm{Ca}\left(\mathrm{NO}_{3}\right)_{2}, \mathrm{CaCl}_{2}$, or in a balanced solution.

These results agree with those obtained in the study of Spirogyra. ${ }^{28}$

The experiments on conductivity were carried out by means of the apparatus described on page 34. As it was desirable to surround the cell by a solution of the same conductivity as that of the cell sap determinations of the latter were made by filling a small tube with sap and inserting an electrode at each end (taking great care to avoid the inclusion of air bubbles). It was found that the sap had approximately the conductivity of sea water plus three parts of distilled water (this will be called for convenience 0.25 sea water). The cells were accordingly placed in this for some time before beginning the determination of the conductivity of the living cell. Under these circumstances it was assumed that alterations in conductivity during the course of the experiment must be due (in great part at least) to changes in the protoplasm, rather than in the cell sap.

In general, it was found that in 0.25 sea water, the resistance remained unaltered for a long time, while in $\mathrm{NaNO}_{3}$ of the same conductivity it soon began to fall.

${ }^{23}$ See page 201. 
This harmonizes with the results obtained with Laminaria.

Direct tests of the sap were made by determining $\mathrm{NO}_{3}$, since it was found that the cells normally give tests for $\mathrm{Na}$ and $\mathrm{Ca}$. The method employed was not sensitive enough to detect $\mathrm{NO}_{3}$ in the sap of the control cells under any circumstances, so that if a test was obtained after exposure to a solution containing $\mathrm{NO}_{3}$, it must have been due to penetration from without. The sap was tested by placing it on a glass slide, adding a drop of a solution of nitron in $10 \%$ acetic acid, and observing it under the microscope. If $\mathrm{NO}_{3}$ is present, it may be recognized by the formation of characteristic crystals.

Cells kept for 24 hours in 100 c.c. $\mathrm{NaNO}_{3} 0.05 M+10$ c.c. $\mathrm{Ca}\left(\mathrm{NO}_{3}\right)_{2} \quad 0.05 M$ gave no test, which shows conclusively that the method is safe as far as contamination by $\mathrm{NO}_{3}$ on the surface is concerned. After 48 hours a test was obtained. As the cells continued to live in this solution for 3 weeks (at which time the experiment was discontinued) and as they appeared normal in every way, it is evident that the penetration was not the result of injury.

It is probable that in 24 hours some $\mathrm{NO}_{3}$ penetrated which was not revealed by the test. This, however, is of no significance in the present investigation which does not aim to determine the absolute amount of penetration, but merely to compare the relative penetration in balanced and unbalanced solutions.

The results of such a comparison are very striking. After 3 hours in $\mathrm{NaNO}_{3} 0.05 M$ a good test was obtained. The cells had lost some of their turgidity; if left in the the solution of $\mathrm{NaNO}_{3}$ or if transferred to tap water they subsequently lost all their turgidity, indicating death. It is therefore evident that this rapid penetration was accompanied by injury. Similar results were obtained by Mrs. Brooks (1922) with Li, Ba, and Sr. 
It may be remarked that the turgidity of the cells affords good indication of their condition. It is easily tested by lifting them partly out of the solution; if turgid they appear stiff, otherwise they collapse or appear flaccid. It is, however, necessary to distinguish between loss of turgidity in isotonic or hypotonic solutions, which indicates injury, and a similar appearance in hypertonic solutions, which may indicate nothing of the sort. In the latter case the cell promptly recovers its turgidity when placed in tap water; in the former it does not.

Another criterion of injury is afforded by the appearance of the chlorophyll bodies. In the normal cell they are arranged in regular rows and are of a clear transparent green color. Where injury occurs they lose their regular arrangement and the color becomes more opaque.

In $0.05 \mathrm{M} \mathrm{Ca}\left(\mathrm{NO}_{3}\right)_{2}$ the cells live for a week or more. During the first few days, at least, penetration is not more rapid (perhaps less so) than in a balanced solution.

Similar results were obtained with other salts.

The outcome of these direct tests is therefore an unqualified confirmation of the results obtained by the indirect methods. We find that penetration in injurious solutions is relatively rapid as compared with penetration in non-toxic solutions. This corresponds to the fact that recovery from plasmolysis is more rapid in injurions solutions as well as to the fact that conductivity increases in such solutions.

It would therefore seem that we may regard determinations of electrical conductivity, and, in some cases, of recovery from plasmolysis as reliable means of detecting alterations in permeability. It is, however, desirable to go further, if possible, and analyze the factors involved in electrical resistance. 
If we consider the behavior of the current from this point of view, it is evident that in the simplest cases, where the plant is a membrane only one cell thick (as in Porphyra and Monostroma) and the current passes through this membrane at right angles to its surface, we need consider only a single cell and its adjacent cell wall, as shown in Fig. 93, $A$. The part of the current which goes through the protoplasm may be designated as $C_{P}$. while that which traverses the cell may be called $C_{W}$.

Experiments show that the resistance of the living tissue is much greater than that of tissue which has been carefully killed with all possible precautions to prevent any alteration of the cell wall. ${ }^{29}$ We therefore feel confident that the conductivity of the living protoplasm is less than that of the cell wall.

In order to see how the current may distribute itself, let us suppose the protoplasm to be replaced by a wire, ${ }^{30}$ $P$, as in Fig. 93, $B$ and the cell wall to be replaced by

${ }^{29}$ Osterhout $(1918, C ; 1921, D)$.

${ }^{30} \mathrm{We}$ might consider the protoplasm to be replaced by two wires, one of which corresponds to the thin layers of protoplasm which are traversed by the current in a direction at right angles to their planes, the other corresponding to the similar layers of protoplasm in each cell (around the edges of the cell shown in Fig. 93, A) in which the current flows in the plane of the layer. It is evident, however, that these latter may be neglected in our calculations since they occupy such exceedingly small fractions of the cross-section.

If we neglect these we may say that in traversing a cell the current passes through a thin layer of cell wall and then one of protoplasm (in both cases at right angles to the plane of the layer), then through the cell sap, and finally through a layer of cell wall and one of protoplasm (at right angles to their planes). It is evident that in this case we may neglect the effect of the cell wall and of the cell sap since their resistance is very small in comparison with that of the protoplasm and is in series with it. We may therefore consider the protoplasm to be replaced by a single wire having a resistance equal to that of the two layers of protoplasm which are traversed by the current in a direction at right angles to their planes. 
a wire, $W$. The current flowing between the points $X$ and $Y$ in the wire $P$ may be called $C_{P}$; that in the other wire $C_{W}$. The total current, $C$, flowing between $X$ and $Y$ will be the sum of the partial currents, or,

$$
C=C_{P}+C_{W}
$$

We may consider the current (conductance) as equal to the reciprocal of the resistance and write

$$
\frac{1}{R}=\frac{1}{R_{P}}+\frac{1}{R}{ }_{W}
$$

in which $R$ is the total resistance between $X$ and $Y, R_{P}$ is
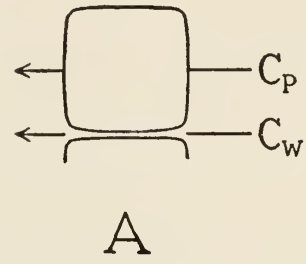

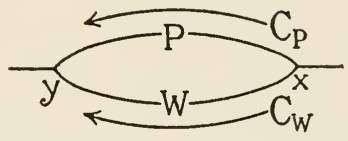

B

Fig. 93

the resistance of the wire $P$, and $R_{W}$, that of $W$. Applying this equation to Laminaria ${ }^{31}$ (and expressing the resistance in the usual way as the per cent. of the normal) we may calculate the values of $C_{W}, C_{P}, R_{W}$, and $R_{P}$.

Under normal conditions in sea water, the resistance is taken as 100 and therefore $C=1 \div 100$, but in certain

${ }^{81}$ So far we have considered only the simplest case, when the plant is only one cell thick. But it is evident that these considerations also apply when several membranes are placed together, forming a mass comparable to the tissue of Laminaria. The only difference is in that case the current would traverse a very thin layer of cell wall in passing from one protoplasmic mass to the next, so that what we have spoken of as the resistance of the protoplasm would be composed in part of the resistance of these cell walls. When the protoplasm is dead the total resistance is only 10.29 and the resistance of these cell walls must be only a small fraction of this. Consequently their resistance in the living tissue of Laminaria is undoubtedly less than 1 when that of the protoplasm is 140 . The resistance of these cell walls may therefore be neglected. 
solutions (having the same conductivity as sea water) the resistance may rise to 300 or more; and in this case $C$ would equal $1 \div 300=.0033$ (or less), and since some of it must flow in the protoplasm the amount which traverses the cell wall must be less than this. We are therefore safe in putting it as low as $1 \div 350=.002857$.

All the experiments hitherto made indicate that the conductivity of the cell wall remains unaltered in spite of changes in the chemical character of the solution, provided the conductivity of the solution remains the same. We may therefore take .002857 as the fixed value of $C_{W}$.

Let us now consider what values $C_{P}$ assumes as the resistance changes. In sea water we have ${ }^{32} R=100$ and

$$
C=\frac{1}{100}=.002857+C_{P}
$$

whence $C_{P}=.007143$ and $R_{P}=1 \div C_{P}=140$. In the same manner we find that when $R=90, R_{P}=121.15$, and when $R=10, R_{P}=10.29$.

The changes in resistance thus far discussed have been treated as though they occurred in sea water; in this case the experiments indicate that the conductivity of the cell sap remains practically constant and hence need not be taken into account in our calculations. We may now ask whether this is also the case when the changes in resistance occur in other solutions. In order to investigate this, experiments were made with solutions of $\mathrm{NaCl}$ and $\mathrm{CaCl}_{2}$ (of the same conductivity as sea water). The tissue was placed in these solutions and removed after various intervals of exposure. It was cut into small bits and ground (so as to open the cells) and in some cases

32 The total conductance of the protoplasm is greater than that of the cell walls, but the protoplasm occupies a much greater fraction of the conducting cross-section than the cell walls, so that the actual conductivity of the protoplasm is much less than that of the cell wall. 
the tissue was killed by heat: the conductivity of the expressed juice was compared with that of sea water. As no significant difference was found we may consider that the conductivity of the cell sap does not change sufficiently in these solutions to alter our calculations.

Let us now consider the changes in protoplasmic resistance which occur in toxic solutions. When tissue is placed in $\mathrm{NaCl} 0.52 M$ the net resistance falls rapidly. The death curve may be obtained by means of the formula ${ }^{33}$

Resistance $=2700\left(\frac{K_{A}}{K_{M}-K_{A}}\right)\left(e^{-K_{A} T}-e^{-K_{M} T}\right)+90 e^{-K_{M} T}+10$ in which $T$ is the time of exposure, $K_{A}$ and $K_{M}$ are constants, and $e$ is the basis of natural logarithms. We find by means of this formula that in a solution of $\mathrm{NaCl} 0.52 \mathrm{M}$ (for which $K_{A}=.018$ and $K_{M}=.540$ ) the net resistance after 10 minutes is $87.76 \%$ of the normal; after 30 minutes it is 64.26 , and after 60 minutes it is 41.62 . Knowing the net resistance we can calculate the protoplasmic resistance, as explained above. After 10 minutes the protoplasmic resistance is $117.12 \%$ (corresponding to the net resistance of $87.76 \%$ ). Since it is desirable to express all resistances as per cent. of the resistance in sea water we divide 117.12 by 140 (which is the protoplasmic resistance in sea water) and obtain $83.66 \%$. Proceeding in this way we find that after 30 minutes the protoplasmic resistance is $56.22 \%$ and after 60 minutes $33.74 \%$. In order to fit the formula to these values we must change the constants, puting $K_{A P}=0.0234$ (in place of $K_{A}=0.018$ ) and $K_{M P}=0.702$ (in place of $K_{M}=0.54$ ). It is therefore evident that in

${ }^{3}$ For the explanation of this formula see page 61 . 
changing from net resistance to protoplasmic resistance we merely shift the value of the constants. The question arises whether this affects the general conclusions drawn from the study of net resistance. In order to decide this question the constants for $\mathrm{CaCl}_{2}$ and for various mixtures of $\mathrm{NaCl}$ and $\mathrm{CaCl}_{2}$ were ascertained; these are given in Table XII. ${ }^{34}$

TABLE XII.

Velocity Constants at $15^{\circ} \mathrm{C}$.

\begin{tabular}{|c|c|c|c|c|c|}
\hline $\begin{array}{l}\mathrm{CaCl}_{2} \text { in } \\
\text { solution }\end{array}$ & $\begin{array}{l}\mathrm{CaCl}_{2} \text { in } \\
\text { surface }\end{array}$ & $K_{A}$ & $K_{M}$ & $K_{A P}$ & $K_{M P}$ \\
\hline per cent. & per cent. & 0.018 & 0.540 & 00234 & 0.702 \\
\hline 1.41 & 12.5 & 0.000222 & 0.00666 & 0.000293 & 0.00878 \\
\hline 2.44 & 20.0 & 0.000187 & 0.00546 & 0.000237 & 0.00708 \\
\hline 4.76 & 33.33 & 0.000245 & 0.00590 & 0.00032 & 0.007136 \\
\hline 15.0 & 63.73 & 0.000364 & 0.0073 & 0.0005035 & 0.00855 \\
\hline 35.0 & 84.34 & 0.000481 & 0.00859 & 0.000678 & 0.00955 \\
\hline 62.0 & 94.22 & 0.00053 & 0.009 & 0.000761 & 0.00989 \\
\hline 100.0 & 100.0 & 0.0018 & 0.0295 & 0.002685 & 0.0323 \\
\hline
\end{tabular}

There are two points of principal importance in the consideration of these constants: (1) It has been shown ${ }^{35}$ that the value of $K_{A} \div K_{M}$ increases regularly as the per cent. of $\mathrm{CaCl}_{2}$ in the surface of the cell increases. That this is also true in the case of protoplasmic resistance is evident from Fig. 94. (2) It was also pointed out that as the per cent. of $\mathrm{CaCl}_{2}$ in the solution decreases from 62 to $1.41 \%$ the value of $K_{M}$ first decreases (reaching a minimum at $4.76 \%$ ) and then increases. It was found that the

${ }^{34}$ These are approximate values, obtained graphically. The constants of the curves of protoplasmic resistance are designated as $K_{A P}$ (corresponding to $K_{A}$ ) and $K_{M P}$ (corresponding to $K_{M}$ ). The curves of protoplasmic resistance may show less inhibition at the start than those of net resistance.

${ }^{35}$ See page 151 . 
amount of decrease corresponds to the amount of a hypothetical salt compound $\left(\mathrm{Na}_{4} \mathrm{XCa}\right)$. This is also true in the case of protoplasmic resistance, as shown in Fig. 95. ${ }^{36}$

It would therefore appear that we arrive at the same conclusions whether we study net resistance or protoplasmic resistance. When the solution is changed the con-

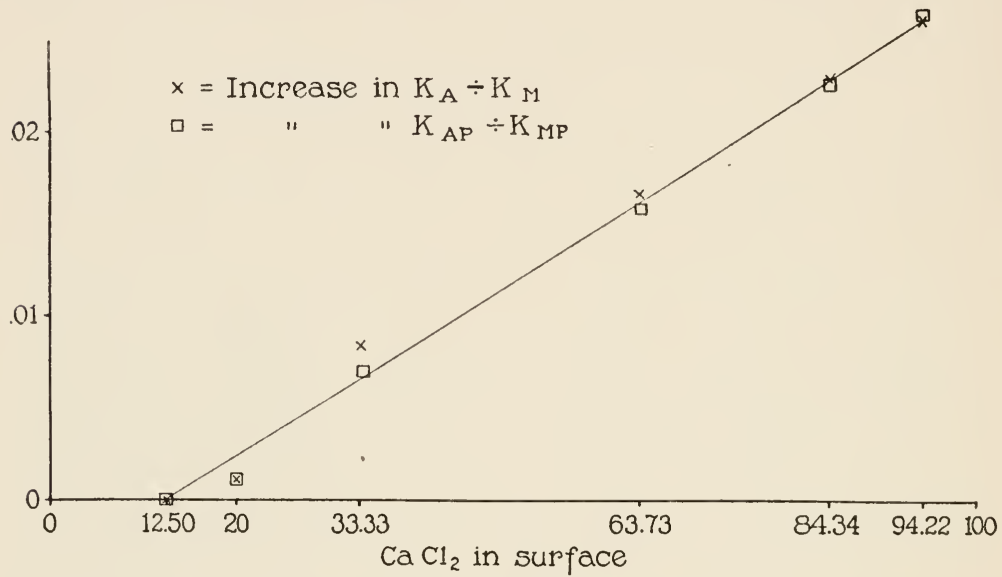

Fig. 94.-Ordinates represent the increase in value of $K_{A} \div K_{M}$ and $\mathrm{K}_{A P} \div K_{M P}$. In each case the value given represents the increase over the corresponding value in the solution containing $1.41 \% \mathrm{CaCl}_{2}$ (the per cent. in the surface being 12.5). Abscissa represent per cent. of $\mathrm{CaCl}_{2}$ in the surface. In order to facilitate comparison the values of $K_{A P} \div K_{M P}$ have been divided by 1.685 .

stants change in a corresponding manner in both cases, the only difference being in their absolute values, but it is evident that in this case differences in absolute values are of no importance.

It should be emphasized that this general conclusion would remain valid in case it should be found that the values given here for $C_{P}$ and $C_{W}$ are incorrect. There seems to be no doubt that the value of $C_{W}$ is constant under the conditions of these experiments and as long as

${ }^{38} \mathrm{~A}$ rough calculation shows that this is also true of $K_{N P}$ and $K_{O P}$ (corresponding to the $K_{N}$ and $K_{O}$ mentioned on page 98 ). 


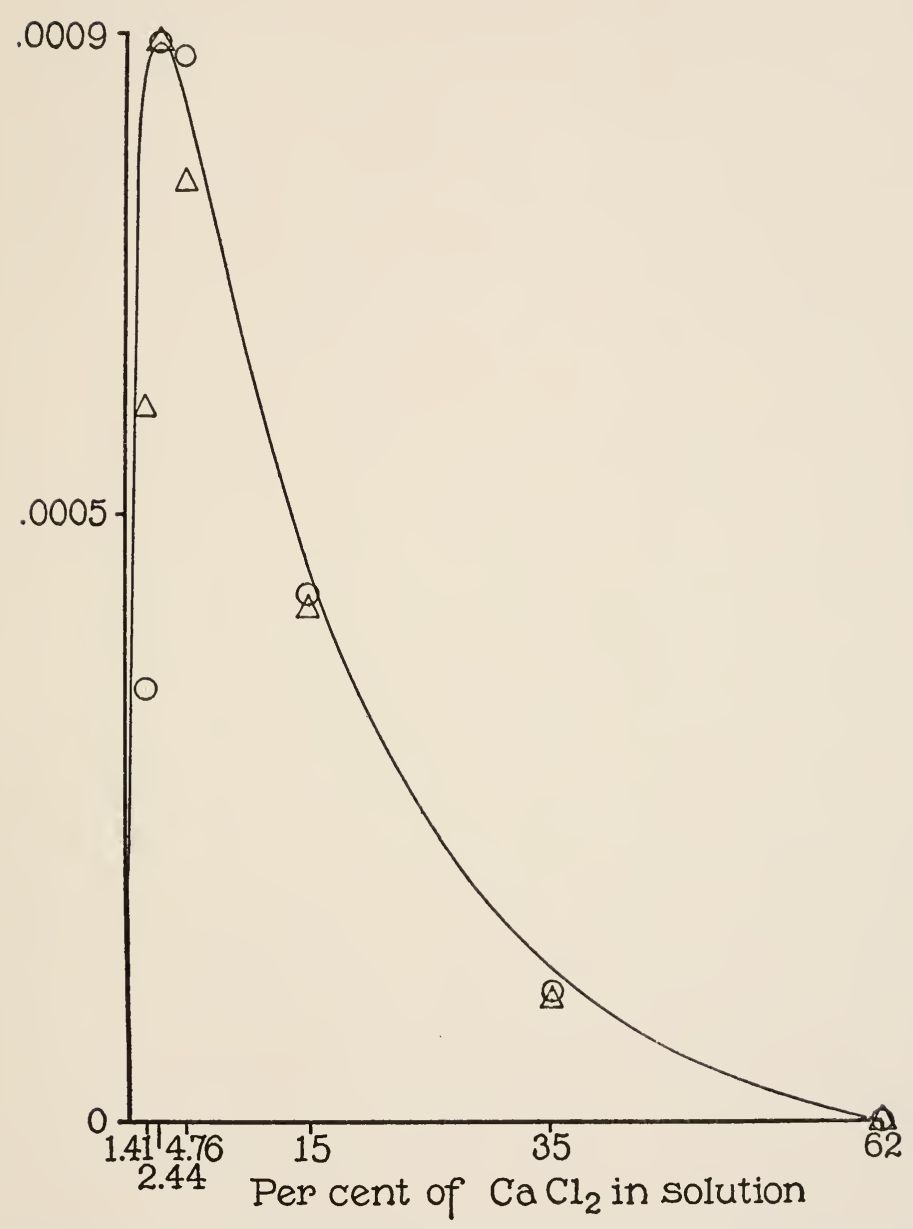

FIG. 95.-Ordinates represent the amount of $\mathrm{Na}_{4} \mathrm{XCa}$ and also the dccrease in the value of $K_{M} \triangle$ and of $K_{M P O}$ as compared with the corresponding value in the solution containing $62 \% \mathrm{CaCl}_{2}$. Abscisse represent per cent. of $\mathrm{CaCl}_{2}$ in the solution. In order to facilitate comparison the values of $K_{M}$ have been multiplied by 0.251 and those of $K_{M P}$ by 0.321 .

this is true the conclusions drawn from the study of net resistance apply also to protoplasmic resistance.

The results of this investigation may be summarized 
as follows: An electrical current passing through a living plant flows partly through the cell wall and partly through the protoplasm. The relative amounts of these two portions of the current can be calculated. The outcome of such calculations shows that the conclusions drawn from the study of the resistance of the tissue as a whole apply also to the resistance of the protoplasm, and consequently to the permeability of the protoplasm to ions.

If these conclusions are sound it is evident that permeability may be measured with considerable accuracy. Measurements under a variety of conditions indicate that marked fluctuations of permeability are possible, and, when their duration is brief, no permanent injury results. It is obvious that the effect of such fluctuations on metabolism may be of great importance.

Some writers ${ }^{37}$ seem to think that under normal conditions the cell is quite impermeable to salts. This is at variance with the results obtained from measurements of permeability by the method outlined above. If the net resistance of the tissue under normal circumstances is taken as 100, we find that in certain solutions (having the conductivity of sea water) it may rise to 300 . The protoplasmic resistance under normal conditions may be taken as 140. When the net resistance of the tissue rises to only 250 , the protoplasmic resistance increases to 874.89 , a gain of $524.92 \%$.

It is therefore evident that the permeability of the cell is by no means at a minimum under normal conditions. This conclusion is borne out by the results of experiments on plasmolysis ${ }^{38}$ carried out by the writer as well as by

${ }^{37} \mathrm{Cf}$. Osterhout $(1915, C)$.

${ }^{3} \mathrm{Cf}$. Osterhout $(1913, B)$. 
the investigations of Brooks cited above. It would seem that it is well founded, since if the cell were impermeable, it could not obtain the salts necessary for its existence. ${ }^{39}$ It is, of course, true that the electrical resistance of the cell is much higher when alive than when dead, as is shown by the work of Róth (1897), Bugarsky and Tangl (1897), Stewart (1897), and Woelfel (1908), on blood corpuscles, that of McClendon (1910), and Gray $(1913,1916)$ on sea urchin eggs, that of Shearer (1919) on bacteria, as well as the results of the writer.

The seat of this higher resistance might be sought in the interior of the cell, or at the surface. Plant cells offer especially good material for this sort of investigation, since in most cases the protoplasm forms a thin layer surrounding a large central vacuole filled with cell sap. It has been shown above, (pp. 198 and 199) that, in the cases investigated, the sap has a conductivity which does not differ greatly from that of the external solution. It would therefore seem that the cause of the high resistance is to be sought in or near the surface. Höber (1914, pp. 383, 442) has reached this conclusion as the result of experiments on red blood corpuscles and muscles. He employed two methods for measuring the conductivity of the interior of the cell. The first depends on the fact that a conducting body increases the capacity of a condenser when inserted between the plates. The second is based upon the fact that a conductor placed in the centre of a coil of wire diminishes the strength of an alternating current in the coil. Using these methods, Höber finds that the conductivity is higher than when it is measured in the usual way (in which the current passes through the cell). He therefore concludes that the surface

${ }^{80} C f$. Osterhout $(1916, E)$. 
has a higher resistance than the interior. It should be noted, however, that in these methods the experimental errors are so great that the results must be accepted with caution.

The view that the surface layer of the protoplasm is less permeable than the interior has long been current. Such a layer need not be a visible membrane: ${ }^{40}$ on the contrary, it need only have the thickness of a single layer ${ }^{41}$ of molecules. This surface layer is commonly spoken of as the plasma membrane, but the writer prefers the term cell surface (since a morphologically distinct membrane is not necessary in order to ensure selective permeability). If it is not necessarily a visible structure, we may ask what evidence there is for its existence and whether it is anything more than a convenient fiction.

It is easy to understand how the idea of the plasma membrane was accepted by botanists. In many cases the interior of the plant cell is filled with cell sap around which the protoplasm forms a layer, so thin as to be almost invisible under the microscope, except under the most favorable conditions. In such a case the whole of the protoplasm might be looked upon as constituting the plasma membrane.

When the layer of protoplasm is thicker, it may be shown that there are differences between the permeability of its inner and outer surfaces. de Vries found that

${ }^{40} \mathrm{~A}$ layer of liquid may serve as in the experiment of Nernst (1904) where a layer of water is interposed between pure ether and benzene dissolved in ether; such a layer is permeable to ether, but not to benzene. In the same way a layer of air may be employed, e.g., the layer of air over an aqueous solution of cane sugar is permeable to water molecules, but not to sugar. If we place under a bell jar two beakers, one containing pure water and the other sugar solution, the water will pass over, in the form of vapor, into the sugar solution.

${ }^{41} \mathrm{Cf}$. Langmuir, I. (1917). 
certain dyes penetrated the $\mathrm{e}^{42}$ outer surface much more readily than the inner. ${ }^{43}$ The experiments of the writer show a difference in the two surfaces and emphasize the conception that the permeability of the protoplasm is not alike in all its parts. ${ }^{4}$

The real question is whether a special layer exists at the outermost surface of the cell which admits some substances, but not others. Furthermore, is it possible that substances which penetrate the outermost layer with difficulty can spread freely throughout the cell when they have passed the outer layer?

It is a well-known fact that substances, which, like protoplasm, contain a considerable amount of protein readily form films at their surfaces when brought into contact with liquid. ${ }^{45}$ By means of the ultra-microscope Gaidukov ${ }^{46}$ observed a differentiated film at the surface of the cell. Such films or membranes have been shown to exist in some cells by micro-dissection and there are indications that they also exist at the surfaces of vacuoles, ${ }^{47}$ and of nuclei. ${ }^{48}$ The surface of Amoba and of some other protozoa is covered with a thin membrane capable of

${ }^{42}$ de Vries (1885).

${ }^{43}$ The objection might be made that the dye cannot penetrate the inner surface until the protoplasm has become saturated with it, and this might be confused with a difference in permeability.

${ }^{4}$ See page 229 .

${ }^{45}$ Nägeli (1855) I, pp. 9, 10; Hanstein (1870); Pfeffer (1900); Robertson (1908); Höber (1914) p. 65; Harvey (1912, A, B) ; Metcalf (1904); Kühne (1864); Ramsden (1905); Rosenthal (1901); Schütt (1904); Shorter (1909); Rhode (1906). For a general summary, see Zangger (1908).

${ }^{46}$ Gaidukov (1910) ; Marinesco (1912); Price (1914).

${ }^{47}$ Seifriz (1918); Chambers (1915, 1917, 1920, 1921); Kite (1912); Pfeffer (1900) 1:107: Overton (1895, 1900, 1901, 1902).

${ }^{48}$ Chambers (1921). 
forming wrinkles. What part these films or membranes play in permeability is not known.

When a cell is crushed, so that drops of protoplasm are extruded, it is often observed that each drop behaves as if surrounded with a plasma membrane, and a rupture is in most cases instantly repaired (as long as the cell remains in the normal condition). This might be explained as due to the formation of films upon contact with liquid.

Küster $(1909 ; 1910$ A, B.) found that when the protoplasm of a cell was separated into several pieces by plasmolysis the parts would fuse if brought together at once, but if left for a time would no longer do so, indicating that a change had taken place in the surface film.

Kite (1913) states that a dye which could not penetrate the cell was able to spread freely in its interior, when introduced by a Barber pipette. ${ }^{49}$

The nature of the cell surface has been the subject of much dispute. Overton based his view that it is lipoid in nature on the ground that lipoid-soluble substances readily penetrate, while those which are not soluble in lipoid do not enter the cell, and stated that this was particularly the case with inorganic salts. It was subsequently found, however, that cells are permeable to salts, ${ }^{50}$ and to other substances insoluble in lipoid. He found ${ }^{51}$ an apparent confirmation of his theory in the behavior of dyes. It had been shown by Ehrlich ${ }^{52}$ that basic dyes are taken up by nerves and by lipoid substances. Overton extended this notion to living cells in general and assumed

\footnotetext{
${ }^{49}$ Cf. Pfeffer (1900) 1:107.

${ }^{50}$ See page 203.

${ }^{51}$ Overton (1900, 1902).

${ }^{52}$ Ehrlich (1893).
} 
that the penetration of dyes is dependent on their solubility in lipoid. Subsequent investigations have brought to light so many exceptions to this rule that it can no longer be regarded as conclusive evidence in favor of Overton's views. ${ }^{53}$

Overton's views gained wide support through their application to the explanation of narcosis. Overton ${ }^{54}$ and Meyer $^{55}$ independently arrived at the conclusion that the more soluble a substance is in lipoid, the more effective it is as a narcotic. They explained this by saying that the more soluble the anesthetic is in lipoid, the more easily it penetrates the lipoid membrane.

Although this hypothesis has found wide acceptance, there are serious objections to it.

If it be true that anesthetics are generally effective in proportion to their solubility in lipoid, ${ }^{56}$ it does not by any means follow that the plasma membrane is lipoid. As we have already seen, ${ }^{57}$ the effectiveness of a dye in coloring the cell does not depend on its rate of penetration, but on its ability to accumulate within the cell by combining with substances in the protoplasm. If this is also the case with anesthetics, lipoids in the interior of the cell may be the determining factor, and there is no necessity for the assumption of a lipoid membrane.

It is not the desire of the writer to enter into further

${ }^{63}$ Höber (1914) 426 ff. Also p. 645; Küster (1911) Ruhland (1912, $A, B)$; Schulemann (1912) ; Goldman (1912) ; Garmus (1912) ; Robertson (1908); Kite (1913); Ruhland (1909).

${ }^{54}$ Overton (1901).

${ }^{65}$ Meyer (1899).

$\omega$ There are some substances which act as anesthetics (e.g., magnesium salts) which are only slightly soluble in lipoid.

${ }^{67}$ See page 210 . 
discussion of the nature of the cell surface. ${ }^{58}$ Enough has been said to show that there is considerable evidence that there is a layer at the surface which is different from the underlying protoplasm and that some substances penetrate it more rapidly than others. It is doubtful, whether there are many substances to which it can be regarded as wholly impermeable. It is, however, able to protect the metabolism of the cell from various kinds of interference from without, and to provide for the differentiation of multicellular organisms by making it possible to keep various processes separate. The principal advantage of cell division may consist in providing the semipermeable membranes, which make differentiation possible.

A good illustration of this differentiation is seen in those cases where diverse chemical operations go on in adjoining cells without mutual interference. In many plants deeply colored cells are surrounded by colorless ones, and the soluble coloring matter does not show any tendency to diffuse into the surrounding cells. We may even observe that the color is confined to the vacuole of the cell, and does not diffuse into the surrounding protoplasm. In the same way we observe in some plant cells colored plastids (chromatophores) containing soluble pigments which do not diffuse out into the cytoplasm. A cell of this sort is shown in Fig. 96.

In the case of Griffithsia, each of these plastids is surrounded by a semipermeable membrane which retains

${ }^{58}$ Czapek (1914) has suggested that the plasma membrane is composed of soaps. Nathanson (1914) regards it as mosaic of lipoid and non-lipoid particles. This would not provide an entrance for lipoidsoluble and lipoid-insoluble substances into the cell-sap unless each element of the mosaic extended continuously, without a break, from the outer surface to the vacuole. For a general summary see Bayliss (1915), Höber (1914), and McClendon (1917). 
the pigment. 'This can easily be shown by killing the cell, whereupon the semipermeable membranes are destroyed and the pigment at once begins to diffuse out. In this case, we have to do with variety of semipermeable membranes, such as the plasma membrane, the surfaces of the plastids, the vacuolar surface, ${ }^{59}$ and the nuclear surface. It is to be expected that these surfaces may differ somewhat in permeability. Fach of them is in contact with

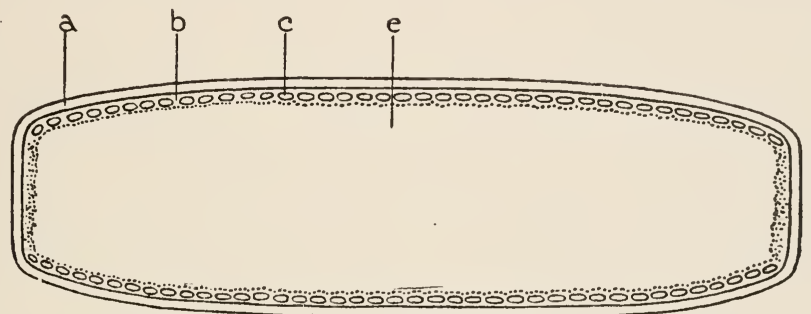

FIG. 96.-A cell of Griffithsia Bornetiana (in optical section). $a$, cell wall; $b$, protoplasm $c$, chromatophore containing chlorophyll and a red pigment (phycoerythrin) which is soluble in water; $e$, vacuole filled with cell sap. (Diagrammatic).

a somewhat different environment, and this, as we have already seen, might produce differences in permeability. That such differences really exist is indicated by treating. the cells with $\mathrm{NH}_{4} \mathrm{Cl}$ (neutralized by adding $\mathrm{NH}_{4} \mathrm{OH}$ ) which is not strong enough to plasmolyze. The vacuolar surface then contracts while the plasma membrane maintains its original position. At the same time the surfaces of the plastid become permeable and the red pigment comes out: it cannot, however, pass through the plasma membrane or the vacuolar surface. We see that all three sorts of surfaces act differently, and to these we may add

${ }^{89}$ de Vries (1885) states that certain dyes penetrate the outer surface more easily that the surface of the vacuole. It has been objected that the dye may combine with the protoplasm and hence cannot penetrate the vacuole until the protoplasm is saturated. This might cause an appearance of a difference in permeability. 
a fourth, the nuclear surface, which does not agree in behavior with any of the others. ${ }^{60}$ It is quite possible that there are other surfaces within the cell which likewise differ in their behavior.

If we suppose that these surfaces not only differ among themselves, but that their permeability fluctuates under normal circumstances, we shall probably get a fairly correct picture of the complex relations which obtain in the cell. This conception is not as simple as that of the "reaction chamber" hypothesis of Hofmeister, ${ }^{61}$ but it agrees more nearly with our present knowledge. ${ }^{62}$

The conception that the cell contains a variety of membranes which are capable of alterations in permeability, is capable of explaining some important phenomena. Among these may be mentioned certain effects of injury. It is well known that mechanical injury is followed by increased respiration: ${ }^{63}$ this may be explained by the increased permeability of membranes which have previously kept the oxidizable material from being attacked. Increased respiration due to chemical agents ${ }^{64}$ might be explained in the same way.

An illustration of a different reaction is the bitter almond, which evolves HCN upon injury. In this case a glucoside and an enzyme are brought together when

${ }^{60}$ Osterhout $(1913, D)$.

ar Hofmeister (1891).

${ }^{62}$ It may be added that while changes in the permeability of internal membranes may affect the electrical conductivity of cells which are filled with protoplasm (as in the case of most animal cells) they can hardly play an important role in cells like those of Laminaria (and most plant cells) in which the interior of the cell is occupied by a large central vacuole. In the latter, however, the permeability of the vacuole membrane must be of importance.

${ }^{63}$ Cf. Czapek (1913-20) ; Tashiro (1917).

${ }^{64}$ For recent investigations see Brooks, M. M., (1918, 1919, 1920, 1921, $A, B)$; Gustafson $(1918,1919)$; Haas $(1919, A, B)$; Irwin $(1918, A, B)$; Thomas (1918). 
injury occurs, and the resulting reaction produces HCN. Such illustrations might be multiplied indefinitely.

Another important question which may be considered in this connection is that of mechanical stimulation. The effects of certain kinds of stimuli can be referred directly to chemical changes which they produce in the protoplasm, but there are other kinds which appear to operate by physical means only. In the latter category are such stimuli as contact, mechanical shock and gravitation. While their action appears at first sight to be purely mechanical, they are able to produce effects so much like those of chemical stimuli that it appears probable that in every case their action must involve chemical changes.

The chief difficulty which confronts a theory of mechanical stimulation appears to be this: How can purely physical alterations in the protoplasm give rise to chemical changes? It would seem that a satisfactory solution of this problem might serve to bring all kinds of stimulation under a common point of view, by showing that a stimulus acts in every case by the production of chemical reactions.

The writer has observed when one of the larger cells of Griffithsia (Fig. 96) is placed under the microscope (without a cover glass) and touched near one end (with a needle or a glass rod or a splinter of wood) a change occurs in the chromatophores directly beneath the spot which is touched. The surfaces of the chromatophores in this region become permeable to the red pigment, which begins to diffuse out into the surrounding protoplasm. This change begins soon after the cell is touched. As the red pigment diffuses through the protoplasm it soon reaches neighboring chromatophores and it may then be seen that their surfaces also become permeable and their pigment 
begins to diffuse out. In this way a wave-which may be compared to a wave of stimulation-progresses along the cell until the opposite end is reached.

The rate of propagation of this wave corresponds to that of the diffusion of the pigment. It would seem that at the point where the cell is touched, pigment, and probably other substances, are set free, diffuse out and set up secondary changes as they progress. These changes are doubtless chemical in nature.

The important question then arises: How does the contact initiate the outward diffusion of the pigment or other substances?

It seems to the writer that this may be due to a mechanical rupture of the surface layer of the chromatophore which is either not repaired at all or only very slowly. Many cases are now known in which the surface layers of protoplasmic structures behave in this way. ${ }^{65}$ If, therefore, such structures exist within the cell, it is evident that any deformation of the protoplasm which is sufficient to rupture their surface layers, will permit their contents to diffuse out into the surrounding protoplasm. A great variety of cellular structures (plastids, vacuoles, " microsomes," inclusions, etc.), possess surface layers of great delicacy, and it is easy to see how some of these might be ruptured by even the slightest mechanical disturbance.

It would seem, therefore, that deformation may rupture the surface lavers of certain structures and cause their contents to diffuse out. If the diffusing substances meet others, from which they were separated by the semipermeable surface layer before it was ruptured, it is

${ }^{65}$ In many caises rupture of the plasma membrane causes the protoplasm to disintegrate and mix with the surrounding medium. In other cases the surface layer is at once reconstituted. 
easy to see that reactions may occur which may produce the responses characteristic of mechanical stimulation. The occurrence of such reactions seems probable, since many cases are known where substances in close juxtaposition are prevented from reacting by the presence of semipermeable layers: when these layers are destroyed (by crushing the cells) the reaction at once takes place.

If these processes occur it is evident that purely physical alterations in the protoplasm can give rise to chemical changes. Responses to contact and mechanical stimuli may thus be explained; and since gravitational stimuli involve deformation of the protoplasm we may extend this conception to geotropism. ${ }^{66}$

In this conception of mechanical stimulation the essential things are (1) substances which are more or less completely prevented from reacting by semipermeable surfaces, (2) a deformation of the protoplasm sufficient to produce in some of these surfaces a rupture which is not at once repaired, (3) a resulting reaction which produces the characteristic response to the stimulus.

Some authors (particularly Lillie and Höber) ${ }^{67}$ assume that stimulation is always associated with a change in permeability, whereby the cell surface (which is

${ }^{60}$ Small (1918) has made experiments on geotropism by inserting electrodes (a short distance apart) near the tip of the root and measuring the electrical conductivity before and during stimulation. He states that when the root is placed at angle to the vertical the resistance of both the upper and lower sides decreases, but the decrease is less in the upper side. He interprets this to mean that the permeability of both sides increases, but the increase is less in the upper side: in consequence it is more turgid and thus causes the downward bending of the tip.

Owing to the source of error in this method it is difficult to judge of the value of the results. It seems highly probable that upon changing position of the root there would be a movement of liquids and gases in the intercellular spaces which would change the conductivity.

${ }^{67}$ Lillie $(1911,1913,1914, A, B)$; Hölser (1914). 
assumed to be permeable in the resting state to kations, but impermeable to anions $)^{68}$ suddenly becomes permeable to anions, and hence becomes electrically negative. This hypothesis has been favorably received in some quarters, but according to Loeb and Beutner, ${ }^{69}$ such assumptions are unnecessary. The conclusions of Loeb and Beutner are based on accurate quantitative experiments and in addition they have succeeded in imitating artificially some of the most important phenomena, both qualitatively and quantitatively.

It may be added that the facts mentioned above ${ }^{70}$ show that the electric current passes readily through the protoplasm. This could not be the case if it were not permeable to both anions and kations.

For further information, the reader is referred to the literature quoted, as a detailed discussion lies outside the scope of the present work.

The facts set forth in this chapter indicate that changes in permeability may be followed by determining electrical conductivity. These alterations are evidently important, since they may affect all the fundamental lifeprocesses. It has been shown that a study of such changes by means of electrical measurements makes it possible to treat such conceptions as vitality, injury, recovery, and death in a quantitative manner. It also enables us to predict the behavior of tissues, especially in respect to injury and recovery, and leads directly to a quantitative theory of the mechanism of certain fundamental life processes.

${ }^{68}$ The idea that the cell surface may be permeable to only one kind of ions was suggested by Ostwald (1890).

${ }^{69}$ Loeb $(1915, B)$; Loeb and Beutner $(1911,1912,1913, A, B, 1914)$; Beutner, (1912, $A, B ; 1913, A, B, C, D, E, 1920$ ).

${ }^{70}$ See pages 46 and 200. 


\section{BIBLIOGRAPHY*}

Alcork, N. H. 1906. The action of anesthetics on living tissue. I. Action on the isolated nerve. II. The frog's skin. Proc. Roy. Soc., London, Ser. B, $77: 267,1905,78: 159,1906$.

Baskerville, C. 1911. The chemistry of anesthetics. Science $N$. S. $34: 161$.

Becker, G. F. and Van Orstrand, C. E. 1909. Smithsonian mathematical tables, hyperbolic functions. Washington.

Bernard, Claude. 1879. Leçons sur les phénoménes de la vie communs aux animaux et aux végétaux. 1:28. Paris.

Beutner, R. 1912, A. Potential differences at the junction of immiscible phases. Trans. Am. Electrochem. Soc. 21:219.

Beutxer, R. 1912, B. Die physikalische Natur bioelektrischer Potentialdifferenzen. Biochem. Zeit. $47: 73$.

Beutrer, R. 1913, A. New galvanic phenomena. Am. Jour. Physiol. $31: 343$.

Beutner, R. 1913, B. Water-immiscible organic liquids as central conductors in galvanic cells. Trans. Am. Electrochem Soc. 23:401.

Beutner, R. 1913, C. Neue Erscheinungen der Elektrizitätserregung welsche einige bioelektrische Phänomene erklären. Ztschr. f. Elektrochemie $319: 467$.

Beutser, R. 1913, D. On a new kind of electromotive force and some possible applications of physico-chemical reactions. Jour. Am. Chem. Soc. $35: 344$.

BeutNer, R. 1913, E. New electric properties of a semi-permeable membrane of copper ferrocyanide. Jour. Phys. Chem. 17:344.

Beutner, R. 1920. Die Enstehung elektrischer Ströme in lebenden Geweben. Stuttgart.

Botazzi, F. 1911. Das Cytoplasma und die Körpersäfte, in H. Winterstein's Handbuch der vergl. Physiol. I.

Bugarsky, S. and Tangl, F. 1897. Eine Methode zur Bestimmung des relativen Volums der Blutkörperchen und des Plasmas. Zentralbl. $f$. Physiol. 2:297.

Brooks, M. M. 1918. Comparative studies on respiration. III. The effect of ether on the respiration and growth of Bacillus subtilis. Jour. Gen. Physiol. $1: 193$.

* No attempt has been made to give a complete bibliography. In general only those papers are listed which are mentioned in the text. 
Brooks, M. M. 1919. Comparative studies on respiration. VIII. The respiration of B. subtilis in relation to antagonism. Jour. Gen. Physiol. $2: 5$.

Brooks, M. M. 1920. Comparative studies on respiration. X. Toxic and antagonistic effects of magnesium in relation to the respiration of B. subtilis. Jour. Gen. Physiol. 2:331.

Brooks, M. M. 1921, A. Comparative studies on respiration. XIV. Antagonistic action of lanthanum as related to respiration. Jour. Gen. Physiol. $3: 337$.

Brooks, M. M. 1921, B. Comparative studies on respiration. XV. The effect of bile salts and of saponin on respiration. Jour. Gen. Physiol. 3:527. Brooks, M. M. 1922. The penetration of kations into living cells. Jour. Gen. Physiol. $4: 347$.

Brooks, S. C. 1916, A. Studies on exosmosis. Am. Jour. of Botany 9:483.

Brooks, S. C. 1916, B. A study of permeability by the method of tissue tension. Am. Jour. of Botany 10:562.

Brooks, S. C. 1917, A. Methods of studying permeability of protoplasm to salts. Bot. Gaz. 64:230.

Brooks, S. C. 1917, B. A new method of studying permeability. Bot. Gaz. $64: 306$.

Brooks, S. C. 1917, C. Permeability of the cell walls of Allium. Bot. Gaz. $64: 509$.

Carson-White, E. P. and Loeb, L. 1910. Ueber den Einfluss physikalisch schädigender Agentien (Wärme) auf das Wachstum der Tumorzellen. Centralbl. f. Baht. I Abt. 56:325.

Chambers, R. 1915. Microdissection studies of the physical properties of protoplasm. The Lancet-Clinic. Cincinnati. (March, 1915).

Chambers, R. 1917. Microdissection studies. I. The visible structure of cell protoplasm and death changes. Am. Jour. Physiol. 43:1.

Chambers, R. 1920. Some studies on the surface layer in the living egg cell. Proc. Soc. Exp. Biol. and Med. 17:41.

Chambers, R. 1921. Studies on the organization of the starfish egg. Jour. Gen. Physiol. 4:41.

CrIle, G. W. 1921. A physical interpretation of shock, exhaustion and restoration. London.

Crozier, W. J. 1916, A. Cell penetration by acids. Jour. Biol. Chem. $24: 255$.

Crozier, IV. J. 1916, B. Cell penetration by acids III. Data on some additional acids. Jour. Biol. Chem. 26:225.

Crozier, W. J. 1918. Cell penetration by acids IV. Note on the penetration of phosphoric acid. Jour. Biol. Chem. $33: 463$. 
Crozier, W. J. 1919. Intereellular aeidity in Valonia. Jour. Gen. Physiol. $1: 581$.

CzapeK, F. 1911. Ueber eine Methode zur direkten Bestimmung der Oberfliehenspannung der Plasmahaut von Pflanzenzellen. Jena.

CzapeK, F. 1913-20. Bioehemie der Pflanzen. Jena.

Dixov, H. H., and Atkixs, W. R. G. 1913. Osmotic pressure in plants I. Methods of extracting sap from plant organs. Sci. Proc. Roy. Dub. Soc. $13: 422$.

EHrLICH, P. 1893. Konstitution, Verteilung und Wirkung chemischer Körper. Leipzig.

Fenn, W. O. 1916, A. Salt antagonism in gelatine. Proc. Nat. Acad. of Sciences. $2: 534$.

FENN, W. O. 1916, B. Similarity in the behavior of protoplasm and gelatine. Proc. Nat. Acad. of Sciences. 2:539.

Fens, W. O. 1918. The effects of mixtures of salts on the preeipitation of gelatine by aleohol. Antagonism. Jour. Biol. Chem. 34:141.

Fleischer, M. S., Corson-White, E. P., and Loeb, L. 1912. Ueber die gegenseitige Beeinflussung des Wachstums zweier Tumoren mit variabler Waehstumenergie. Centralb. f. Bakt. 63:450.

Gaidukov, N. 1910. Dunkelfeldbeleuchtung und Ultramikroscopie in der Biologie und in der Medizin. Jena.

Galeotт, G. 1901. Ueber die elektrische Leitfiihigkeit der tierisehen Gewebe. Zeitschr. f. Biologie 43:289.

Galeotri, G. 1903. Neue Untersuehungen iiber die elektrisehe Leitfähigkeit und den osmotisehen Druck der tierisehen Gewebe. Zeitschr. f. Biologie 45:65.

Garmus, A. 1912. Die Permeabilität der Drüisenzellen für Farbstoffe. Zeitschr. f. Biol. 58:185.

Gildemeister, M. 1913. Ueber die physikalisehen-ehemisehen und physiologisehen Vorgänge im mensehliehen Körper auf denen der psyehogalvanische Reflex beruht. Münch. Mediz. Wochenschr. 43:2389.

Goldmans, E. E. 1912. Die äussere und innere Sekretionen des Organismus in Liehte der vitalen Farbung. Tübingen.

Gortner, R. A., Lawrence, J. V., and Harris, J. A. 1916. The extraetion of sap from plant tissues by pressure. Biochem. Bull. 5:139.

Gortner, R. A., and Harris, J. A. 1914. Notes on the teehnique of the determination of the freezing point of vegetable saps. Plant World $17: 49$.

Gray, J. 1913, A. The effeets of hypertonic solutions on the eggs of Echinus. Proc. Camb. Phil. Soc. $17: 1$.

GraY, J. 1913, B. The electrieal conductivity of fertilized and unfertilized eggs. Jour. Marine Biol. Assoc. 10:50.

GraY, J. 1915. Note on the relation of spermatozoa to electrolytes and its bearing on fertilization. Quart. Jour. Micros. Soc. 61:119. 
Gray, J. 1916. The electrical conductivity of echinoderm eggs and its bearing on the problems of fertilization and artificial parthenogenisis. Phil. Trans. Roy. Soc. Lond. Ser. B. $207: 481$.

Grees, N. B. 1917. The use of the vibration galvanoneter with a 60cycle alternating current in the measurement of the conductivity of electrolytes. Am. Jour. Bot. 4:411.

Green, N. B. 1918. The effect of ions of sodium chloride and calcium cliloride upon the electrical conductivity of certain colloid mixtures. Plant World 21:303.

Gustafson, F. G. 1918. Comparative studies on respiration. II. The effect of anæstletics and other substances on the respiration of Aspergillus niger. Jour. Gen. Physiol. $1: 181$.

Gustafson, F. G. 1919. Comparative studies on respiration. IX. The effects of antagonistic salts on the respiration of Aspergillus niger. Jour. Gen. Physiol. 2:17.

HAAs, A. R. C. 1916, A. The effect of the addition of alkali to sea-water upon the lydrogen ion concentration. Jour. Biol. Chem. 26:515.

HAAS, A. R. C. 1916, B. The permeability of living cells to acids and alkalies. Jour. Biol. Chem. 27:225.

HAAs, A. R. C. 1919, A. Respiration after deatl. Botan. Gazette, $67: 347$. HAAs, A. R. C. 1919, B. Effect of anestheties on respiration. Botan. Gazette $67: 377$.

Hall, R. E., and Adams, L. H. 1919. Application of the thermionic amplifier to conductivity measurements. Jour. Am. Chem. Soc. 41:1515.

Hansteen-Cranner, B. 1910. Ueber das Verhalten der Kulturpflanzen zu den Bodensalzen. I und II. Prings. Jahrb. f. w. Bot. 47:289.

Hansteen-Cranner, B. 1914. Ueber das Verhalten der Kulturpflanzen zu den Bodensalzen III. Beiträge zur Biochemie und Physiologie der Zellwand lebender Zellen. Prings, Jahrb. f. w. Bot. 53:536.

Hanstein, J. 1870. Ueber die Bewegungsercheinungen des Zellkerns in ihren Beziehungen zum Protoplasma. Sitzungsber d. niederrhein. Ges, in Bonn. 27:217.

HARver, E. N. 1912, A. A simple method of making artificial cells resembling sea urchin eggs in certain of their physical properties. Science N. S. $36: 564$.

Harvey, E. N. 1912, B. A new type of artificial cell suitable for permeability and other biochemical studies. Biochem. Bull. 2:50.

Harvey, E. N. 1914. The permeability of cells for acids. Internat. Zeitschr. für physik-chem. Biologie 1:463.

Henri, V. et Calugareanu, D. 1902, A. Étude de la résistance des globules rouges par la méthode de conductibilité électrique. $C$. $R$. Soc. d. Biol. 54:210. 
Henri, V. et Calugareanu, D. 1902, B. La résistance des globules rouges du sang déterminée par la conductibilité électrique. $C . R$. Acad. d. sc. 134:483.

Hibbard, R. P. and Chapman, C. W. 1915. A simplified apparatus for measuring the conductivity of electrolytes. Mich. Agr. Coll. Tech. Bull. 23.

Höвer, R. 1914. Physikalische Chemie der Zelle u. der Gewebe. Vierte auflage. Leipzig.

Hofmeister, Fr. 1891. Die Beteilung gelöster Stoffe an Quellungsvorgängen. Arch f. exper. Path. u. Pharm. 28:223.

Hofmeister, Fr. 1901. Die chemische Organisation der Zelle. Naturw. Rundschau. $16: 581,600,612$.

Hopkins, F. G. 1913. The dynamic side of biochemistry. Nature 92:213

Huxley. T. H. 1906. On the physical basis of life. Lay sermons. addresses and reviews. London.

Inmax, O. L. 1921, A. Comparative studies on respiration. XVII. Decreased respiration and recovery. Jour. Gen. Physiol. 3:663.

InmaN, O. L. 1921, B. Comparative studies on respiration. XX. The cause of partial recovery. Jour. Gen. Physiol. 4:1.

IRwIN, M. 1918, A. Comparative studies on respiration. V. The effect of ether on the production of carbon dioxide by animals. Jour. Gen. Physiol. 1:209.

InwIN, M. 1918, B. Comparative studies on respiration. VI. Increased production of carbon dioxide accompanied by decrease of acidity. Jour. Gen. Physiol. 1:399.

JoEx, A. 1915. Ueber die Einwirkung einiger indifferenter Narcotica auf die Permeabilität roter Blutkörperchen. Pflüger's Archiv. 161:5.

Kanitz, A. 1915. Temperatur und Lebensvorgänge. Berlin.

Katz, G. 1918. Ueber den Einfluss der Narcotica auf die Durchlässigkeit von Blutkörperchen für Traubenzucker und Harnstoff. Biochem. Zeitschr. $90: 153$.

KITE, G. L. 1913. The relative permeability of the surface and interior portions of the cytoplasm of animal and plant cells. Biol. Bull. 25:1. KodIs, T. 1901. The electrical resistance in dying muscle. Am. Jour. Physiol. $5: 267$.

KüнNE, W. 1864. Untersuchungen über das Protoplasma und die Kontraktibilität. Leipzig.

Küster, E. 1909. Ueber die Verschmelzung nakter Protoplasten. Ber. d. d. bot. Ges. $27: 589$.

Küster, E. 1910, A. Über Veränderungen der Plasmaoberfäche bei Plasmolyse. Zeitschr. f. Bot. 2:689. 
Küster, E. 1910, B. Eine Methode zur Gewinnung abnormer grossen Protoplasten. Arch f. Entwicklungsmech. 30:351.

Küster, E. 1911. Ueber die Aufnahme von Anlinfarben in lebenden Pflanzenzellen. Prings. Jahrb. f. wiss. Bot. 50:261.

LANGMUIR, I. 1917. The constitution and fundamental properties of solids and liquids. II. Liquids. Jour. Am. Chem. Soc. 39:1848.

LePeschkin, W. W. 1911. Zur Kenntniss der chemischen Zusammensetzung der Plasmamembran. Ber. deutsch. bot. Ges. 29:247.

LILLIE, R. S. 1911. The relation of stimulation and contraction in irritable tissues to changes in the permeability of the limiting membranes. Am. Jour. Physiol. 28:197.

LILlIE, R. S. 1912, A. Antagonism between salts and anesthetics. I. On the conditions of the anti-stimulating action of anesthetics with observations on their protective or antitoxic action. Am. Jour. Physiol. $29: 372$.

LILliE, R. S. 1912, B. Antagonism between salts and anesthetics. II. Decrease by anesthetics in the rate of toxic action of pure isotonic salt solutions on unfertilized starfish and sea urchin eggs. Am. Jour. Physiol. $30: 1$.

LILlIE, R. S. 1913, A. Antagonism between salts and anesthetics. III. Further observations showing parallel decrease in the stimulating, permeability-increasing, and toxic actions of salt solutions in the presence of anesthetics. Am. Jour. Physiol. 31:255.

LILliE, R. S. 1913, B. The physico-chemical conditions of anesthetic action. Sci. N. S. $37: 959$.

LiLlie, R. S. 1913, C. The rôle of the membranes in cell-processes. Pop. Sci. Mo. $82: 132$.

LILliE, R. S 1914, A. The general physico-chemical conditions of stimulation of living organisms. Pop. Sci. Mo. 84:579.

LILLIE, R. S. 1914, B. The conditions determining the rate of conduction in irritable tissues and especially in nerve. Am. Jour. Physiol. 34:414.

Jillie, R. S. 1916. Theory of anesthesia. Biol. Bull. 30:311, 334, 363.

LILliE, R. S. 1918. Comparative permeability of fertilized and unfertilized eggs to water. Sci., N. S. 47:147.

Lillie, R. S. 1921. A simple case of salt antagonism in starfish eggs. Jour. Gen. Physiol. 3:783.

LIPMAN, C. B. 1909. Toxic and antagonistic effects of salts as related to ammonification by Bacillus subtilis. Bot. Gaz. 48:105.

LipmaN, C. B. 1912-13, A. Antagonism between anions as affecting ammonification in soils. Centralb. f. Bakteriol. 2te Abt. 36:389.

Lipman, C. B. 1914. Antagonism between anions as related to nitrogen transformation in soils. Plant World $17: 295$. 
Lipman, C. B. and Burgess, P. S. 1914, A. Antagonism between anions as affecting soil bacteria. Centralb. f. Bakteriol. 2te Abt. 41:430.

LipMAN, C. B. and Burgess, I'. S. 1914, B. Antagonism between anions as affecting soil bacteria. III. Nitrogen fixation. Centralb. f. Bakteriol. 2te Abt. 42:502.

Lıpschürz, A. 1915. Allegemeine Physiologie des Todes. Braunschweig. LoEB, J. 1897. Physiologische Untersuchungen ïber Ionenwirkungen. I. Versuche am Muskel. Pflüger's Archiv. 69:1.

Losb, J. 1899. Ueber die Aehnlichkeit der Fliissigkeitsresorption in Muskeln und in Seifen. Pflüger's Archiv. 75:308.

LoEs, J. 1900. On ion-proteid compounds and their rôle in the mechanics of life phenomena I. Poisonous character of a pure $\mathrm{NaCl}$ solution. Am. J. Physiol. 3:327.

LoEb, J. 1902. Studies on the physiological effects of the valency and possibly the electrical charges of anions. I. The toxic and anti-toxic effects of ions as a function of their valency and possibly their electrical charge. Am. Jour. Physiol. 6:411.

Loeb, J. 1903. Ueber die relative Giftigkeit von destillirtem Wasser, Zuckerlösungen und Lơsungen von einzelnen Bestandtheilen des Seewassers für Seethiere. Pflüger's Archiv. 97:394.

LokB, J. 1905. Weitere Bemerkungen zur Theorie der antagonistichen Salzwirkungen. Pflüger's Archiv. 107:252.

Loeв, J. 1906, A. Ueber die Ursachen der Giftigkeit einer reinen Chlornatriumlösung und ihrer Entgiftung durch $\mathrm{K}$ und $\mathrm{Ca}$. Biochem. Zeit. $2: 87$.

LoEB, J. 1906, B. Dynamics of living matter. New York.

LOEB, J. 1909. Ueber physiologische Ionenwirkungen, inbesondere die Bedeutung der Na-, Ca- unù K-ionen. Opperheimer's Handbuch der Biochemie des Menschen und der Tiere. Jena.

Lовв, J. 1911, A. Die Erhöhung der Giftwirkung von $\mathrm{KCl}$ durch niedrige Konzentrationen von $\mathrm{NaCl}$. Biochem. Zeitschr. 32:155.

Lоeв, J. 1911, B. Ueber die Entgiftung von Kaliumsalzen durch die Salze von Calcium und anderen Erdalkalimetallen. Biochem. Zeitschr. $32: 308$.

Loeb, J. 1911, C. Ueber den Mechanismus der antagonistischen Salzwirkungen. Biochem. Zeitschr. 36:275.

LoEB, J. 1911, D. The role of salts in the preservation of life. Science N. S. $34: 653$.

Loeb J. 1912, A. Ueber die Entgiftung von Natriumbromid. Biochem. Zeitschr. 39:185.

Lokв, J. 1912, B. Ueber die Hemmung der Giftwirkung von $\mathrm{NaJ}, \mathrm{NaNO}_{2}$, NaCNS und anderen Natriumsalzen. Biochem. Zeitschr. 43:181. 
LoEB, J. 1912, C. Untersuchungen über Permeabilität und antagonistische Elekrolytwirkung nach einer neuen Methode. Biochem. Zeitschr. $47: 127$.

Loks, J. 1912, D. The mechanistic conception of life. Chicago.

LOEB, J. 1912, E. Antagonistic action of electrolytes and permeability of the cell membrane. Science N. S. 36:637.

LoEB, J. 1913. Artificial parthenogenesis and fertilization. Chicago.

LoEB, J. 1914. Is the antagonistic action of salts due to oppositely charged ions? Jour. Biol. Chem. 19:431.

Loeb, J. 1915, A. Weber's law and antagonistic salt action. Proc. Nat. Acad. Sci. 1:439.

LоEв, J. 1915, B. Electromotive phenomena and membrane permeability. Science N. 8. $42: 643$.

LoeB, J. 1915, C. The mechanism of antagonistic salt action. Proc. Nat. Acad. Sciences 1:473, 439 .

LosB, J. 1916, A. The mechanism of the diffusion of electrolytes through the membranes of living cells I. The necessity of a general salt effect upon the membrane as a prerequisite for this diffusion. Jour. Biol. Chem. $27: 339$.

Loeb, J. 1916, B. II. The diffusion of $\mathrm{KCl}$ out of the egg of Fundulus and the relative efficiency of different ions for the salt effect. Jour. Biol. Chem. $27: 353$.

LoEb, J. 1916, C. III. The analogy of the mechanism of the diffusion for acids and potassium salts. Jour. Biol. Chem. 27:363.

LoEB, J. 1916, D. IV. The ratio of the concentration required for the accelerating and antagonistic action upon the diffusion of potassium salts. Jour. Biol. Chem. 28:175.

Loeb, J. 1916, E. The organism as a whole. New York.

LoEв, J. 1917. V. The additive effect of salt and base and antagonistic efiect of salt and acid. Jour. Biol. Chem. 32:147.

LoEB, J. 1918. Ionization of proteins and antagonistic salt action. Jour. Biol. Chem. $33: 531$.

Loeb, J., and Beutner, R. 1911, A. On the nature and seat of the electromotive forces manifested by living organs. Science N. S. 34:884.

Loeb, J., und Beutner. R. 1911, B. Ueber die Potentialdifferenzen an der unverletzten und verletzten Oberfläche pflanzlicher und tierischer Organe. Biochem. Zeitschr. $41: 1$.

Loeb, J., und Beutner, R. 1912. Die Ursachen des Verletzungsstromes. Biochem. Zeitschr. $44: 303$.

Loeb, J. and Beutner, R. 1913, A. The nature of substances which cause the bio-electrical potential differences. Science N. \&. 37:672. 
Loeb, J., und Beutner, R. 1913, B. Einfluss der Anesthetica auf die Potentialdifferenz an der Oberfiliche pflanzlicher und tierischer Gewehe. Biochem. Zeitschr. $51: 300$.

Loeb, J., und Beutner, R. 1914. Ueber die Bedeutung der Lipoide fuir die Enstehung von Potentialunterschieden an der Oberfläche tierischer Organe. Biochem. Zeitschr. 59:195.

Loeb, J., und Wasteneys, II. 1910. Warum hemmt Natriumcyanid die Giftwirkung einer Chlornatriumlösung für das Seeigelei? Biochem. Zeitschr. $28: 340$.

Loeb, J., und Wasteners, H. 1911, A. Die Entgiftung von Natriumchlorid durch Kaliumchlorid. Biochem. Zeitschr. 33:480.

Loeb, J., und Wasteneys, H. 1911, B. Die Entgiftung von Säuren durch Salze. Biochcm. Zeitschr. $33: 489$.

Loeb, J., und Wasteners, H. 1912. Weitere Versuche iiber die Entgiftung von Säure durch Salze. Biochem. Zeitschr. 39:167.

Loeb, J., and Cattell, McKeen. 1915. The influence of electrolytes on the diffusion of potassium out of the cell and into the cell. Jour. Biol. Chem. $23: 41$.

Loes, L. 1903. Der normale und pathologische Zyklus im Ovarium des Säugetiers. Virchow's Archiv. 162:345.

Loeb, L. 1905. On some conditions determining variations in the energy of tumor growth. Amer. Medicine 10:265.

Loewe, S. 1913. Membran und Narkose. Weitere Beiträge zu einer kolloidchemischen Theorie der Narkose. Biochem. Zeitschr. 57:161.

Magowax, F. N. 1908. The toxic effect of certain common salts of the soil on plants. Bot. Gaz. 45:45.

MAMELI, E. 1908. Sulla conducibilita elettrica dei succhi e dei tessuti vegetali. Atti del $R$. istit. Botan. di Pavia. 12:285.

McClendon, J. F. 1910, A. On the dynamics of cell division. II. Changes in permeability of developing eggg to electrolytes. Am. Jour. Physiol. $27: 240$.

McClendon, J. F. 1910, B. The increased permeability of striated muscle to ions during contraction. Am. Jour. Physiol. 29:302.

McClendon, J. F. 1917. Physical chemistry of vital phenomena. Princeton. McClendon, J. F. 1920. Methods used in determining the electric conductivity of solutions. Jour. Biol. Chem. $43: 317$.

Marriesco, G. 1912. Forschungen über den kolloiden Bau der Nervenzellen und ihre erfahrungs-gemäissen Verïnderungen. Koll. Zeitschr. $11: 203$.

Mellor, J. W. 1909. Chemical statics and dynamies. London.

Metcalf, M. V. 1905. Über feste Peptonhaiitchen auf einer Wasserfiäche und die Ursache ihrer Entstehung. Zeit. f. Physik. Chemie. 52:1. 
Merer, A. 1891. Notiz über die Zusammensetung des Zellsaftes von Valonia utricularis. Bericht. deut. bot. Gesell $9: 77$.

Meyer, H. H. 1899. Zur Theorie der Alkoholnarkose. Welche Eigenschaft der Anæsthetica bedingt ihre narkotische Wirkung? Arch. exper. Pathol. 42:109.

MIYAKe, $K$. 1913. The influence of salts common in alkali soils upon the growth of the rice plant. Jour. Biol. Chem. 16:235.

Moore, A. 1901. The effect of ions on the contraction of the lymph hearts of the frog. Am. Jour. Physiol. 5:87.

Moone, A. 1902. On the power of $\mathrm{Na}_{2} \mathrm{SO}_{4}$ to neutralize the ill effects of NaCl. Am. Jour. Physiol. 7:315.

Moore, B., and RoAf, H. E. 1905. On certain physical and chemical properties of solutions of chloroform and other anesthetics. Proc. Roy. Soc. Lond. B $77: 98$.

NÄgeri, C. voN. 1S85. Primordialschlauch und Diosmose der Pflanzenzelle. Pflanzenphysiologische Untersuchungen von C. von Nägeli und C. Cramer. $1: 5$.

Nathasson, A. 1904. Ueber die Regulation der Aufnahme anorganischer Salze durch die Knollen von Dahlia. Prings. Jahrb. f. utss. Bot. $39: 607$.

Nernst, W. 1904. Theoretical chemistry. London.

Newberry, E. 1919. A new method for the determination of conductivity. Jour. Chem. Soc. $113: 701$.

van Orstrand, C. E. 1921. Tables of the expotential functions. Washington.

Osterhout, W. J. V. 1908. On plasmolysis. Bot. Gaz. 46: 53-55.

Osterhout, W. J. V. 1909. On the penetration of inorganic salts into living protoplasm. Zeit. für physik. Chemie 70: 408-413.

(Isterhout, W. J. V. 1911. The permeability of living cells to salts in pure and balanced solutions. Science N. S. 34: 187-189.

Osteriout, W. J. V. 1912, A. The permeability of protoplasm to ions and the theory of antagonism. Science N. S. 35: 112-115.

Osteriout, W. J. V. 1912, B. Reversible changes in permeability produced by electrolytes. Science N. S. 36: 350-352.

Osterhout, W. J. V. 1912, C. Some chemical relations of plant and soil. Ścience $N$. S. 36: 571-576.

Osterhout, W. J. V. 1913, A. The effect of anesthetics upon permeability. Science N. S. 37: 111-112.

Osterhout, W. J. V. 1913, B. Some quantitive researches on the permeability of plant cells. Plant World 16: 129-144.

Osterhout, W. J. V. 1913, C. Protoplasmic contractions resembling plasmolysis which are caused by pure distilled water. Bot. Gaz. 55: 446-451. 
Osterhout, W. J. V. 1913, D. The organization of the cell with reference to permeability. Science $N$. S. 38: 408-409.

Osterhout, IV. J. V. 1914, A. The chemical dynamies of living protoplasm. Science N. S. 39: 544-546.

Osteriout, W. J. V. 1914, B. Quantitative criteria of antagonism. Bot. Gaz. 58: 178-186.

Osterhout, IV. J. V. 1914, C. The mcasurement of antagonism. Bot. Gaz. 58: 272-276.

Osterhout, W. J. V. 1914, D. Vitality and injury as quantitative conceptions. Science $N$. S. $40: 488-491$.

Osterhout, W. J. V. 1914, E. The forms of antagonism curves as affected by concentration. Bot. Gaz. 58: 367-371.

Osternout, W. J. V. 1914, F. The effect of alkali on permeability. Jour. Biol. Chem. 19: 335-343.

Osterhout, IV. J. V. 1914, G. The effect of acid on permeability. Jour. Biol. Chem. 19: 493-501.

Osterhout, W. J. V. 1914, H. Antagonism between acids and salts. Jour. Biol. Chem. 19: 517-520.

Osteriout, W. J. V. 1914, I. Ueber den Temperaturkoeffizient des elektrischen Leitvermögens im lebenden und toten Gewebe. Biochem. Zeitschr. 67: 272-277.

Osteritout, W. J. V. 1915, A. The nature of antagonism. Science $N$. S. 41 : $255-256$.

Osterhout, W. J. V. 1915, B. Extreme alterations of permeability without injury. Bot. Gaz. 59: 242-253.

Osteriout, W. J. V. 1915, C. Normal and abnormal permeability. Amer. Jour. of Botany 2: 93-94.

Osterhout, W. J. V. 1915, D. On the decrease of permeability due to certain bivalent kations. Bot. Gaz. 59: 317-330.

Osterhout, W. J. V. 1915, E. The effect of some trivalent and tetravalent kations on permeability. Bot. Gaz. 59: 464-473.

Osterhout, W. J. V. 1915, F. The determination of additive effects. Bot. Gaz. 60 : 22S-234.

Osterhout, W. J. V. 1915, G. The measurement of toxicity. Jour. Biol. Chem. 23: 67-70.

Osterhout, W. J. V. 1916, A. The decrease of permeability produced by anesthetics. Bot. Gaz. 61: 148-158.

Osterhout, W. J. V. 1916, B. Permeability and viscosity. Science $N$. S. $43: 857-859$.

Osterhout. W. J. V. 1916, C. Antagonism and Weber's law. Science N. S. $44: 318-320$.

()sternout, W. J. V. 1916, D. A dynamical theory of antagonism. Proc. Am. Phil. Soc. 55: 533-553. 
Osterhout, W. J. V. 1916, E. The penetration of balanced solutions and the theory of antagonism. Science N. S. 44: 395-396.

Osterhout, W. J. V. 1917, A. Similarity in the effects of potassium cyanide and of ether. Botan. Gaz. 63: 77-80.

Osterhout, W. J. V. 1917, B. Antagonism and permeability. Science N. S. 45: $97-103$.

Osterhout, W. J. V. 1917, C. Does the temperature coefficient of permeability indicate that it is chemical in nature? Bot. Gaz. 63: 317-320.

Osterhout, W. J. V. 1917, D. The dynamics of the process of death. Jour. Biol. Chem. 31: 585-589.

Osterirout, IV. J. V. 1917, E. Some aspects of the temperature coefficients of life processes. Jour. Biol. Chem. 32: 23-27.

Osteкночт, IV. J. V. 1917, F. An adaptation of Winkler's method to biological work. Jour. of Biol. Chem. 32: 141-146.

Osterhout, IV. J. V. 1918, A. The basis of measurement of antagonism. Jour. Biol. Chem. 34: 363-368.

Usterhout, W. J. V. 1918, B. Note on measuring the relative rates of life processes. Science N. S. 45: 172-174.

Osterhout, W. J. V. 1918, C. Conductivity as a measure of permeability. Jour. Biol. Chem. 36: 485-488.

Osterhout, W. J. V. 1918, D. Note on the effect of diffusion upon the conductivity of living tissue. Jour. Biol. Chem. 36: 488-490.

Osterhout, IV. J. V. 1918, E. A method of measuring the electrical conductivity of living tissues. Jour. Biol. Chem. 36: 557-568.

Osterhout, W. J. V. 1919, A. A comparative study of permeability in plants. Jour. Gen. Physiol. 1: 299-304.

Osterhout, W. J. V. 1919, B. Decrease of permeability and antagonistic effects caused by bile salts. Jour. Gen. Physiol. 1: 405-408.

Osterhout, IV. J. V. 1919, C. A comparison of permeability in plant and animal cells. Jour. Gen. Physiol. 1: 409-413.

Osterhout, IV. J. V. 1919, D. Antagonism between alkaloids and salts in relation to permeability. Jour. Gen. Physiol. 1: 515-519.

Osterhout, W. J. V. 1920, A. The mechanism of injury and recovery. Jour. Gen. Physiol. $3: 15$.

Osterhout, IV. J. V. 1920, B. A theory of injury and recovery. I. Experiments with pure salts. Jour. Gen. Physiol. $3: 145$.

Osterhout, W. J. V. 1921, A. A theory of injury and recovery. II. Experiments with mixtures. Jour. Gen. Physiol. 3:415.

Osterhout, W. J. V. 1921, B. The mechanism of injury and recovery of the cell. Science N. S. $53: 352$.

Osterhout, W. J. V. 1921, C. A theory of injury and recovery. III. Repeated exposures to toxic solutions. Jour. Gen. Physiol. 3:611. 
Osternout, W. J. V. 1921, D. Conductivity and permeability. Jour. Gen. Physiol. $4: 1$.

Osterhout, IV. J. V. 1922. Direct and indirect determinations of permeability. Jour. Gen. Physiol. 4:275.

Ostwald, Wr. 1890. Elektrische Figenschaften halbdurchliissiger Scheidewände. Zeitschr. f. physik. Chem. 6:71.

Overton, E. 1895. Ueber die osmotischen Eigenschaften der lebenden Pflanzen- und Thierzelle. Vierteljahrschr. d. Naturf. Ges. in Zïrich. $40: 159$.

Overton, E. 1900. Studien über die Aufnahme der Anilinfarben durelı die lebende Zelle. Jahrb. f. wiss. Botan. 43:669.

Overton, E. 1901. Studien über die Narkose. Jena.

Overton, E. 1902. Beiträge zur allgemeinen Muskel und Nerven-physiologie. I. Ueber die Eigenschaften der Muskclı. Pflüger's Arch. 92:115.

Pferfer, W. 1900. Physiology of plants. Trans. by A. J. Ewart. Cambridge.

Philippson, M. 1920. Sur la résistance électrique des cellules et des tissus. C. R. Soc. Belge Biol. $83: 1399$.

Philippson, M. 1921. Les lois de la résistance électrique des tissus vivants. Bull. de l'Acad. Roy. de Belgique, No. 6, juin, 1921.

PollaccI, G. 1907. Elettricitia e vegetazione. Atti dell'Inst. Bot. della. R. Università di Pavia. vol. 13 (N. S.).

Price, R. S. 1914. Some studies on the structure of the plant cell by the method of darkground illumination. Ann. of Bot. 28:601.

Raber, O. L. 1917. The synergetic action of electrolytes. Proc. Nat. Acad. Sci. $3: 688$.

RABER, O. L. 1920, A. A quantitative study of the effect of anions on the permeability of plant cells. Jour. Gen. Physiol. 2:535.

RABER, O. L. 1920, B. The antagonistic action of anions. Jour. Gen. Physiol. 2:541.

Raber, O. L. 1921, A. A quantitative study of the effect of anions on the permeability of plant cells. II. Am. Jour. Bot. $8: 366$.

RABER, O. L. 1921, B. The effect upon permeability of polyvalent kations in combination with polyvalent anions. Am. Jour. Bot. 8:382.

Raber, O. L. 1921, C. The effect upon permeability of (I) the same substance as kation and anion, and (II) changing the valency of the same ion. Am. Jour. Bot. 8:464.

RAMSDEN, W. 1904. Separation of solids in surface layers of solutions and suspensions. Proc. Roy. Soc. Lond. B. $72: 156$.

RIVERS-Moore, H. R. 1919. The conductivity of sea water. Electrician $82: 176$.

Robertson, T. B. 1906. Studies in the chemistry of the ion-proteid compounds. III. On the influence of electrolytes upon the toxicity of alkaloids. Jour. Biol. Chem. 1:507. 
Robertson, T. B. 1908. On the nature of the superficial layer in cells and its relation to their permeability and to the staining of tissues by dyes. Jour. Biol. Chem. $4: 1$.

Robertson, T. B. 1909. The proteins. University of California. Pub. in Physiology. $3: 115$.

Robertson, T. B. 1910. Ueber die Verbindungen der Proteine mit anorganischen Substanzen und ihre Bedeutung für die Lebensvorgänge. Ergebnisse der Physiologie 10:216.

Robertson, T. B. 1918. The physical chemistry of the proteins. N. Y. Rонре, Отто. 1906. Ueber Oberflächenfestigkeit bei Farbstofflösungen, uiber lichtelektrische Wirkung bei denselben und bei den Metallsulfiden. Drude's Ann. d. Physik. 19:935.

Rosentral, J. 1901. Lehrbuch der allegemeine Physiologie. Leipzig. Rотн, W. 1897. Elektrische Leitfähigkeit thierischer Flüssigkeiten. Zentralbl. f. Physiol. $11: 217$.

Ruhland, W. 1908. Die Bedeutung der Kolloiduatur wiisseriger Farbstofflösungen für ihr Eindringen in lebende Zellen. Ber. deutsch. bot. Ges. 26a : 772 .

Ruhland, W. 1909, A. Zur Frage der Ionenpermeabilität. Ztschr. $f$. Bot. $1: 747$.

Ruhland, IV. 1909, B. Beiträge zur Kenntnis der Permeabilität der Plasmahaut. Jahrb. f. wiss. Bot. 46:1.

Ruhland, W. 1912, A. Studien ïber die Aufnahme von Kolloiden durch die pflanzliche Plasmahaut. Prings. Jahrb. f. w. Bot. 51:376.

Ruhland, W. 1912, B. Die Plasmahaut als Ultrafilter bei der Kolloidaufnahme. Ber. deutsch. bot. Gesell. 30:130.

Ruhland, IV. 1913. Kolloidchemische Protoplasmastudien. Koll. Zeitschr. $12: 113$.

Rutherford, E. 1913. Radioactive substances and their radiations. Cambridge.

Schlesinger, H. I. and Reed, F. H. 1919. Studies in conductivity. V. Notes on the measurement of the conductivity of solutions. Jour. Am. Chem. Soc. $41: 1727$.

Schulemann, W. 1912. Vitalfärbung und Chemotherapie. I und II. Arch. d. Pharmazie 250:252.

ScHürt, K. 1904. Über Zähigkeit und Festigkeit in der Oberfläche von Flüssigkeiten und über flüssige Lamellen. Drude's Annalen der Physik. 4 teF, $13: 71$.

Schwartz, R. 1913. Ueber das galvanische Verhalten der konstant durchströmten Froschhaut bei Reizung ihrer Nerven. 'Änderung der Polarisation durch die Erregung. Zentralbl. f. Physiol. $27: 734$. 
Seifriz, W. 1918. Observations on the structure of protoplasm by the aid of microdissection. Biol. Bulletin 34:307.

Shearer, C. 1919, A. Studies on the action of electrolytes on bacteria. Part I. The action of monovalent and divalent salts on the conductivity of bacterial emulsions. Jour. of Iygienc 18:337.

Shearer, C. 1919, B. The action of electrolytes on the electrical conductivity of the bacterial cell and their effect on the migration of these cells in the electrical field. Proc. Camb. Phil. Soc. 19:263.

SHEARER, C. 1919, C. On the action of electrolytes on the conductivity of bacterial emulsions and their effect on the rate of migration of bacteria in an electric field. Contributions to medical and biological research dedicated to Sir William Osler in honour of his seventictl birthday, July 12, 1919.

SHoR'TER, S. G. 1909. The surface separation from solutions of saponin, peptone and albumin. Phil. Mag. 15:560.

SmalL, J. 1918. Changes of electrical conductivity under geotropic stimulation. Proc. Roy. Soc. Lond. 90:349.

SpaEth, R. 1916. The vital equilibrium. Science N. S., 43:502.

Stewart, G. N. 1897. Elektrische Leitfähigkeit thierische Flüssigkkeiten. Zentralbl. f. Physiol. $2: 332$.

Stewart, G. N. 1899. The behavior of the hæmoglobin and electrolytes of the colored corpuscles when blood is laked. Jour. of Physiol. 24:211.

Stewart, G. N. 1909. The mechanism of hæmolysis with special reference to the relation of electrolytes to cells. Jour. of Pharm. and Exper. Therap. $1: 49$.

Strles, W. and Jörgenson, I. 1914. The measurement of electrical conductivity as a method of investigation in plant physiology. New Phytologist 13:226.

Stone, G. E., and Chapman, G. H. 1912. Electrical resistance of trees. Twenty-fourth annual report of the Mass. Agric. Exp. Sta.

Szücs, J. 1912. Experimentelle Beiträge zu einer Theorie der antagonischen Ionenwirkungen. Prings. Jahrb. f. wiss. Bot. 52:85.

TAshiro, S. 1917. A chemical sign of life. Chicago.

TAYLOR, W. A., and ACREe, S. F. 1916. Studies in the measurement of the electrical conductivity of solutions at different frequencies. VII. Investigations of the true and apparent resistances, etc. Jour. Am. Chem. Soc. 38:2415.

TAYlor, W. A., and Curtis, H. L. 1915. An accurate method for the measurement of the conductivity of electrolytes. Phys. Rev. 6:61.

Tromas, H. S. 1918. Comparative studies on respiration. IV. The effect of ether on the respiration of wheat. Jour. Gen. Physiol. 1:203. 
Thornton, IV. M. 1912. The electrical conductivity of bacteria and the rate of sterilization of bacteria by electric currents. Proc. Roy. Soc. Lond. B. $85: 331$.

LE VRIES, H. 1885. Plasmolytische Studien über die Wand der Vacuolen. Jahrb. f. wiss. Bot. 16:465.

IVALLER, A. D. 1919. Concerning emotive phenomena. III. Influence of drugs on the electrical conductivity of the palm of the hand. Proc. Roy. Soc. Lond. (B) $91: 32$.

Washburn, E. W, and BeLL, J. E. 1913. An improved apparatus for measuring the conductivity of electrolytes. Jour. Am. Chem. Soc. $35: 177$.

Washburi, E. IV. 1916. Measurement of electrical conductivity. I. Theory of the design of conductivity cells. Jour. Am. Chem. Soc. $38: 2431$.

Washburn, E. W., and Parker, K. 1917. Measurement of electrolytic conductivity. II. Telephone receiver as an indicating instrument for use with the alternating current bridge. Jour. Am. Chem. Soc. $39: 235$.

Weibel, E. E., and Thuras, A. L. 1918. An electrical conductivity recorder for sanitary measurements. Jour. Ind. and Eng. Chem. $10: 626$.

Winterstein, H. 1916. Beiträge zur Kenntnis der Narkose und Permeabilitït. Biochem. Zeitschr. 71:75.

Wodehouse, R. P. 1917. Direct determinations of permeability. Jour. Biol. Chem. $29: 453$.

Woelfel, A. 1908. A note on the distribution of salts in hæmolysis. Biochem. Jour. 3:146.

Z d. Physiol. $7: 99$. 


\section{INDEX}

\section{A}

Acid, antagonism of, 163 effect on conductivity, 50, 51 penetration of, 211

Acree, 31

Additive eflect, $124 \mathrm{ff}$

Asculus, 182

Alcock, 21

Alcohol, effect on conductivity, 189

Alkali, effect on conductivity, 42 penetration of, 211

Alkaloids, antagonism of, $169 \mathrm{ff}$ effect on conductivity, 169 , ff 194

Alum, effect on conductivity, 49

Aluminum, penetration of, 203, 209 Ammonium, penetration of, 203, 208 Anweba, 227

Anesthetics, effect on conductivity, $184 \mathrm{fi}$

in relation to lipoid theory, 229

Anions, effect on conductivity, 40 Antagonism, 16, $124 \mathrm{ff}$

among anions, $175 \mathrm{ff}$

effect on penetration, 205

in relation to permeability, 214

opposite of, $124 \mathrm{fr}$, $179 \mathrm{ff}$

Arsenate, effect on conductivity, 40 Autocatalysis, 69

\section{B}

Bacteria, antagonism, 175

effect of acid on the conductivity of, 55

effect of calcium on the conductivity of, 175

effect of cerium on the conductivity of, 50

effect of lantianum on the conductivity of, 50 effect of potassium on the conductivity of, 175
Bacteria, effect of sodium on the conductivity of, 175

measurement of conductivity of, 22

Barium, effect on conductivity, 49 penetration of, 215

Baskerville, 184

Bayliss, 230

Becker, 67

Bell, 31

Beutner, 236

Bile salts, see sodium taurocholate

Bitter almond, 232

Brooks, M. M., 215, 232

Brooks, S. C., 159, 205, 206, 208, 225

Bugarsky, 21, 225

Burgess, 176

\section{C}

Cadmium, effect on conductivity, 46

Cæsium, penetration of, 203, 214

Caffeine, antagonism of, $171 \mathrm{ff}$ effect on conductivity, $171 \mathrm{fr}, 194$

Calcium chloride, penetration of, 206 , 209

Calcium, effect on conductivity, 48, $49,64,65,115 \mathrm{ff}$ effect on growth, 127 effect on viscosity, 179 penetration of, 203, 211, $214,215,216$ recovery after exposure to, $83,86,107$

Catenary reactions, $57 \mathrm{ff}, 75,98,122$ Cell sap, chemical tests of, 210,215 conductivity of, 199,200

Cerium, effect on conductivity, 49

Cerium chloride, penetration of, 209

Cevadine, antagonisin of, $171 \mathrm{ff}$ effect on conductivity,

$$
171 \mathrm{ff}, 194
$$

Chambers, 227

Chapman, 31 
Chlorella, 95, 96

measurement of conductivity of, 21

Chloride, effect on conductivity, 40 188

Chloroform, effect on conductivity, 188

Clowes, 182

Cobalt, effect on conductivity, 46

Conductivity, as a measure of permeability, 17

as affected by alcohol, 189

as afiected by alkali, 42

as affected by alkaloids, $169 \mathrm{ff}, 194$

as affected by alum, 49

as affected by anesthetics, $184 \mathrm{ff}$

as affected by anions, 40

as affected by arsenate, 40

as affected by barium, 49

as affected by cadmium, 46

as affected by caf. feine, $171 \mathrm{ff}, 194$

as affected by calcium, 48, 49, 64, 65

as affected by cerium, 49

as affected by cevadine, $171 \mathrm{ff}, 194$

as affected by chloral hydrate, 188

as affected by chlorate, 40

as affected by chloroform, 188

as affected by cobalt, 46

as affected by ether, $184 \mathrm{ff}$

as affected by formate, 40

as affected by gelation, 181

as affected by hydroxylion, 42
Conductivity, as affected by iron, 47

as affected by kations, 45

as affected by lanthanum, 47,49

as affected by mag. nesium, 49

as affected by manganese, 46,49

as affected by molybdate, 40

as affected by nickel, $46, \widetilde{49}$

as affected by nicotine, 169, 194

as affected by sodium chloride, 59 , $62,92,102 \mathrm{ff}, 178$

as affected by sodium citrate, 178

as affected by sodium iodide, 178

as affected by sodium nitrate, 178

as affected by sodium suphate, 178

as affected by sodium sulphocyanide, 178

as affected by strontium, 49

as affected by sulphate, 40

as affected by thorium, 47

as affected by tin, 47

as affected by vttrium, 47

as affected by zinc, 47

in relation to permeability, 17, $195 \mathrm{ff}$ measurement of, 21-39 of bacteria, $22,50,55$,

175

of Chlorella, 21

of Euglena, 21

of frog skin, 49, 50, $55,87,97,175,192$ of muscle, 21

of red blood corpuscles, 21 
Conductivity of Nittella, 35, 36

of Rhodymenia, 49, 50 , $56,87,97,174,175$, 193,197

of sea urchin eggs, 23, 50,225

of Ulva, 35, 49, 55, $87,97,174,193,196$ of Zostera, 35, 49, 87,

$88,97,174$

temperature coeffi-

cient of, 39

Corpora lutea, 97

Corson-White, 97

Crozier, 199, 211

Czapek, 232

D

Death, a normal part of life processes, 16

monomolecular curve of, 15

Diffusion method of measuring permeability, 159, $206 \mathrm{ff}$

Distilled water, preparation of, 38, 213

Dulse, see Rhodymenia

Dyes, penetration of, 210

Dynamic equilibrium, 183

\section{E}

Eel grass, see Zostera

Ehrlich, 228

Error, probable, 38

Erythrocytes, effect of anesthetics on conductivity of, 193

Ether, effect on conductivity, $184 \mathrm{ff}$

Euglena, measurement of conductivity, 21

Exosmosis as measure of permeability, 206 ff, 207

\section{F}

Fenn, 176

Fleischer, M. S., 97

Formate, effect on conductivity, 40 Frog skin, antagonism, 175

effect of acid on the conductivity of, 55

effect of anesthetics on the conductivity of, 192
Frog skin, effect of calcium on the conductivity of, 49

effect of lanthanum on

the conductivity of, 49

effect of magnesium on the conductivity of, 49

effect of potassium on the conductivity of, 50

effect of sodium on the conductivity of, 50

partial recovery of, 97

recovery after exposure to sodium and calcium, 87

Fundulus, 205

\section{G}

Gaidukov, 227

Galeotti, 21, 195

Garmus, 229

Gelation, effect on conductivity, 181

Geotropism, 235

Glucoside, 232

Goldman, 229

Gray, 21, 50, 225

Griffithsia, 230, 233

Growth, effect of calcium chloride on, 127

Gustafson, 232

\section{H}

Haas, 43, 232

Hall, 31

Hansen, 211

Hansteen-Cranner, 179

Hanstein, 227

Harvey, 227

Henri et Calugareanu, 21

Hibbard, 31

Höber, 21, 79, 192, 225, 227, 229, 230

Hofmeister, 232

Hopkins, 122

Horse chestnut, 182

Hydrogen ion, effect on conductivity, 50

Hydroxyl ion, effect on conductivity, 44

Hypertonic solutions, 95, 96 


\section{I}

Injury, 18, $79 \mathrm{ff}$

permanent, $92 \mathrm{ff}, 9 \mathrm{~S}$

Inman, 95, 96

Iron, effect on conductivity, 47

Irwin, 232

\section{$J$}

Janse, 212

Joel, 193

Jörgensen, 21, 31, 188, 196

\section{K}

Kations, effect on conductivity, 45

Katz, 192

Kite, 227, 228, 229

Kodis, 21, 22, 195

Kiihne, 227

Küster, 228, 229

\section{$\mathbf{L}$}

Laminaria, conductivity of cell sap, 199

measurement of conduc-

tivity, 23-39

Langmuir, 226

structure of, 197

Lanthanum, antagonism of, 166

effect on conductivity, 47,49

effect on viscosity, 179 recovery after exposure

Lasareff, 148

to, 83

Lepeschkin, 192

Life processes, effect of tempera-

ture on, 75

measurement of, 68

Lillie, R. S., 179, 192, 235

Lipman, 176, 179

Lipoid theory, $228 \mathrm{ff}$

Lithium, penetration of, 203, 215

Loeb, J., antagonism, 124

antagonism between acids and salts, 163

antagonism between

anions, 175

catenary reactions, 122

electrical phenomena and permeability, 236
Loeb, J., explanation of antagonism, 159,161

measurement of permeability in Fundulus, 205

opposite of antagonism, 179

Loeb, L., 97

Weber's law; 147

Loewe, 191

\section{M}

Magnesium, effect on conductivity, 49

penetration of, 203, 209

Mamelli, 21

Manganese, effect on conductivity, 46,49

Marinesco, 227

McClendon, 21, 225, 230

Measurement of antagonism, $124 \mathrm{ff}$ of life processes, 68 of toxicity, $71 \mathrm{ff}, 94$

Mechanical stimulation, 233

Mellor, 64, 66, 69

Metcalf, 227

Meyer, 211, 229

Miyake, 176

Nolybdate, effect on conductivity, 40

Monostroma, 196, 217

Monomolecular reactions, 57 ff, 62

Noore, 175, 191

Muscle, measurement of conductivity of, 21

\section{$\mathrm{N}$}

Nägeli, 227

Nathanson, 230

Nernst, 226

Newberry, 31

Nickel, effect on conductivity, 46,43

Nicotine, antagonism of, 169 effect on conductivity, 163 , 194

Nitella, 213

measurement of conductiv. ity of, 35

Nutritive effects, 146

Nitron, 215

\section{$\mathrm{O}$}

Osmotic pressure, 202

Ostwald, 236

Ovary, partial recovery of, 97

Overton, 227, 228, 229 


\section{INDEX}

\section{P}

Penetration from balanced solution's, 205, 214

Permeability, as measured by conductivity, 17, 195

as measured by diffusion, 206

as measured by exosulosis, 206, 207

as measured by tissue tellsion, 208

as a measure of vitality, 161

in relation to stimulation, $233 \mathrm{ff}, 235$

of unlike membranes

Pfeffer, 227, 228 in the cell, $231 \mathrm{II}^{\circ}$

Plasma membrane, $227 \mathrm{ff}$

Plasmolysis, 159, 201, 213

Pierce, 29

Polacci, 21

Porphyra, 217

Potassium cyanide, effect on permeability, 55 penetration of, 203

nitrate, penetration of, 208, 212

Price, 227

Probable error, 38

Protoplasm, conductance of, $219 \mathrm{ff}$

\section{$\mathbf{R}$}

Raber, 40, 41

Ramsden, 227

Reaction, catenary, 57 ff, 98, 122 monomolecular, 15

Reaction chamber hypothesis, 232

Recovery, 19, $79 \mathrm{ff}$

after exposure to alcohol 190

after exposure to calcium chloride, 107, $115 \mathrm{ff}$

after exposure to chloroform, 188

after exposure to ether, 186

after exposure to hyper-

tonic solutions, 95, 96
Recovery, after exposure to mixtures of sodium and calcium, 151 ff

after exposure to sodium chloride, $92,102 \mathrm{if}$, 110 ff

measured by rate of гевpiration, 95

partial, 92 ff

Red blood corpuscles, measurement of conductivity, 21 effect of anesthetics on conductiv-

Reed, 31 ity of, 19:3

Respiration, as affected by hypertonic solutions, 9; , 96

as affected by hypotonic solutions, 95,96 as affected by sodium

Rhode, 227 chloride, $95,96^{\circ}$

Rhodymenia, 49, 50

antagonism, 174

color changes of, 175 effect of aluminum on the conductivity of, 49

effect of anesthetics on the conductivity of, 193

effect of barium on the conductivity of, 49

effect of calcium on the conductivity of, 49

effect of cerium on the conductivity of, 49

effect of lanthanum on the conductivity of, 49

effect of magnesium on the conductivity of, 49

effect of manganese on the conductivity of, 49

effect of nickel on the conductivity of, 49 effect of potassium on the conductivity of, 50 
Rhodymenia, effect of sodium on the conductivity of, 50 effect of sodium taurocholate on the conductivity of, 56 effect of strontium on the conductivity of, 49

partial recovery of, 97 recovery after exposure to sodium and calcium, 87

structure of, 197

Rivers-Moore, 31

Roaf, 191

Robertson, 169, 227, 229

Rosenthal, 227

Róth, 21, 225

Rubidium, penetration of, 203, 214 Ruhland, 192, 229

\section{S}

Schlesinger, 31

Schulemann, 229

Schütt, 227

Sea-lettuce, see Ulva

Sea urchin eggs, effect of cerium on the conductivity of, 50

effect of lanthanum on the conductivity of, 50

measurement of the conductivity of,

Seifriz, 227 23

Shearer, 23, 50, 175, 225

Shorter, 227

Small, 21, 235

Sodium chlorate, effect on conductivity, 59

chloride, effect on conductivity, 62, 92, $102 \mathrm{ff}$ $110 \mathrm{ff}, 178$

effect on growth, 127

effect on respiration, 95,96

effect on viscosity, 179
Sodium chloride, penetration of, 203, 206, 208, 214,215

recovery after exposure to, 86 , $92 \mathrm{ff}, 99 \mathrm{ff}$

citrate, effect on conductivity, 178

iodide, effect on conductivity, 178

nitrate, effect on conductivity, 178

sulphate, effect on conductivity, 178

sulphocyanide, effect on conductivity, 178

taurocholate, antagonism of, 167

taurocholate, effect on conductivity, 55, 167

Spaeth, 181

Spirogyra, 203, 212

Stewart, 21, 225

Stimulation, changes in permeability associated with, $233 \mathrm{ff}$, 235

Stiles, 21, 31, 188, 196

Stone and Chapman, 21

Strontium, effect on conductivity, 49 penetration of, 203,215

Sulphate, effect on conductivity, 40 Szuiics, 169

\section{$\mathbf{T}$}

Tangl, 21, 225

Tashiro, 232

Temperature coefficient of life processes, $75 \mathrm{ff}$ coefficient of electrical conductivity, 39

Thomas, 232

Thorium, effect on conductivity, 47 Thornton, 22

Tin, effect on conductivity, 47

Tissue tension as measure of permeability, 159, 208

Toxicity, 131

measurement of, $71 \mathrm{ff}, 94$

Tumor tissue, partial recovery of, 97 
U

Ulva, antagonism, 174

effect of anesthetics on conductivity of, 193

effect of calcium chloride on the conductivity of, 49

effect of magnesium on the conductivity of, 49

effect of sodium taurocholate on the conductivity of, 55

recovery after exposure to sodium and calcium, 87

partial recovery of, 97

structure of, 196

Valonia, 211

\section{V}

conductivity of cell sap of, 199

Van Orstrand, 67

Vitality as measured by permeability, 18, 161

quantitative study of, $88 \mathrm{ff}$

Vries, H. de, 226, 227, 231

\section{W}

Waller, 188

Washburn, 31

IVasteneys, 163
Weber's law, 147

Weibel and Thuras, 30

Weinstein, 192

Winterstein, 191

Wodehouse, 211

Woelfel, 19, 225

Woods Hole, 44

\section{Y}

Yttrium, effect on conductivity, 47

Z

Zangger, 227

Zine, effect on conductivity, 47

Zostera, antagonism, 174

appearance after death, $88 \mathrm{ff}$

effect of calcium on the conductivity of, 49

effect of magnesium on the conductivity of, 49

measurement of conductivity of, 35

partial recovery of, 97

recovery after exposure to sodium and calcium, 87 




